LUÍS FILIPE FRAGOSO DE BARROS E SILVA ROSSI

\title{
DESENVOLVIMENTO E IMPLEMENTACÃO DE UM ALGORITMO BIOINSPIRADO PARA O CONTROLE DE MARCHA EM ROBÔS BÍPEDES
}

Tese apresentada à Escola Politécnica da Universidade de São Paulo para obtenção do Título de Doutor em Ciências. 


\section{LUÍS FILIPE FRAGOSO DE BARROS E SILVA ROSSI}

\section{DESENVOLVIMENTO E IMPLEMENTACÃO DE UM ALGORITMO BIOINSPIRADO PARA O CONTROLE DE MARCHA EM ROBÔS BÍPEDES}

Tese apresentada à Escola Politécnica da Universidade de São Paulo para obtenção do Título de Doutor em Ciências.

Área de Concentração:

Engenharia de Controle e Automação Mecânica

Orientador:

Arturo Forner-Cordero 
Este exemplar foi revisado e corrigido em relação à versão original, sob responsabilidade única do autor e com a anuência de seu orientador.

São Paulo, de de

Assinatura do autor:

Assinatura do orientador:

Catalogação-na-publicação

Rossi, Luís Filipe Fragoso de Barros e Silva

DESENVOLVIMENTO E IMPLEMENTAÇÃO DE UM ALGORITMO

BIOINSPIRADO PARA O CONTROLE DE MARCHA EM ROBÔS BÍPEDES / L.

F. F. B. S. Rossi -- versão corr. -- São Paulo, 2017. $147 \mathrm{p}$.

Tese (Doutorado) - Escola Politécnica da Universidade de São Paulo. Departamento de Engenharia Mecânica.

1.ROBÓTICA 2.MARCHA (LOCOMOÇÃO) 3.CONTROLE ÓTIMO

I.Universidade de São Paulo. Escola Politécnica. Departamento de

Engenharia Mecânica II.t. 
Aos meus pais e à minha irmã. 


\section{AGRADECIMENTOS}

À minha família, pelo apoio em todos os momentos difíceis.

Ao professor Doutor Arturo Forner Cordero, meu orientador, pela confiança, paciência e ajuda prestada.

Ao grupo do Laboratório de Biomecatrônica, pelas conversas e sugestões.

Ao Conselho Nacional de Desenvolvimento Científico e Tecnológico (CNPq), pelo apoio financeiro concedido por meio de bolsa de doutorado. 


\section{RESUMO}

Os dispositivos robóticos bípedes tem um grande potencial de aplicações tanto comerciais como para pesquisa. Dentre as presentes lacunas existentes que limitam a sua aplicabilidade prática tem um destaque especial a incapacidade de realizar uma marcha estável, robusta, versátil e eficiente no ponto de vista energético. No presente estado da arte, existem três principais estratégias de abordagem para o problema e algumas de suas implementações obtiveram sucesso em satisfazer pelo menos um dos requisitos listados, porém nunca todos eles de forma simultânea. Dentro deste cenário, este trabalho se propôs desenvolver um novo critério de estabilidade para marcha bípede que possibilite marchas versáteis, robustas e eficientes. Inicialmente foi realizada uma avaliação de diversos simuladores de código aberto e o Simbody foi definido como o mais apropriado para ser utilizado no desenvolvimento das simulações dinâmicas realizadas nesta Tese. Uma toolbox de MATLAB para auxiliar nos cálculos cinemáticos e dinâmicos foi desenvolvida em conjunto com um módulo de Inter Process Communication para realizar a comunicação entre o MATLAB e o simulador. Foi realizado um estudo da marcha bípede, implementando e avaliando as estratégias do Zero Moment Point e do Limit Cycle Walking. Este estudo resultou numa proposta de controlador não linear comutado para robôs em Ciclo Limite. Na procura de um novo critério de estabilidade foi abordado o estudo da marcha humana. Um procedimento para identificar os mecanismos que controlam a estabilidade da marcha humana é analisar a mesma sob perturbações, como tropeços, ou na ultrapassagem de obstáculos. Na literatura existiam bastantes referências sobre este tema, porém, faltou uma comparação da marcha humana sob diferentes condições de visão com a marcha de robôs que utilizam o ZMP. Foi descoberto que os seres humanos privados de visão têm uma estratégia de ultrapassagem de obstáculos semelhante a um robô com ZMP. A partir do conhecimento adquirido deste estudo é proposto e formulado um novo critério de estabilidade, o Step Viability, inspirado na marcha humana e no conceito de N-Step Capturability. O Step Viability baseia-se na definição de restrições que garantem a viabilidade de realizar passos futuros que garantam a convergência para um ponto fixo em tempo finito. O critério foi implementado utilizando-se uma otimização de trajetória multi-fase. Múltiplos testes foram realizados utilizando-se o modelo Compass Gait com diferentes parâmetros (distribuição de massa, torque máximo disponível), com diferentes inclinações e com vários padrões de marcha desejados (periódico, aumento uniforme e até aleatório não periódico). Adicionalmente o critério foi testado em um modelo de 5 segmentos, sintetizando uma marcha com variação tanto linear quanto aleatória. O critério foi bem-sucedido na geração de uma marcha estável em todos os testes e os resultados foram consistentes. A marcha pode ser sintetizada completamente desacoplada do critério de estabilidade, e o modelo renunciou automaticamente do padrão desenhado em favor da estabilidade.

Palavras-chave: robô bípede, marcha bípede, estabilidade, controle, ciclo-limite, zero moment point. 


\section{ABSTRACT}

Bipedal robots present a great potential for both commercial and research applications. However, there are some drawbacks that limit their applicability in the real world. The most prominent is the inability to perform a stable, robust, versatile and efficient gait. There are three main state of the art strategies to approach this problem. However, none of them has been successful in satisfying all the listed requirements simultaneously. In this context, this work conducted a study of bipedal gait, both in humans and robots, in order to implement and evaluate existing stability strategies. As a first step, an evaluation of several open source simulators was performed and Simbody was chosen as the most adequate for the dynamic simulations carried out in this Thesis. A MATLAB toolbox to help in the kinematic and dynamic calculations was developed in conjunction with a module of an Inter Process Communication to perform the communication between MATLAB and the simulator. A bipedal gait study was carried out, implementing and evaluating Zero Moment Point and Limit Cycle Walking strategies. This study resulted in a proposed nonlinear switched controller for Limit Cycle robots. In the search for a new stability criterion, human gait was analyzed. A procedure to identify the mechanisms controlling human gait stability is to analyze gait under disturbances such as stumbling or overcoming obstacles. In the literature, there were many references on this subject, however, there was a lack of comparison of the human gait under different vision conditions with the gait of robots that use the ZMP. It was found that vision-deprived humans have an obstacle crossing strategy similar to robots with ZMP. From the knowledge acquired from this study, it is proposed a novel stability criterion, the Step Viability, inspired on human gait and the N-Step Capturability concept. The Step Viability is based on the definition of constraints that ensure the viability of performing future steps that guarantee convergence to a fixed point in finite time. The criterion was implemented using a multi-phase trajectory optimization. Multiple tests were performed using the Compass Gait model with different parameters (mass distribution, maximum available torque), with different slopes and with several desired gait patterns (periodic, uniform increase and even random non-periodic). Additionally, the criterion was tested in a 5-links model, synthesizing a gait with both linear and random velocity variation. The criterion was successful on generating a stable gait in all the tests and the results presented consistent data. The gait could be designed completely uncoupled from the stability criterion, yet the model automatically renounced to follow the desired pattern in favor of maintaining stability.

Key-words: biped robot, biped gait, stability, control, limit cycle walking, zero moment point. 


\section{LISTA DE ILUSTRAÇÕES}

Figura 1 - Definição do ZMP . . . . . . . . . . . . . . . . . . 20

Figura 2 - Calculo do ZMP a partir da dinâmica completa do robô . . . . . . 21

Figura 3 - Ciclo-Limite de um Simplest Walker . . . . . . . . . . . . . 23

Figura 4 - Simulação de marcha ZMP no Choreonoid . . . . . . . . . 35

Figura 5 - Simulação de marcha no Gazebo. . . . . . . . . . . . . 37

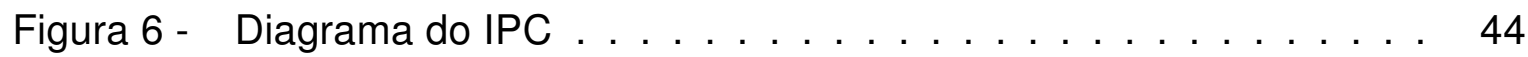

Figura 7 - Modelo do Compass Gait Walker . . . . . . . . . . . . . 47

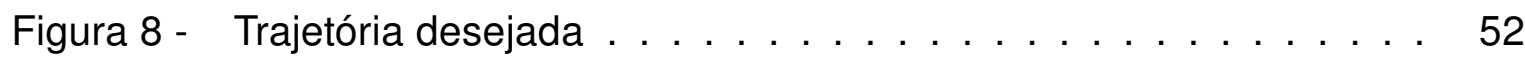

Figura 9 - Função de Densidade da Bacia de Atração: $\theta_{s} \times \dot{\theta}_{s} \times \Delta \theta_{n s} \quad \ldots \quad 54$

Figura 10 - Função de Densidade da Bacia de Atração: $\theta_{s} \times \dot{\theta}_{s} \times \Delta \dot{\theta}_{n s} \quad \ldots \quad 54$

Figura 11 - Função de Densidade da Bacia de Atração: $\theta_{n s} \times \dot{\theta}_{n s} \times \Delta \theta_{s} \ldots \quad \ldots 5$

Figura 12 - Função de Densidade da Bacia de Atração: $\theta_{n s} \times \dot{\theta}_{n s} \times \Delta \dot{\theta}_{s} \ldots \quad \ldots 5$

Figura 13 - Modelo do robô utilizado . . . . . . . . . . . . . . . . . 59

Figura 14 - Trajetória ântero-posterior do quadril x Tempo . . . . . . . . . 61

Figura 15 - Trajetória ântero-posterior do pé x Tempo . . . . . . . . . . 62

Figura 16 - Trajetória vertical do pé x Tempo . . . . . . . . . . . 63

Figura 17 - Trajetória ântero-posterior x trajetória vertical da distancia entre o quadril e o pé normalizados . . . . . . . . . . . . . . . . . . . 64

Figura 18 - Modelo de caminhada do ser humano com visão . . . . . . . . 65

Figura 19 - Modelo de caminhada do ser humano vendado . . . . . . . . . 65

Figura 20 - Modelo de caminhada do robô . . . . . . . . . . . . . 65

Figura 21 - Sugestão de arquitetura geral do controle da marcha de robôs bípedes ... . . . . . . . . . . . . . . . . . . . 69 
Figura 22 - Marcha baseada em ZMP . . . . . . . . . . . . . . 69

Figura 23 - Marcha Dinâmica . . . . . . . . . . . . . . . . . 70

Figura 24 - Robô em um estado caído . . . . . . . . . . . . . . . 71

Figura 25 - Rimless Wheel . . . . . . . . . . . . . . . . 73

Figura 26 - Compass Gait com pernas sem massa. . . . . . . . . . . . 74

Figura 27 - Exemplo do Capture Point antes da Passada . . . . . . . . . 76

Figura 28 - Exemplo do Capture Point depois da Passada . . . . . . . . 76

Figura 29 - Capture Point de um pêndulo invertido linear. . . . . . . . . 76

Figura 30 - Exemplo de solução . . . . . . . . . . . . . . . 83

Figura 31 - Razão do tempo calculada com a equação (6.42) considerando $x_{f}=0.866 \mathrm{~m}$ e $\Delta r_{i c}=0.11 \mathrm{~m}$ para $r_{i c 0}$ variando entre 0.12 até $0.76 \mathrm{~m}$. $\mathrm{O}$ ponto vermelho é o valor mínimo do intervalo. . . . . . . . . . .

Figura 32 - Exemplo do procedimento utilizado para encontrar os estados iniciais adequados para permitir um primeiro passo viável. Torque máximo $=15 \mathrm{Nm}$, inclinação $=20^{\circ}$ e massa da perna $=5 \mathrm{~kg}$.

Figura 33 - Exemplo de solução com padrão aleatório, massa da perna de 5 $\mathrm{kg}$, inclinação de $20^{\circ}$ e torque máximo de $50 \mathrm{Nm}$

Figura 34 - Comparação de $\dot{\theta}_{s}^{t a r} \times \dot{\theta}_{s}$ executado no teste: Inclinação $=3^{\circ}$ Massa da Perna $=1 \mathrm{~kg}$ - Padrão: linear $\ldots \ldots \ldots \ldots$

Figura 35 - Comparação de $\dot{\theta}_{s}^{\text {tar }} \times \dot{\theta}_{s}$ executado no teste: Inclinação $=3^{\circ}$ Massa da Perna $=1 \mathrm{~kg}$ - Padrão: aleatório $\ldots \ldots \ldots \ldots$

Figura 36 - Comparação de $\dot{\theta}_{s}^{\text {tar }} \times \dot{\theta}_{s}$ executado no teste: Inclinação $=3^{\circ}$ Massa da Perna $=5 \mathrm{~kg}$ - Padrão: linear $\ldots \ldots \ldots \ldots$

Figura 37 - Comparação de $\dot{\theta}_{s}^{\text {tar }} \times \dot{\theta}_{s}$ executado no teste: Inclinação $=3^{\circ}$ Massa da Perna $=5 \mathrm{~kg}$ - Padrão: aleatório $\ldots \ldots \ldots \ldots \ldots$

Figura 38 - Comparação de $\dot{\theta}_{s}^{\text {tar }} \times \dot{\theta}_{s}$ executado no teste: Inclinação $=3^{\circ}$ Massa da Perna $=9 \mathrm{~kg}$ - Padrão: linear $\ldots \ldots \ldots \ldots \ldots$ 
Figura 39 - Comparação de $\dot{\theta}_{s}^{\text {tar }} \times \dot{\theta}_{s}$ executado no teste: Inclinação $=3^{\circ}$ Massa da Perna $=9 \mathrm{~kg}$ - Padrão: aleatório . . . . . . . . . . . 96

Figura 40 - Comparação de $\dot{\theta}_{s}^{\text {tar }} \times \dot{\theta}_{s}$ executado no teste: Inclinação $=20^{\circ}$ Massa da Perna $=1 \mathrm{~kg}$ - Padrão: linear . . . . . . . . . . 97

Figura 41 - Comparação de $\dot{\theta}_{s}^{\text {tar }} \times \dot{\theta}_{s}$ executado no teste: Inclinação $=20^{\circ}$ Massa da Perna $=1 \mathrm{~kg}$ - Padrão: aleatório . . . . . . . . . 97

Figura 42 - Comparação de $\dot{\theta}_{s}^{\text {tar }} \times \dot{\theta}_{s}$ executado no teste: Inclinação $=20^{\circ}$ -

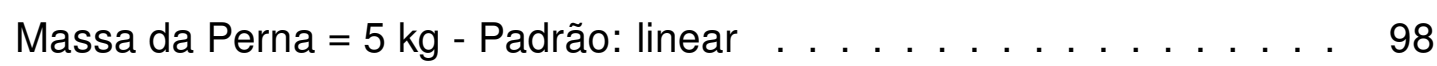

Figura 43 - Comparação de $\dot{\theta}_{s}^{\text {tar }} \times \dot{\theta}_{s}$ executado no teste: Inclinação $=20^{\circ}$ -

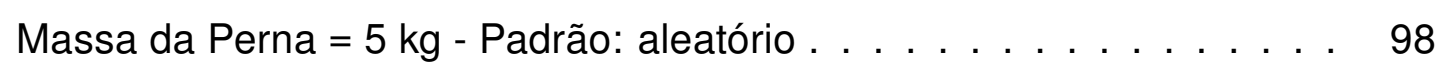

Figura 44 - Comparação de $\dot{\theta}_{s}^{\text {tar }} \times \dot{\theta}_{s}$ executado no teste: Inclinação $=20^{\circ}$ Massa da Perna $=9 \mathrm{~kg}$ - Padrão: linear . . . . . . . . . . . . 99

Figura 45 - Comparação de $\dot{\theta}_{s}^{\text {tar }} \times \dot{\theta}_{s}$ executado no teste: Inclinação $=20^{\circ}$ Massa da Perna $=9 \mathrm{~kg}$ - Padrão: aleatório . . . . . . . . . . . 99

Figura 46 - Comparação de $\dot{\theta}_{s}^{\text {tar }} \times \dot{\theta}_{s}$ executado no teste: Inclinação $=30^{\circ}$ Massa da Perna $=1 \mathrm{~kg}$ - Padrão: linear . . . . . . . . . . 100

Figura 47 - Comparação de $\dot{\theta}_{s}^{\text {tar }} \times \dot{\theta}_{s}$ executado no teste: Inclinação $=30^{\circ}$ -

Massa da Perna $=1 \mathrm{~kg}$ - Padrão: aleatório . . . . . . . . . . 101

Figura 48 - Comparação de $\dot{\theta}_{s}^{\text {tar }} \times \dot{\theta}_{s}$ executado no teste: Inclinação $=30^{\circ}$ -

Massa da Perna $=5 \mathrm{~kg}$ - Padrão: linear . . . . . . . . . . . 101

Figura 49 - Comparação de $\dot{\theta}_{s}^{\text {tar }} \times \dot{\theta}_{s}$ executado no teste: Inclinação $=30^{\circ}$ -

Massa da Perna $=5 \mathrm{~kg}$ - Padrão: aleatório . . . . . . . . . . 102

Figura 50 - Comparação de $\dot{\theta}_{s}^{\text {tar }} \times \dot{\theta}_{s}$ executado no teste: Inclinação $=30^{\circ}$ -

Massa da Perna $=9$ kg - Padrão: linear . . . . . . . . . . . 102

Figura 51 - Comparação de $\dot{\theta}_{s}^{\text {tar }} \times \dot{\theta}_{s}$ executado no teste: Inclinação $=30^{\circ}$ -

Massa da Perna $=9 \mathrm{~kg}$ - Padrão: aleatório . . . . . . . . . . 103

Figura 52 - Modelo de 5 segmentos. . . . . . . . . . . . . . . . 103 
Figura 53 - Razão do tempo calculada com a equação (6.42) considerando $x_{f}=1.2124 \mathrm{~m} \mathrm{e} \Delta r_{i c}=0.17 \mathrm{~m}$ para $r_{i c 0}$ variando entre 0.21 até $1.042 \mathrm{~m}$. O ponto vermelho é o valor mínimo do intervalo. . . . . . . . . . 107

Figura 54 - Exemplo de solução da marcha com padrão aleatório de referência.108 Figura 55 - Exemplo de falha em gerar a marcha quando o critério de Step Viability não é usado. . . . . . . . . . . . . . . . . . . . . . . . . . . 109

Figura 56 - Resultado do teste com padrão linear . . . . . . . . . . . . 109

Figura 57 - Resultado do teste com padrão aleatório . . . . . . . . . . . 110

Figura 58 - Notação utilizada para a matriz de transformação . . . . . . . . . 124

Figura 59 - Manipulador de 3 graus de liberdade . . . . . . . . . . . . 125

Figura 60 - Cinemática Inversa em um robô bípede . . . . . . . . . . . 131 


\section{LISTA DE TABELAS}

Tabela 1 - Tabela comparativa dos simuladores . . . . . . . . . . . . . . 40

Tabela 2 - Atributos do Modelo . . . . . . . . . . . . . . . . . . . . 49

Tabela 3 - Modelo da Bacia de Atração . . . . . . . . . . . . . . . . . . 51

Tabela 4 - Valores Iniciais . . . . . . . . . . . . . . . . . . 52

Tabela 5 - Intervalo Simulado . . . . . . . . . . . . . . . 53

Tabela 6 - Características Físicas dos Participantes . . . . . . . . . . 58

Tabela 7 - Parametros dos modelos durante os testes . . . . . . . . . 90

Tabela 8 - Ganhos da função objetivo utilizados durante os testes . . . . . 107

Tabela 9 - Parâmetros do modelo durante os testes . . . . . . . . . . . 108 


\title{
LISTA DE ABREVIATURAS E SIGLAS
}

\author{
API Application Programming Interface \\ COM Center of Mass \\ COP Center of Pressure \\ CPG Central Pattern Generator \\ DLS Dumped Least Square \\ DRC DARPA Robotics Challenge \\ IPC Inter Process Comunication \\ LCP Linear Complementarity Problem \\ LCW Limit Cycle Walking \\ LIPM Linear Inverted Pendulum Model \\ MPC Model Predictive Control \\ PFL Partial Feedback Linearization \\ ROS Robot Operating System \\ ZMP Zero Moment Point
}




\section{SUMÁRIO}

$1 \quad$ INTRODUÇÃO 16

$1.1 \quad$ Motivação . . . . . . . . . . . . . . . . . . . 16

1.2 Revisão Descritiva Histórica dos Robôs Bípedes . . . . . . . . . . . . . 17

1.2.1 Controle de Marcha Bípede . . . . . . . . . . . . . . . . . . . . 19

1.2.1.1 Zero Moment Point . . . . . . . . . . . . . . . . . . . . . . . . 20

1.2.1.2 Limit Cycle Walking . . . . . . . . . . . . . . . . . . . . . 22

1.2.1.3 N-Step Capturability . . . . . . . . . . . . . . . . . . . . . . 24

1.3 Problema Tratado na Tese . . . . . . . . . . . . . . 25

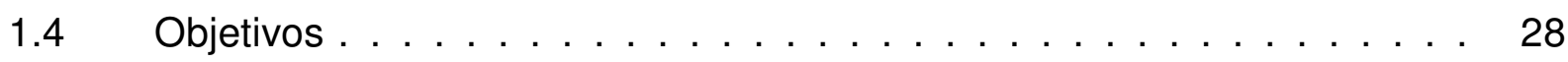

$1.5 \quad$ Metodologia . . . . . . . . . . . . . . . 28

1.5.1 Definição das Ferramentas . . . . . . . . . . . . . . . . . 28

1.5.2 Desenvolvimento de Ferramentas . . . . . . . . . . . . . . . 28

1.5.2.1 Desenvolvimento de Interface Simulador - MATLAB . . . . . . . . . . . . 29

1.5.2.2 Desenvolvimento de Toolbox para Controle de Marcha Bípede em Matlab 29

1.5.2.3 Desenvolvimento de Rotinas para Avaliação dos Resultados das Simulações . . . . . . . . . . . . . . . . . . . . . 29

1.5.3 Estudo da Marcha . . . . . . . . . . . . . . . . . . . . 29

1.5.3.1 Estudo das Estratégias de Controle Existentes . . . . . . . . . . . . . . 30

1.5.4 Estudo da Marcha Humana . . . . . . . . . . . . . . . . . . 30

1.5.5 Desenvolvimento do Critério de Estabilidade . . . . . . . . . . . . . 30

1.5.5.1 Desenvolvimento de um Controlador Baseado no Novo Critério de Esta-

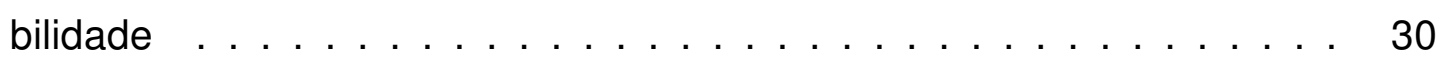


1.5.5.2 Testes . . . . . . . . . . . . . . . 30

1.5 .6 Materiais . . . . . . . . . . . . . . . . . . . 31

1.6 Estrutura do texto . . . . . . . . . . . . . . . 31

2 SIMULADORES 32

2.1 Avaliação dos Simuladores de Código Aberto . . . . . . . . . . . . 33

2.1.1 OpenHRP3/Choreonoid . . . . . . . . . . . . . . . 35

2.1 .2 Gazebo . . . . . . . . . . . . . . . . . . . 37

2.1 .3 OpenRave . . . . . . . . . . . . . . . . . . 38

2.1 .4 Simulation Construction Set . . . . . . . . . . . . . . . . . . 39

2.1 .5 Simbody . . . . . . . . . . . . . . . . . . 39

2.1 .6 Comparação . . . . . . . . . . . . . . . . . . . . . . . 40

$2.2 \quad$ Conclusões . . . . . . . . . . . . . . . . . . . . . . . 42

$3 \quad$ FERRAMENTAS DESENVOLVIDAS 43

3.1 Inter Process Comunication - IPC . . . . . . . . . . . . . 44

3.2 Toolbox Biped Robot Control . . . . . . . . . . . . . . . . . . . . . . . . . 44

4 CONTROLE DE UM BÍPEDE COMPASS GAIT WALKER BASEADO EM PARTIAL FEEDBACK LINEARIZATION COM REFERÊNCIA COMUTADA 46

$4.1 \quad$ Modelo . . . . . . . . . . . . . . . . . . . . . . . 46

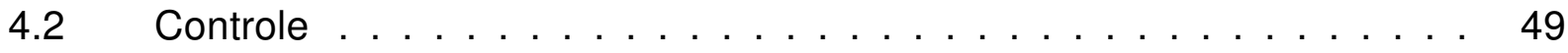

4.2 .1 Lei de Comutação . . . . . . . . . . . . . . . . . . . . . 50

4.2 .2 Leis de Controle . . . . . . . . . . . . . . . . . . . . 51

$4.3 \quad$ Simulação . . . . . . . . . . . . . . . . . . . . . . 52

$4.4 \quad$ Resultados . . . . . . . . . . . . . . . . . . . . 53 
$4.5 \quad$ Publicações . . . . . . . . . . . . . . . . . . 56

5 ANALISE DA MARCHA DO SER HUMANO EM DIFERENTES CONDIÇÕES DE VISÃO

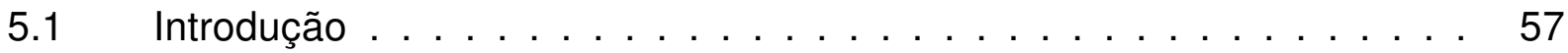

$5.2 \quad$ Metodologia . . . . . . . . . . . . . . . . . . 58

5.2 .1 Protocolo Experimental . . . . . . . . . . . . . . . . . 58

5.2 .2 Modelo do Robô. . . . . . . . . . . . . . . . . . . . . . . . . 59

5.2.3 Processamento dos Dados dos Sujeitos . . . . . . . . . . . . . . 60

$5.3 \quad$ Resultados . . . . . . . . . . . . . . . . . . . . . 61

5.4 Discussão . . . . . . . . . . . . . . . . . . . . . . . . 64

$5.5 \quad$ Publicações . . . . . . . . . . . . . . . . . . 67

6 DESENVOLVIMENTO DO STEP VIABILITY 68

$6.1 \quad$ O que é estabilidade $? \ldots \ldots \ldots \ldots \ldots \ldots \ldots$

6.2 Entendendo a Marcha $\ldots \ldots \ldots \ldots . \ldots \ldots$

6.2.1 Teoria do Capture Point $\ldots \ldots \ldots \ldots$

6.3 Step Viability . . . . . . . . . . . . . . . . . . . . . . . . . . 78

6.4 Análise do Critério de ZMP Desde o Ponto de Vista do Critério de Estabilidade Proposto . . . . . . . . . . . . . . . . . . . . 81

6.5 Testes do Step Viability . . . . . . . . . . . . . . . . . . . . . 83

6.5.1 Exemplo 1: Compass Gait em uma Rampa . . . . . . . . . . . . . 84

6.5 .1 .1 Modelo . . . . . . . . . . . . . . . . . . . . . . . . . . . . . . . 84

6.5 .1 .2 Implementação . . . . . . . . . . . . . . . . . . 85

6.5.1.3 Simulação e Testes . . . . . . . . . . . . . . . . . . . . . . . . 90

6.5 .1 .4 Resultados . . . . . . . . . . . . . . . . . . . . . . . . . 91

6.5.2 Exemplo 2: Modelo Planar de 5 Segmentos . . . . . . . . . . . 103 
6.5 .2 .1 Modelo . . . . . . . . . . . . . . . . . . . . . . . . . . . . 103

6.5.2.2 Implementação . . . . . . . . . . . . . . . . . . . . . . . 104

6.5.2.3 Simulação e Testes . . . . . . . . . . . . . . . . . . . . . . . 106

6.5 .2 .4 Resultados . . . . . . . . . . . . . . . . . . . . . . . . . . 108

6.5 .3 Discussão . . . . . . . . . . . . . . . . . . . . . . . . 110

6.5 .4 Publicações . . . . . . . . . . . . . . . . . . . . . . 112

7 CONCLUSÕES 113

7.1 Desenvolvimento de Ferramentas Abertas para Auxiliar no Desenvolvimento de Algoritmos de Controle de Robôs Bípedes . . . . . . . . . . 114

7.2 Estudo da Marcha Humana e Comparação com os Critérios de Estabilidade de Robôs Bípedes . . . . . . . . . . . . . . . . . . . . 114

7.3 Desenvolvimento de um Critério de Estabilidade que uma marcha versátil 115

7.4 Implementação e Avaliação de um Controlador Baseado no Critério de Estabilidade Desenvolvido . . . . . . . . . . . . . . . . . 115

7.5 Trabalhos Futuros . . . . . . . . . . . . . . . . . . . . 115

$\begin{array}{ll}\text { REFERÊNCIAS } & 117\end{array}$

APÊNDICE A - TEORIA DE ROBÓTICA BÍPEDE 124

A.1 Matriz de Transformação . . . . . . . . . . . . . . . . . . . . . 124

A.2 Cinemática Direta . . . . . . . . . . . . . . . . . . . . 125

A.3 Jacobiano . . . . . . . . . . . . . . . . . . . . . 126

A.3.1 Cinemático . . . . . . . . . . . . . . . . . . . . . . . 126

A.3.2 Centro de Massas . . . . . . . . . . . . . . . . . . . . . . . . . . . 127

A.4 Cinemática Inversa . . . . . . . . . . . . . . . . . . . . . . . . . 128

A.4.1 Bípede . . . . . . . . . . . . . . . . . . . . . . . . . 130

A.5 Zero Moment Point . . . . . . . . . . . . . . . . . . . . . . . . 132 
A.5.1 Quadratic Programming . . . . . . . . . . . . . . . . . 132

APÊNDICE B - INSTRUÇÕES DE INSTALAÇÃO E USO DA TOOLBOX 136

B.1 Instalação . . . . . . . . . . . . . . . . . . . 136

B.2 Instruções Uso . . . . . . . . . . . . . . . . . . . 136

APÊNDICE C - EQUAÇÕES DO MODELO DE 5 SEGMENTOS 137

C.1 Dinâmica Contínua . . . . . . . . . . . . . . . . . . 137

C.2 Equções de Impacto . . . . . . . . . . . . . . . . . . . . . . . . . . . . 142 


\section{INTRODUÇÃO}

\subsection{Motivação}

Existe uma grande gama de potenciais utilizações de robôs em ambientes projetados para humanos. Essas podem variar desde robôs para puro entretenimento, até robôs que possam substituir humanos em tarefas repetitivas. Porém, uma das mais eminentes necessidades de tais sistemas é a sua utilização para efetuar tarefas perigosas para seres humanos.

Um exemplo recente bastante expressivo foi o acidente nuclear na usina de Fukushima I, que ocorreu em 11 de março de 2011, devido à um tsunami. Tal desastre acarretou no superaquecimento dos núcleos dos reatores e consequentemente uma fusão parcial dos mesmos. Com isto, um ambiente extremamente perigoso e danoso à seres humanos foi criado. Ao mesmo tempo, se algumas tarefas facilmente realizáveis por seres humanos pudessem ser efetuadas no local, uma parte das consequências poderiam ser mitigadas. Houve a tentativa de uso de robôs, mas o estado-da-arte da tecnologia não permitiu que tais feitos fossem completados com sucesso.

Tal eminente necessidade estimulou o Defense Advanced Research Projects Agency (DARPA) dos Estados Unidos a criar o Darpa Robotics Challenge (DRC) (DARPA, 2013): uma competição onde os grupos participantes tem que desenvolver robôs e algoritmos de controle para efetuar algumas tarefas pré-determinadas, emulando situações de desastres, tanto em ambiente simulado como com robôs reais. A seguinte citação retirada do site da própria DARPA demonstra a motivação por trás da competição.

"The DARPA Robotics Challenge (DRC) will attempt to address this capability gap by promoting innovation in robotic technology for disaster-response 
operations."

Além das motivações diretas de aplicações de robôs bípedes, muito de sua tecnologia e algoritmos de controle criam uma base de conhecimento para aplicação em exoesqueletos robóticos de membros inferiores, cuja utilização tem grande utilidade para reabilitação e assistência motora. De forma aos mesmos poderem funcionar com efetividade, algoritmos de controle de marcha estáveis e eficientes são necessários.

\subsection{Revisão Descritiva Histórica dos Robôs Bípedes}

No Japão, WL-1, o primeiro robô bípede foi apresentado em 1969 por Ichiro Kato e sua equipe na Waseda University. Posteriormente Kato desenvolveu o primeiro robô bípede antropomórfico: O WABOT 1. Este foi capaz de realizar alguns passos em equilíbrio estático baseado em um esquema de controle bastante simplório.

Em paralelo, Miomir Vukobratovic e sua equipe exibiram, no começo dos anos 70, a primeira tentativa de formalizar o uso da estabilidade dinâmica no controle de robôs bípedes: o Zero Moment Point (ZMP) (VUKOBRATOVIC; STEPANENKO, 1972; VUKOBRATOVIC; BOROVAC, 2004; VUKOBRATOVIC; BOROVAC; POTKONJAK, 2006). Este por sua vez, é um dos conceitos mais utilizados no controle de marcha bípede e foi uma das principais bases teóricas que possibilitou a implementação de um caminhar estável em diversos robôs. O primeiro robô bípede que efetivamente utilizou este conceito para gerar uma marcha estável foi o WL-10RD em 1985 (TAKANISHI et al., 1985b). Em sua implementação uma trajetória de marcha era prescrita para os membros inferiores e uma massa posicionada no torso era utilizada para estabilizar o robô.

Na mesma década, nos Estados Unidos, Marc Raibert fundou o LegLab no Carnegie Mellon University, e posteriormente o moveu o mesmo para Massachusetts Institute of Technology (MIT). Fundador da Boston Dynamics (empresa que desenvolveu o Atlas, robô oficial da DRC), foi responsável pelo desenvolvimento de diversos robôs com pernas, os quais eram capazes de caminhar, correr e até pular (RAIBERT, 1986). Os trabalhos de seu laboratório sempre se focaram em tentar entender como os sistemas biológicos funcionam e tentar copiar seus princípios para serem implementados nos robôs. 
No início de 1990, McGeer apresentou a ideia de estudar sistemas mecânicos bípedes puramente passivos. Estes, quando colocados em rampas com condições iniciais bem especificas, geravam movimentos bastante similares à marcha de seres humanos, tudo alimentado pela energia potencial gravitacional. Tais marchas eram fundamentalmente ciclos-limite com uma bacia de atração bastante estreita. Deste trabalho, McGeer introduziu conceito de Passive Dynamic Walking (MCGEER, 1990b, 1990a).

Posteriormente alguns pesquisadores começaram a estudar o uso de ciclos-limite na geração de marcha em robôs bípedes (passivos e ativos) de forma a conseguir uma maior eficiência energética. Por se tratar de uma dinâmica hibrida não linear, foram inicialmente estudados modelos simplificados como o Compass-Gait ou Simplest Walker (GOSWAMI; ESPIAU; KERAMANE, 1997; GARCIA et al., 1998). De forma a tornar o problema tratável para modelos mais complexos, Westervelt, Grizzle e Koditschek (2003) apresentaram uma metodologia para reduzir a quantidade de graus de liberdade do sistema, tornando o processo de analise de ciclos-limite viável. Tal método foi denominado de Hybrid Zero Dynamics. Finalmente Hobbelen e Wisse (2007) formalizaram o conceito de Limit Cycle Walking como:

"Limit Cycle Walking is a nominally periodic sequence of steps that is stable as a whole but not locally stable at every instant in time"

A Honda já havia começado seu desenvolvimento na área de robôs bípedes em 1986 com o E0 (HONDA, 2014) e em 2000 seus investimentos culminaram em um dos robôs humanoides mais famosos da atualidade: o ASIMO (SAKAGAMI et al., 2002). No final dos anos 90 uma serie de outras empresas desenvolveram robôs bípedes no Japão, como a Sony com o QRIO. Por volta de 1997 houve a criação do programa Humanoid Robotic Project, finanaciado pelo Ministry of Economy, Trade and Industry no Japão. Os primeiros robôs utilizados pelo programa foram os P3 desenvolvidos pela Honda, cujos projetos foram posteriormente adaptados e se transformaram no HRP-1. Os grandes responsáveis pelos principais desenvolvimentos fomentados por tal programa foram o National Institute of Advanced Industrial Science and Technology (AIST) e a Kawada Industries. Posteriormente uma série de robôs bípedes foram desenvolvidos (KANEKO et al., 2004), passando por robôs capazes de operarem em ambientes industriais (KANEKO et al., 2008), até robôs capazes de dançar (KANEKO 
et al., 2009).

Também no Japão, Kajita et al. (2001) apresentaram o conceito de 3D Linear Inverted Pendulum Model (3D-LIPM). Tradicionalmente o calculo de trajetórias de marcha baseada em ZMP era possível apenas antes de efetivamente ocorrer a marcha do robô devido ao elevado custo computacional que não permitia um cálculo em tempo real. Isto gerou uma limitação do método já que tais marchas não teriam nenhuma utilidade funcional. De modo a resolver tal problema, foi proposta a simplificação da dinâmica de um robô bípede para a de um pendulo invertido, possibilitando a geração de marcha em tempo real. Tal simplificação se mostrou razoavelmente satisfatória e o modelo gerado é amplamente utilizado em trabalhos relacionados à marcha bípede.

Durante o resto do decorrer da década o desenvolvimento de robôs focados no uso de Limit Cycle Walking cresceu significativamente (COLLINS et al., 2005). Em 2006 Andy Ruina e sua equipe apresentaram o Cornell Ranger (KARSSEN, 2006), um robô que caminhava com um consumo energético baixo. Mais recentemente uma versão atualizada do Cornell Ranger foi apresentado (BHOUNSULE et al., 2014) com um algoritmo de controle que conseguiu um custo de transporte próximo aos dos seres humanos.

Mais recentemente a Boston Dynamics apresentou vídeos (DYNAMICS, 2016) do robô ATLAS caminhando e correndo com boa estabilidade e movimentos que se assemelhavam muito aos dos seres humanos. Porém, não houve divulgação do algoritmo utilizado no robô.

Após o DRC, foi realizado um relatório contendo, descrições, avaliações e críticas dos resultados da competição, agoritmos entre outros pontos (DRC-TEAMS, 2015). Neste relatório foi comentado que basicamente grande parte das equipes utilizaram uma marcha baseada em ZMP utilizando outros aspectos de estabilização (como capture point e centroidal momentum) e alguma forma de controle ótimo.

\subsubsection{Controle de Marcha Bípede}

De modo geral existem duas estratégias amplamente utilizadas para o controle de marcha bípede: Zero Moment Point (ZMP) e Limit Cycle Walking. A primeira é utilizada comumente em robôs totalmente atuados por ser extremamente flexível e de 
implementação bem definida. A segunda é utilizada majoritariamente em estudos de marcha bípede eficiente, porém bastante restrita em seu escopo de aplicabilidade por gerar uma marcha pouco flexível, sensível a perturbações, dependente das condições iniciais e ser de difícil implementação. De uma forma complementar, recentemente foi apresentado o conceito de $N$-Step Capturability, cujo foco principal é aumentar a robustez da marcha de um robô.

\subsubsection{Zero Moment Point}

O ZMP pode ser descrito como o ponto no qual a força de reação dinâmica no contato do pé com o solo não produz qualquer momento na direção horizontal. Como pode ser visto na figura 1, considerando uma certa distribuição de forças na região de contato entre o pé e o solo, o ZMP pode ser definido como o ponto onde está localizada a resultante de tais forças.

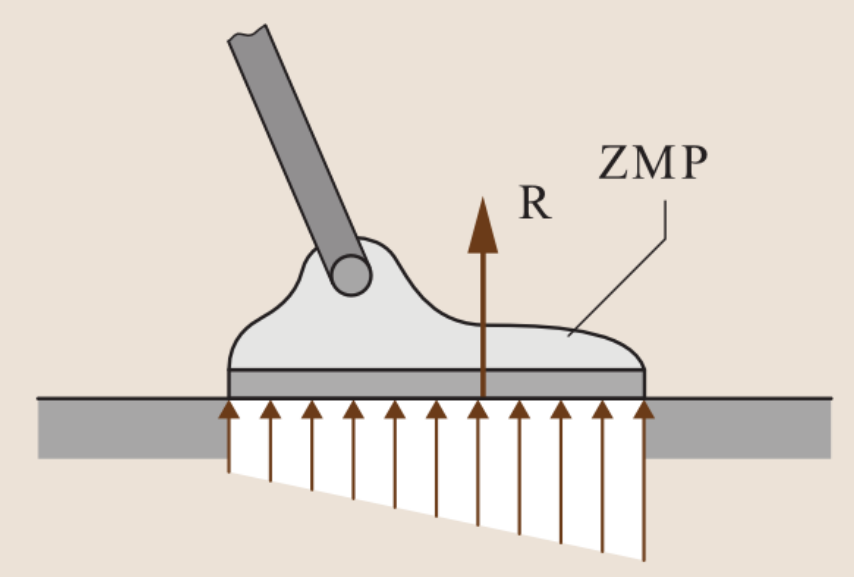

Figura 1: Definição do ZMP (KAJITA; ESPIAUR, 2008)

O ZMP tem uma grande importância para a robótica bípede pois, no caso ideal, o fato de a sua localização estar dentro da base de apoio de um robô bípede, garante o equilíbrio dinâmico naquele instante.

Tradicionalmente o seu calculo era realizado levando em consideração a dinâmica completa do corpo de um robô. Basicamente se calcula a posição e aceleração de todos os corpos rígidos que compõe o robô e, partir dessa informação, se calcula a contribuição de cada corpo na dinâmica total do sistema. A Figura 2 ilustra tal calculo. 


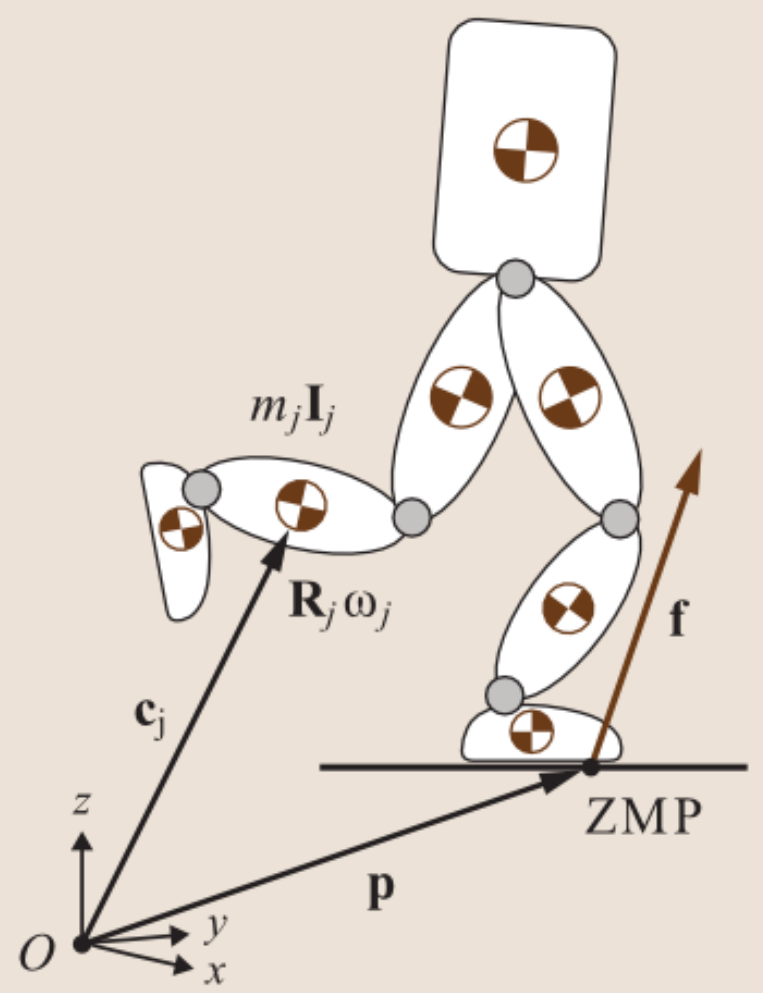

Figura 2: Calculo do ZMP a partir da dinâmica completa do robô (KAJITA; ESPIAUR, 2008)

No WL-10RD inicialmente se descreveu a movimentação das pernas do robô para se sintetizar uma marcha (TAKANISHI et al., 1985a). A partir disso era definido a posição da massa no torso do mesmo de forma a garantir que o ZMP estivesse localizado dentro de sua base de apoio. Apesar de efetivo, tal conceito se mostrou pouco flexível se considerarmos que o robô em questão terá alguma funcionalidade além de caminhar.

De forma a superar tal limitação, Huang et al. (2001) apresentaram uma nova metologia de cálculo de trajetória de marcha baseada em ZMP levando à duas possibilidades. Na primeira é gerada uma trajetória do centro de massas do robô e então a trajetória de todas as outras juntas é calculada de forma a manter a marcha estável. A segunda possibilidade é a geração da trajetória do pé em balanço e posteriormente gerar a trajetória das outras juntas forma a manter o ZMP dentro da base de apoio. Este último método foi posteriormente aperfeiçoado por Kajita et al. (2003) utilizando o que foi chamado de Preview Control.

Diversos robôs bípedes desenvolvidos na atualidade como o ASIMO (SAKAGAMI 
et al., 2002), o HRP-4 (KANEKO et al., 2009) e o HUBO (PARK et al., 2005) fazem uso deste conceito para gerar as trajetórias do controle de suas caminhadas. Os algoritmos baseados no ZMP normalmente tem como requisito básico a necessidade de 0 robô ter pernas com diversos graus de liberdade (normalmente no mínimo seis) totalmente atuados (KAJITA; ESPIAUR, 2008). Isto se faz necessário pois estes algoritmos tem como saída o controle de posição das juntas articuladas do robô. Este mesmo fato permite que o robô possa realizar uma grande variedade movimentos complexos finos. No entanto, como contrapartida robôs baseados no ZMP tem um alto consumo energético além de terem uma baixa rejeição natural à distúrbios externos e variações nas características do chão onde estão caminhando. Para finalizar os cálculos envolvidos para implementar o ZMP demandam uma grande capacidade de processamento computacional.

Apesar de grande parte do controle de marcha dos robôs bípedes existentes estar baseado no ZMP, não houve um avanço significativo na evolução deste conceito nos últimos anos. Os trabalhos mais recentes publicados nesta área tiveram como foco majoritariamente o estudo de modelos mais complexos do que o pendulo invertido, porém mantendo a capacidade de gerar a marcha em tempo real, como em Shimmyo, Sato e Ohnishi (2012), e no estudo de metodologias de metodologias de cálculo do ZMP mais precisas, como em Ugurlu e Kawamura (2012). Como ja comentado anteriormente, o ZMP foi amplamente utilizado durante o DRC em aplicações de síntese de marcha no Atlas (FENG et al., 2014; TEDRAKE et al., 2015).

\subsubsection{Limit Cycle Walking}

Diferente de controles que utilizam o ZMP como uma métrica de estabilidade, algoritmos baseados em Limit Cycle Walking não estão preocupados em uma estabilidade instantânea, mas sim em uma estabilidade cíclica do sistema. Para entendermos meIhor este conceito, tomemos o modelo do Simplest Walker como referência, que é bidimensional e consiste de dois segmentos conectados por uma junta de revolução.

Se colocarmos este mecanismo em uma rampa descendente com certas condições iniciais, ele será capaz de realizar um movimento bastante similar a uma marcha. Isto acontece pois, quando a perna de balanço do mecanismo bate no chão, ela faz o sistema perder exatamente a mesma quantidade de energia cinética que foi ganha 
da energia potencial gravitacional. Desta forma o sistema consegue andar indefinidamente (ou pelo menos ate a rampa acabar). Desta maneira se gera uma marcha em ciclo-limite (Figura 3).

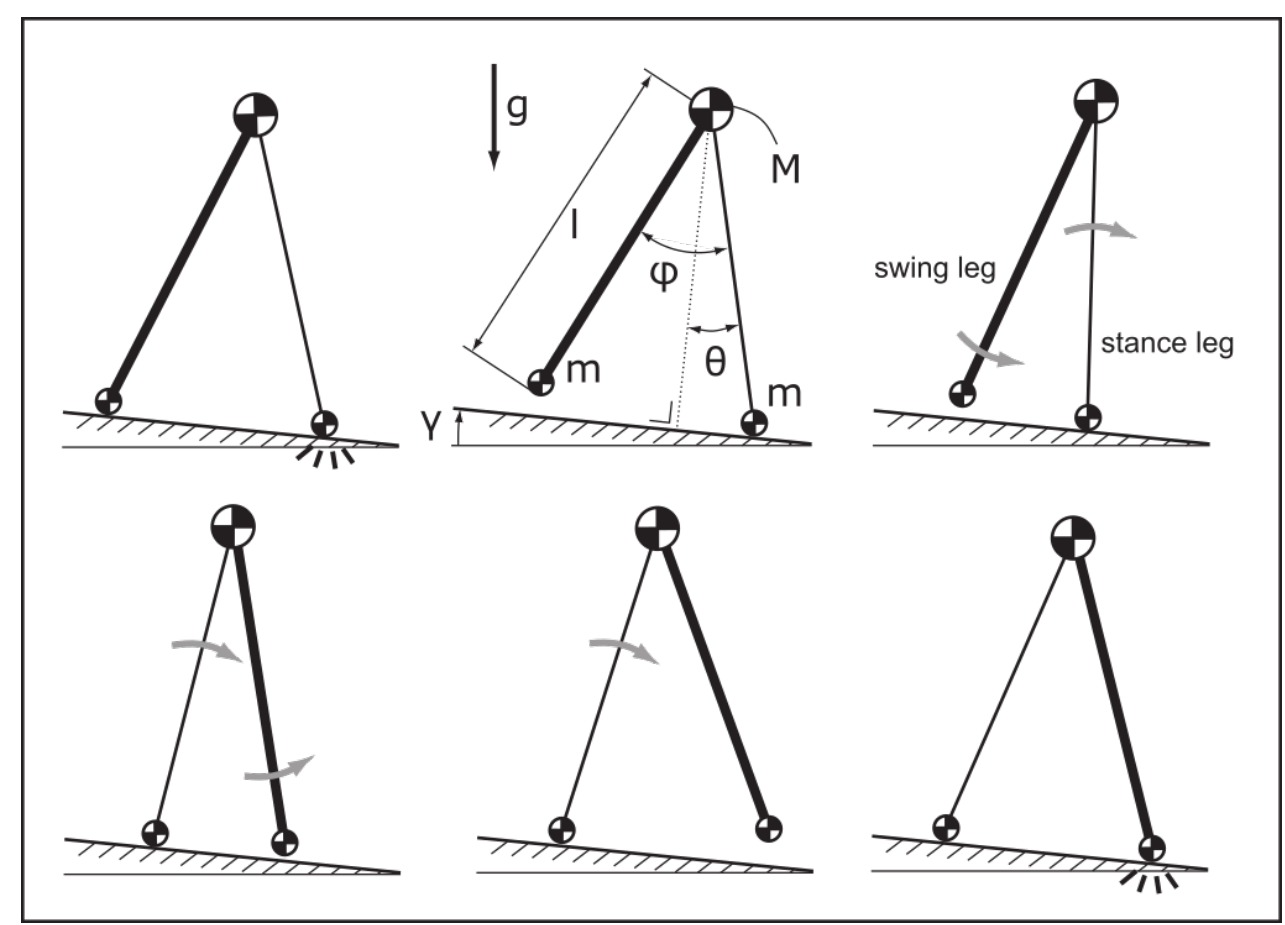

Figura 3: Ciclo-Limite de um Simplest Walker (HOBBELEN; WISSE, 2007)

Este conceito tem sido bastante estudado em diversos trabalhos recentes pois faz uso da dinâmica natural do robô, levando à uma grande eficiência energética. Além disso, por não fazer uso de um controle de posição rígido das juntas, acaba tendo um certo grau de adaptabilidade a pequenas variações no terreno onde está sendo executada a marcha. Isto ocorre devido à existência de uma Bacia de Atração (Basin of Atraction). Esta é uma região no espaço de estados envolta do ciclo-limite nominal no qual o sistema volta a convergir à orbita desejada. Em contrapartida, sua aplicação ainda é relativamente limitada, não possibilitando a realização de movimentos complexos finos ou o caminhar sobre terrenos com desníveis abruptos como escadas. Um dos grandes desafios em sua implementação é encontrar as condições de ciclo-limite estáveis em tempo real.

Recentemente os trabalhos na área de Limit Cycle Walking vem tendo foco principalmente em três aspectos. O primeiro é o aumento da bacia de atração e robustez dos robôs que utilizam tal paradigma como base de controle. 
lida e Tedrake (2010) apresentaram um método de controle de um Compass-Gait de modo a gerar uma marcha estável em um terreno acidentado. Em conjunto com Manchester (MANCHESTER et al., 2011) tal método foi posteriormente aperfeiçoado e testado em um protótipo com sucesso. Kochuvila, Tripathi e Sudarshan (2012) apresentaram um controle de um Compass-Gait utilizando Partial Feedback Linearization, consequentemente alargando a bacia de atração do modelo.

O segundo aspecto em foco é o aumento da versatilidade do Limit Cycle Walking. Hobbelen e Wisse (2008) apresentaram um método de controlar a velocidade de uma marcha em ciclo-limite. Gregg et al. (2012) apresentaram uma metodologia de controle de marcha em ciclo-limite utilizando primitivas pré-computadas de forma a conseguir uma maior flexibilidade na marcha em tempo real.

Para finalizar, o terceiro aspecto em foco é na detecção de pertubações e "perda" de estabilidade. Visto que um ciclo-limite não tem um ponto de equilíbrio, não é simples determinar quando uma marcha pode ser considerada estável. Em Manchester et al. (2010) foi proposto um método para estimar a bacia de atração de uma marcha em ciclo-limite. Gallego et al. (2011) propuseram uma metodologia para detectar tais perturbações possibilitando o uso de rotinas de recuperação ou proteção do sistema.

\subsubsection{N-Step Capturability}

O conceito de $\mathrm{N}$-Step Capturability teve sua primeira formulação apresentada por Pratt e Tedrake (2006) e posteriormente foi melhor formalizado e extendido para outros modelos por Koolen et al. (2012). Ele é baseado nos conceitos de Capture Point e Capture Region, que foram definidos por Pratt et al. (2006) como:

"A Capture Point is a point on the ground where the robot can step to in order to bring itself to a complete stop. A Capture Region is the collection of all Capture Points"

Posteriormente o conceito de $\mathrm{N}$-step capturable foi apresentado e definido por Pratt e Tedrake (2006). Este conceito define se um bípede consegue chegar à uma situação estável em $\mathrm{N}-1$ passos. De forma complementar foi definido o $\mathrm{N}$-step capture point, que seria a expansão do Capture Point para um número $\mathrm{N}$ de passos. Para finalizar 
foi definido o $\mathrm{N}$-step capture region, que seria uma região formada por todos os $\mathrm{N}$ step capture points. Koolen et al. (2012) apresentaram os N-step capture regions de 3 modelos baseados no pendulo invertido de Kajita, demonstrando o impacto de atributos de um bípede em sua estabilidade.

Posteriormente Pratt et al. (2012) projetaram um controlador baseado no conceito de N-Step Capturability permitindo que um robô consiga manter uma marcha prédeterminada, mesmo mediante a perturbações. De forma complementar, a rotina de controle em questão também permite que sejam escolhidos os pontos onde serão realizadas as passadas do robô, adicionando um grau de flexibilidade ao método. $O$ controle projetado foi implementado no robô M2V2 com sucesso como apresentado por Pratt et al. (2012) possibilitando o robô se manter estável, mesmo com pequenos empurrões.

Este novo paradigma se mostrou bastante promissor por abordar a recuperação da marcha mediante a perturbações de uma forma compatível com a estratégia utilizada por seres humanos, como foi demonstrador por Forner-Cordero, Koopman e Helm (2003). De uma forma similar, humanos fazem uso de diversos passos, se necessário, para se recuperar de uma perturbação.

\subsection{Problema Tratado na Tese}

Como pode ser visto nas seções anteriores, robôs bípedes já são estudados há mais de 40 anos, porém na última década houve um grande crescimento de trabalhos desenvolvidos nesta área devido aos recentes avanços tecnológicos em atuadores, baterias e sensores. Apesar de diversos trabalhos terem tido sucesso em desenvolver robôs bípedes capazes de realizar rotinas pré-programadas, ainda existem algumas lacunas que impossibilitam o seu uso ubíquo em aplicações reais. Dentre elas se destaca o controle da marcha, o qual é um aspecto essencial para possibilitar o uso de robôs em ambientes variados de uma forma robusta e confiável.

Dentro deste aspecto se destacam três pontos principais a serem considerados como críticos: consumo energético, robustez e versatilidade. Um robô que não possa atender aos três requisitos não terá utilidade prática. Sem robustez a sua confiabilidade não será aceitável. Sem versatilidade seus movimentos ficarão restritos, impe- 
dindo a sua ampla utilização e movimentação. Para finalizar, sem eficiência energética, a sua utilização ficará limitada à poucos minutos, como acontece no estado da arte.

Pode-se notar então que o estado da arte em controle de marcha bípede consegue atender cada um dos requisitos de uma forma independente, porém nunca de uma forma abrangente. Algoritmos baseados em Zero Moment Point permitem um grau de controle dos movimentos do robô com muita flexibilidade, garantindo em todos os momentos uma estabilidade estática do sistema. Porém, o uso de controladores de posição nas juntas com altos ganhos para garantir o posicionamento desejado cria um movimento extremamente rígido e ineficiente energeticamente, além de ter pouca adaptabilidade natural a pequenos distúrbios externos, os quais devem ser previstos e incluídos no modelo e no controlador.

Sistemas controlados baseados no conceito de Limit Cycle Walking oferecem uma grande eficiência energética, porém são pouco flexíveis (caminham a velocidade quase constante sobre a superfície para a qual foram projetados) e trabalha no limite da instabilidade, tendo uma baixa rejeição a distúrbios.

O conceito N-Step Capturability proporciona um método para escolher posicionamento dos passos para síntese de marcha e recuperação de distúrbios de forma robusta. Porém trabalha com um modelo da passada extremamente simplificado. Sua utilização hoje em dia ainda é restrita na geração de marcha, existindo poucos trabalhos como Pratt et al. (2012) que conseguiram a implementação em um robô real. Sua utilização atual é mais focada como um método para recuperação de balanço (STEPHENS, 2011) para servir como um critério adicional estabilizador aos controladores baseados em ZMP.

Por outro lado, os seres humanos desenvolveram a capacidade de realizar uma marcha bípede em diferenciados tipos de terrenos e condições, conseguindo lidar com grandes perturbações inesperadas e realizar uma ampla variedade de movimentos. Tudo isso com um eficiente consumo energético. Estes fatos indicam que os princípios fundamentais do controle da caminhada ainda não foram adequadamente compreendidos.

Podemos considerar como hipótese que controle do ser humano se adaptou de forma quasi-ótima aos ambientes existente, levando em consideração todos os aspec- 
tos importantes para um robô bípede. Desta forma, tentar entender e se inspirar na marcha do ser humano é um caminho promissor para se tentar sintetizar uma marcha robótica utilizável em aplicações reais.

Podemos assumir que quando um ser humano está andando ele emprega estratégias diferentes de acordo com a situação. Se está caminhando em um terreno desconhecido e potencialmente instável ele controla o posicionamento de suas juntas com maior rigidez e tem um maior esforço consciente em sua marcha. Quando existe perigo de queda, eficiência energética não é a função-objetivo mais importante.

Se está caminhando em um terreno conhecido e estável, o posicionamento das suas juntas é realizado de forma mais relaxada, sem rigidez, de forma a ter uma marcha mais confortável (mais eficiente e menos cansativa). Existe apenas uma mudança de estratégia (maior consciência da marcha) caso o padrão de sua marcha esteja fora do que é previsto.

Caso esteja em uma situação completamente instável, como após um tropeço, a sua estratégia de recuperação varia de acordo com a situação, tentando se estabilizar com a sua base de apoio atual ou dando passos para criar uma nova base de apoio estável (FORNER-CORDERO; KOOPMAN; HELM, 2004).

O fato de existirem essas diferentes estratégias com diferentes níveis de esforço consciente sugere que existem diferentes formas de controlar a marcha. Poderia ser o resultado de um controle baseado na optimização de diferentes funções-objetivo que poderiam ter fatores de ponderação variáveis dependendo das condições externas. Em todos os casos deve existir um critério de estabilidade amplo que consiga englobar todas essas situações e fornecer a informação do grau de instabilidade do bípede. $O$ mesmo conceito pode ser estendido para robôs bípedes. Dentro deste cenário, o autor propõe a necessidade da criação de um novo critério de estabilidade mais amplo que possa, de forma contínua, avaliar a estabilidade de uma marcha e ao mesmo tempo identificar os limites de estabilidade do bípede (se é necessária uma marcha estável estaticamente, ou se pode ser efetuada uma marcha dinâmica, etc...). 


\subsection{Objetivos}

O objetivo geral deste projeto é desenvolver e implementar um critério de estabilidade para controle marcha de sistemas robóticos bípedes que tenha a capacidade de ser robusto, flexível e energeticamente eficiente. Porém, para tal, foram identificados alguns objetivos específicos, em forma de desafios científicos-tecnológicos, os quais destacam-se:

(a) Desenvolvimento de ferramentas abertas para auxiliar no desenvolvimento de algoritmos de controle de robôs bípedes e análise das ferramentas existentes.

(b) Estudo da marcha humana de forma a compreender os mecanismos de controle da mesma e aplicá-los na marcha de robôs bípedes.

(c) Desenvolvimento de um critério de estabilidade mais amplo que os existentes que contemple marchas estáticas e dinâmicas e a implementação de marchas eficientes.

(d) Implementação e avaliação de um controlador baseado no critério de estabilidade desenvolvido.

Desde o ponto de vista científico-tecnológico este trabalho aporta um modelo de controle da marcha bípede inspirado na marcha humana e que capture os princípios de controle da mesma e que supere os problemas atuais dos robôs bípedes.

\subsection{Metodologia}

\subsubsection{Definição das Ferramentas}

Inicialmente foi feita uma avaliação crítica das ferramentes que teriam que ser utilizadas no decorrer do projeto, com especial enfoque no simulador.

\subsubsection{Desenvolvimento de Ferramentas}

Após a avaliação das ferramentas existentes, foi avaliado a necessidade de desenvolvimento de ferramentas complementares para acelerar o desenvolvimento deste 
trabalho.

\subsubsection{Desenvolvimento de Interface Simulador - MATLAB}

Grande parte dos simuladores existentes tem como principal forma de interface programas feitos em $\mathrm{C}++$. Visto que de modo geral, apesar de extremamente eficiente em um ponto de vista computacional, a linguagem de programação $\mathrm{C}++$ demanda um esforço razoavelmente grande para a implementação de algoritmos, foi considerado que a mesma seria muito custosa para ser utilizada durante o decorrer do projeto. MATLAB, por sua vez, é um ambiente de desenvolvimento de algoritmos bastante amigável, eficiente e como diversos recursos já desenvolvidos, desta forma foi considerado como o ambiente base para o desenvolvimento deste trabalho. De forma a poder integrar o ambiente de desenvolvimento do MATLAB e do simulador, foi desenvolvida uma camada de interface síncrona baseada em sockets TCP/IP.

\subsubsection{Desenvolvimento de Toolbox para Controle de Marcha Bípede em Ma- tlab}

Notou-se uma necessidade de rotinas específicas para o controle de marcha em robôs bípedes para MATLAB e desta forma foi desenvolvida uma toolbox contendo diversas funções para tal.

\subsubsection{Desenvolvimento de Rotinas para Avaliação dos Resultados das Simu- lações}

De forma a poder avaliar os resultados das simulações de uma forma quantitativa foram desenvolvidas rotinas em MATLAB para analisar os dados brutos gerados pelo simulador dinâmico.

\subsubsection{Estudo da Marcha}

De forma a poder trabalhar em um novo controlador, foi realizado um estudo da marcha para um melhor entendimento dos fatores que realmente eram importantes para ser definir a estabilidade em um sistema bípede. Este estudo foi dividido em duas etapas apresentadas a seguir. 


\subsubsection{Estudo das Estratégias de Controle Existentes}

De forma a poder se entender as principais capacidades e limitações de algumas das principais estratégias de controle existentes, as mesmas foram estudadas e implementadas.

\subsubsection{Estudo da Marcha Humana}

Foram realizados estudos sobre a marcha de seres humanos de forma a entender e modelar objetivamente como é o seu comportamento de forma a sintetizar o mesmo em um robô bípede.

\subsubsection{Desenvolvimento do Critério de Estabilidade}

Com todas as ferramentas bem estabelecidas, começou então o principal foco deste trabalho: o desenvolvimento do Critério de Estabilidade. Depois de avaliar as estratégias implementadas e os dados da marcha do ser humano, um novo critério de estabilidade foi formulado.

\subsubsection{Desenvolvimento de um Controlador Baseado no Novo Critério de Esta- bilidade}

Tendo o critério de estabilidade formulado, foi desenvolvido um controlador que gere uma marcha que tem como suporte o critério de estabilidade desenvolvido.

\subsubsection{Testes}

Para finalizar o controlador foi testado em dois modelos: no Compass-Gait como forma de teste de conceito e em um modelo de 5 segmentos para uma validação mais rigorosa. 


\subsubsection{Materiais}

Para realizar as simulações foi e está sendo utilizado um computador ja disponível no laboratório com processador Intel Core 17 e placa de vídeo Nvidia GeForce GT430 e um Notebook pertencente ao aluno com um processador Intel Core 17, 8GB de RAM e SSD de 512 GB.

\subsection{Estrutura do texto}

No Capítulo 2 se encontra uma comparação de vários simuladores multi-corpos que foram testados e avaliados, assim como a definição e justificativa do simulador utilizado durante o desenvolvimento da tese.

No Capítulo 3 são apresentadas algumas ferramentas desenvolvidas no âmbito deste trabalho, incluindo uma toolbox de controle de robôs bípedes para MATLAB/Octave.

No Capítulo 4 é apresentado o desenvolvimento, simulações e resultados de um algoritmo de controle com o objetivo de aumentar a bacia de atração de um modelo de um Compass-Gait.

O Capítulo 5 apresenta um estudo que foi realizado comparando a forma de um ser humano ultrapassar um obstáculo em diferentes condições de visão com um robô bípede utilizando um critério de estabilidade baseado em ZMP.

No Capítulo 6 é apresentado desenvolvimento do critério de estabilidade proposto, do controlador empregando este critério assim como as simulações para sua validação.

O Capítulo 7 apresenta as conclusões deste trabalho. 


\section{SIMULADORES}

Considerando que o presente trabalho foi desenvolvido em ambiente de simulação, a escolha do simulador multi-corpos foi considerado um ponto de extrema importância para garantir que os resultados obtidos tenham validade prática. Desta forma, foi despendido um tempo pesquisando e avaliando os simuladores existentes para robôs.

Antes de entrar no assunto da avaliação dos simuladores em si, é valido fazer um pequeno parenteses sobre simuladores multi-corpos. Existem diversas possibilidades para a arquitetura de um simulador, mas, no caso de softwares para simulação de robôs, normalmente eles são compostos por uma interface visual, um motor de física (engine dinâmica), uma interface para interagir com a simulação (extrair dados de sensores e controlar atuadores) e uma componente para orquestrar tudo isso. O motor de física é o componente mais importante quando estamos lidando com simulação de marcha de robôs bípedes. Ele é a responsável por gerar todos os comportamentos dinâmicos dos corpos, incluindo colisões e atritos. Se o motor de física utilizado não computar uma solução de forma estável e precisa, a simulação como um todo não terá validade prática.

Existem diversos aspectos que tem que ser levados em consideração sobre o motor de física. Peters e Hsu (2015) apresentaram uma comparação entre os motores de física utilizadas pelo Gazebo ${ }^{1}$ e demonstrou os principais aspectos a serem considerados quando comparando motores de física. O primeiro a ser citado é se ele trabalha com coordenadas generalizadas ou máximas coordenadas. No primeiro caso o sistema é descrito por suas mobilidades (e.g. juntas) enquanto no segundo caso, cada corpo é descrito pelos seus 6 graus de liberdade e restrições são impostas entre os corpos para que eles se comportem da forma desejada. A grande desvantagem do sistema de máximas coordenadas é que ele trabalha com matrizes grandes e espar-

\footnotetext{
${ }^{1}$ Gazebo é um simulador computacional focado em simulações de robôs.
} 
sas, e durante a evolução dos cálculos esse tipo de sistema tende a ter um potencial acumulo de erro e maior imprecisão nos cálculos (BARAFF, 1996). Usualmente o algorítimo de Featherstone (FEATHERSTONE, 1987) é utilizado para a implementação do sistema de coordenadas generalizadas.

O segundo ponto relevante a ser considerado é como são tratados os contatos. Estes podem ser tratados como restrições unilaterais de forma impulsiva, ou como forças de reação entre corpos com diferentes impedâncias. A vantagem de contatos tratados de forma impulsiva é que eles são mais rápidos de serem calculados pois requerem um passo de simulação menor (BARAFF, 1996). Em contrapartida, sistemas biomecânicos usualmente tem materiais de diferentes impedâncias, e é necessário que essas sejam levadas em consideração durante a simulação. O ultimo ponto citado por Peters e Hsu (2015) é como são formulados sistemas amortecedor-mola nos motores de física. Quando são formuladas de forma explicita a simulação pode ser instável numericamente dependendo do passo utilizado.

No presente contexto existem dois motores de física amplamente utilizadas em simuladores para robôs em geral: ODE (SMITH, 2016) e Bullet (COUMANS, 2016). Ambos motores de física foram projetados de forma a sacrificarem um pouco a precisão em seus resultados a favor de uma simulação mais rápida. A razão por este compromisso é por que são muito utilizados para gerarem os comportamentos dinâmicos de objetos em jogos de computador. Ambos os motores de física utilizam sistema de máximas coordenadas (Novas versões do Bullett tem coordenadas generalizadas, porém os simuladores avaliados não implementam essa opção) e ambos utilizam contatos impulsivos implementados com Linear Complementarity Problem (LCP). Adicionalmente, o Bullet utiliza formulação explicita de sistemas amortecedor-mola.

\subsection{Avaliação dos Simuladores de Código Aberto}

Todos os simuladores avaliados pelo autor são de código aberto. Os seguintes critérios foram os principais aspectos utilizados durante a comparação dos simuladores

(a) Documentação: Um bom simulador sem documentação é praticamente inutilizável. 
(b) Suporte e assistência técnica: Sem um suporte técnico mínimo acaba sendo virtualmente impossível resolver problemas encontrados no simulador.

(c) Sistemas Operacionais Compatíveis: Apesar de o presente trabalho ter a possibilidade de ser desenvolvido tanto em ambiente Windows como Linux, a disponibilidade de distribuições dos simuladores avaliados para os dois sistemas operacionais foi considerada relevante visto que pode criar futuras limitações.

(d) Estabilidade do software: Estabilidade no sentido de o software travar e dar erros constantes. Caso o simulador se demonstre instável, irá impactar diretamente no desenvolvimento deste trabalho.

(e) Motores de Física: Um dos pontos mais relevantes a serem avaliados são os motores de física utilizadas pelos simuladores.

Apenas simuladores testados pelo autor foram avaliados. Houve um workshop sobre simuladores no ICRA 2013 devido ao DARPA Robotics Challenge com artigos que citam outros simuladores (DALLALI et al., 2013).

Os simuladores aqui avaliados foram:

1. OpenHRP3/Choreonoid

2. Gazebo

3. OpenRave

4. Simulation Construction Set

5. Simbody 


\subsubsection{OpenHRP3/Choreonoid}

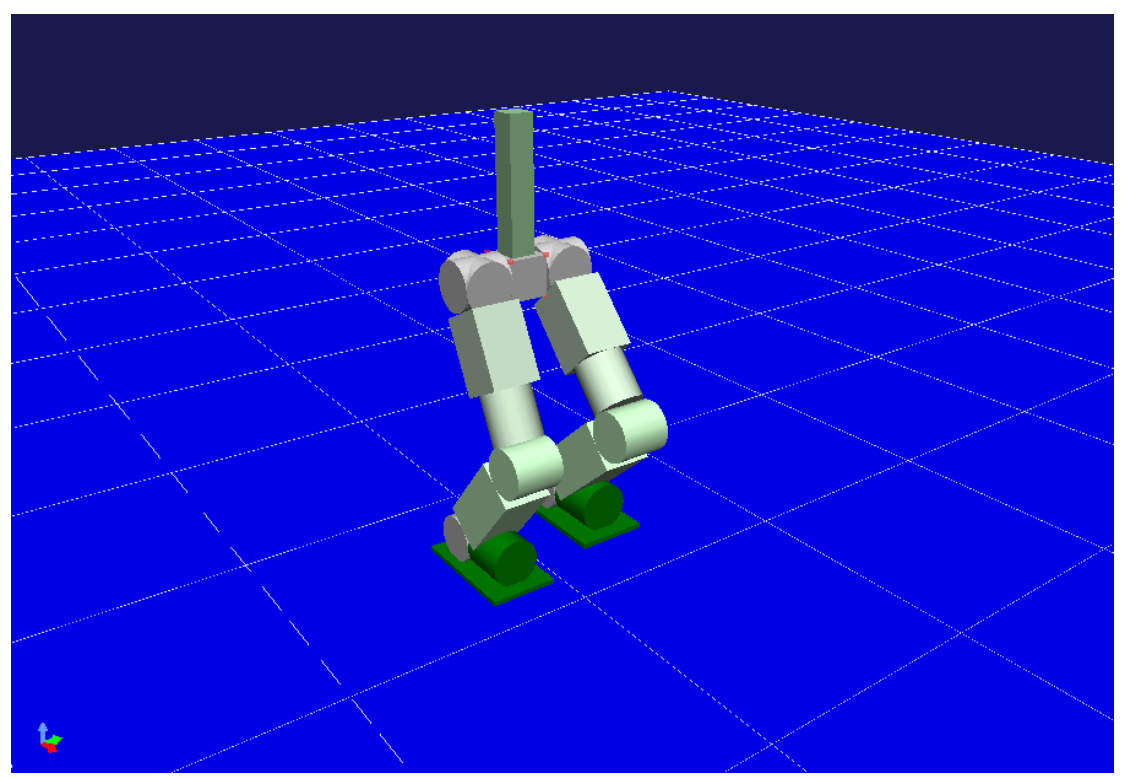

Figura 4: Simulação de marcha ZMP no Choreonoid

OpenHRP3 foi desenvolvido por um conjunto de institutos e empresas japonesas dentro do programa japonês Cooperation of Next Generation Robots especificamente para simulação de robôs bípedes.

O desenvolvimento de algoritmos de controle é baseado em $\mathrm{C}++$ utilizando a framework OpenRTM. O Simulador tem uma arquitetura com componentes distribuídos. A GUI foi implementada como um plugin para a IDE eclipse em Java. Esta, por sua vez, se demonstrou bastante instável e de difícil usabilidade.

O simulador oferece tanto versões para Linux quanto para Windows. A documentação disponível no website do simulador, junto com os exemplos disponíveis, é suficiente para se desenvolver programas de controle, porém bastante incompleta. Os modelos de robôs utilizados são baseados VRML e podem ser criados a partir do próprio software sem a necessidade de entender a estrutura do arquivo-fonte.

O suporte técnico do simulador é fornecido através de um fórum, porém grande parte das informações já disponibilizadas no mesmo estão em japonês, reduzindo bastantes quantidade de informações disponíveis sem a necessidade do uso de um tradutor.

O simulador tem suporte a dois motores de física, sendo um desenvolvido pela 
Tokyo University (YAMANE; NAKAMURA, 2008) e outro pelo AIST (NAKAOKA et al., 2007). O motor de física distribuído com o simulador é o desenvolvido pelo AIST é baseado no algoritmo de Featherstone.

O simulador tem código-fonte aberto, porém bastante complicado de se compilar em Windows e o procedimento descrito no site falhou diversas vezes, em especial devido à diferentes versões do Java instalado no computador. Em Linux o procedimento demonstrou algumas complicações, porém foi mais simples.

O simulador Choreonoid (NAKAOKA, 2012) foi concebido para ser um sucessor do OpenHRP3. Também desenvolvido pelo AIST, continua com suporte tanto para Linux quanto para Windows. Acabou com os componentes distribuídos, deixando o software muito mais rápido e estável.

A nova GUI feita em $\mathrm{Qt}^{2}(\mathrm{C}++)$ e se demonstrou bem mais estável e amigável. O Choreonoid também tem código-fonte aberto e muito simples de compilar. $O$ autor deste trabalho encontrou uma instabilidade no software e reportou para o desenvolvedor e o mesmo encontrou um bug no código como causa da instabilidade. Foi possível modificar o código-fonte do programa e recompilar, não necessitando esperar o desenvolvedor criar um release novo do código.

O Choreonoid utiliza o mesmo motor de física que o OpenHRP3, desenvolvido pelo AIST, além de oferecer suporte para ODE e Bullet. Um dos pontos desfavoráveis do Choreonoid em relação ao OpenHRP3 é que não é possível desenvolver modelos no próprio software, porém o mesmo suporta os modelos utilizados e criados no OpenHRP3.

O suporte do simulador é via lista de e-mails, porém o tempo de resposta é bastante alto.

\footnotetext{
${ }^{2}$ QT é uma framework de desenvolvimento de aplicações em C++ multiplataforma
} 


\subsubsection{Gazebo}

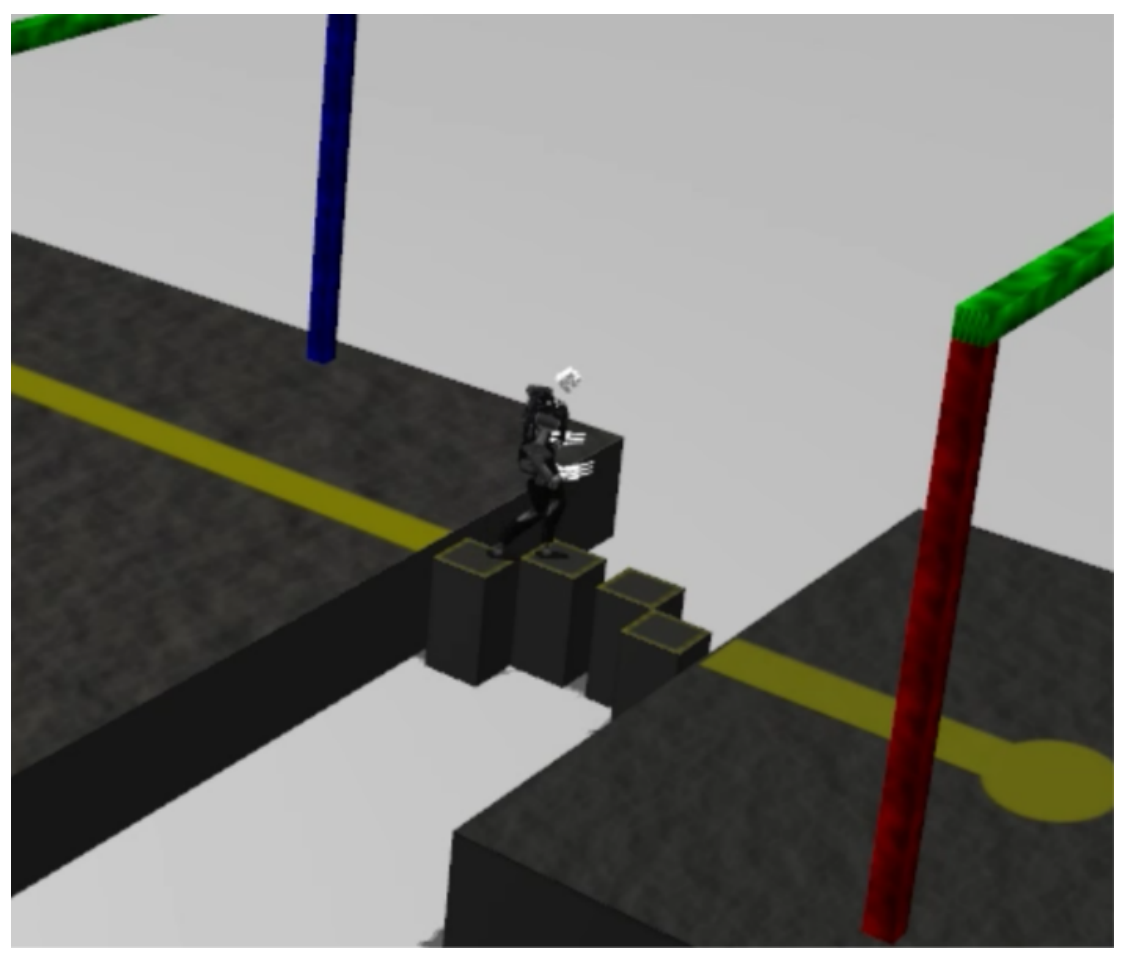

Figura 5: Simulação de marcha no Gazebo.

O Gazebo (KOENIG; HOWARD, 2004) é um simulador de robôs inicialmente desenvolvido por Nate Koenig, porém hoje em dia conta com uma equipe maior de desenvolvedores. O seu desenvolvimento ganhou bastante momentum durante o desenvolver desta tese por o mesmo ter sido escolhido como o simulador oficial do DARPA Robotics Challenge. Mesmo após a competição, o ritmo de desenvolvimento continua bastante expressivo. Oferece distribuições para Linux e Windows e tem uma ótima integração com o $\operatorname{ROS}^{3}$ (QUIGLEY et al., 2009), o qual é um aspecto muito positivo pois o ROS aparece como uma ferramenta emergente na área da robótica como um todo. A distribuição em Windows é relativamente recente e não foi testada.

Desenvolvimento de programas é focado em ROS, porém não existe como sincronizar os processos fazendo com que o tempo de processamento do algoritmo de controle seja uma limitação crítica.

O simulador em si oferece apenas suporte a linguagem de programação em $\mathrm{C}++$,

\footnotetext{
${ }^{3}$ Robotic Operating System (ROS) é uma framework para escrever softwares para controle e sensoriamento de robôs. É composta por uma coleção de ferramentas, bibliotecas e padronizações de forma a simplificar o desenvolvimento de sistemas robóticos complexos.
} 
porém o desenvolvimento utilizando ROS pode ser realizado tanto em Python como $\mathrm{C}++$

Os motores de física suportados na época em que o autor utilizou o simulador eram ODE e Bullet. Porém, ganhou recentemente suporte para novos motores de física como o Simbody (SHERMAN; SETH; DELP, 2011).

Durante a utilização do simulador o mesmo se demonstrou bastante pesado e instável. O mesmo foi comentado por outros usuários que o autor teve contato. A API do simulador tem mudanças bastante drástica entre releases, dificultando o desenvolvimento de códigos pois os mesmos não eram compatíveis entre diferentes versões.

O suporte é dado por um fórum razoavelmente ativo e com bastante informação em inglês já disponível.

\subsubsection{OpenRave}

+index*4+64 OpenRave (DIANKOV, 2010) foi desenvolvido e é suportado por Rosen Diankov como o principal objetivo de oferecer um ambiente integrado para testes cinemáticos e dinâmicos de algoritmos de planejamento de movimentação de robôs. O desenvolvimento do simulador ainda está ativo, porém com releases bastante esporádicos.

Oferece tanto versões para Linux quanto para Windows e os algoritmos podem ser programados tanto em Python como em $\mathrm{C}++$. É relatado uma certa integração com Octave, porém o autor deste trabalho teve uma certa dificuldade para utilizar tal capacidade.

Utiliza ODE e Bullet como motor de física e provê um algoritmo chamado ikfast para gera cinemática inversa analítica de manipuladores robóticos. Porém tal algoritmo não está atrelada diretamente ao simulador, gerando um código em C++ portável.

Oferece suporte através de uma lista de e-mails, sendo que o desenvolvedor responde as dúvidas na mesma com bastante frequência. 


\subsubsection{Simulation Construction Set}

Desenvolvido pelo Florida Institute for Human and Machine Cognition (IHMC) (IHMC, 2014), oferece um motor de física baseada no algoritmo de Feathestone e com resultados de simulações compatíveis com medidos na realidade.

O simulador é desenvolvido em Java e utiliza a mesma como linguagem de programação tanto para a criação das simulações quanto para a criação do controle do robô.

A documentação do simulador é praticamente inexistente e o suporte técnico é oferecido apenas enviando e-mail para os desenvolvedores, os quais nem sempre respondem.

Após uma série de complicações, foi possível de se testar os exemplos, porém não foi possível o desenvolvimento próprio devido à falta de documentação. Houve uma grande dificuldade para conseguir fazer o simulador funcionar por falta de informação. Caso a documentação fosse mais bem detalhada, seria um simulador com bom potencial. Vale ressaltar que muitas das simulações realizadas pelo grupo de Jerry Pratt são feitas nesse simulador, como os testes do N-Step Capturability (PRATT et al., 2012).

\subsubsection{Simbody}

Desenvolvido originalmente por Michael Sherman no Simbios Center de Stanford (SHERMAN; SETH; DELP, 2011), no fundo é motor de física, porém oferece uma quantidade suficiente de componentes extras para realizar simulações sem necessitar de outros softwares. O Simbody utiliza coordenadas generalizadas, contatos complacentes com modelagem de impedância dos corpos e com resultados de simulações compatíveis com medidos na realidade.

O simulador é desenvolvido em $\mathrm{C}++$ e fornece uma ampla biblioteca auxiliar para se lidar com a dinâmica de corpos rígidos, como matrizes de transformação, cálculo do jacobiano, acesso à matriz de inércia do sistema, entre outros. O simulador disponibiliza a possibilidade de utilizar integradores de passo fixo e passo variável, além de possibilitar gerar uma simulação apenas via código, não precisando interagir com uma interface gráfica. Adicionalmente oferece a possibilidade de implementar even- 
tos síncronos e assíncronos o que possibilita a utilização de dinâmicas hibridas, com impactos instantâneos.

A documentação do simulador é completa e disponibilizada utilizando doxygen. Existem diversos exemplos já disponibilizados com o código que facilitam em muito a implementação de novos modelos e simulações.

Segundo a documentação disponibilizada no site para instalar o simulador não houve complicações e o sistema funcionou sem problemas.

\subsubsection{Comparação}

A Tabela 1 apresenta uma comparação objetiva entre os simuladores apresentados.

Tabela 1: Tabela comparativa dos simuladores

\begin{tabular}{|l|c|c|}
\hline \multicolumn{1}{|c|}{ Simulador } & \multicolumn{2}{c|}{ Documentação } \\
\hline Opene & Descrição & Qualidade \\
\hline Gazebo & Tutorial e Exemplos & Ruim \\
\hline OpenRave & Doxygen, Tutorial e Exemplos & Razoável \\
\hline Simulation Construction Set & Doxygen e Exemplos & Boa \\
\hline Simbody & Tuorial e Exemplos & Muito ruim \\
\hline
\end{tabular}

\begin{tabular}{|l|c|c|c|c|}
\hline \multicolumn{1}{|c|}{ Simulador } & \multicolumn{2}{c|}{ Suporte } & \multicolumn{2}{c|}{ Sist. Operacionais } \\
\hline \multicolumn{1}{|c|}{ Nome } & Descrição & Qualidade & Windows & LinuX \\
\hline OpenHRP3/Choreonoid & Lista de e-mails & Ruim & X & X \\
\hline Gazebo & Forum & Boa & NT & X \\
\hline OpenRave & Lista de e-mails & Razoável & X & X \\
\hline Simulation Construction Set & e-mail & Muito ruim & X & NT \\
\hline Simbody & Forum & Boa & X & X \\
\hline
\end{tabular}

NT: Teoricamente possível, porém não testado.

\begin{tabular}{|l|c|}
\hline \multicolumn{1}{|c|}{ Simulador } & Performance/Estabilidade \\
\hline \multicolumn{1}{|c|}{ Nome } & Descrição \\
\hline OpenHRP3/Choreonoid & Estável \\
\hline Gazebo & $\begin{array}{c}\text { Requer uma boa placa de vídeo. } \\
\text { Instável. }\end{array}$ \\
\hline OpenRave & Estável \\
\hline Simulation Construction Set & Não foi possível de se avaliar \\
\hline Simbody & Estável \\
\hline
\end{tabular}




\begin{tabular}{|l|c|c|}
\hline \multicolumn{1}{|c|}{ Simulador } & \multicolumn{2}{c|}{ Motor de Física } \\
\hline Nome & Descrição & Sist. Coordenadas \\
\hline OpenHRP3/Choreonoid & Próprio & Generalizadas \\
\hline Gazebo & ODE/Bullet/Simbody/DART & Generalizadas e Máximas \\
\hline OpenRave & ODE/Bullet & Máximas \\
\hline Simulation Construction Set & Próprio & Generalizadas \\
\hline Simbody & Próprio & Generalizadas \\
\hline
\end{tabular}

O SimulationConstructionSet foi desclassificado por suporte e documentação praticamente inexistentes. O OpenRave foi desclassificado pois próprio desenvolvedor indicou que os motores de física utilizadas (ODE e Bullet) não são apropriados para marcha bípede e recomendou o OpenHRP3.

O Gazebo se demonstrou um simulador muito promissor, porém foi desclassificado por, na época de avaliação, não suportar os motores de física apropriados para simulações de robôs bípedes, se mostrar extremamente instável e com API não bem estabelecida. Vale comentar que provavelmente em algum tempo o Gazebo se tornará um simulador bastante poderoso e forte na área da robótica.

Choreonoid foi inicialmente escolhido por:

1. Motor de física preciso para simulações de marcha bípede.

2. Ser estável e com API bem estabelecida.

3. Apesar de carecer um pouco de documentação, existe um suporte por lista de e-mail, sendo que o próprio desenvolvedor do simulador responde as dúvidas.

Porém, com o ganho de maturidade do Simbody ele acabou se tornando um simulador mais interessante por possuir um motor de física preciso, uma ótima documentação e uma boa estabilidade do código. Também oferece o suporte é razoável através do fórum disponibilizado, além de a grande variedade dos exemplos disponibilizados ajudar em grande parte das dúvidas. A possibilidade de implementar sistemas híbridos se mostrou essencial para as implementações do capítulo 6 


\subsection{Conclusões}

A modo de conclusão, seria relevante reconhecer a importância do tipo de aplicação para escolher cada simulador, pois cada um apresenta diferentes vantagens e desvantagens.

Para as simulações com foco em testes conceituais, onde não necessitem de ambientes muito complexos, o Simbody tende a ser o simulador mais apropriado. Para simulações complexas, envolvendo diferentes ambientes e múltiplos robôs, o Gazebo tende a ser mais apropriado. Para simulações intermediárias o Choreonoid oferece um bom simulador com um custo computacional muito menor que o Gazebo e a possibilidade de trabalhar com controladores sincronizados com o passo da simulação. 


\section{FERRAMENTAS DESENVOLVIDAS}

Como apresentado no Capítulo 2, o três principais simuladores (Choreonoid, Gazebo e Simbody) que foram candidatos para serem utilizados para as simulações realizadas nesta tese de doutorado utilizam $\mathrm{C}++$ como linguagem de programação para implementação do controle dos robôs simulados (adicionalmente Python no caso do Gazebo).

Durante a participação do Darpa Robotic Challange, o autor deste trabalho desenvolveu suas rotinas de controle inicialmente em $\mathrm{C}++$. O desenvolvimento se mostrou muito custoso e demorado devido à rigidez da linguagem. Apesar de o processo de desenvolvimento ter se mostrado bem mais produtivo quando o mesmo começou a ser realizado em Python, tal linguagem não poderia ser utilizada com o Choreonoid e com o Simbody.

Em contra partida, MATLAB é uma ferramenta bastante poderosa para implementação de controladores, processamento de dados e análises, deixando o processo de desenvolvimento muito mais ágil e objetivo. Além disso, existem diversas componentes já existentes que porém ser reutilizadas sem grandes complicações de compatibilidade.

De forma a possibilitar o uso de MATLAB e agilizar o desenvolvimento desta tese, duas ferramentas foram desenvolvidas: Um Inter Process Comunication (IPC) entre o simulador e o MATLAB e uma toolbox para MATLAB de controle de robôs bípedes disponíveis online. 


\subsection{Inter Process Comunication - IPC}

De forma a poder fazer uso de ferramentas do MATLAB de forma integrada com as simulações se fez necessário criar uma comunicação entre os processos (Inter Process Communication - IPC) do MATLAB e do Simulador.

Foi implementado uma IPC (llustrado na Figura 6) baseada em comunicação TCP/IP entre os simuladores Gazebo, Choreonoid e Simbody com o MATLAB. A IPC é basicamente composta por uma parcela de código implementada em $\mathrm{C}++$ (Servidor) e outra implementada em código para o MATLAB (Cliente).

$\mathrm{O}$ código em $\mathrm{C}++$ abre um socket TCP-IP e envia informações coletadas na simulação para o MATLAB. MATLAB recebe tais informações, processa na malha de controle e salva um arquivo com os dados recebidos. MATLAB envia resposta para aplicação em $\mathrm{C}++$ que devolve os comandos para os atuadores do robô.

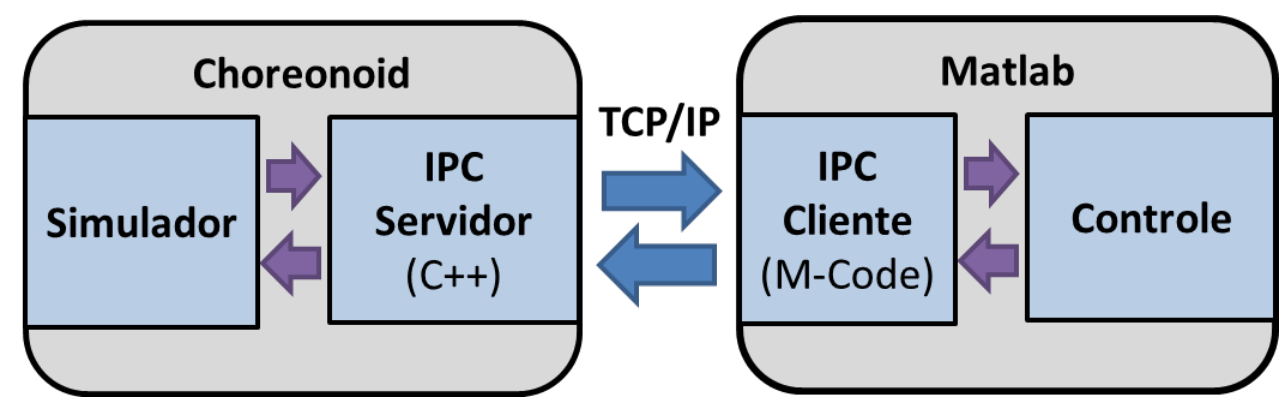

Figura 6: Diagrama do IPC

\subsection{Toolbox Biped Robot Control}

Existe uma grande quantidade de ferramentas desenvolvidas para MATLAB destinadas à desenvolvimento de rotinas de controle de robôs. Porém, tais ferramentes tem foco em robôs manipuladores e não robôs bípedes. Desta forma, para suprir tal lacuna, foram desenvolvidas algumas ferramentas para MATLAB e Octave em parceria com o estudante de Doutorado Kirill Van Heerden da Yokohama National University. O código resultante de tal parceria pode ser encontrado em Rossi e Heerden (2014).

Foi desenvolvido um suporte para modelagem cinemáticas dinâmica de um robô bípede baseado nos parâmetros de Denavit-Hatenberg e características dinâmicas 
dos segmentos, como massa, posição do centro de massas e matriz de inércia.

Tendo uma estrutura resultante que representa o robô, a mesma pode ser utilizada nas funções desenvolvidas, as quais incluem cinemática direta, Jacobiano, cinemática inversa, mudança de base, entre outras.

Duas funções desenvolvidas de grande utilidade para controle de marcha bípede são o COM-IK e o DUAL-IK. A primeira consiste em uma cinemática inversa que gera uma pose do robô para satisfazer simultaneamente a posição do centro de massas do mesmo $(\mathrm{COM})$ e da extremidade de um manipulador. Isto é muito útil para sintetizar marchas com critérios de estabilidade baseados em ZMP e modelados como um pendulo invertido.

A DUAL-IK por sua vez, consiste em uma cinemática inversa que gera uma pose do robô satisfazendo simultaneamente a posição de dois pontos do mesmo. Esta função por sua vez tem bastante utilidade para controles que queiram sintetizar marchas prescrevendo simultaneamente a posição do pé de balança e do quadril, por exemplo.

Adicionalmente foi desenvolvida uma função para gerar a trajetória do centro de massas de um robô de forma a poder satisfazer o posicionamento de um ZMP de referência baseado em Quadratic Programming (WIEBER, 2006). Em conjunto às funções desenvolvidas, estão inclusos na toolbox alguns exemplos completos com síntese de uma marcha baseada em ZMP.

Para finalizar, foi desenvolvido em conjunto com o aluno de graduação um simulador simplório em SimMechanics de forma a possibilitar fechar as malhas de controle desenvolvidas apenas utilizando o MATLAB, agilizando o processo de desenvolvimento. Apesar de o simulador não ter uma precisão e complexidade comparáveis aos abordados no Capítulo 2, o mesmo se mostrou bastante útil para dar um insight se os controladores desenvolvidos estão se comportando corretamente.

O Apêndice A tem uma descrição de teoria de robótica bípede utilizada para o desenvolvimento da toolbox descrita e o Apêndice B uma instrução breve de como fazer download e usar a toolbox. A toolbox é código livre e está disponível para MATLAB e Octave (que também é código livre). 


\section{CONTROLE DE UM BÍPEDE COMPASS GAIT WALKER BASEADO EM PARTIAL FEEDBACK LINEARIZATION COM REFERÊNCIA COMUTADA}

Como foi apresentado no Capítulo 1, os bípedes caminhantes baseados no conceito da marcha em ciclo-limite apresentam problemas para se manter dentro da bacia de atração mediante a distúrbios.

Para que um controle que implemente o conceito do Limit Cycle Walking seja eficaz, existe a necessidade da implementação de uma estabilização do sistema mediante a distúrbios que o levem para fora de sua bacia de atração natural.

Neste capítulo é apresentado a implementação de um controlador de Partial Feedback Linearization em um Passive Dynamic Walker, a fim de melhorar sua estabilidade e rejeição de distúrbios. A novidade desta implementação consiste na aplicação de um algoritmo de comutação possibilitando a recuperação de ambas as pernas do robô.

\subsection{Modelo}

O modelo utilizado para estudar Limit Cycle Walking é o Compass Gait Walker, que consiste em dois segmentos com massa, unidos por um articulação, também com massa. Devido à sua natureza simplista, já foi extensivamente estudado do ponto de vista mecânico, dinâmica e de controle. Por esta razão foi escolhido para ser utilizado para testar o conceito proposto por este trabalho. O modelagem utilizada (Fig. 7) foi adaptada de (GOSWAMI; ESPIAU; KERAMANE, 1997). 


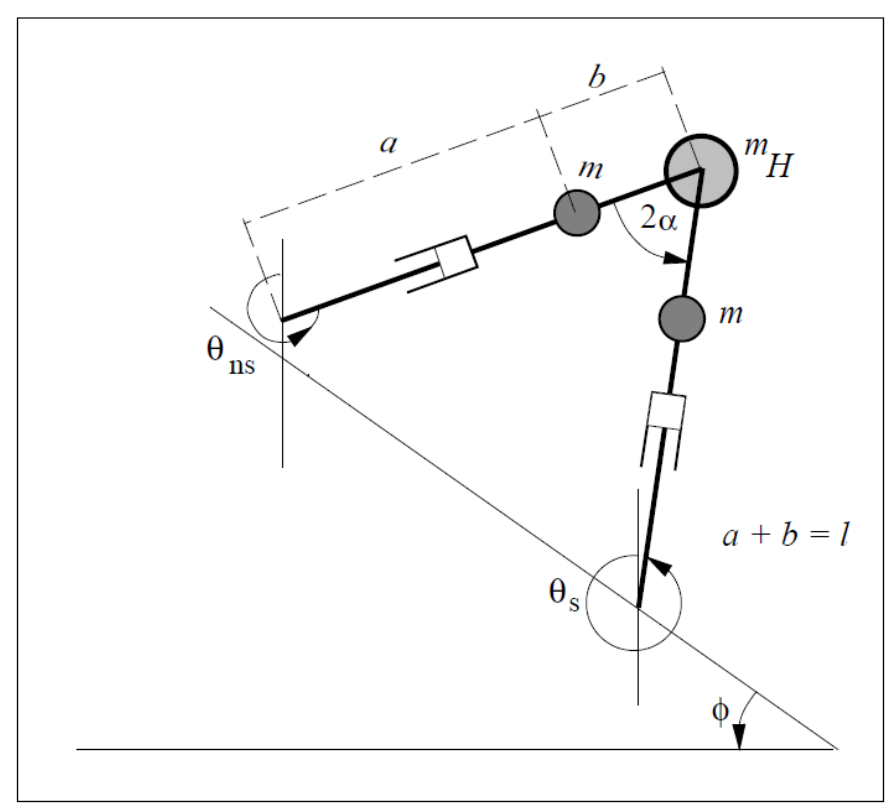

Figura 7: Modelo do Compass Gait Walker (GOSWAMI; ESPIAU; KERAMANE, 1997)

$$
M(\theta) \ddot{\theta}+N(\theta, \dot{\theta}) \dot{\theta}+G(\theta)=B u
$$

A equação (4.1) descreve a dinâmica do sistema onde $u=\left(\begin{array}{c}u_{H} \\ u_{a}\end{array}\right), u_{H}$ sendo 0 torque da junta do quadril e $u_{a}$ o torque da junta do tornozelo, $\theta=\left(\begin{array}{c}\theta_{n s} \\ \theta_{s}\end{array}\right)$, onde $\theta_{n s}$ é o ângulo da perna de balanço com a vertical e $\theta_{s}$ o ângulo da perna de apoio com a vertical, e:

$$
\begin{array}{r}
M(\theta)=\left(\begin{array}{ll}
M_{11} & M_{12} \\
M_{21} & M_{22}
\end{array}\right) \\
M_{11}=m b^{2} \\
M_{12}=-m l b \cos \left(\theta_{s}-\theta_{n s}\right) \\
M_{21}=-m l b \cos \left(\theta_{s}-\theta_{n s}\right) \\
M_{22}=\left(m_{H}+m\right) l^{2}+m a^{2}
\end{array}
$$




$$
\begin{gathered}
N(\theta, \dot{\theta})=\left(\begin{array}{ll}
N_{11} & N_{12} \\
N_{21} & N_{22}
\end{array}\right) \\
N_{11}=0 \\
N_{12}=m l b \dot{\theta}_{s} \sin \left(\theta_{s}-\theta_{n s}\right) \\
N_{21}=-m l b \dot{\theta}_{n s} \sin \left(\theta_{s}-\theta_{n s}\right) \\
N_{22}=0 \\
G(\theta)=\left(\begin{array}{l}
G_{1} \\
G_{2}
\end{array}\right) \\
G_{1}=m g b \sin \left(\theta_{n s}\right) \\
B=-\left(m_{H} l+m a+m l\right) g \sin \left(\theta_{s}\right) \\
\left.-1 \quad \begin{array}{ll}
1 \\
1
\end{array}\right)
\end{gathered}
$$

Reorganizando as expressões acima em uma forma mais compacta, temos:

$$
N(\theta, \dot{\theta}) \dot{\theta}+G(\theta)=\left(\begin{array}{l}
C_{1} \\
C_{2}
\end{array}\right)
$$

São assumidas as seguintes premissas durante a fase de impacto:

- Mudança instantânea na velocidade angular e colisão inelástica perfeita.

- A resultante da perda de energia cinética é restaurada pela força da gravidade, uma vez que a rampa é inclinada.

- Conservação do momento angular.

Considerando o mesmo modelo de impacto que em (GOSWAMI; ESPIAU; KERAMANE, 1997), que o impacto ocorre no instante $t=T$ e que $2 \alpha=\theta_{s}(T)-\theta_{n s}(T)$, o seguinte modelo de impacto é definido: 


$$
\begin{gathered}
\dot{\theta}\left(T^{+}\right)=I(\theta(T)) \dot{\theta}\left(T^{-}\right) \\
I(\theta(T))=Q(\alpha)^{-1} P(\alpha) \\
P(\alpha)=\left(\begin{array}{cc}
-m a b & -m a b+\left(m_{H} l^{2}+2 m a l\right) \cos (2 \alpha) \\
0 & -m a b
\end{array}\right) \\
Q(\alpha)=\left(\begin{array}{cc}
m b^{2}-m b l \cos (2 \alpha) & \left(m l^{2}+m a^{2}+m_{H} l^{2}\right)-m b l \cos (2 \alpha) \\
m b^{2} & -m b l \cos (2 \alpha)
\end{array}\right)
\end{gathered}
$$

No presente trabalho $u_{a}$ foi considerado como nulo em todos os instantes e os parâmetros definidos na Tabela 2 foram utilizados durante as simulações.

\begin{tabular}{cc} 
Tabela 2: Atributos do Modelo \\
\cline { 2 - 2 } Atributo & Valor \\
\hline$m_{H}$ & $10 \mathrm{Kg}$ \\
$\mathrm{m}$ & $5 \mathrm{Kg}$ \\
$\mathrm{a}$ & $0.5 \mathrm{~m}$ \\
$\mathrm{~b}$ & $0.5 \mathrm{~m}$ \\
$\mathrm{~g}$ & $9.8 \mathrm{~m} / \mathrm{s}^{2}$ \\
$\phi$ & $0.0524 \mathrm{rad}$ \\
\hline
\end{tabular}

\subsection{Controle}

A fim de alcançar um ciclo limite, todos os estados controlados devem ser levados à uma condição adequada. Considerando que o modelo proposto é sub-atuado, não é possível a utilização de Feedback Linearization. No entanto, Partial Feedback Linearization (PFL) pode ser utilizado (KOCHUVILA; TRIPATHI; SUDARSHAN, 2012). Ainda assim, como temos apenas uma entrada de controle, apenas $\theta_{S}$ ou $\theta_{n s}$ podem ser controlados a cada instante. Portanto, foi um controle de referência alternada com duas leis de controle: uma para controlar o par $\theta_{s} / \dot{\theta}_{S}$ e uma segunda para controlar o $\operatorname{par} \theta_{n s} / \dot{\theta}_{n s}$. Finalmente, foi criada uma lei de comutação para selecionar qual das leis de controle deve ser utilizada em cada instante. 


\subsubsection{Lei de Comutação}

A Lei de Comutação é fator chave para possibilitar que o algoritmo de controle seja capaz de fazer o sistema convergir ao ciclo limite com sucesso. O principio fundamental implementado neste trabalho é tratar $\theta_{s}$ como o ponto base para encontrar o valor de todos os outros estados, devido ao fato de a perna de apoio ser mais difícil de se controlar. Se esta estiver fora do intervalo do ciclo limite passivo amostrado, $\theta_{s}^{\text {tar }}$ é escolhido como o valor mais próximo disponível e $u_{H}^{s}$ é aplicado a $u_{H}$. Caso contrário, o atual $\theta_{s}$ é considerado como $\theta_{s}^{t a r}$ e são aplicados a lei de comutação, as leis de controle (apresentadas na seção 4.2.2) descritas pelas equações (4.11) e (4.12) e o algoritmo 1.

$$
\begin{aligned}
E_{n s} & =K_{0} *\left(\theta_{n s}^{t a r}-\theta_{n s}\right)^{2}+K_{1} *\left(\dot{\theta}_{n s}^{t a r}-\dot{\theta}_{n s}\right)^{2} \\
E_{s} & =K_{0} *\left(\theta_{s}^{t a r}-\theta_{s}\right)^{2}+K_{1} *\left(\dot{\theta}_{s}^{t a r}-\dot{\theta}_{s}\right)^{2}
\end{aligned}
$$

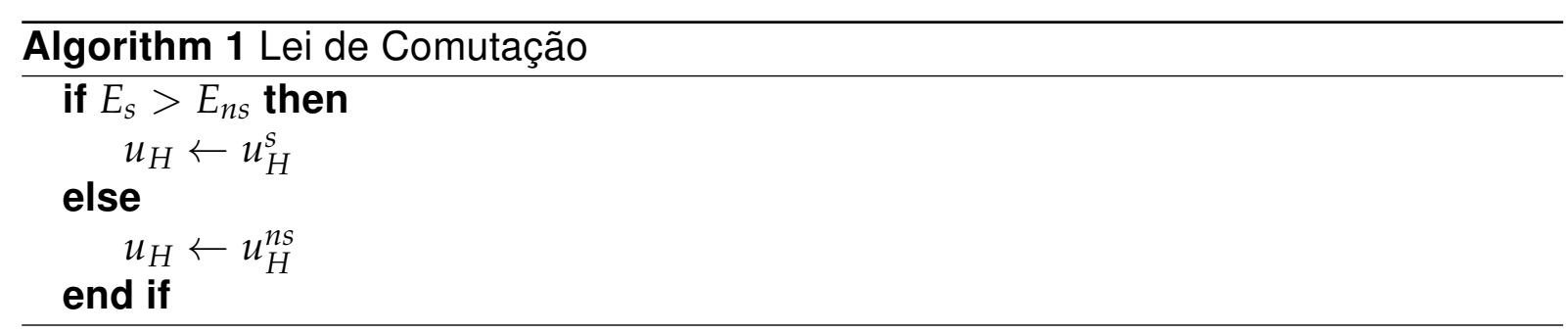

Os erros quadráticos da posição e velocidade foram calculados para $\theta_{n s}$ e $\theta_{s}$, utilizando os ganhos proporcionais do controlador. Se $E_{s}$ é maior que $E_{n s}, u_{H}^{s}$ é aplicado à $u_{H}$ e no caso contrário $u_{H}^{n s}$ é aplicado à $u_{H}$. Finalmente, assim que o controlador julgar que o modelo atingiu a sua bacia de atração passiva, ele deve parar de atuar, deixando o sistema para a sua dinâmica natural. Entretanto, deve notar-se que descobrir da bacia de atração real não é uma tarefa simples, desta forma um modelo simplificado foi utilizado. A Tabela 3 demonstra os intervalos dos valores da bacia de atração. Se todas as variáveis de estados estiverem dentro deste intervalo simultaneamente, comparado à trajetória de referência, o sistema é considerado dentro da bacia de atração. 
Tabela 3: Modelo da Bacia de Atração

\begin{tabular}{cc}
\hline Estado & Valor \\
\hline$\theta_{n s}$ & $0.02 \mathrm{rad}$ \\
$\theta_{s}$ & $0.02 \mathrm{rad}$ \\
$\dot{\theta}_{n s}$ & $0.21 \mathrm{rad} / \mathrm{s}$ \\
$\dot{\theta}_{s}$ & $0.21 \mathrm{rad} / \mathrm{s}$
\end{tabular}

\subsubsection{Leis de Controle}

Duas leis de controle foram geradas aplicando o procedimento de Partial Feedback Linearization para controlar a perna de balanço e apoio respectivamente. Expandindo (4.1) e (4.6) temos:

$$
\begin{gathered}
M_{11} \ddot{\theta}_{n s}+M_{12} \ddot{\theta}_{s}+C_{1}=-u_{H} \\
M_{21} \ddot{\theta}_{n s}+M_{22} \ddot{\theta}_{s}+C_{2}=u_{H}
\end{gathered}
$$

Isolando $\ddot{\theta}_{n s}$ e $\ddot{\theta}_{S}$ em (4.13) temos:

$$
\begin{aligned}
& \ddot{\theta}_{S}=-\frac{1}{M_{12}}\left(u_{H}+M_{11} \ddot{\theta}_{n S}+C_{1}\right) \\
& \ddot{\theta}_{n S}=-\frac{1}{M_{11}}\left(u_{H}+M_{12} \ddot{\theta}_{S}+C_{1}\right)
\end{aligned}
$$

Considerando $\theta_{s}^{t a r}, \theta_{n s}^{\text {tar }}, \dot{\theta}_{s}^{\text {tar }}$ e $\dot{\theta}_{n s}^{\text {tar }}$ os valores de referência desejados em um determinado instante de tempo, teremos as seguintes leis de controle:

$$
\begin{gathered}
\mathcal{V}_{s}=\ddot{\theta}_{s}^{t a r}-K_{0}\left(\theta_{s}-\theta_{s}^{t a r}\right)-K_{1}\left(\dot{\theta}_{s}-\dot{\theta}_{s}^{t a r}\right) \\
\mathcal{V}_{n s}=\ddot{\theta}_{n s}^{t a r}-K_{0}\left(\theta_{n s}-\theta_{n s}^{t a r}\right)-K_{1}\left(\dot{\theta}_{n s}-\dot{\theta}_{n s}^{t a r}\right)
\end{gathered}
$$

Substituindo (4.15), (4.16), (4.17) e (4.18) em (4.14) teremos:

$$
u_{H}^{s}=\frac{M_{21}\left(-\frac{1}{M_{11}}\left(M_{12} \mathcal{V}_{s}+C_{1}\right)\right)+M_{22} \mathcal{V}_{s}+C_{2}}{1+\frac{M_{21}}{M 11}}
$$




$$
u_{H}^{n s}=\frac{M_{21} \mathcal{V}_{n s}+M_{22}\left(-\frac{1}{M_{12}}\left(M_{11} V_{n s}+C_{1}\right)\right)+C_{2}}{1+\frac{M_{22}}{M 12}}
$$

As equações (4.19) e (4.20) são as resultantes do partial feedback linearization considerado em respeito a $\theta_{s}$ e $\theta_{n s}$ respectivamente.

De forma a encontrar $\theta_{s}^{t a r}, \theta_{n s}^{\text {tar }}, \dot{\theta}_{s}^{\text {tar }}$ e $\dot{\theta}_{n s}^{\text {tar }}$ o modelo descrito foi simulado sem nenhum controle e com as condições iniciais descritas na Tabela 4.

\begin{tabular}{cc} 
Tabela 4: & Valores Iniciais \\
\hline Estado & Valor \\
\hline$\theta_{n s}$ & $0 \mathrm{rad}$ \\
$\theta_{s}$ & $0 \mathrm{rad}$ \\
$\dot{\theta}_{n s}$ & $2 \mathrm{rad} / \mathrm{s}$ \\
$\dot{\theta}_{s}$ & $-0.4 \mathrm{rad} / \mathrm{s}$ \\
\hline
\end{tabular}

As Figuras 8(a) e 8(b) ilustram as trajetórias adquiridas com a simulação.

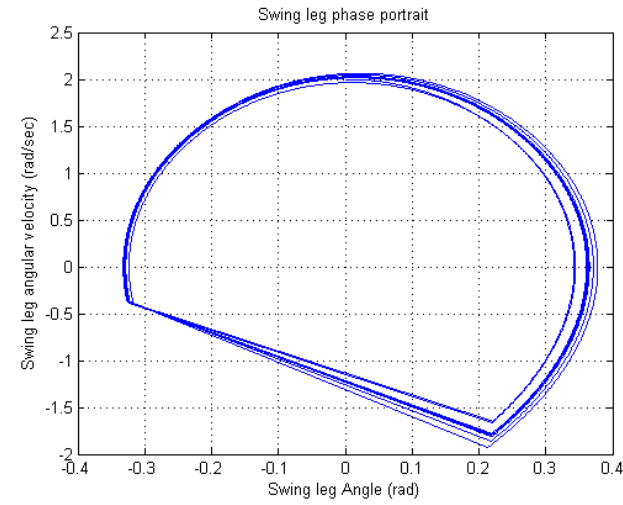

(a) Perna de Balanço

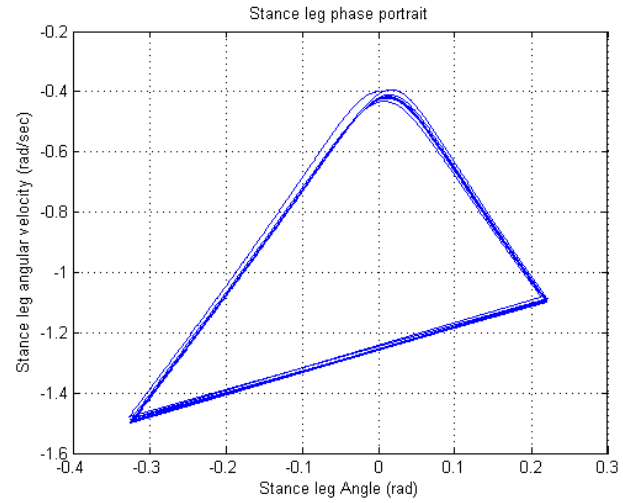

(b) Perna de Apoio

Figura 8: Trajetória desejada

\subsection{Simulação}

As simulações foram realizados com o software MATLAB utilizando ODE45 integrador numérico. O conjunto das quatro variáveis que definem as condições de estado do movimento foram variadas conforme descrito na Tabela 5: aproximadamente 
290.000 casos foram simulados para avaliar se o controle empregado foi capaz de aumentar a bacia de atração em comparação ao caso sem controle.

Tabela 5: Intervalo Simulado

\begin{tabular}{cccc}
\hline Variável de Estado & Valor Inicial & Valor Final & Passo \\
\hline$\theta_{n s}$ & $-0.7 \mathrm{rad}$ & $0.7 \mathrm{rad}$ & $0.05 \mathrm{rad}$ \\
$\theta_{s}$ & $-0.7 \mathrm{rad}$ & $0.7 \mathrm{rad}$ & $0.05 \mathrm{rad}$ \\
$\dot{\theta}_{n s}$ & $-5 \mathrm{rad} / \mathrm{s}$ & $2.5 \mathrm{rad} / \mathrm{s}$ & $0.4 \mathrm{rad} / \mathrm{s}$ \\
$\dot{\theta}_{s}$ & $-3 \mathrm{rad} / \mathrm{s}$ & $0.2 \mathrm{rad} / \mathrm{s}$ & $0.18 \mathrm{rad} / \mathrm{s}$ \\
\hline
\end{tabular}

\subsection{Resultados}

Uma análise quantitativa revelou que o sistema passivo tem 3.883 condições iniciais simuladas diferentes que levam à uma marcha estável, contra 12.043 no caso do sistema controlado. Isto significa que houve um aumento da bacia de atração de aproximadamente $310,1 \%$. Este resultado definitivamente prova a eficácia da abordagem de controle proposto. É importante mencionar que, embora o número de configurações iniciais estáveis é muito pequeno em comparação com o conjunto total que foi testada, existem várias configurações que, com o limite de torque do modelo, são dinamicamente impossível de ser recuperados.

O número relativamente elevado de variáveis (quatro) que definem a condição do estado do bípede é tal que toda a informação não pode ser incluída em um único gráfico. Uma alternativa válida foi concebida através da representação dos dados em um gráficos 3D. Em essência, o eixo $X$ e $Y$ representam, respectivamente, o ângulo e a velocidade angular da perna em análise, enquanto a coordenada $Z$ representa $a$ largura do intervalo (de qualquer ângulo ou a velocidade angular, dependendo sobre o parâmetro escolhido) em que o sistema converge para esse dado par de valores indicados no plano $x-y$. O valor representado em $Z$ foi denominado Função de Densidade da Bacia de Atração.

Variando todos os parâmetros cinemáticos disponíveis sob análise (a perna de referência, tanto para o $x-y$ ou a coordenada $z$, bem como a variável representada no eixo z) temos um total de oito gráficos. A primeira informação notável inferida a partir do gráfico é o aumento da bacia de atração do sistema controlado com respeito ao sistema passivo. Mesmo que o número de pares de velocidades angulares/ângulos 
que garantam a estabilidade não aumenta de uma maneira expressiva nos planos $x-y$, existem muito mais picos na coordenada z (uma concentração mais elevada de pontos de vermelho marcada), que significa uma bacia de atração mais larga.

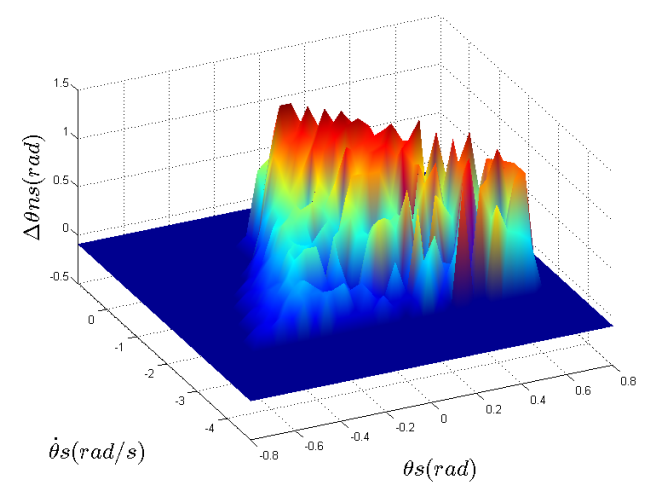

(a) Passivo

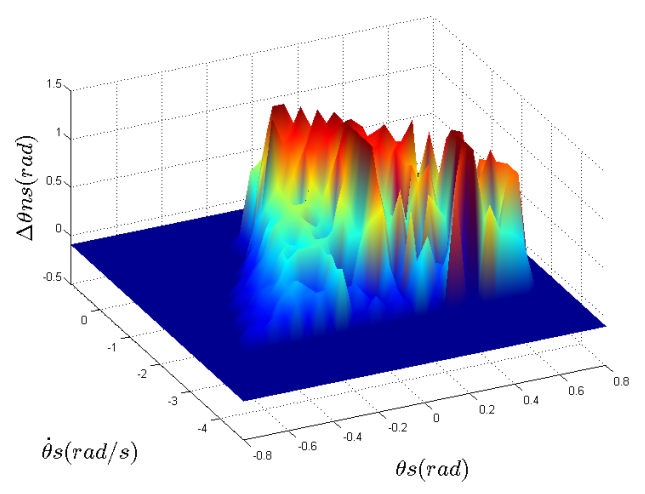

(b) Controlado

Figura 9: Função de Densidade da Bacia de Atração: $\theta_{s} \times \dot{\theta}_{s} \times \Delta \theta_{n s}$

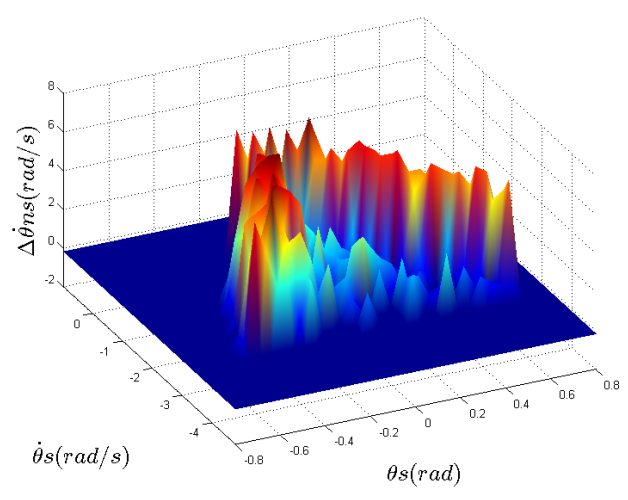

(a) Passivo

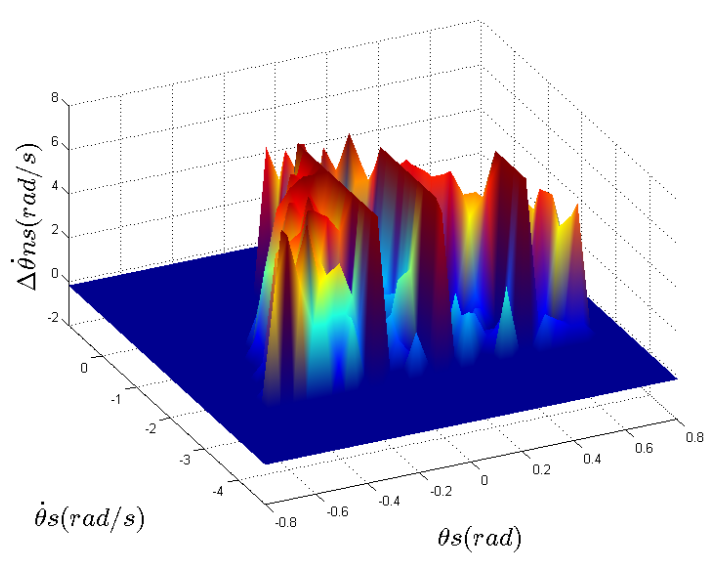

(b) Controlado

Figura 10: Função de Densidade da Bacia de Atração: $\theta_{s} \times \dot{\theta}_{s} \times \Delta \dot{\theta}_{n s}$ 


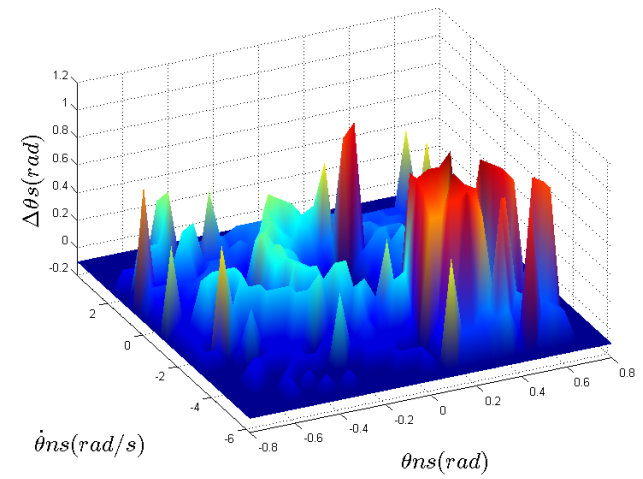

(a) Passivo

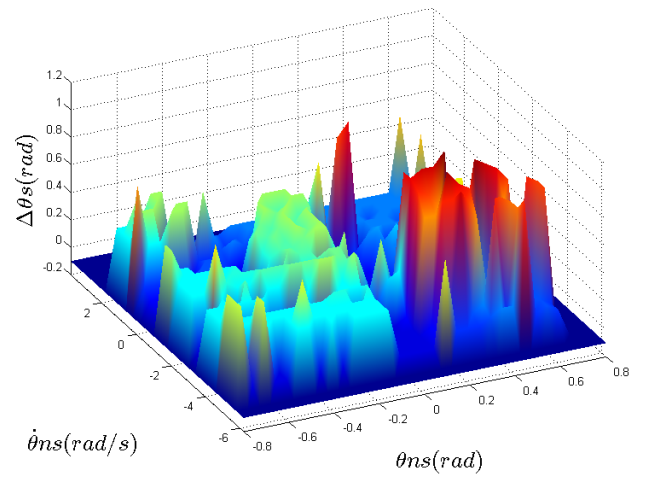

(b) Controlado

Figura 11: Função de Densidade da Bacia de Atração: $\theta_{n s} \times \dot{\theta}_{n s} \times \Delta \theta_{s}$

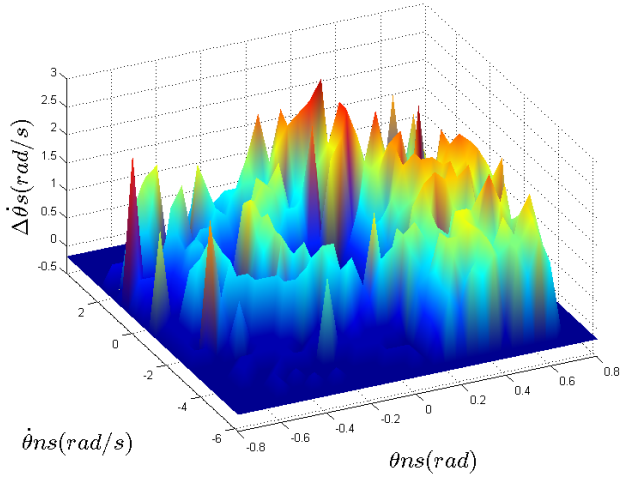

(a) Passivo

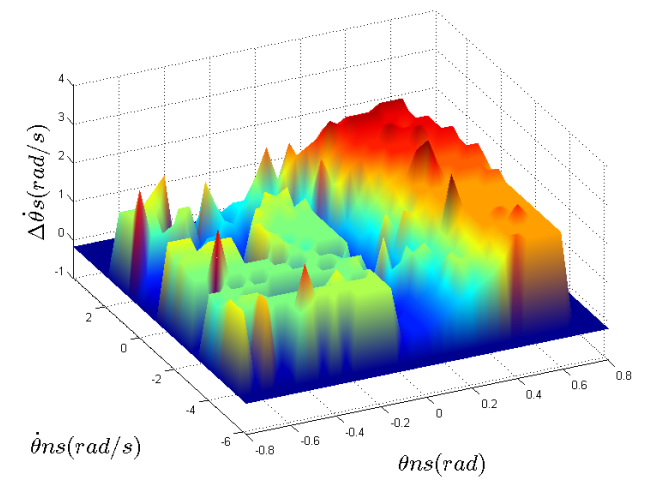

(b) Controlado

Figura 12: Função de Densidade da Bacia de Atração: $\theta_{n s} \times \dot{\theta}_{n s} \times \Delta \dot{\theta}_{s}$

A análise gráfica (Figuras 9 e 10) revela uma certa dificuldade em controlar a posição da perna de apoio, com picos distribuídos de forma caótica no gráfico. Assim, uma análise mais acurada inclui uma investigação de uma explicação razoável para esta peculiaridade. Um resultado interessante é encontrado no comportamento regular da perna de balanço. Isto é crucial para a execução do passo subsequente (WISSE, 2004). 
Uma melhor compreensão do desempenho do controlador poderia ser alcançada com uma analise mais aprofundada das leis de controle e de comutação. Além disso, os seres humanos implementam várias estratégias diferentes quando estão se recuperando de tropeços (FORNER-CORDERO; KOOPMAN; HELM, 2005). Uma melhor compreensão destas estratégias pode levar a insights de como melhorar o desempenho do algoritmo proposto.

Como um inconveniente do controlador apresentado, o ciclo limite de referência deve ser conhecida de antemão. Isto acaba sendo uma restrição real, já que a maior parte das condições de trabalho de um robô normalmente envolvem terrenos irregulares e com imperfeições em suas modelagens. Para superar esta limitação é altamente recomentado a implementação de um detector de ciclo limite automático. Finalmente, este novo controlador poderia ser um bom candidato a ser implementado em um robô real, devido à sua simplicidade e baixa carga computacional.

\subsection{Publicações}

Este trabalho foi aceito e apresentado no 5th IEEE RAS \& EMBS International Conference on Biomedical Robotics and Biomechatronics (ROSSI; NICHILO; FORNERCORDERO, 2014). 


\section{ANALISE DA MARCHA DO SER HUMANO EM DIFERENTES CONDIÇÕES DE VISÃO}

É possível utilizar os mecanismos de controle da marcha bípede humana como inspiração no desenvolvimento de novos algoritmos. Infelizmente tal sistema é uma caixa preta aos nossos olhos, desta forma nos obrigando a realizar procedimentos de "engenharia reversa" para o seu entendimento. Neste capítulo é apresentando um estudo que compara a marcha de um robô bípede baseada no critério do ZMP com seres humanos ultrapassando um obstaculo com diferentes condições de visão.

\subsection{Introdução}

Estudos anteriores demonstraram que os seres humanos, quando com os olhos vendados, apresentam várias mudanças nos padrões de cruzamento obstáculo com relação quando realizam a mesma tarefa com a visão (RODRIGUES et al., 2009). Essas diferenças, que podem ser descritos como um padrão mais cauteloso para as pessoas com os olhos vendados, resultam em menor velocidade e movimentos mais amplos do pé (RODRIGUES et al., 2009; FORNER-CORDERO et al., 2016). Na literature foi-se sugerido que a tarefa é realizada com o pé mais avançado do que o centro de massas do corpo, permitindo assim uma redução da velocidade de avanço e realizando uma passada mais cautelosa (RODRIGUES et al., 2009; FORNER-CORDERO; KOOPMAN; HELM, 2003, 2004). Por outro lado, nos robôs bípedes que caminham usando o critério de Zero Moment Point (ZMP) apresentam uma velocidade da marcha mais lenta do que a marcha humana. Estes robôs caminham avançando a perna até depositar o pé no chão de forma a garantir uma base de apoio antes de avançar o corpo.

O objetivo do presente estudo foi comparar a tarefa de ultrapassagem de um obs- 
táculo entre seres humanos, realizando a tarefa tanto com a visão e com os olhos vendados, e os robôs bípedes. Para gerar a trajetória do pé ultrapassando o obstáculo foi usado o critério do ZMP. Postula-se que as trajetórias das articulações do quadril e do pé dos sujeitos vendados seria muito semelhantes às do robô. Portanto, ao cruzar um obstáculo privado de visão, os seres humanos devem confiar em um modelo para controlar a tarefa que poderia assemelhar-se o critério do ZMP e gerar trajetórias similares.

\subsection{Metodologia}

\subsubsection{Protocolo Experimental}

É importante ressaltar que os dados deste trabalho foram coletados pelo Professor Sergi Tosi Rodrigues e por Valéria Duarte Garcia, ambos do Laboratório de Informação, Visão e Ação (LIVIA) da UNESP Bauru.

\begin{tabular}{cccc}
\multicolumn{4}{c}{ Tabela 6: Características Físicas dos Participantes } \\
\hline Sujeito & Idade(Anos) & Altura $(\mathrm{m})$ & Peso $(\mathrm{kg})$ \\
\hline AB04 & 42.0 & 1.70 & 75 \\
AB05 & 18.2 & 1.75 & 57 \\
AB06 & 26.9 & 1.71 & 75 \\
AB07 & 53.2 & 1.70 & 74 \\
AB08 & 46.7 & 1.85 & 91 \\
AB09 & 40.3 & 1.72 & 86 \\
AB10 & 47.8 & 1.74 & 77 \\
\hline
\end{tabular}

Sete indivíduos com visão normal participaram voluntariamente no presente estudo. As características individuais de idade, altura e peso são apresentados na Tabela 6 . Todos os participantes assinaram um termo de consentimento antes de participar e o teste foi realizado de acordo com as diretrizes éticas da Universidade Estadual Paulista (UNESP) de Bauru. Os sujeitos entravam sem visão na sala e podiam explorar hapticamente a localização do objeto e a porta. Os sujeitos caminharam ao longo de uma via plana de cinco metros (cerca de 0,2 $\mathrm{m}$ acima do nível do chão) com um obstáculo de 0,26 m de altura localizado a $3 \mathrm{~m}$ do ponto de partida. Os sete indivíduos com visão normal cruzaram o obstáculo com sucesso 30 vezes com olhos vendados e com visão normal (olhos abertos). A velocidade da marcha era auto-selecionada. 
O movimento da perna de que realizava a travessia do obstaculo foi gravado por vídeo a $60 \mathrm{~Hz}$. Havia cinco marcadores colocados no membro nos seguintes locais anatômicos: quadril, joelho, tornozelo, retropé e antepé.

\subsubsection{Modelo do Robô}

Um modelo de robô, juntamente com um controlador baseado no critério de ZMP foi desenvolvido em ambiente MATLAB. No que diz respeito à configuração mecânica do robô bípede, foi escolhido um modelo planar com sete segmentos. Os segmentos representam o tronco, duas coxas, duas pernas e dois pés. Esses segmentos foram conectados por juntas de revolução, representando o quadril, o joelho e as articulações do tornozelo.

A fim de corresponder um modelo de robô a cada um dos participantes humanos, foram usados a altura e a massa dos indivíduos para definir os parâmetros inerciais da contrapartida robótica. As massas e dimensões dos modelos de robôs segmento foram então escalados utilizando os parâmetros dados por Winter (WINTER, 2009).

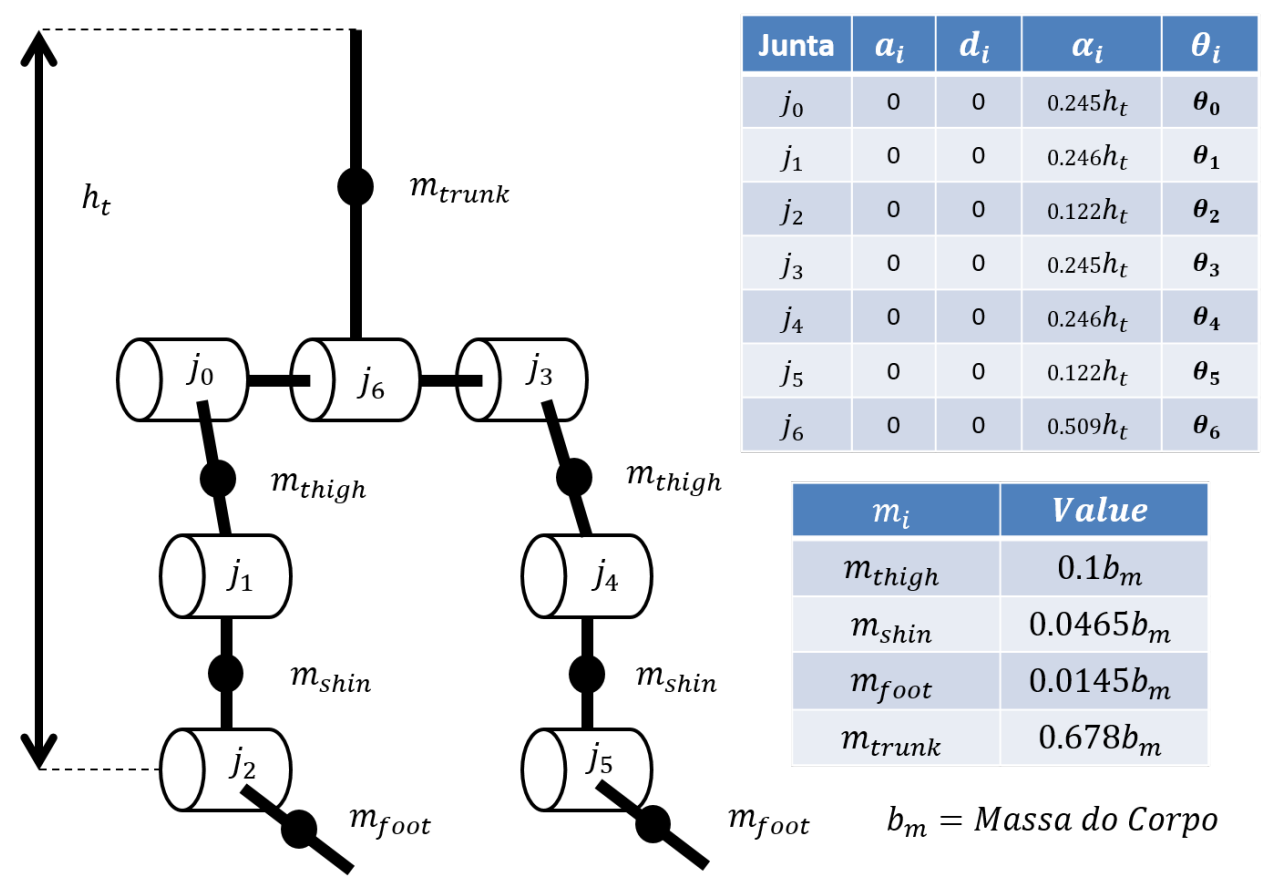

Figura 13: Modelo do robô utilizado

As trajetórias articulares dos robôs foram derivadas da composição da trajetória 
do COM e da trajetória do pé de balanço utilizando o algoritmo numérico cinemática inversa da toolbox desenvolvida (Capítulo 3). A trajetória COM foi gerado usando Quadratic Programming, a fim de manter a ZMP no interior da base de suporte como descrito por Wieber (2006). A trajetória do pé de balanço na direção ântero-posterior foi prescrita e definida com uma velocidade constante. A trajetória vertical foi descrita com uma função senoidal a fim de desacelerar o pé na aterrissagem e evitar grandes impactos.

\subsubsection{Processamento dos Dados dos Sujeitos}

Os dados de movimento foram filtrados com um filtro Butterworth de quarta ordem com uma frequência de corte de $4 \mathrm{~Hz}$. Com este processamento foram obtidas as trajetórias ântero-posterior e vertical das articulações.

Os seguintes parâmetros foram obtidos a partir dos dados de movimento, a fim de avaliar as diferenças entre a visão e resultados experimentais vendados:

1. Momento Crítico: o instante, quando o pé atravessa o obstáculo dado como uma percentagem do passo.

2. Posição vertical do pé no momento crítico.

3. Velocidade média da perna de balanço durante o cruzamento do obstáculo (dividindo o comprimento do passo pela duração do mesmo).

As trajetórias das diferentes articulações dos voluntários durante a realização do primeiro teste nas duas condições visuais (com visão e com os olhos vendados) foram plotadas juntamente com os resultados da simulação do modelo robótico correspondente. Apenas o primeiro ensaio foi escolhido de forma a evitar a influência de adaptação durante os 30 ensaios consecutivos.

As distâncias quadril-pé nas direções ântero-posterior e vertical foram obtidos subtraindo a posição do pé dianteiro e do quadril. À medida que o pé está sempre a frente do quadril, durante a passagem de obstáculos, temos um valor positivo na direção ântero-posterior. No entanto, na direção vertical o quadril está sempre mais elevado que o pé, o que resulta em valores negativos. 


\subsection{Resultados}

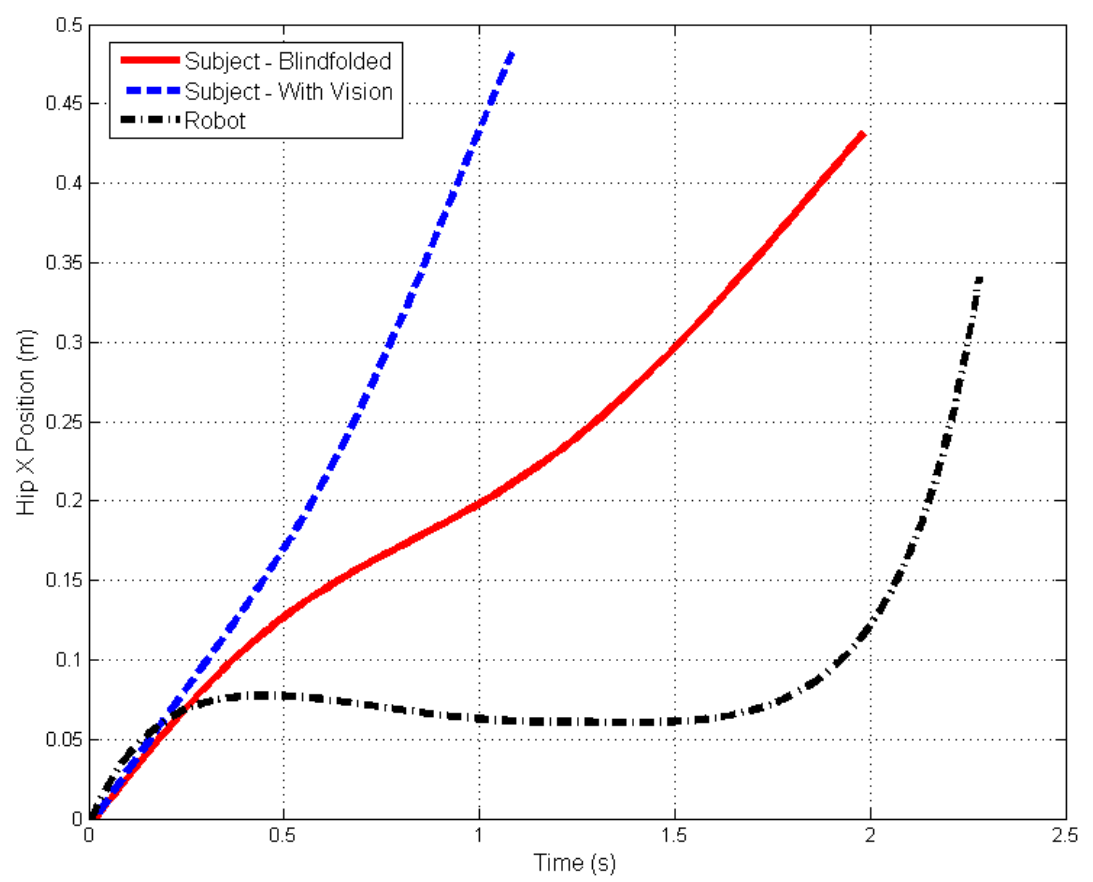

Figura 14: Trajetória ântero-posterior do quadril x Tempo

A Figura 14 mostra a trajetória ântero-posterior da articulação do quadril durante a travessia do obstáculo. Com a visão, o quadril avança a uma velocidade constante. $\mathrm{Na}$ condição de olhos vendados, o sujeito reduziu a velocidade, enquanto o robô manteve o quadril praticamente parado até o instante em que o pé está prestes a tocar o chão. $A$ condição de olhos vendados representou uma trajetória do quadril intermediária entre a visão e as trajetórias do robô. Além disso, na falta de visão e no modelo do robô, a duração do passo é maior, de acordo com uma velocidade significativamente mais lenta do passo. 


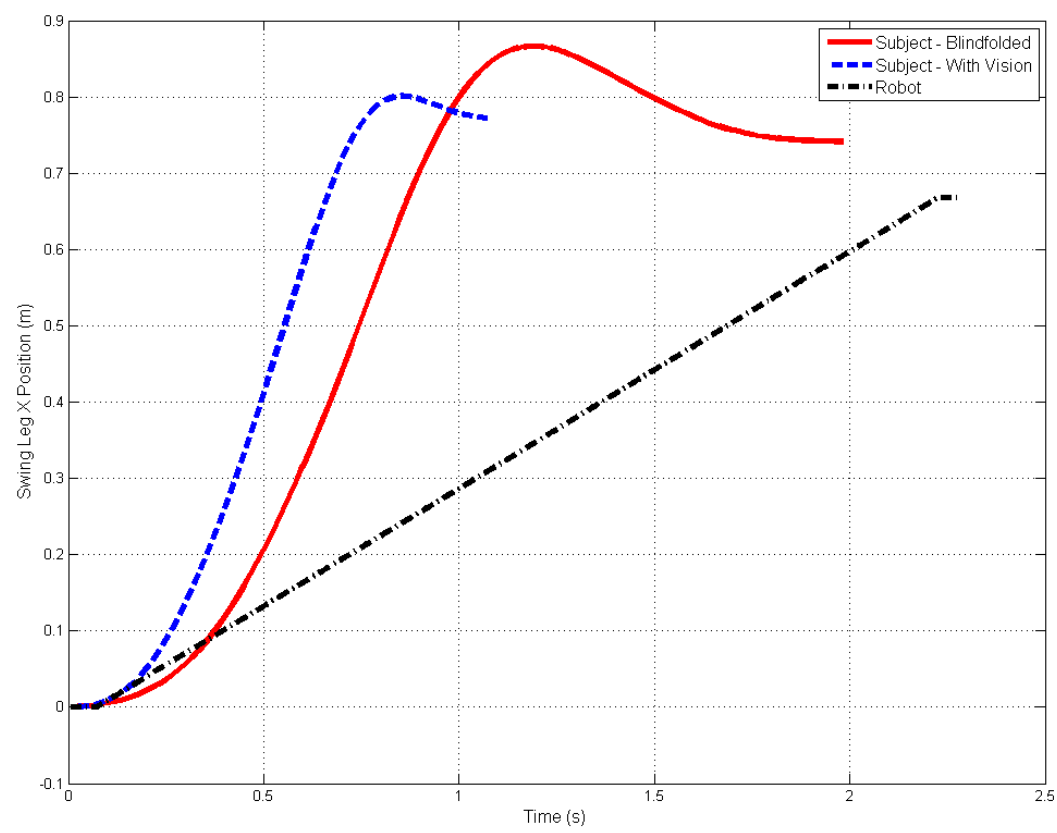

Figura 15: Trajetória ântero-posterior do pé x Tempo

Os resultados na Figura 15 mostra os dados medidos comparados com a trajetória imposta sobre o pé do modelo de robô como uma função do tempo. A trajetória ânteroposterior do pé do robô foi definida como uma velocidade constante, com uma relação linear entre os pontos de início e fim. Pode-se notar que os seres humanos, seja com visão ou olhos vendados mostraram um padrão diferente. 


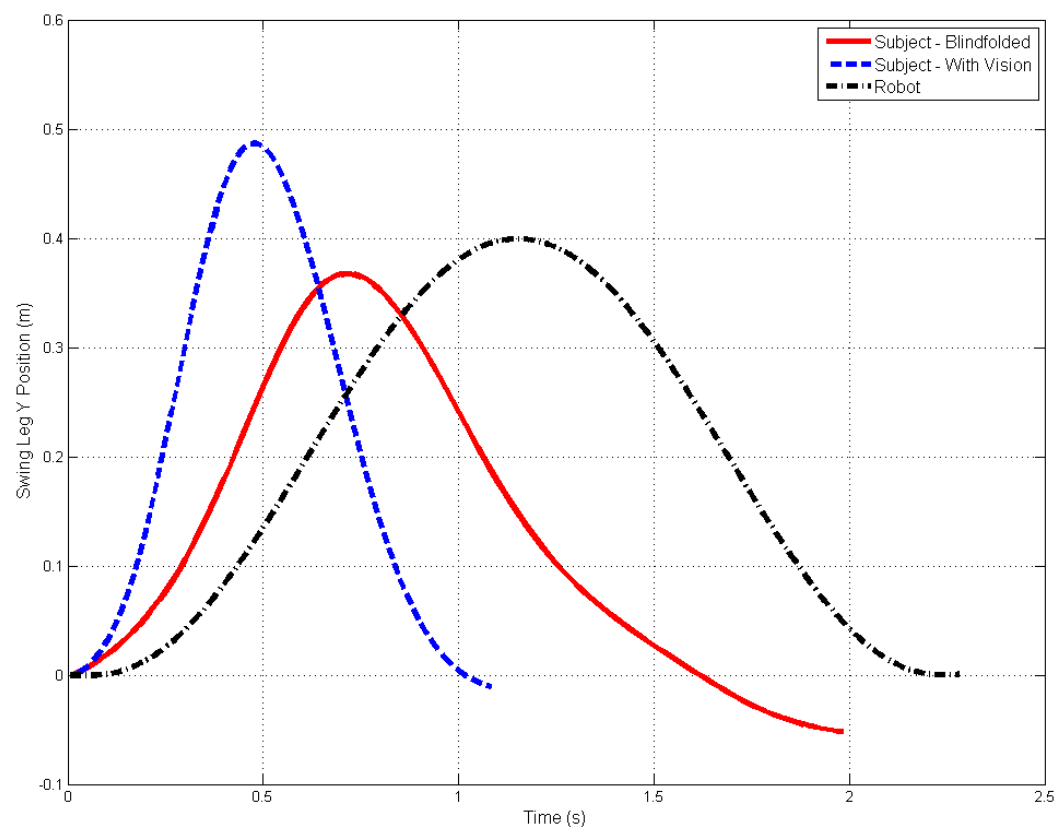

Figura 16: Trajetória vertical do pé x Tempo

No que diz respeito às trajetórias verticais dos pés, a função senoidal escolhida para reduzir a velocidade do pé antes do contacto coincide com o comportamento do ser humano como pode ser visto na Figura 16.

A Figura 17 mostra a distância entre o quadril e o pé, normalizada para a distância máxima das condição de visão. A distância ântero-posterior é representada em função da distância vertical. A distância horizontal entre o quadril e o pé é menor para o sujeito com a visão do que para os olhos vendados e o robô. 


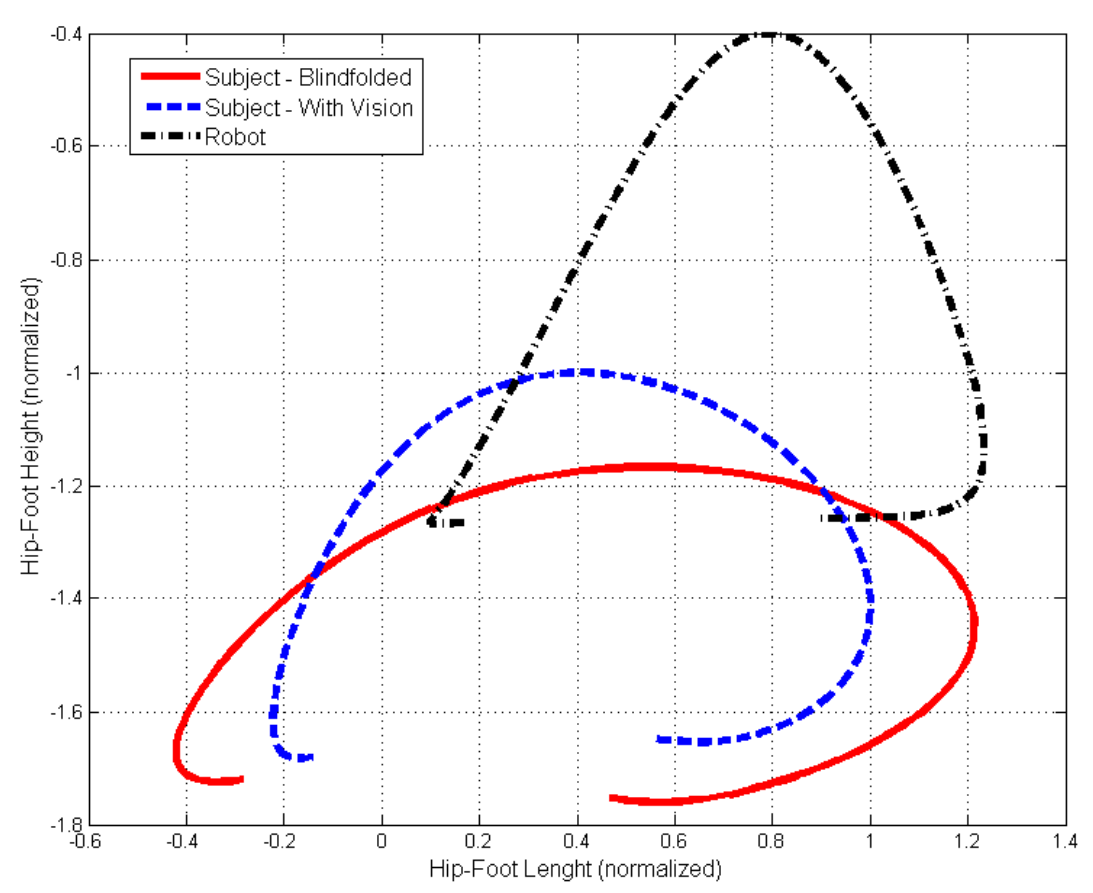

Figura 17: Trajetória ântero-posterior x trajetória vertical da distancia entre o quadril e o pé normalizados

A distância vertical entre o quadril e o pé do modelo robô tem um padrão que é diferente daquela dos seres humanos. Também pode ser observado o comportamento de pêndulo das pernas dos seres humanos (por ambas as condições), em contraste com a trajetória da perna do robô.

\subsection{Discussão}

A hipótese original sobre as semelhanças entre os sujeitos com os olhos vendados e do modelo de robô foi parcialmente confirmada. Portanto, ao cruzar um obstáculo privado de visão, os humanos confiam em um modelo para controlar a tarefa que é mais semelhante ao conceito ZMP. No entanto, existem outros mecanismos que influenciaram as respostas dos seres humanos. Mesmo privado de visão, o ser humano avançou seu quadril em conjunto com o pé, porém menos que com visão. Pelo contrário, o robô manteve o quadril praticamente estático para cumprir o critério de estabilidade ZMP (ver Figuras 18, 19 e 20). 

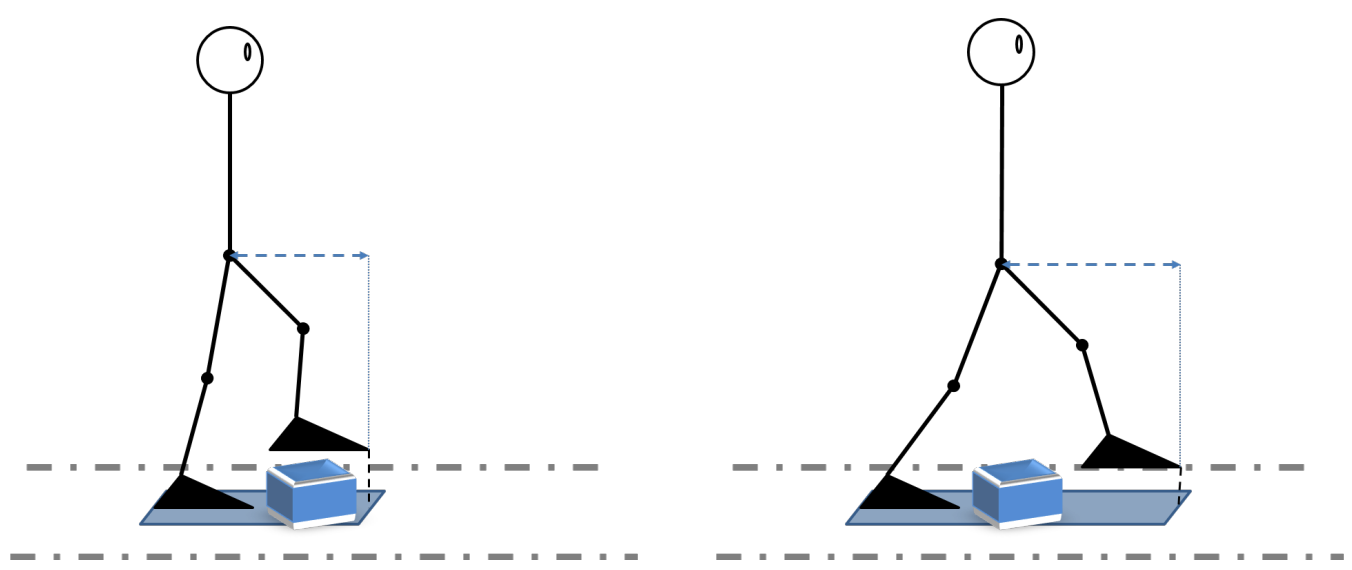

Figura 18: Modelo de caminhada do ser humano com visão
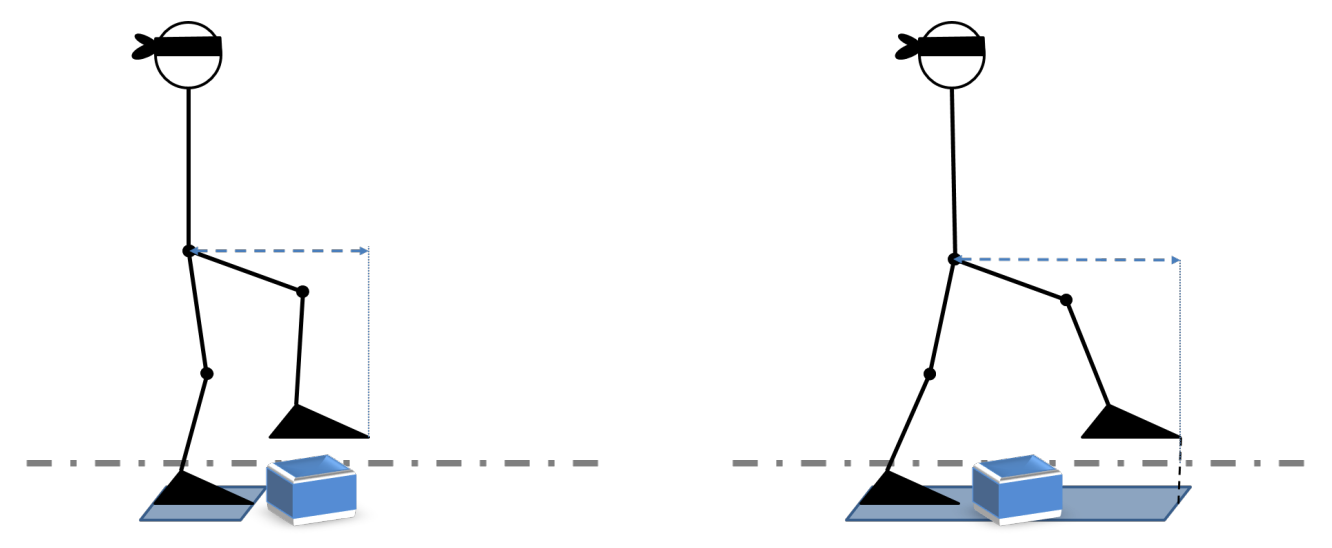

Figura 19: Modelo de caminhada do ser humano vendado
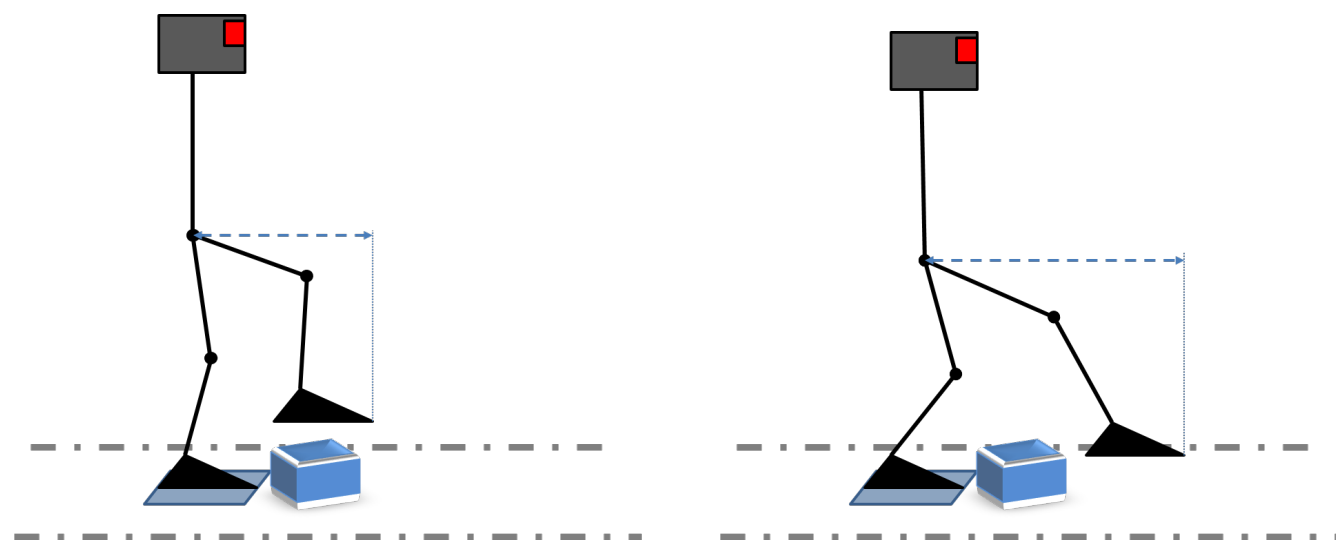

Figura 20: Modelo de caminhada do robô

A indisponibilidade de informação visual resultou em estratégias diferentes para atravessar o obstáculo, como uma maior elevação do pé de balanço e maior ou menor 
velocidade de passo (PATLA; DAVIES; NIECHWIEJ, 2004; PATLA et al., 1996; PATLA; GREIG, 2006). A velocidade do passo ao cruzar o obstáculo sem visão é reduzida. Neste caso, os indivíduos devem confiar em seus modelos internos do ambiente e informações proprioceptivas. Parece que, sem a visão, o padrão do movimento parece ser mais cauteloso e mais lento do que com a visão, assemelhando-se ao do robô com ZMP.

A distância ântero-posterior entre o quadril e o pé , para o sujeito e para o robô de olhos vendados, apresentaram valores de pico semelhante. Isso pode ser reflexo de uma estratégia mais conservadora em termos de evitar um tropeço e queda do que os seres humanos andando com visão.

A manutenção do quadril (e do centro de massas corporal) sobre o pé de apoio até que o pé tenha ultrapassado o obstáculo pode ser um mecanismo para manter uma base segura de apoio para o caso de pé se colidir com o obstáculo. Esta pode ser considerada uma abordagem conservadora no sentido de que o quadril não é deslocado até a existência de uma nova base de suporte estável, a qual é formada quando o pé de balanço atinge o chão. Isto é reforçado pela fato de que os humanos com olhos vendados se comportaram com um padrão intermediário entre o ser humano com visão e o robô nos dados da trajetória ântero-posterior do quadril. A possível explicação para isso poderia ser a minimização do risco de queda em caso de um tropeço. Foi relatado na literatura que tropeços na fase final do balanço tendem a abaixar o pé no chão como estratégia de recuperação (FORNER-CORDERO; KOOPMAN; HELM, 2003; ENG; WINTER; PATLA, 1994). Nesta estratégia o pé que faz contato com o obstáculo é trazido imediatamente para o chão. Portanto, avançando o pé de balanço enquanto o quadril é mantido por trás permite uma maior margem para reduzir a velocidade da marcha para a frente (FORNER-CORDERO; KOOPMAN; HELM, 2004). No entanto, esta estratégia não só resulta em velocidades da marcha mais baixas, mas também em maior consumo de energia devido à aceleração e desaceleração do quadril. O caso extremo seria o robô ZMP que para completamente o movimento ântero-posterior do quadril e depois ele tem que acelerá-lo. Em contraste, os sujeitos vendados moveram o quadril para a frente a uma velocidade menor do que indivíduos com visão. Provavelmente, eles mantêm uma certa relação entre as posições / velocidades do pé de balanço e do quadril. 


\subsection{Publicações}

Este trabalho foi aceito e apresentado no 5th IEEE RAS \& EMBS International Conference on Biomedical Robotics and Biomechatronics (ROSSI; RODRIGUES; FORNER-CORDERO, 2014). 


\section{DESENVOLVIMENTO DO STEP VIABILITY}

Até o presente Capítulo foi feito um estudo para entender as vantagens e limitações das duas principais estratégias de controle (ZMP e Limit Cycle Walking) utilizadas para se sintetizar marchas bípedes. Desse estudo foi entendido que o critério de estabilidade é um ponto chave para se poder sintetizar marchas de forma versátil. Um critério de estabilidade pode ser definido como um conjunto de regras que impõem restrições ao movimento de caminhada que, se seguidas, garantem que o robô não cairá. Sua formulação e implementação pode ser dificultada por limitações, suposições e simplificações do modelo. De modo geral, o critério de estabilidade é utilizada dentro do módulo de Planejamento do Movimento como pode ser visto na Figura 21.

Como descrito no Capítulo 3, foi implementada uma marcha bípede utilizando o critério de ZMP. Dessa implementação foi entendido que o critério de ZMP cria uma restrição que limita o CoP e o COM a estarem sob a base de apoio do bípede (Figura 22), reduzindo em muito a gama de possíveis marchas a serem geradas e impossibilitando qualquer marcha dinâmica (Figura 23). 


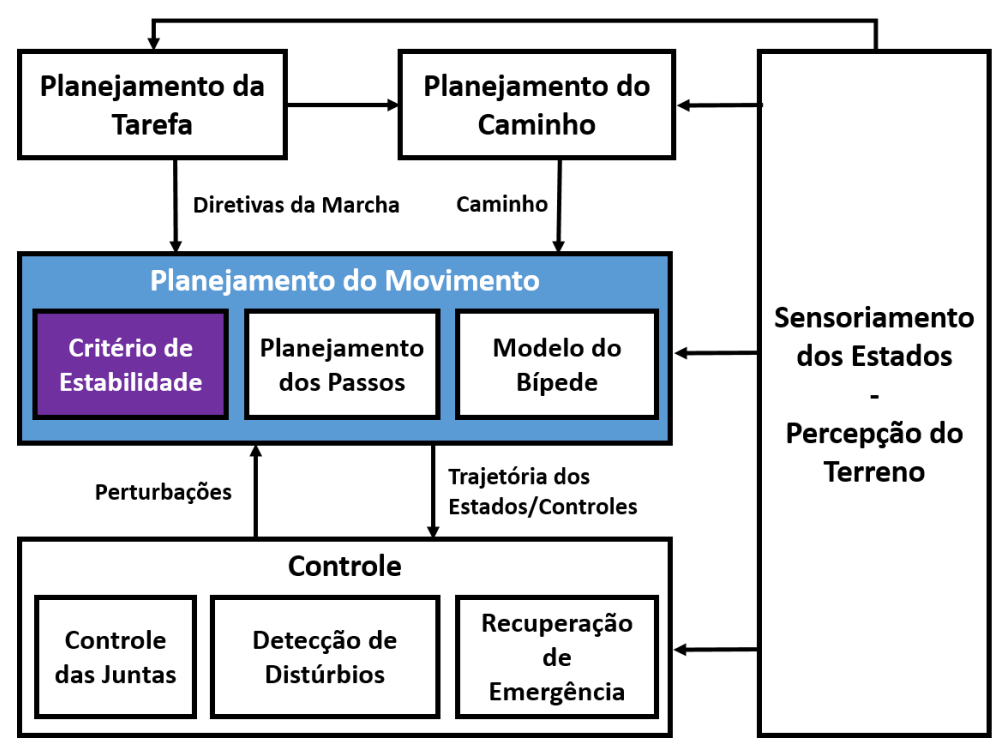

Figura 21: Sugestão de arquitetura geral do controle da marcha de robôs bípedes. 0 critério de estabilidade é parte do algoritmo de Planejamento de Movimento.

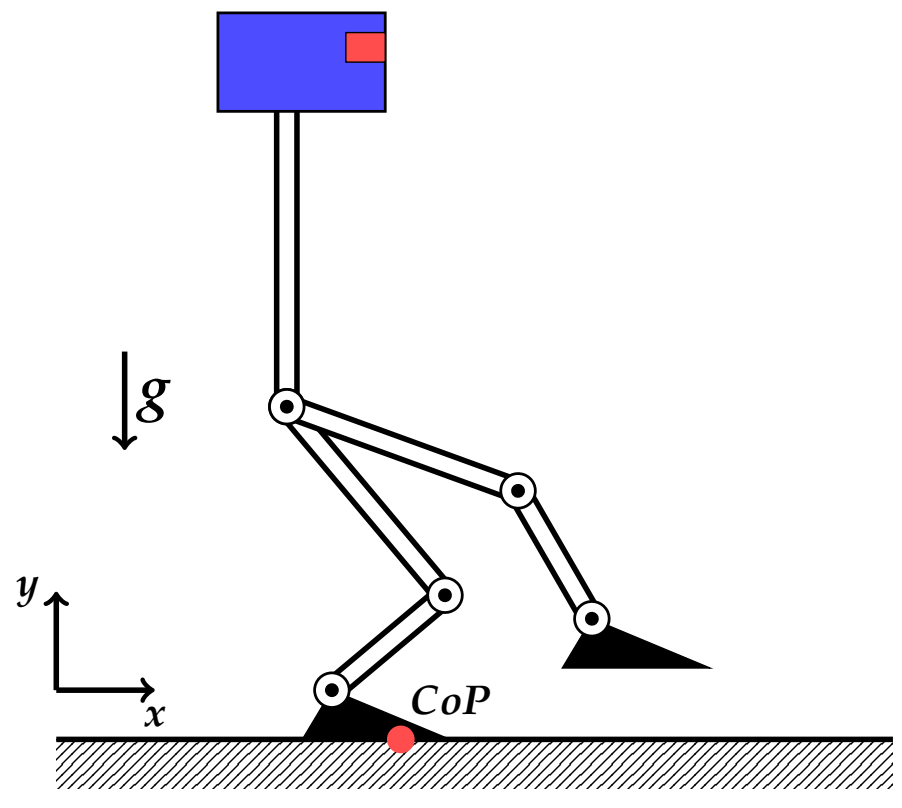

Figura 22: Marcha baseada em ZMP 


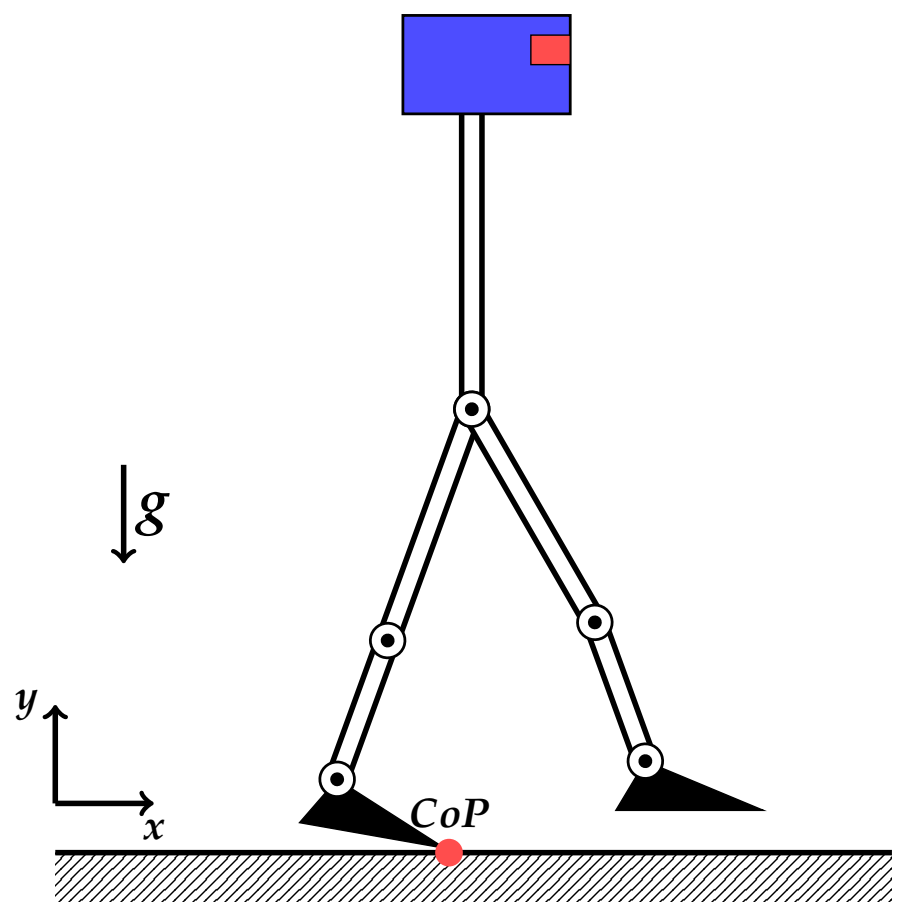

Figura 23: Marcha Dinâmica

Em seguida foi realizado um estudo de Limit Cycle Walking no Capítulo 4 que utiliza o conceito de estabilidade orbital como critério de estabilidade. Desse estudo foi entendido que o critério de estabilidade o LCW emprega requer que a marcha seja cíclica, o que é uma restrição que limita seriamente a flexibilidade da marcha além de ter uma robustez baseada em convergir para um conjunto bem específico de estados com uma bacia de atração pequena.

Para finalizar, no Capítulo 5 foi realizada uma análise comparativa da marcha de um ser humano com e sem visão realizando a tarefa de se atravessar um obstáculo com uma marcha sintetizada utilizando o critério de ZMP. Desse estudo realizado pode-se entender que o ser humano tem um critério de estabilidade global para avaliar a situação e informações da marcha atual e variar entre marchas dinâmicas e estáticas de forma contínua.

Após realizar esses estudos foi entendido que para se poder desenvolver um controle de marcha bípede que não limite a robustez, eficiência energética e flexibilidade, é necessário o desenvolvimento de um novo critério de estabilidade mais global que 1) possibilite geração de marchas dinâmicas e estáticas assim como 2) não crie restrições que limitem a robustez, eficiência energética e flexibilidade dos movimentos. 


\subsection{O que é estabilidade?}

Em primeiro lugar, é importante definir o que é estabilidade no contexto deste trabalho. Para isso precisamos definir alguns conceitos. Genericamente, podemos considerar que uma marcha bípede é estável quando o sistema bípede não cai no chão. Neste caso qual seria então a definição de queda? Isto é uma definição bastante subjetiva, porém, dentro do contexto deste trabalho, um bípede vai ser considerado como caído quando um segmento diferente dos segmentos compostos pelos pés do mesmo entrar em contato com o chão. Um exemplo pode ser visto na Figura 24.

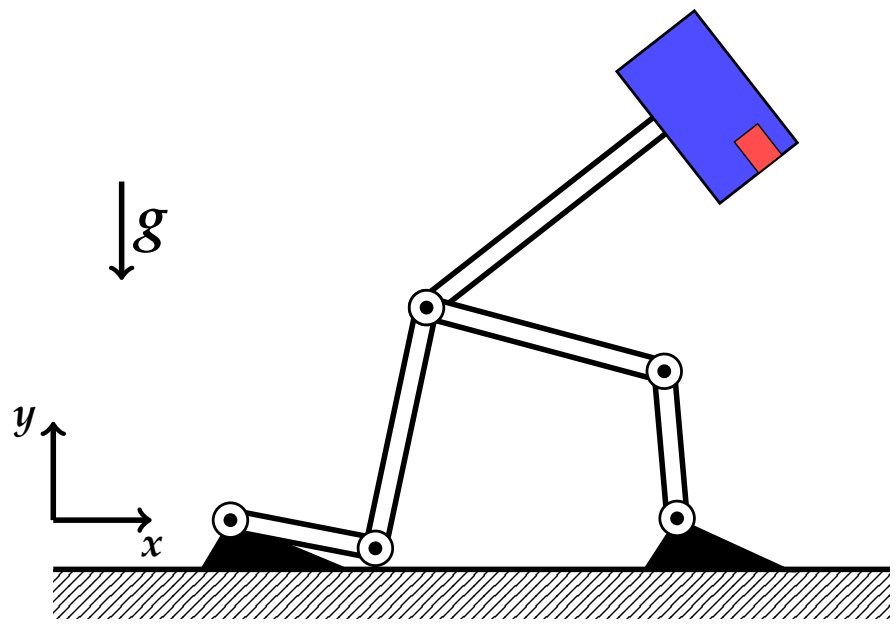

Figura 24: Robô em um estado caído

Para uma definição mais formal, seja s os estados do sistema composto pelas posições e velocidades do bípede, ou seja, $\mathbf{s}=[\mathbf{x}, \dot{\mathbf{x}}]$, e dado $\mathbb{F}$ como o conjunto de todos os estados em que um segmento diferente dos segmentos compostos pelos pés do bípede estiver em contato com o chão, o bípede é considerado como caído quando $\mathbf{s} \in \mathbb{F}$.

O segundo conceito que precisa ser definido é o ponto fixo. Este or sua vez tem uma definição mais clara dentro da matemática, sendo um elemento de uma função que é mapeado para ele mesmo, ou seja, $f(x)=x$. Porém, no nosso caso ele terá a restrição de não ser um estado caído, ter todos os seus estados de velocidade, assim como todas as suas derivadas como 0. Logo, é um estado onde, caso o bípede permaneça parado, ele irá continuar imóvel.

Para finalizar vamos definir o que é um estado estável. Um estado estável será 
definido neste trabalho como um estado em que o bípede tem a capacidade de alcançar um ponto fixo em um tempo finito ou de não passar por um ponto fixo e um estado caído por um tempo infinito.

Para o propósito deste trabalho vamos considerar apenas condições de tempo finito, desta forma estados em que o bípede tenha a capacidade de não passar por um ponto fixo e um estado caído por um tempo infinito, não serão consideradas.

Tendo essas definições mais claras, podemos definir de maneira mais objetivas as condições que podem ser consideradas como um estado estável. Um bípede está estável se:

1. O bípede está em um ponto fixo.

2. O bípede está fora de um ponto fixo e tem a capacidade de:

(a) Alcançar um ponto fixo.

(b) Realizar uma passada que:

i. Leve o bípede à um ponto fixo.

ii. Mantenha a capacidade de levar o bípede à um ponto fixo em um tempo finito.

Não existe muito a ser comentado quanto ao caso 1 . O item 2 a pode ser calculado numericamente. Além disso, existem alguns trabalhos como Stephens (2011) que propõe simplificações para calculá-lo em uma solução de forma analítica. Em resumo, o procedimento sobre como calcular se existe uma solução não é um problema considerado não resolvido. Trata-se de um compromisso entre a simplificação do modelo e a complexidade do cálculo.

O item 2(b)i pode ser resolvido numericamente ou dividindo-o em dois subproblemas: calcular onde realizar o passo e calcular se o bípede é capaz de pisar no local calculado. Cálculo de onde realizar o passo foi abordado para vários níveis de simplificação com uma solução de forma analítica: o capture point de um pêndulo inverso linear (PRATT et al., 2006) e de um pêndulo invertido (PRATT; TEDRAKE, 2006), o Foot Placement Estimator (WIGHT; KUBICA; WANG, 2008) e o Foot Placement Indicator (ZUTVEN; KOSTIC; NIJMEIJER, 2012). Para o segundo subproblema, o autor tem apenas o conhecimento da simplificação feita no trabalho onde a capacidade de 
pisar é modelada como um comprimento máximo fixo e um tempo mínimo para calcular uma solução de forma fechada. Ele também pode ser calculado numericamente.

O item 2(b)ii é o mais complexo de se implementar. No entanto, ele tem o potencial para gerar restrições que permitam marchas versáteis. Em Manchester e Umenberger (2013) foi apresentado um trabalho onde várias primitivas de movimento são pré-calculadas e posteriormente ligadas a sintetizado um movimento desejado. $\mathrm{N}$ Step Capturability (KOOLEN et al., 2012) também é apresenta uma solução de forma fechada para este problema, onde a dinâmica do sistema é simplificada para um pêndulo invertido linear, um pêndulo invertido linear com um pé e um pêndulo invertido linear com um pé e um elemento inercial na pélvis.

Para definir um critério de estabilidade que não crie demasiadas restrições na marcha bipada, o critério de Step Viability foi definido tentando implementar matematicamente a frase "o bípede está fora de um ponto fixo e é capaz de fazer um passo que mantém a possibilidade de trazer o bípede para um ponto fixo no futuro". Para implementar essa restrição, devemos primeiro entender um pouco a dinâmica da marcha.

\subsection{Entendendo a Marcha}

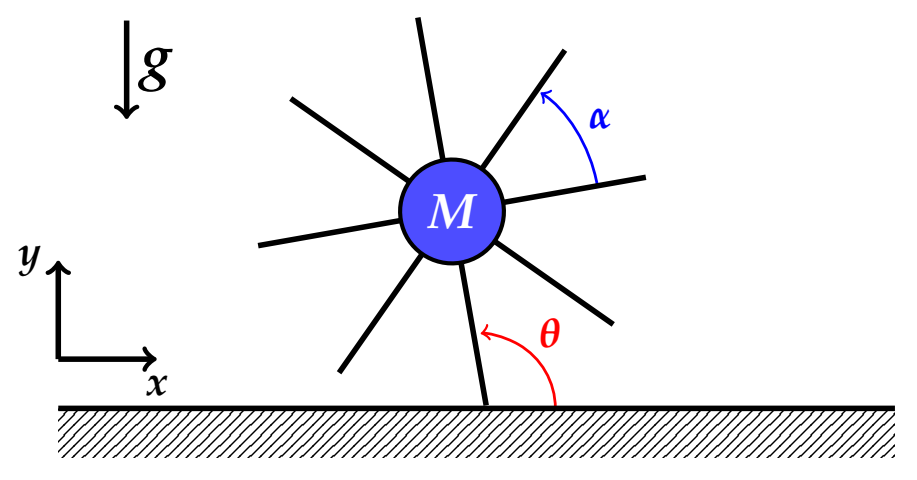

Figura 25: Rimless Wheel

Vamos olhar o modelo de uma Rimless Wheel como apresentado na Figura 25. O modelo é composto por uma massa $M$ e $n$ pernas sem massa, com $n>=3$, e um mesmo ângulo $\alpha$ entre as pernas. O modelo tem um ângulo $\theta$ com o chão e uma velocidade angular $\dot{\theta}$. É um modelo bem estudado e tem sido utilizada na área de robótica bípede para entender ciclo-limites. Normalmente, ele é apresentado em um plano in- 
clinado e o mapa de retorno Poincaré é analisado. Aqui não vamos nos preocupar com a estabilidade de ciclo-limite e vamos analisar o modelo em uma superfície plana. Se considerarmos o nosso critério para a estabilidade indicado na seção 6.1 , é evidente que o modelo Rimless Wheel é sempre estável para qualquer dado par $\theta$ e $\dot{\theta}$ iniciais visto que nada mais do que a os "pés" do modelo vão tocar o chão. Caso o impacto tenha qualquer dissipação de energia, o modelo vai eventualmente parar apoiado em 1 ou 2 destes "pés", mas nenhuma outra parte do modelo vai tocar o chão. Em outros termos, $\mathbb{F}=\varnothing$.

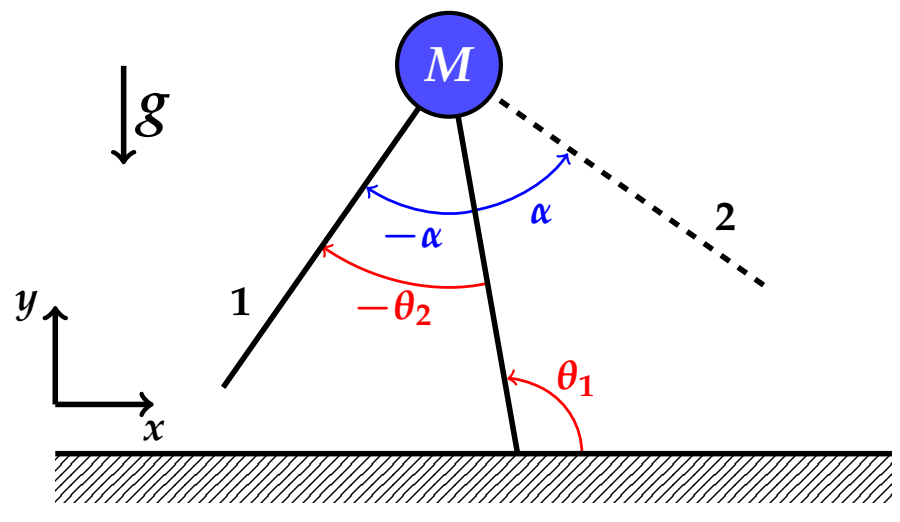

Figura 26: Compass Gait com pernas sem massa.

Agora vamos analisar o modelo de um Compass Gait com pernas sem massa, como apresentado na Figura 26. O modelo é composto por uma massa $M$ e com apenas duas pernas sem massa e um ângulo variável entre as pernas $\theta_{2}$, e um ângulo com o chão $\theta_{1}$. Além disso, podemos considerar que $\theta_{1}$ é função do ângulo inicial $\theta_{1}^{0}$, da velocidade angular inicial $\dot{\theta}_{1}^{0}$ e do tempo $t$, desta forma $\theta_{1}\left(\theta_{1}^{0}, \dot{\theta}_{1}^{0}, t\right)$. Se considerarmos que as pernas sem massa são totalmente controláveis e podem instantaneamente se mover para qualquer ângulo entre as pernas $\theta_{2}$ dentro do intervalo ] $-\pi / 2, \pi / 2$ [ e considerarmos a seguinte regra:

$$
\theta_{2}\left(\theta_{1}\right)= \begin{cases}-\alpha & \text { se } \theta_{1}>\pi / 2 \\ \alpha & \text { se } \theta_{1} \leq \pi / 2\end{cases}
$$

Nesta condição, o modelo do Compass Gait com pernas sem massa vai ter exatamente o mesmo comportamento que o modelo Rimless Wheel.

Agora vamos adicionar alguma restrição ao movimento das pernas. Vamos consi- 
derar que $\theta_{2}$ é função do valor inicial $\theta_{2}^{0}$, da velocidade inicial $\dot{\theta}_{2}^{0}$ e do tempo $t$, ou seja $\theta_{2}\left(\theta_{2}^{0}, \dot{\theta}_{2}^{0}, t\right)$.

Assim temos que para o sistema ser capaz de dar um passo existe a seguinte condição:

$$
\theta_{2}\left(\theta_{2}^{0}, \dot{\theta}_{2}^{0}, t\right)=\pi-2 \theta_{1}\left(\theta_{1}^{0}, \dot{\theta}_{1}^{0}, t\right)
$$

No entanto, diferente do caso anterior, não existe nenhuma garantia de que o sistema será capaz de dar um passo em qualquer situação, e mesmo que seja possível, nós não podemos garantir que o sistema é estável em um longo prazo. Então basicamente o que precisamos é uma métrica para entender se é possível dar uma passada e uma métrica melhor para entender se está ficando "mais difícil" ou "mais fácil" dar uma passada ao longo do tempo.

Uma possível ideia seria avaliar $\dot{\theta}_{1}$ visto que a perna de balanço teria mais tempo para dar a passada se a velocidade angular da perna de apoio for menor. No entanto o modelo é um pêndulo invertido, então é esperado que a velocidade angular $\dot{\theta}_{1}$ reduza em algumas partes do movimento. Outra possibilidade é calcular a energia total do sistema, mas essa informação não é trivial se analisar o critério de que será possível dar uma passada. Logo precisamos de uma métrica que combine $\dot{\theta}_{1}$ e $\theta_{1}$. Uma métrica muito útil pode ser derivada do Capture Point, apresentado no Capítulo 1. A seguir será dada uma breve apresentação sobre sua teoria.

\subsubsection{Teoria do Capture Point}

O Capture Point representa o ponto que um sistema teria que pisar naquele instante para convergir à um ponto fixo apoiado apenas na perna que pisou nesse ponto. $\mathrm{Na}$ Figura 27 podemos ver um exemplo. Caso o modelo pise em um ponto depois do Capture Point ele não terá energia suficiente para chegar ao ponto fixo e irá cair para trás (Figura 28(a)). Caso ele pise exatamente no ponto do Capture Point ele irá convergir à um ponto fixo e parar (Figura 28(b)). Caso ele pise antes do Capture Point ele irá passar o ponto fixo e irá cair para frente (Figura 28(c)). 


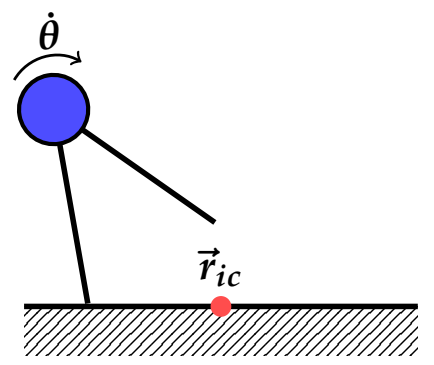

Figura 27: Exemplo do Capture Point antes da Passada

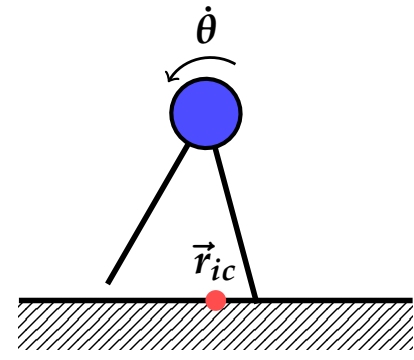

(a) Passada depois do Capture Point

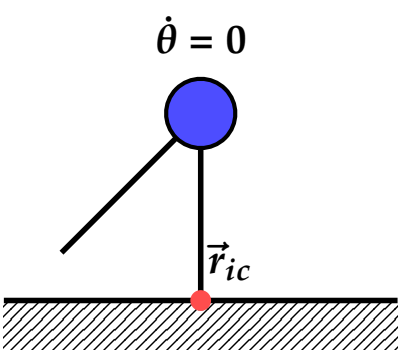

(b) Passada no Capture Point

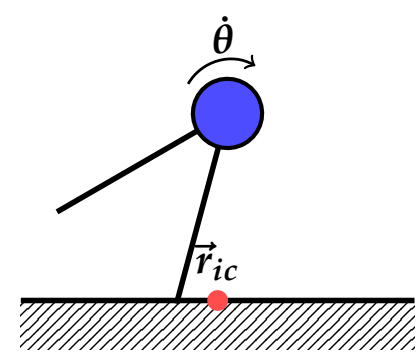

(c) Passada antes do Capture Point

Figura 28: Exemplo do Capture Point depois da Passada

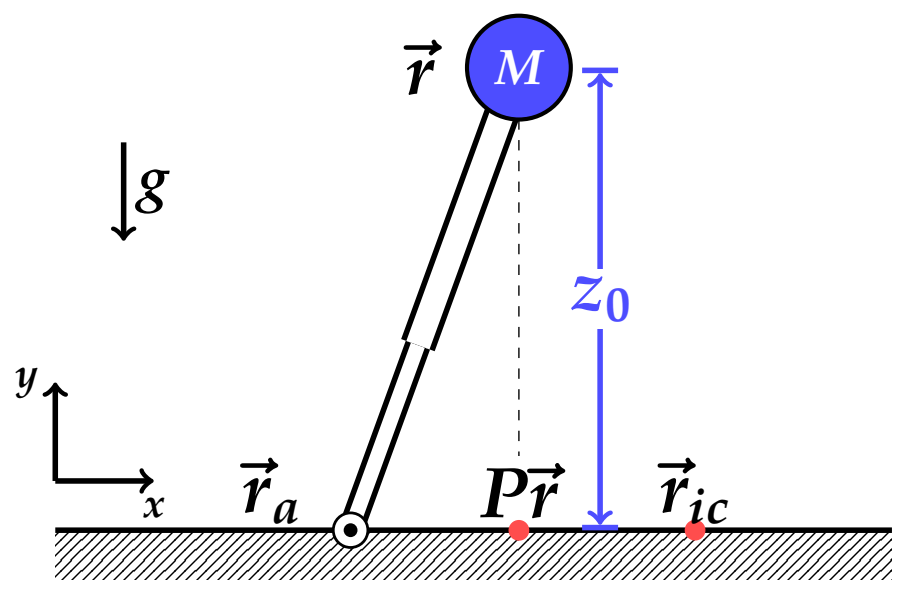

Figura 29: Capture Point de um pêndulo invertido linear.

Conforme apresentado por Pratt e Tedrake (2006), o Capture Point pode ser calculado por conservação de energia. Para um Pêndulo Linear Invertido com o modelo descrito na Figura 29, temos a seguinte dinâmica: 


$$
\begin{gathered}
\omega_{0}=\sqrt{\frac{g}{z_{0}}} \\
\mathbf{r}_{\mathbf{i c}}=\operatorname{Pr}+\frac{\dot{\mathbf{r}}}{\omega_{0}}
\end{gathered}
$$

Onde:

$\mathbf{r}$ : posição do centro de massas.

$\mathbf{r}_{\text {ic }}$ : posição do Capture Point.

Pr : projeção do r no chão.

$\mathbf{r}_{\mathbf{a}}$ : posição do tornozelo

A solução analítica é dada por:

$$
\mathbf{r}_{\mathbf{i c}}(t)=\left[\mathbf{r}_{\mathbf{i c}}(0)-\mathbf{r}_{a}\right] e^{t \omega_{0}}+\mathbf{r}_{a}
$$

As informações mais importantes que obteremos a partir dessas equações são que se o Capture Point estiver no ponto do pé de apoio, ele permanecerá lá e, se estiver fora do ponto de pé de apoio, ele se afastará exponencialmente com o tempo. Para fins de simplificação, usaremos a posição do pé de apoio como nossa referência, portanto:

$$
\left\{\begin{array}{ll}
\mathbf{r}_{\mathbf{i c}}(t)=0 & \text { if } \mathbf{r}_{\mathbf{i c}}\left(t_{0}\right)=0 \\
\mathbf{r}_{\mathbf{i c}}(t)>\mathbf{r}_{\mathbf{i c}}\left(t_{0}\right) & \text { if } \mathbf{r}_{\mathbf{i c}}\left(t_{0}\right) \geq 0
\end{array} \forall t \geq 0\right.
$$

De forma complementar temos que para dois $\mathbf{r}_{\mathbf{i c}}{ }^{1}\left(t_{0}\right)$ e $\mathbf{r}_{\mathbf{i c}}{ }^{2}\left(t_{0}\right)$ onde $\mathbf{r}_{\mathbf{i c}}{ }^{1}\left(t_{0}\right)>$ $\mathbf{r i c}^{2}\left(t_{0}\right)$ temos que:

$$
\mathbf{r}_{\mathbf{i c}}^{1}\left(t_{0}\right)>\mathbf{r}_{\mathbf{i c}}^{2}\left(t_{0}\right) \forall t \geq 0
$$




\subsection{Step Viability}

Para a formulação do Step Viability, vamos considerar as seguintes notações:

1. $\mathbf{r}_{\mathbf{i c}}(\mathbf{s})$ é a posição do Capture Point instantâneo dado os estados s.

2. Caso o sistema não sofra nenhum distúrbio externo (e.g impactos) podemos considerar que o Capture Point instantâneo pode ser descrito pelos estados $\mathbf{s}_{\mathbf{0}}$ no instante $t_{0}$ e o avanço de tempo $\Delta t, \log \mathbf{r} \mathbf{r}_{\mathbf{i c}}\left(t_{0}+\Delta t, \mathbf{s}_{0}\right)$.

3. $\mathbf{r}_{\text {step }}\left(\Delta t, \mathbf{s}_{0}, U(t, \mathbf{s})\right)$ é o tamanho de um passo factível que levou um tempo $\Delta t$, teve como estado iniciais $\mathbf{s}_{\mathbf{0}}$ e uma função de atuação $U$, que é função do tempo $t$ e do estado s.

4. $\mathbf{s}_{\text {step }}^{-}$é o valor do estado do sistema imediatamente antes do impacto de uma passada.

5. $\mathbf{s}_{\text {step }}^{+}$é o valor do estado do sistema imediatamente após do impacto de uma passada.

6. U representa o conjunto de todas as funções de atuação $U$ admissíveis pelo sistema.

7. Dado um estado $\mathbf{s}_{\mathbf{0}}$, o conjunto das funções $U(t, \mathbf{s}) \in \mathbb{U}$ que resulte em um $\mathbf{r}_{\text {step }} \geq 0$ com um $\Delta t \geq 0$ finito será denominado $\mathbb{V}$.

8. X(s) retorna a parcela dos estados de s referentes apenas à posição.

9. $\mathbf{P}_{\mathbf{s w}}(\mathbf{s})$ representa a posição da extremidade da perna de balanço (pé de balanço).

10. $T\left(\mathbf{s}_{1}, \mathbf{X}\left(\mathbf{s}_{2}\right)\right)$ representa o tempo que um estado $\mathbf{s}_{\mathbf{1}}$ demora para evoluír até a posição $\mathbf{X}\left(\mathbf{s}_{2}\right)$.

11. $\mathbf{L}\left(\mathbf{s}_{\text {step }}^{-}, \mathbf{s}_{\text {step }}^{+}\right)$representa a redução no Capture Point causado por um impacto que transforma $\mathbf{s}_{\text {step }}^{-}$em $\mathbf{s}_{\text {step }}^{+}$.

12. $\mathcal{F}$ é o ponto fixo onde $\mathbf{r}_{\mathrm{ic}}=0$. 
A primeira premissa que vamos considerar é que dado uma função de atuação $U_{\max }(t, s)$, onde essa função representa a maior atuação possível dentro de $\mathbb{V}$ (por exemplo torque saturado), teremos, para um mesmo $\Delta t$ e $\mathbf{s}_{0}$, que para qualquer $U(t, \mathbf{s}) \in \mathbb{V}:$

$$
\mathbf{r}_{\text {step }}\left(\Delta t, \mathbf{s}_{0}, U_{\max }(t, \mathbf{s})\right) \geq \mathbf{r}_{\text {step }}\left(\Delta t, \mathbf{s}_{\mathbf{0}}, U(t, \mathbf{s})\right)
$$

De forma complementar, dado $\Delta t_{1}$ sendo o tempo que a atuação $U_{\text {max }}$ demora para dar um passo $\mathbf{r}_{\text {step }}$ e $\Delta t_{2}$ sendo o tempo que uma função de atuação $U \in \mathbb{V}$ demora para dar um passo $\mathbf{r}_{\text {step }}$ temos que:

$$
\Delta t_{1} \leq \Delta t_{2}
$$

Como uma simplificação para a presente análise será assumido que, independentemente do modelo, dado um tempo $t_{0}$ e um tempo $t_{0}+\Delta t$, com $\Delta t>0$, que:

$$
\begin{cases}\mathbf{r}_{\mathbf{i c}}\left(t_{0}+\Delta t, \mathbf{s}_{\mathbf{0}}\right)=0 & \text { se } \mathbf{r}_{\mathbf{i c}}\left(t_{0}, \mathbf{s}_{\mathbf{0}}\right)=0 \\ \mathbf{r}_{\mathbf{i c}}\left(t_{0}+\Delta t, \mathbf{s}_{\mathbf{0}}\right)>\mathbf{r}_{\mathbf{i c}}\left(t_{0}, \mathbf{s}_{\mathbf{0}}\right) & \text { se } \mathbf{r}_{\mathbf{i c}}\left(t_{0}, \mathbf{s}_{\mathbf{0}}\right) \geq 0\end{cases}
$$

Essa é basicamente a mesma informação que deduzimos na equação (6.6), mas generalizada para qualquer modelo.

Além disso, vamos considerar que, dado os estados $\mathbf{s}_{\mathbf{1}}, \mathbf{s}_{\mathbf{2}}$ e $\mathbf{s}_{3}$, onde $\mathbf{r}_{\mathbf{i c}}\left(\mathbf{s}_{\mathbf{1}}\right)>$ $\mathbf{r}_{\mathrm{ic}}\left(\mathbf{s}_{2}\right)$ e $\mathbf{X}\left(\mathbf{s}_{3}\right)>\mathbf{X}\left(\mathbf{s}_{1}\right)$ e $\mathbf{X}\left(\mathbf{s}_{3}\right)>\mathbf{X}\left(\mathbf{s}_{2}\right)$, temos que:

$$
T\left(\mathbf{s}_{1}, \mathbf{X}\left(\mathbf{s}_{3}\right)\right)<T\left(\mathbf{s}_{1}, \mathbf{X}\left(\mathbf{s}_{2}\right)\right)
$$

Como antes, essa é basicamente a mesma informação que deduzimos na equação (6.7), mas generalizada para qualquer modelo.

Por fim, consideraremos que se em uma dada condição, se a $\mathbf{r}_{\mathbf{i c}}\left(t_{0}, \mathbf{s}_{\mathbf{0}}\right) \geq 0$, não é possível trazê-lo de volta para 0 sem realizar um passo.

Sendo assim, temos como condições para estabilidade dado um estado $\mathbf{s}_{\mathbf{0}}$ que se não existir uma passada factível: 


$$
\mathbb{V}\left(\mathbf{s}_{0}\right)=\varnothing
$$

Temos obrigatoriamente que a posição do Capture Point instantâneo após um tempo $\Delta t$ seja:

$$
\mathbf{r}_{\mathbf{i c}}\left(t_{0}+\Delta t, \mathbf{s}_{0}\right)=0 \quad \forall \quad \Delta t \geq 0
$$

Ou seja, ele deve estar no ponto fixo $\mathcal{F}$ :

$$
\mathbf{r}_{\mathbf{i c}}\left(t_{0}, \mathbf{s}_{\mathbf{0}}\right)=\mathcal{F}
$$

Caso existam passadas factíveis:

$$
\mathbb{V}\left(\mathbf{s}_{\mathbf{0}}\right) \neq \varnothing
$$

e o bípede esteja fora de um ponto fixo:

$$
\mathbf{r}_{\mathbf{i c}}\left(t_{0}, \mathbf{s}_{0}\right)>0
$$

deve existir um $U(t, \mathbf{s}) \leq U_{\max }(t, \mathbf{s})$ que:

$$
\mathbf{r}_{\text {step }}\left(\Delta t, \mathbf{s}_{0}, U(t, \mathbf{s})\right)+\mathbf{P}_{\mathbf{s w}}\left(\mathbf{s}_{0}\right)>\mathbf{r}_{\mathrm{ic}}\left(t_{0}+\Delta t, \mathbf{s}_{\mathbf{0}}\right)-\mathbf{r}_{\mathrm{ic}}\left(t_{0}, \mathbf{s}_{0}\right)-\mathbf{L}\left(\mathbf{s}_{\mathbf{s t e p}}^{-}, \mathbf{s}_{\text {step }}^{+}\right)
$$

ou

$$
\mathbf{r}_{\mathrm{ic}}\left(\mathbf{s}_{0}\right)>\mathbf{r}_{\mathrm{ic}}\left(\mathbf{s}_{\text {step }}^{+}\right)
$$

Como o $\mathbf{r}_{\mathbf{i c}}$ da próxima passada será menor ou igual ao da passada que foi realizada, pela equação 6.11 temos que o tempo disponível para se realizar uma nova passada será maior que o disponível na primeira passada. Desta forma, se conseguirmos que o mesmo $U(t, \mathbf{s})$ garanta que uma nova passada de mesmo tamanho com o novo tempo disponível, reduzindo ainda mais o Capture Point, levaremos o bípede ao 
ponto fixo $\mathcal{F}$.

A distancia que uma perna de balanço deve percorrer até chegar em $\mathbf{P}_{\mathbf{s w}}\left(\mathbf{s}_{\text {step }}^{-}\right)$é $\mathbf{r}_{\text {step }}=\mathbf{P}_{\mathbf{s w}}\left(\mathbf{s}_{\text {step }}^{-}\right)-\mathbf{P}_{\mathbf{s w}}\left(\mathbf{s}_{\mathbf{0}}\right)$. Como a cada passo a perna de balanço vira a nova perna de apoio, temos que o $\mathbf{P}_{\mathbf{s w}}\left(\mathbf{s}_{\mathbf{0}}\right)$ é igual à $-\mathbf{P}_{\mathbf{s w}}\left(\mathbf{s}_{\text {step }}^{-}\right)$do passo anterior. Logo temos que:

$$
\begin{array}{r}
\mathbf{r}_{\text {step }}\left(\Delta t_{2}, \mathbf{s}_{\text {step }}^{+}, U(t, \mathbf{s})\right)=2 \mathbf{P}_{\text {sw }}\left(\mathbf{s}_{\text {step }}^{-}\right) \\
\Delta t_{2} \leq \Delta t+T\left(\mathbf{s}_{\text {step }}^{+}, \mathbf{X}\left(\mathbf{s}_{\text {step }}^{-}\right)\right)-T\left(\mathbf{s}_{\mathbf{0}}, \mathbf{X}\left(\mathbf{s}_{\text {step }}^{-}\right)\right)
\end{array}
$$

Porém, tal critério garante a estabilidade apenas se em cada passada $0 \mathbf{r}_{\text {ic }}$ for reduzido comparado ao da passada anterior. Vamos analisar então o caso em que uma passada não reduza o $\mathbf{r}_{\mathbf{i c}}$, ou seja:

$$
\mathbf{r}_{\text {ic }}\left(\mathbf{s}_{\text {step }}^{+}\right)>\mathbf{r}_{\text {ic }}\left(\mathbf{s}_{0}\right)
$$

Essa passada vai terminar em um estado $\mathbf{s}_{\text {step2 }}^{+}$. Se aplicarmos o mesmo critério que anteriormente nesta nova passada como se o $\mathbf{s}_{\text {step }}^{+}$fosse o nosso novo $\mathbf{s}_{\mathbf{0}}$, caso exista um $U(t, \mathbf{s}) \leq U_{\max }(t, \mathbf{s})$ que reduza o Capture Point seguindo (6.18) e (6.19), o sistema está estável e consegue convergir para o ponto fixo $\mathcal{F}$. Generalizando, para qualquer número $\mathrm{N}$ de passos arbitrariamente escolhidos dentro de $\mathbb{V}$, desde que exista potencialmente uma passada começando de $\mathbf{s}_{\text {stepN }}^{+}$que satisfaça o critério das equações 6.18 e 6.19, o sistema mantém a capacidade de se estabilizar, logo está estável. Essa passada potencial não precisa ser de fato efetivada. A existência dela garante que o sistema se encontra em uma situação estável e que futuramente ele conseguirá convergir para o ponto fixo $\mathcal{F}$.

\subsection{Análise do Critério de ZMP Desde o Ponto de Vista do Critério de Estabilidade Proposto}

O critério de estabilidade de ZMP define que o CoP deve permanecer dentro da base de suporte durante a marcha fazendo assim com que o pé de apoio se mantenha 
apoiado no chão. Temos então como demonstrado por Hof et al. (2007) que:

$$
\mathbf{C o P}-\operatorname{Pr}=-\frac{l}{g} \ddot{\mathbf{r}}
$$

Como solução da equação diferencial temos:

$$
\mathbf{P r}=\mathbf{C o P}+\left(\mathbf{P r}_{0}-\mathbf{C o P}\right) \cosh \left(\omega_{0} t\right)+\frac{\dot{\mathbf{r}}}{\omega_{0}} \sinh \left(\omega_{0} t\right)
$$

Ou seja:

$$
\begin{gathered}
0 \geq\left(\mathbf{P r}_{\mathbf{0}}-\mathbf{C o P}\right) \cosh \left(\omega_{0} t\right)+\frac{\dot{\mathbf{r}}}{\omega_{0}} \sinh \left(\omega_{0} t\right) \\
\left(\mathbf{C o P}-\mathbf{P r}_{\mathbf{0}}\right) \geq \frac{\dot{\mathbf{r}}}{\omega_{0}} \tanh \left(\omega_{0} t\right)
\end{gathered}
$$

Para o modelo de pêndulo invertido linear temos que o $\mathbf{r}_{\mathbf{i c}}=\mathbf{P r}+\frac{\overrightarrow{\hat{r}}}{\omega_{0}}$, então:

$$
\mathrm{CoP} \geq \mathbf{r}_{\text {ic }}
$$

Em paralelo temos segundo o critério de estabilidade proposto que:

$$
\begin{cases}\mathbf{r}_{\mathbf{i c}}\left(t_{0}+\Delta t, \mathbf{s}_{\mathbf{0}}\right)=0 & \text { se } \mathbf{r}_{\mathbf{i c}}\left(t_{0}, \mathbf{s}_{\mathbf{0}}\right)=0 \\ \mathbf{r}_{\mathbf{i c}}\left(t_{0}+\Delta t, \mathbf{s}_{\mathbf{0}}\right)>\mathbf{r}_{\mathbf{i c}}\left(t_{0}, \mathbf{s}_{\mathbf{0}}\right) & \text { se } \mathbf{r}_{\mathbf{i c}}\left(t_{0}, \mathbf{s}_{\mathbf{0}}\right) \geq 0\end{cases}
$$

Logo para o Capture Point não ultrapassar o CoP ele deve ser igual à zero sempre, ou seja $\mathbb{V}\left(\mathbf{s}_{0}\right)=\varnothing$

Desta forma podemos ver que o critério de ZMP é uma condição específica do critério de estabilidade proposto para quando não há garantias de que existe uma passada viável. 


\subsection{Testes do Step Viability}

De forma a poder se implementar o critério do Step Viability é necessário se projetar um controlador que implemente uma marcha desejada, com a restrição de terminar em um estado que possibilite realizar uma passada que traga o Capture Point mais próximo da perna de apoio. A Figura 30 ilustra o procedimento. A linha contínua representa o movimento planejado e a linha tracejada representa o passo à frente usado como uma restrição. A linha tracejada não será usada como um movimento de referência, sua existência é a validação da estabilidade. Nomearemos o primeiro passo como o Passo Planejado e o segundo passo como o Passo de Restrição.
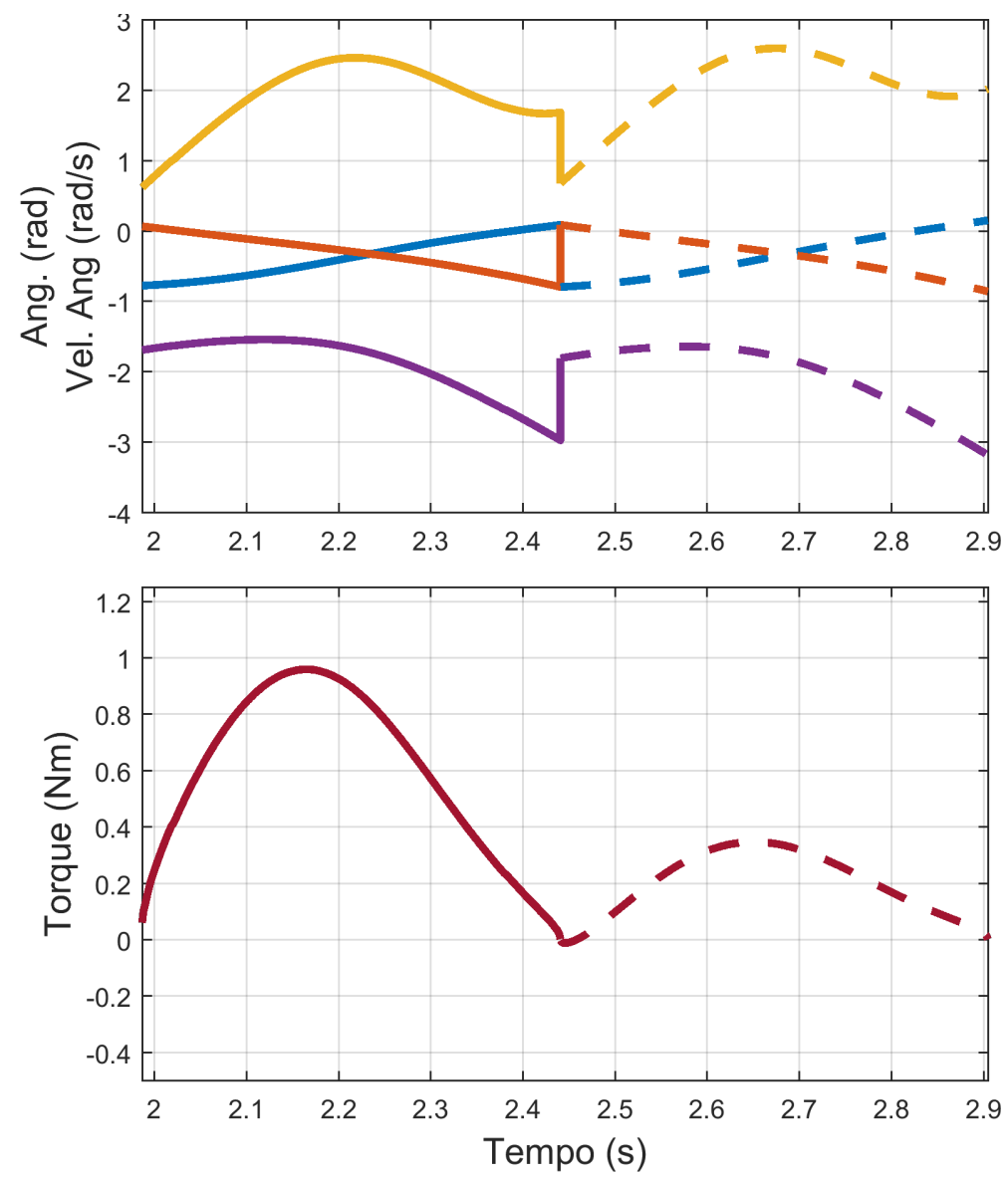

Figura 30: Exemplo de solução: a linha contínua é a solução do passo desejado levando em consideração a existência do segundo passo (linha tracejada) que satisfaz a restrição do Step Viability.

Em resumo, o que temos de fazer é descobrir qual será o estado final do nosso movimento planejado e verificar se existe um passo que satisfaça o critério. Se o passo não existir, temos de planejar um novo movimento e verificar novamente. Uma solu- 
ção mais adequada é resolver o problema inteiro de uma vez como uma otimização de trajetória multi-fases. Na primeira fase, utilizamos os estados iniciais e condições de impacto como restrições e na segunda fase usamos a condição de impacto e o critério de Step Viability como restrição. As restrições de ligação entre as fases são implementadas utilizando a função de transferência de impacto do modelo. Finalmente, o movimento desejado do Passo Planejado é implementado na função de custo.

\subsubsection{Exemplo 1: Compass Gait em uma Rampa}

\subsubsection{Modelo}

O Modelo do Compass Gait aqui utilizado é o mesmo apresentado no Capítulo 4. As seguintes equações são também utilizadas durante a solução do problema.

$$
\begin{gathered}
\theta_{i}=\pi-2 \alpha \\
\alpha=\frac{\theta_{s}-\theta_{n s}}{2} \\
\dot{\theta}_{i}=-2 \dot{\alpha} \\
\dot{\alpha}=\frac{\dot{\theta_{s}}-\dot{\theta}_{n s}}{2}
\end{gathered}
$$

Posição do centro de massas:

$$
\mathbf{X}_{\mathbf{C O M}}=\frac{1}{2 m+m_{H}}\left[\begin{array}{c}
-\left(m a+l m_{H}\right) \sin \left(\theta_{s}\right)-m\left(l \sin \left(\theta_{s}\right)+b \sin \left(\theta_{s}+\theta_{i}\right)\right) \\
\left(m a+l m_{H}\right) \cos \left(\theta_{s}\right)+m\left(l \cos \left(\theta_{s}\right)+b \cos \left(\theta_{s}+\theta_{i}\right)\right)
\end{array}\right]
$$

Jacobiano da posição do centro de massas: 


$$
\mathbf{J}_{\mathbf{C O M}}=\frac{1}{2 m+m_{H}}\left[\begin{array}{ll}
-b m \cos \left(\theta_{s}+\theta_{i}\right) & -\left(m a+l m_{H}\right) \cos \left(\theta_{s}\right)-m\left(l \cos \left(\theta_{s}\right)+b \cos \left(\theta_{s}+\theta_{i}\right)\right) \\
-b m \sin \left(\theta_{s}+\theta_{i}\right) & -\left(m a+l m_{H}\right) \sin \left(\theta_{s}\right)-m\left(l \sin \left(\theta_{s}\right)+b \sin \left(\theta_{s}+\theta_{i}\right)\right)
\end{array}\right]
$$

Velocidade do centro de massas:

$$
\dot{\mathrm{X}}_{\mathrm{COM}}=\mathrm{J} \mathbf{C O M}\left[\begin{array}{c}
\dot{\theta}_{S} \\
\dot{\theta}_{i}
\end{array}\right]
$$

\subsubsection{Implementação}

Como o Compass Gait tem dois graus de liberdade e um tornozelo passivo, há uma limitação no controle do movimento desejado. Uma variável interessante que pode ser usada para ilustrar a versatilidade do Step Viability é a velocidade angular inicial da perna de apoio logo após o impacto. No entanto, uma velocidade angular negativa logo após o passo não garante um Capture Point positivo, o que é desejado para a continuidade do movimento (caso contrário, o bípede não será capaz de avançar). Portanto, um ponto de Capture Point mínimo após o impacto do Passo Planejado também será adicionado na função de custo. Finalmente, para minimizar o torque usado e evitar torques de pico altos, a integral do torque quadrado será adicionada na função de custo. Portanto o problema pode ser descrito como:

$$
\begin{array}{r}
J=G_{v e l}\left({\dot{\theta_{s}}}^{\text {target }}-{\dot{\theta_{s+}}}^{\text {step }}\right)^{2} \\
+G_{i c p 1} \arctan \left(\left(r_{i c}^{\text {min }}-r_{i c}\left(\mathbf{s}\left(t_{\text {step }}^{+}\right)\right)\right) \gamma\right) \\
+G_{i c p 2} \arctan \left(\left(r_{i c}^{\text {min }}-r_{i c}\left(\mathbf{s}\left(t_{f}^{+}\right)\right)\right) \gamma\right) \\
+\int_{0}^{t_{f}} U(t)^{2} G_{u} d t
\end{array}
$$

Sujeito às restrições do primeiro passo: 


$$
\begin{array}{r}
\mathbf{s}(0)=\mathbf{s}_{\mathbf{0}} \\
\theta_{s}\left(t_{\text {step }}\right)+\theta_{n s}\left(t_{\text {step }}\right)+2 \alpha=0 \\
\theta_{s}\left(t_{\text {step }}\right)-\theta_{n s}\left(t_{\text {step }}\right)>0.1 \\
\dot{\theta}_{s}\left(t_{\text {step }}\right)+\dot{\theta}_{n s}\left(t_{\text {step }}\right) \leq-0.1
\end{array}
$$

Sujeito às restrições de ligação no tempo $t_{\text {step }}$ :

$$
\begin{array}{r}
\dot{\theta}\left(t_{\text {step }}^{+}\right)=\mathbf{I}\left(\theta\left(t_{\text {step }}^{-}\right)\right) \dot{\theta}\left(t_{\text {step }}^{-}\right) \\
\theta_{s}\left(t_{\text {step }}^{+}\right)=\theta_{n s}\left(t_{\text {step }}^{-}\right) \\
\theta_{\text {ns }}\left(t_{\text {step }}^{+}\right)=\theta_{s}\left(t_{\text {step }}^{-}\right)
\end{array}
$$

Sujeito às restrições do segundo passo:

$$
\begin{array}{r}
\theta_{s}\left(t_{f}\right)+\theta_{n s}\left(t_{f}\right)+2 \alpha=0 \\
\theta_{s}\left(t_{f}\right)-\theta_{n s}\left(t_{f}\right)>0.1 \\
\dot{\theta}_{s}\left(t_{f}\right)+\dot{\theta}_{n s}\left(t_{f}\right) \leq-0.1 \\
r_{i c}\left(\mathbf{s}\left(t_{\text {step }}^{+}\right)\right)-r_{i c}\left(\mathbf{s}\left(t_{f}^{+}\right)\right) \geq 0.11
\end{array}
$$

Sujeito às restrições de estado e de controle:

$$
\begin{array}{r}
\frac{-\pi}{2} \leq \theta_{s} \leq \frac{\pi}{2} \\
\frac{-\pi}{2} \leq \theta_{n s} \leq \frac{\pi}{2} \\
u_{\text {min }} \leq U \leq u_{\text {max }} \\
0.01 \leq t_{\text {step }} \leq 1.5 \\
t_{\text {step }}+0.01 \leq t_{f} \leq 3.0
\end{array}
$$

Restrições como na equação (6.35c) são usadas para garantir que o passo acon- 
teça quando a perna de balanço estiver na frente da perna de apoio (o passo está avançando). Como não podemos criar uma restrição de caminho evitando que o pé vá sob o chão, restrições como na equação (6.35d) são usadas para garantir que, quando o pé cruza o chão vindo de uma posição debaixo do chão, não é considerado um impacto.

Outro fato que vale a pena mencionar é que no início dos ensaios não usamos o termo $G_{i c p 2} \arctan \left(\left(r_{i c}^{\min }-r_{i c}\left(\mathbf{s}\left(t_{f}^{+}\right)\right)\right) \gamma\right)$ na função de custo. Isso resultou, em algumas situações, que o modelo teve de pisar de tal forma que o Capture Point no segundo passo era negativo, resultando em que o modelo parasse, sem continuar a marcha. Apesar de ser uma condição estável, nós queremos usar uma função de custos que proporcionam uma marcha contínua. Este termo ajudou a reduzir drasticamente as condições que levaram à parada prematura dos testes.

Finalmente, e o fato mais importante, pode-se perguntar onde está a equação (6.19) do critério Step Viability. Não é trivial calcular uma solução de forma analítica qual a diferença de tempo que um deslocamento de um Capture Point representa na evolução do estado do modelo. Adicionalmente também não é fácil de entender qual é a distância que um passo pode cobrir com este tempo extra. No entanto, podemos ter uma visão da natureza de ambas as evoluções olhando a solução analítica do Pêndulo Invertido Linear (PRATT; TEDRAKE, 2006) e do modelo linearizado de um passo. Na equação (6.39) temos equação da dinâmica do Pêndulo Invertido Linear:

$$
x(t)=\left(x_{0}+\frac{v_{0}}{\omega_{0}}\right) e^{w_{0} t}+\left(x_{0}-\frac{v_{0}}{\omega_{0}}\right) e^{-w_{0} t}
$$

Se considerarmos que $t$ é suficientemente grande a equação pode ser aproximada para:

$$
x(t)=\left(x_{0}+\frac{v_{0}}{\omega_{0}}\right) e^{w_{0} t}
$$

Como $x_{0}+\frac{v_{0}}{\omega_{0}}$ é o Capture Point inicial $r_{i c 0}$, portanto o tempo que um determinado $x_{0}$ com o Capture Point $r_{i c 0}$ demora para evoluir para algum $x_{f}$ é :

$$
t=\frac{\ln \left(\frac{x_{f}}{r_{i c 0}}\right)}{\omega_{0}}
$$


Se reduzimos o Capture Point de um passo para outro em $\Delta r_{i c}$ temos a seguinte relação $c$ de tempo comparada com o passo original:

$$
c=\frac{\ln \left(\frac{x_{f}}{r_{i c 0}-\Delta r_{i c}}\right)}{\ln \left(\frac{x_{f}}{r_{i c 0}}\right)}
$$

Vamos olhar agora uma modelagem de uma passada. Se considerarmos que a dinâmica de uma perna de balanço pode ser aproximada para um pêndulo temos:

$$
\ddot{\theta}=\frac{(u-m g l \sin (\theta))}{I}
$$

Se desconsiderarmos o efeito da gravidade teremos:

$$
\begin{gathered}
\ddot{\theta}=\frac{u}{I} \\
\dot{\theta}=\frac{u}{I} t+\dot{\theta}_{0} \\
\theta=\frac{u}{2 I} t^{2}+\dot{\theta}_{0} t+\theta_{0}
\end{gathered}
$$

Se considerarmos que $\dot{\theta}_{0}=0$ teremos:

$$
\theta-\theta_{0}=\frac{u}{2 I} t^{2}
$$

Por simetria podemos assumir que dado que um $\theta_{f}$ resulta em um $P_{\text {sw }}\left(s_{\text {step }}^{-}\right),-\theta_{f}$ resulta em $-P_{s w}\left(s_{s t e p}^{-}\right)$. Se considerarmos que todas as passadas começam com a perna de balanço com um $\theta_{0} \leq 0$, o pior caso será quando $\theta_{0}=0$. Logo temos que:

$$
\begin{gathered}
\theta_{f}-0=\theta_{f}=\frac{u}{2 I} t_{1}^{2} \\
\theta_{f}-\left(-\theta_{f}\right)=2 \theta_{f}=\frac{u}{2 I} t_{2}^{2}
\end{gathered}
$$

Dividindo uma equação pela outra teremos que: 


$$
2=\left(\frac{t_{1}}{t_{2}}\right)^{2}
$$

Ou seja, no pior cenário a razão entre os tempos das duas passadas será $\sqrt{2}$ ou seja 1.4142 .

Se considerarmos que no nosso modelo a altura do centro de massas está no máximo em 1.0 m, e que o ângulo máximo aceitável antes do Compass Gait se comportar muito diferente do modelo linear é $\pi / 3$, a distância máxima horizontal é $x_{f}=$ $0.866 \mathrm{~m}$. Se considerarmos esses valores na equação (6.42) podemos descobrir que para um $\Delta r_{i c}=0.11 \mathrm{~m}$ o mínimo $c$ é 1,4148 (Figura 31). Portanto, se limitarmos que a segunda etapa pode reduzir o Ponto de Captura em $0.11 \mathrm{~m}$, iremos garantir o critério da equação (6.19). Essa restrição é implementada na equação (6.37d) da definição do problema.

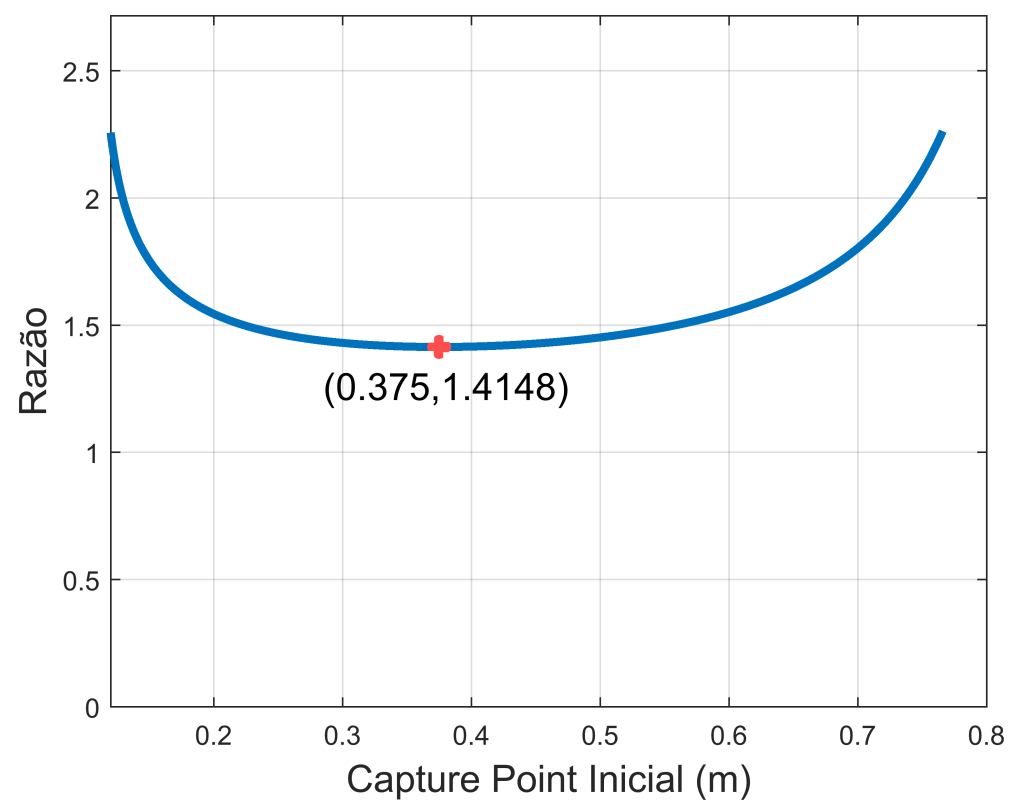

Figura 31: Razão do tempo calculada com a equação (6.42) considerando $x_{f}=0.866$ $\mathrm{m}$ e $\Delta r_{i c}=0.11 \mathrm{~m}$ para $r_{i c 0}$ variando entre 0.12 até $0.76 \mathrm{~m}$. O ponto vermelho é o valor mínimo do intervalo.

O problema de otimização da trajetória foi resolvido usando PSOPT (BECERRA, 2010). PSOPT é um software de código aberto escrito em $\mathrm{C}++$ que é capaz de usar métodos de colocação pseudo-espectral (Legendre e Chebyshev) para resolver problemas multi-fases. Também oferece diferenciação automática, evitando a necessidade de calcular gradientes analíticos. 


\subsubsection{Simulação e Testes}

A otimização da trajetória calcula tanto os estados como o controle do Compass Gait, no entanto, foram realizadas simulações utilizando a saída de controle como uma check de sanidade para cada passo. Todas as simulações foram realizadas usando Simbody (SHERMAN; SETH; DELP, 2011). O modelo utilizado nas simulações e durante a otimização da trajetória foi o mesmo. Os impactos também foram implementados usando os Eventos do Simbody com a mesma função de transferência como no modelo ao invés de usar seu modelo de contato nativo. MATLAB foi usado para gerar Figuras e gráficos.

Para testar o critério de estabilidade proposto, testamos vários passos consecutivos com diferentes inclinações, distribuição de massa e torque máximo. As mudanças nos parâmetros do modelo foram aplicadas com todas as combinações dos valores dados na Tabela 7. Para todas as simulações, a massa total do bípede foi de $20 \mathrm{~kg}$.

\begin{tabular}{llll} 
Tabela 7: Parametros dos modelos durante os testes \\
\\
\hline Parametros & \multicolumn{3}{c}{ Valor } \\
\hline Massa da Perna & $1 \mathrm{~kg}$ & $5 \mathrm{~kg}$ & $9 \mathrm{~kg}$ \\
Torque Máximo & $5 \mathrm{Nm}$ & $15 \mathrm{Nm}$ & $50 \mathrm{Nm}$ \\
Inclinação da Rampa & $3^{\circ}$ & $20^{\circ}$ & $30^{\circ}$ \\
\hline
\end{tabular}

Para avaliar a validade deste critério de estabilidade, o mesmo foi testado com diferentes padrões de marcha. Estas marchas foram definidas por uma diferente velocidade angular de referência da perna de apoio após o impacto $\dot{\theta}_{s_{s t e p}}^{+}$. Usamos dois padrões para realizar o teste:

Velocidade angular de referência da perna de apoio após o impacto $\left(\dot{\theta}_{s}^{\text {tar }}\right)$

- Variação linear: 10 passos, decrescendo $\dot{\theta}_{s}^{t a r}$, começando de $-1.0 \mathrm{rad} / \mathrm{s}$ e decrescendo $-0.2 \mathrm{rad} / \mathrm{s}$ a cada passo.

- Variação aleatória: 20 passos com um $\dot{\theta}_{\mathrm{s}}^{\text {tar }}$ aleatório entre $-1.0 \mathrm{rad} / \mathrm{s}$ e $-3.0 \mathrm{rad} / \mathrm{s}$ gerado para cada passo.

Considerando todas as combinações, um total de 54 testes foram realizados. 


\subsubsection{Resultados}

O critério de Step Viability gerou com sucesso o número definido de passos estáveis consecutivos em todos os 54 testes. Alguns fatos são dignos de menção. Um dos maiores problemas que tivemos no início dos testes foi dar condições iniciais de que o modelo com $9 \mathrm{~kg}$ de massa nas pernas e $5 \mathrm{Nm}$ de torque máximo fosse capaz de realizar um primeiro passo viável na inclinação de $20^{\circ}$ e $30^{\circ}$. Para resolver esse problema, o que fizemos foi remover a restrição das velocidades angulares iniciais do modelo para que o PSOPT pudesse descobrir uma condição inicial que proporcionaria um passo viável. Com um primeiro passo viável, o critério de estabilidade foi capaz de garantir passos adicionais. No entanto, este primeiro passo viável começou com velocidades angulares elevadas, de modo que para inicializar a simulação com uma condição mais razoável, extraímos as condições iniciais de um passo intermediário da simulação e usamos como restrição da condição inicial para todos os valores de torque máximo no mesmo par de massa das pernas/inclinação. A Figura 32 ilustra o procedimento.

Para uma solução geral usando $G_{u}$ como 1/250, $\gamma=10, G_{v e l}=G_{i c p 1}=G_{i c p 2}=10$, pudemos obter resultados para todos os testes. No entanto, como o $G_{v e l}$ estava similar dos outros ganhos, os testes com torque máximo alto não convergiram para $\dot{\theta}_{s}^{\text {tar }}$ com muita precisão. Usando $G_{v e l}=0.4 u_{\text {max }}^{2}$ e $G_{u}=1 / u_{\text {max }}^{2}$ todos os testes foram capazes de executar todas os passo sem ter o problema de ocorrer uma parada prematura devido à um Capture Point pequeno, mas foram capaz de seguir o $\dot{\theta}_{s}^{\text {tar }}$ mais próximo nos casos de torque máximo alto.

A Figura 33 ilustra um resultado dos testes. Podemos ver que o modelo Compass Gait é capaz de andar fazendo vários passos consecutivos, com diferentes comprimentos de passo (comparando $d 1$ e $d 2$ como exemplo) e diferentes padrões de movimento, sem cair. Também é capaz (com limitações), de seguir o $\dot{\theta}_{s}^{\text {tar }}$ prescrito (linha verde tracejada).

Como um resultado colateral podemos verificar como o Compass Gait foi capaz de seguir o $\dot{\theta}_{s}^{t a r}$. Podemos ver a variação do torque máximo influenciou os resultados em diferentes inclinações e massas de pernas.

Tanto para massas da perna de $1 \mathrm{~kg}$ como para $5 \mathrm{~kg}$ na inclinação de $3^{\circ}$ (Figuras 34 36, 35 e 37 ) os modelos não foram capazes de seguir a referência e o torque 

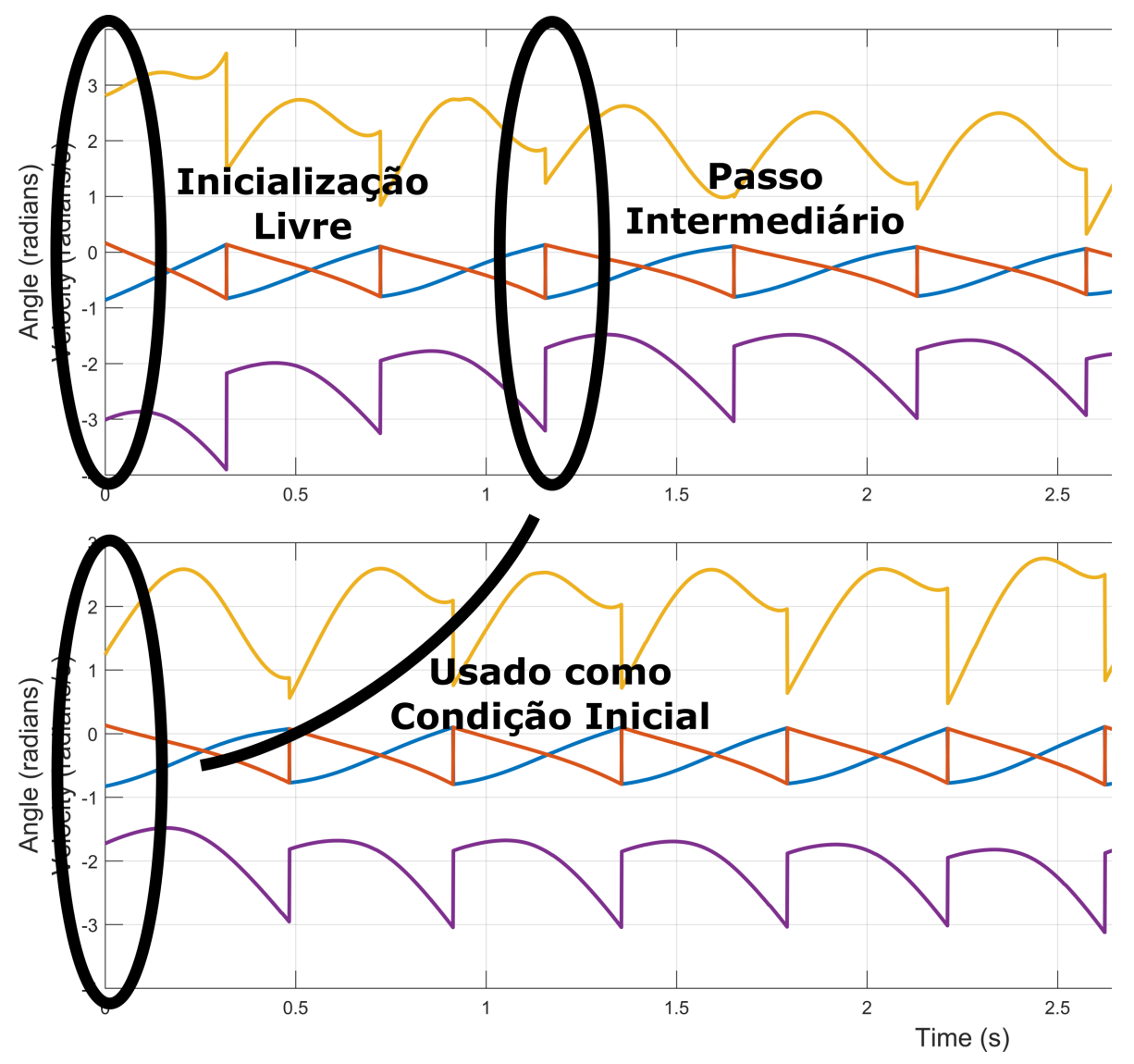

Figura 32: Exemplo do procedimento utilizado para encontrar os estados iniciais adequados para permitir um primeiro passo viável. Torque máximo $=15 \mathrm{Nm}$, inclinação $=$ $20^{\circ}$ e massa da perna $=5 \mathrm{~kg}$.

não influenciou em nada. O resultado foi provavelmente devido ao fato de que o modelo não ter uma inclinação suficiente para ganhar velocidade nem ter massa na perna suficiente para aumentar a energia cinética. Com uma massa de perna de $9 \mathrm{~kg}$ (Figuras 38 e 39), o bípede foi capaz de melhor acompanhar o $\dot{\theta}_{s}^{t a r}$, sendo o melhor caso no torque máximo de $50 \mathrm{Nm}$, conforme esperado.

Com a inclinação de $20^{\circ}$ ambos os torques máximos de $15 \mathrm{Nm}$ e $50 \mathrm{Nm}$ foram capazes rastrear razoavelmente o $\dot{\theta}_{S}^{\text {tar }}$ quando o bípede tinha $1 \mathrm{~kg}$ de massa de perna Figuras 40 e 41). O torque máximo de $5 \mathrm{Nm}$ pode fornecer alguma inclinação para seguir o $\dot{\theta}_{s}^{\text {tar }}$, mas com uma limitação severa. Nos casos de 5 kg (Figuras 42 e 43), novamente o torque máximo de $50 \mathrm{Nm}$ pode rastrear a referência de forma razoável, porém o caso de $15 \mathrm{Nm}$ apresentou um rastreamento muito fraco e os $5 \mathrm{Nm}$ não pode realizar qualquer rastreamento. Com a massa de perna de $9 \mathrm{~kg}$ (Figuras 44 e 45), ocorreu o mesmo, mas de forma mais pronunciada. 

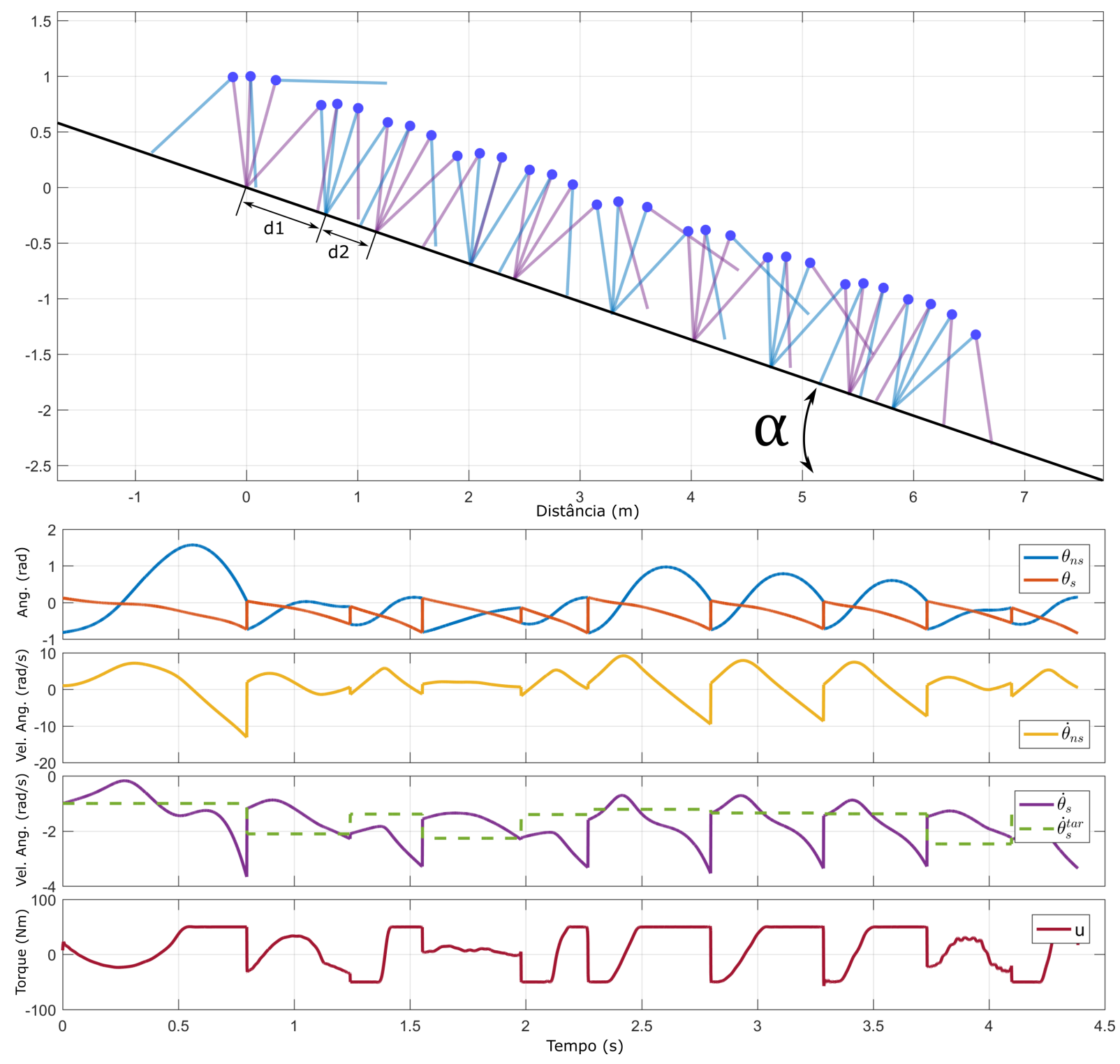

Figura 33: Exemplo de solução com padrão aleatório, massa da perna de 5 kg, inclinação de $20^{\circ}$ e torque máximo de $50 \mathrm{Nm}$ 


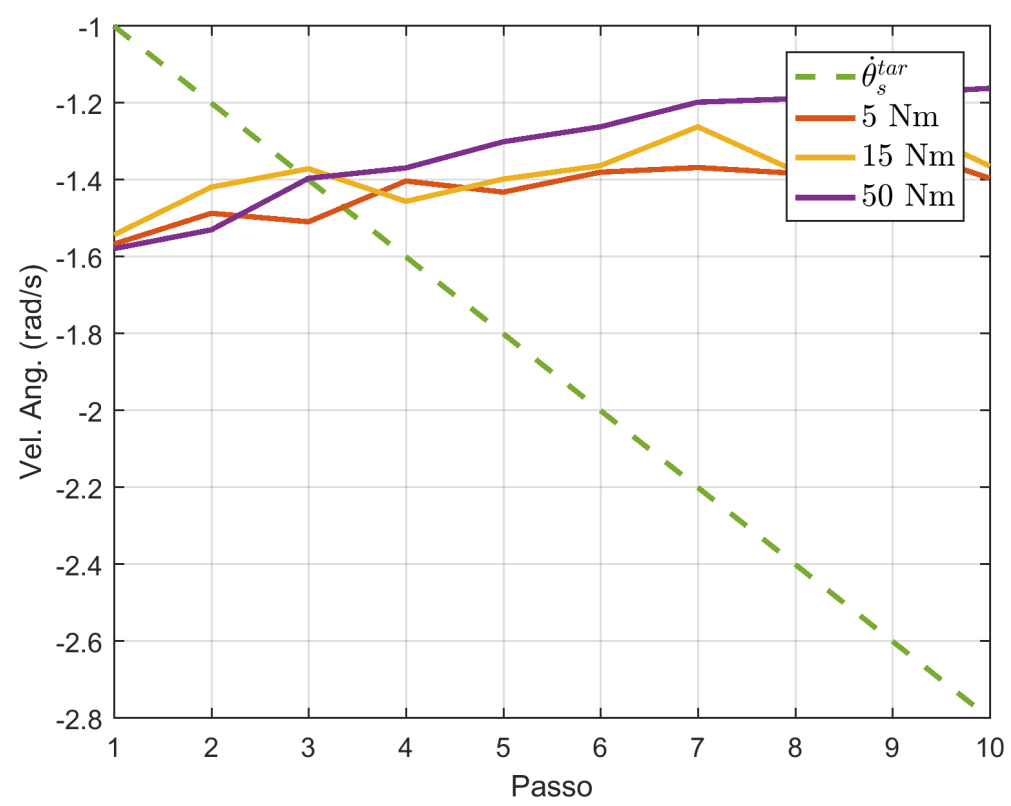

Figura 34: Comparação de $\dot{\theta}_{s}^{\text {tar }} \times \dot{\theta}_{s}$ executado no teste: Inclinação $=3^{\circ}$ - Massa da Perna $=1$ kg - Padrão: linear

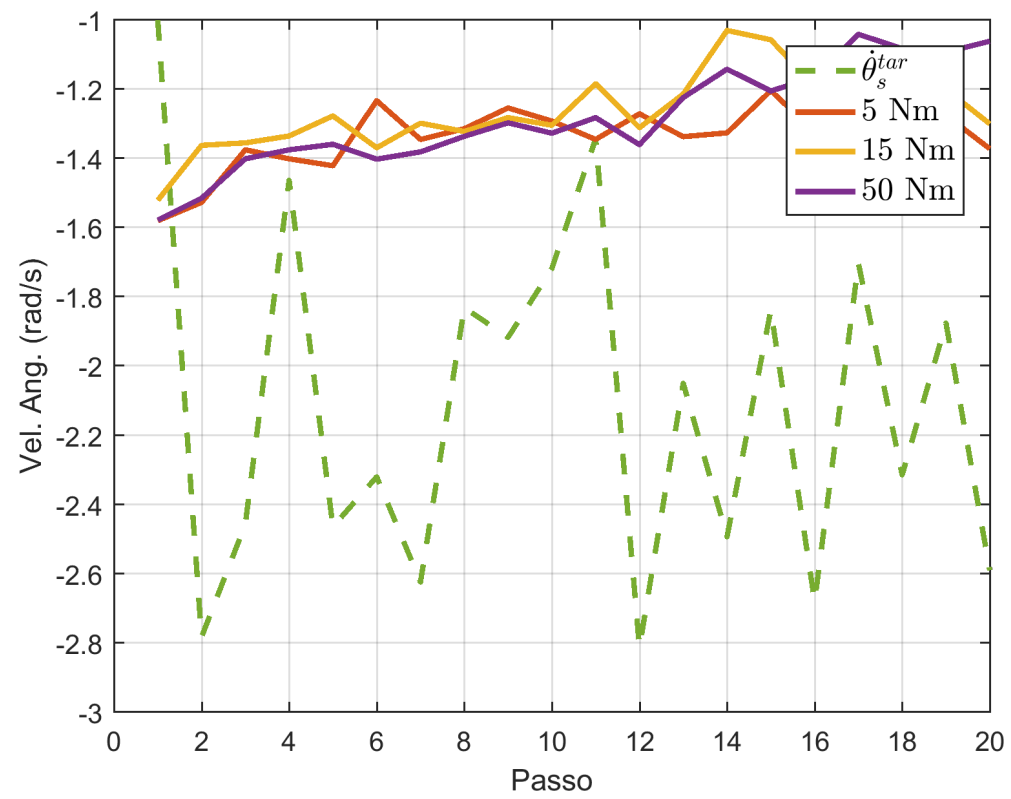

Figura 35: Comparação de $\dot{\theta}_{s}^{\text {tar }} \times \dot{\theta}_{s}$ executado no teste: Inclinação $=3^{\circ}$ - Massa da Perna $=1 \mathrm{~kg}$ - Padrão: aleatório 


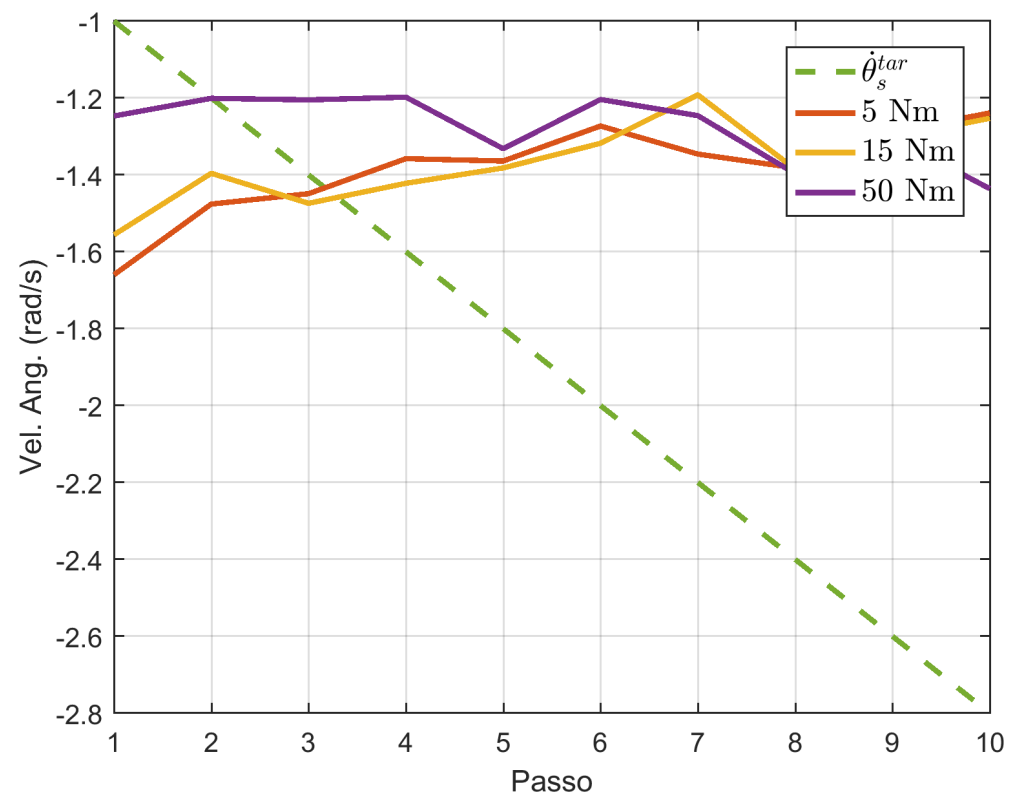

Figura 36: Comparação de $\dot{\theta}_{s}^{\text {tar }} \times \dot{\theta}_{s}$ executado no teste: Inclinação $=3^{\circ}$ - Massa da Perna $=5$ kg - Padrão: linear

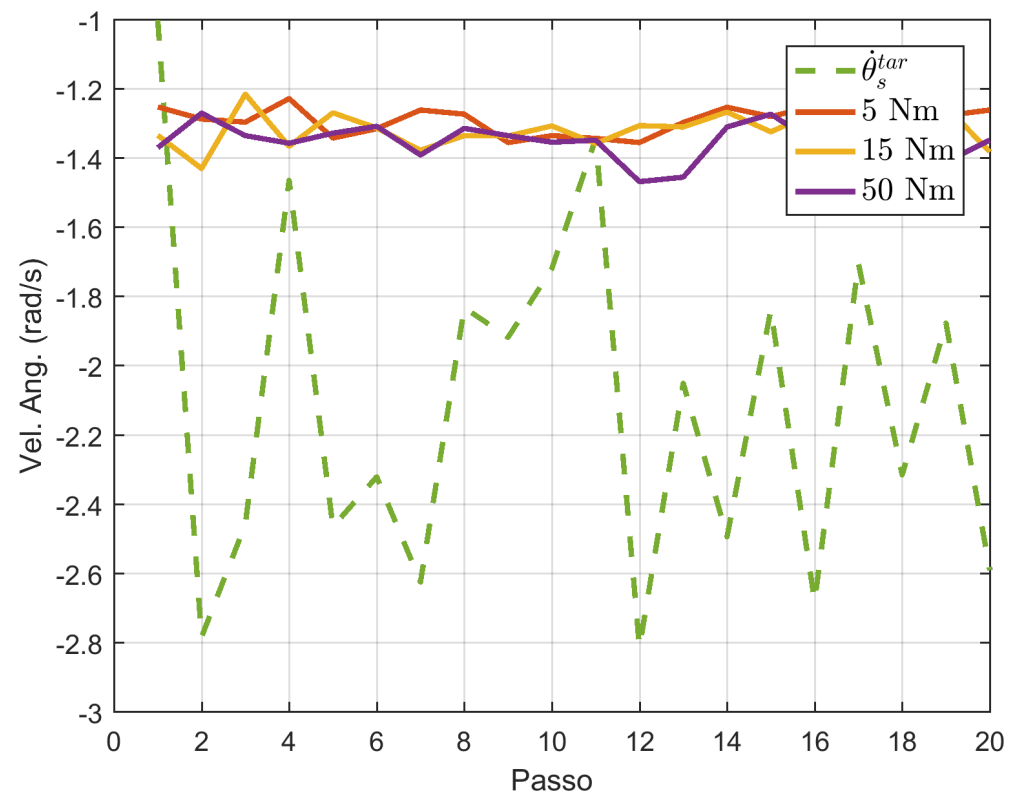

Figura 37: Comparação de $\dot{\theta}_{s}^{\text {tar }} \times \dot{\theta}_{s}$ executado no teste: Inclinação $=3^{\circ}$ - Massa da Perna $=5 \mathrm{~kg}$ - Padrão: aleatório 


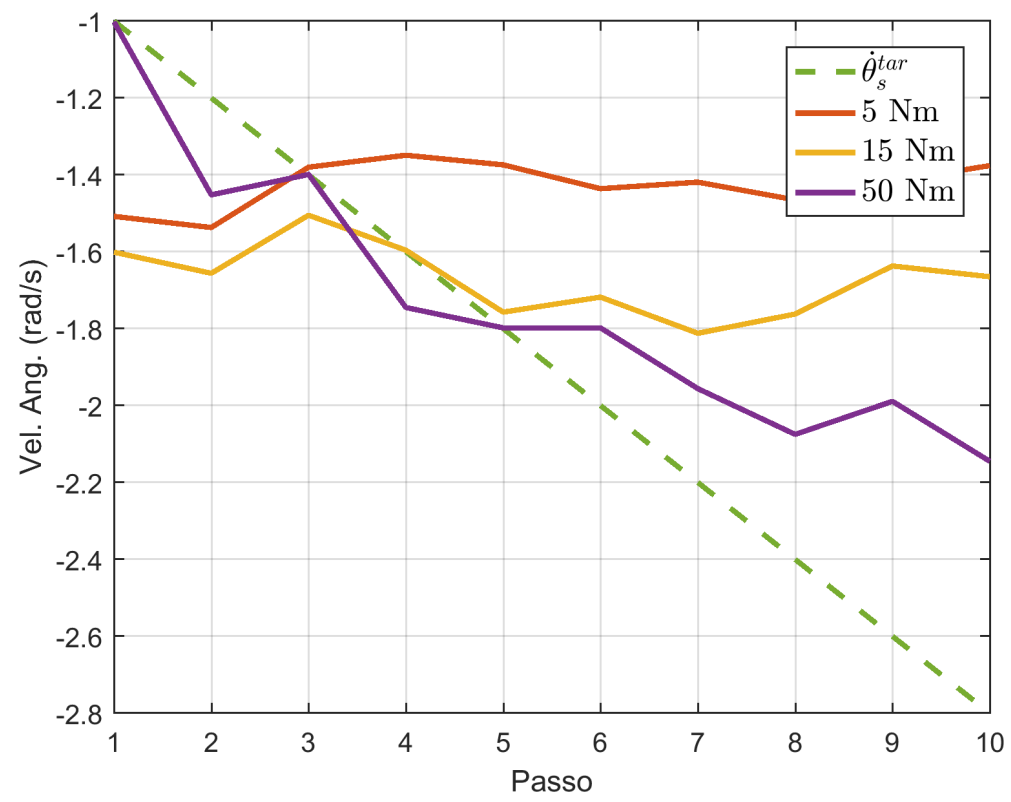

Figura 38: Comparação de $\dot{\theta}_{s}^{\text {tar }} \times \dot{\theta}_{s}$ executado no teste: Inclinação $=3^{\circ}$ - Massa da Perna $=9$ kg - Padrão: linear

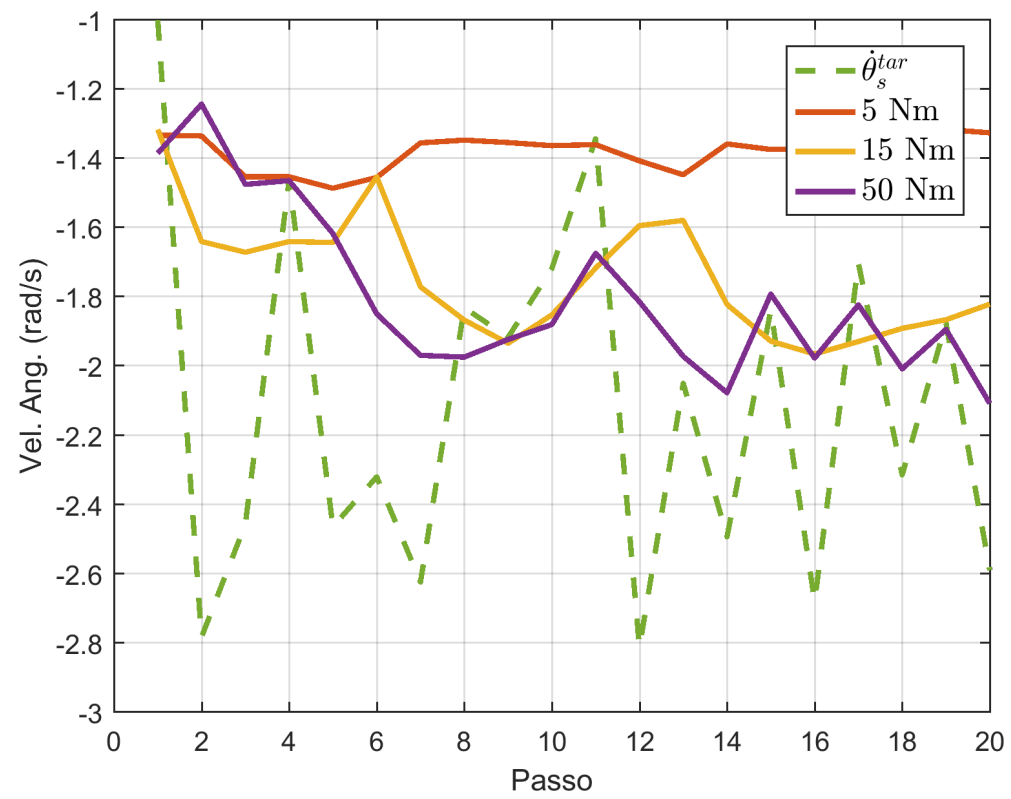

Figura 39: Comparação de $\dot{\theta}_{s}^{t a r} \times \dot{\theta}_{s}$ executado no teste: Inclinação $=3^{\circ}$ - Massa da Perna $=9 \mathrm{~kg}$ - Padrão: aleatório 


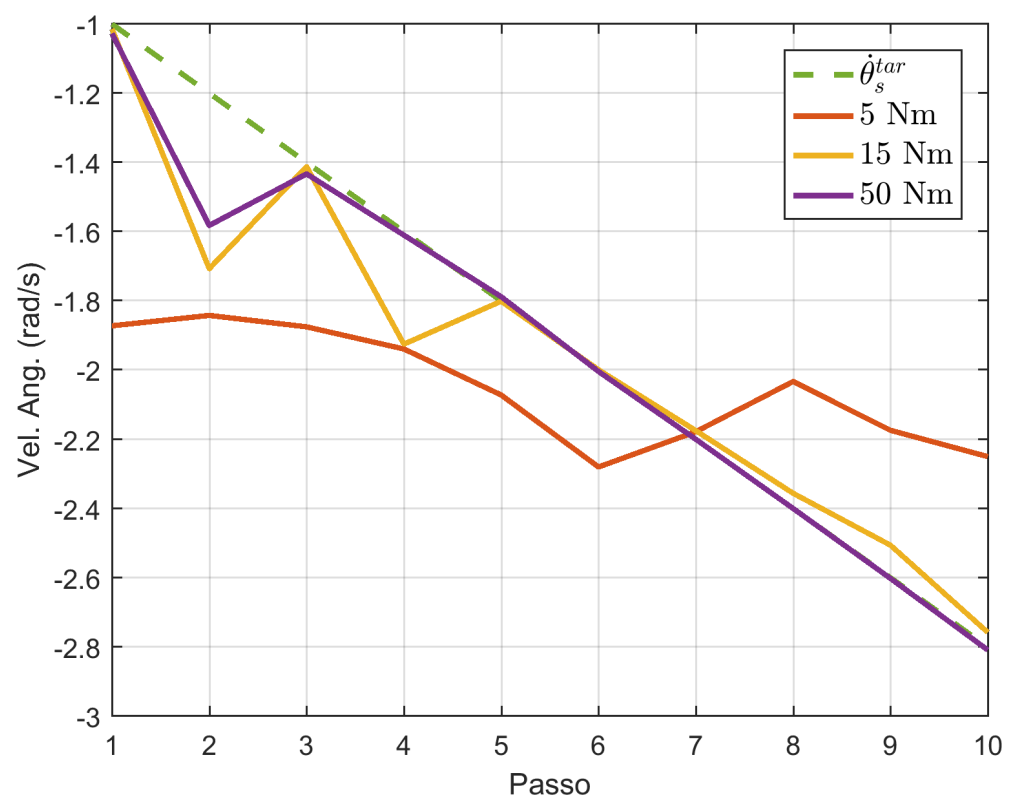

Figura 40: Comparação de $\dot{\theta}_{s}^{\text {tar }} \times \dot{\theta}_{s}$ executado no teste: Inclinação $=20^{\circ}$ - Massa da Perna $=1$ kg - Padrão: linear

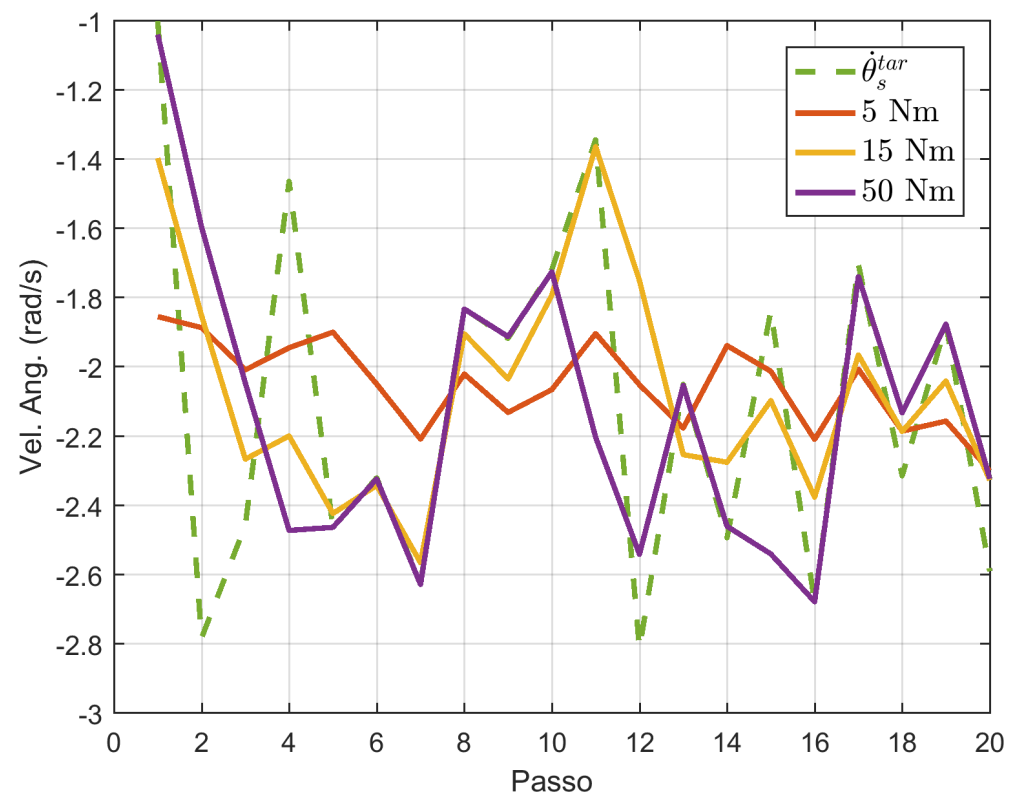

Figura 41: Comparação de $\dot{\theta}_{s}^{\text {tar }} \times \dot{\theta}_{s}$ executado no teste: Inclinação $=20^{\circ}$ - Massa da Perna $=1 \mathrm{~kg}$ - Padrão: aleatório 


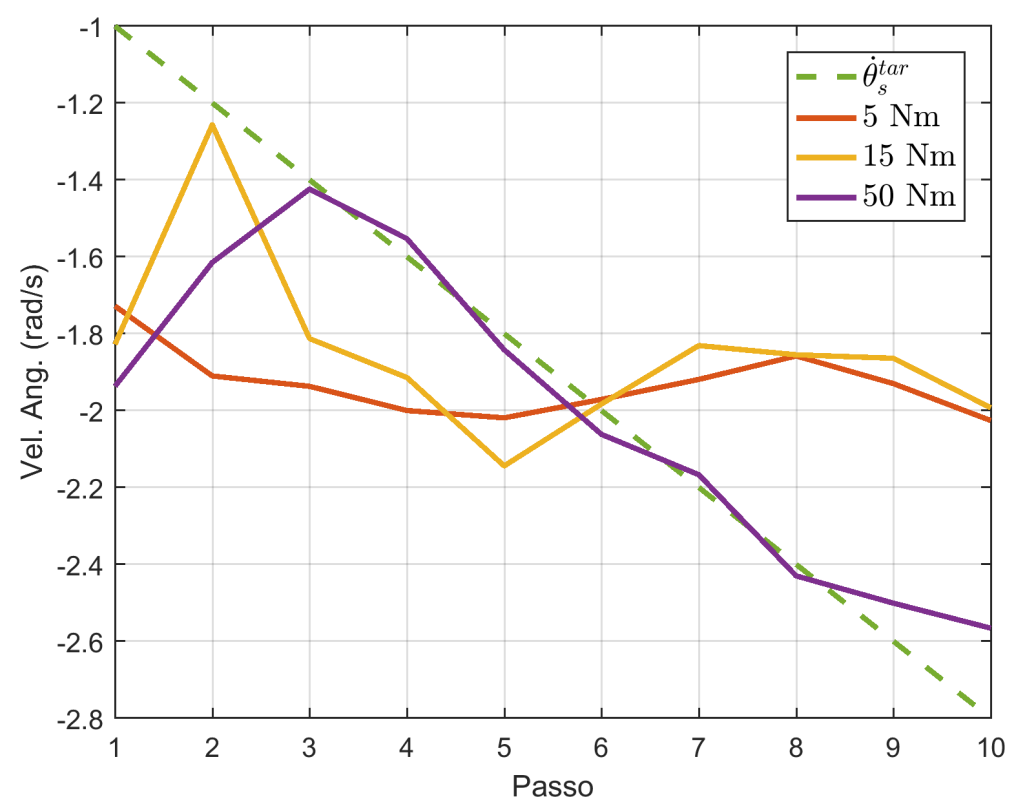

Figura 42: Comparação de $\dot{\theta}_{s}^{\text {tar }} \times \dot{\theta}_{s}$ executado no teste: Inclinação $=20^{\circ}$ - Massa da Perna $=5$ kg - Padrão: linear

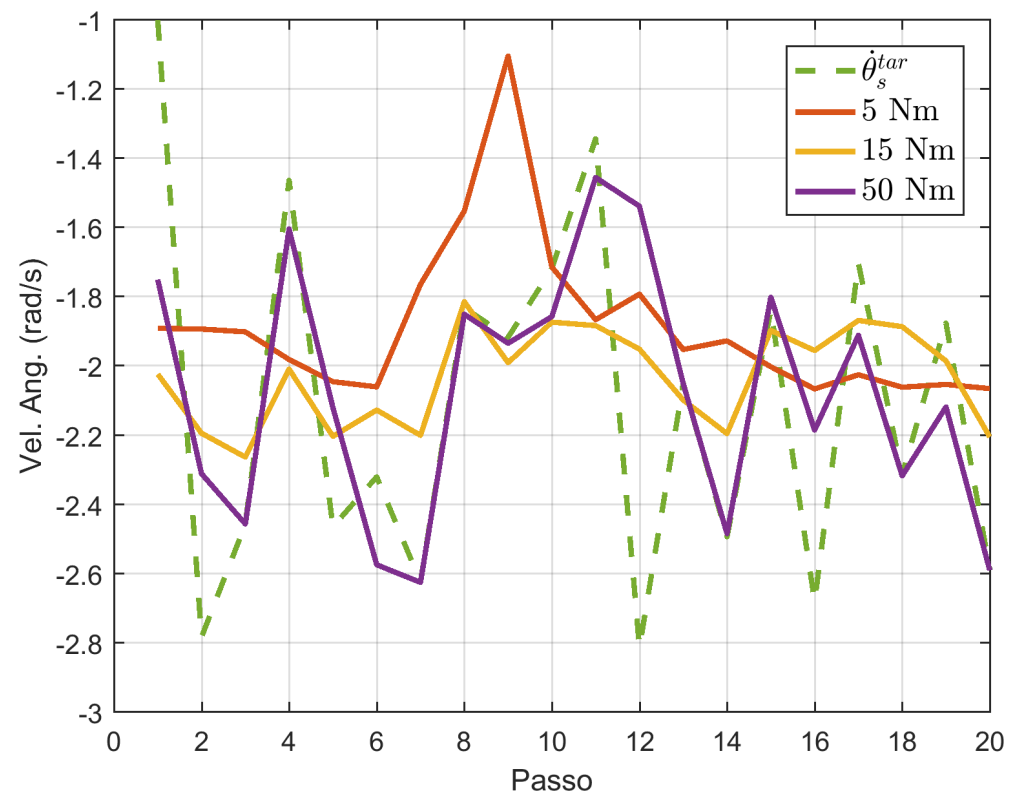

Figura 43: Comparação de $\dot{\theta}_{s}^{t a r} \times \dot{\theta}_{s}$ executado no teste: Inclinação $=20^{\circ}$ - Massa da Perna $=5 \mathrm{~kg}$ - Padrão: aleatório 


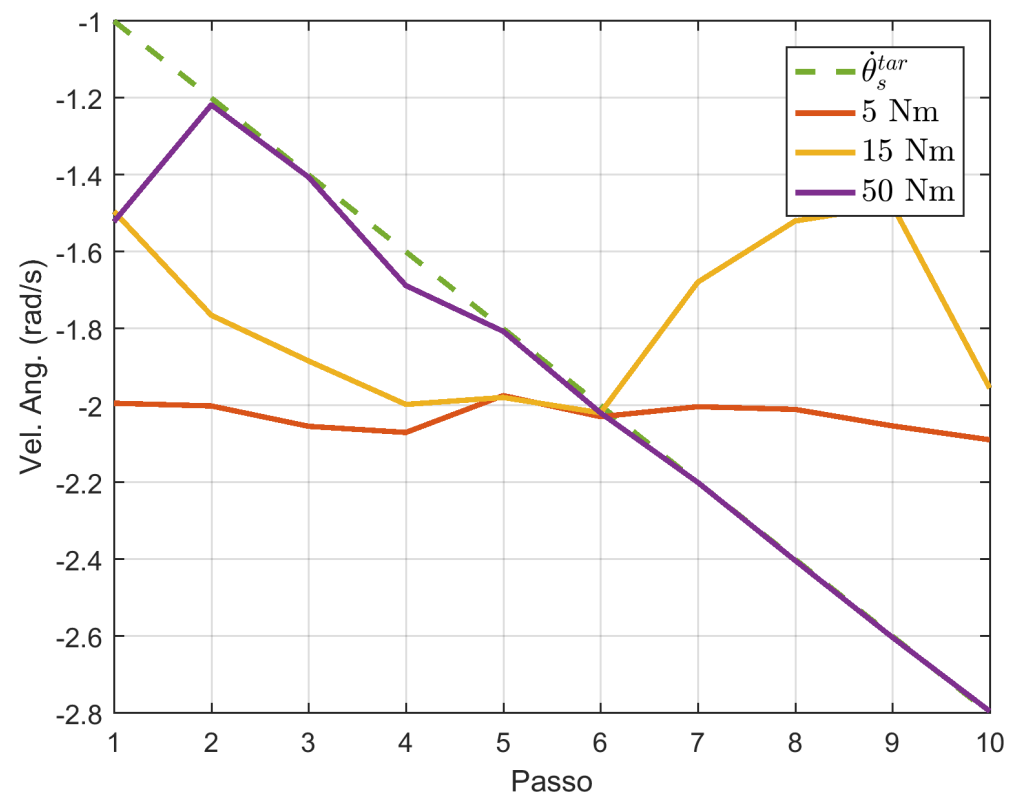

Figura 44: Comparação de $\dot{\theta}_{s}^{\text {tar }} \times \dot{\theta}_{s}$ executado no teste: Inclinação $=20^{\circ}$ - Massa da Perna $=9$ kg - Padrão: linear

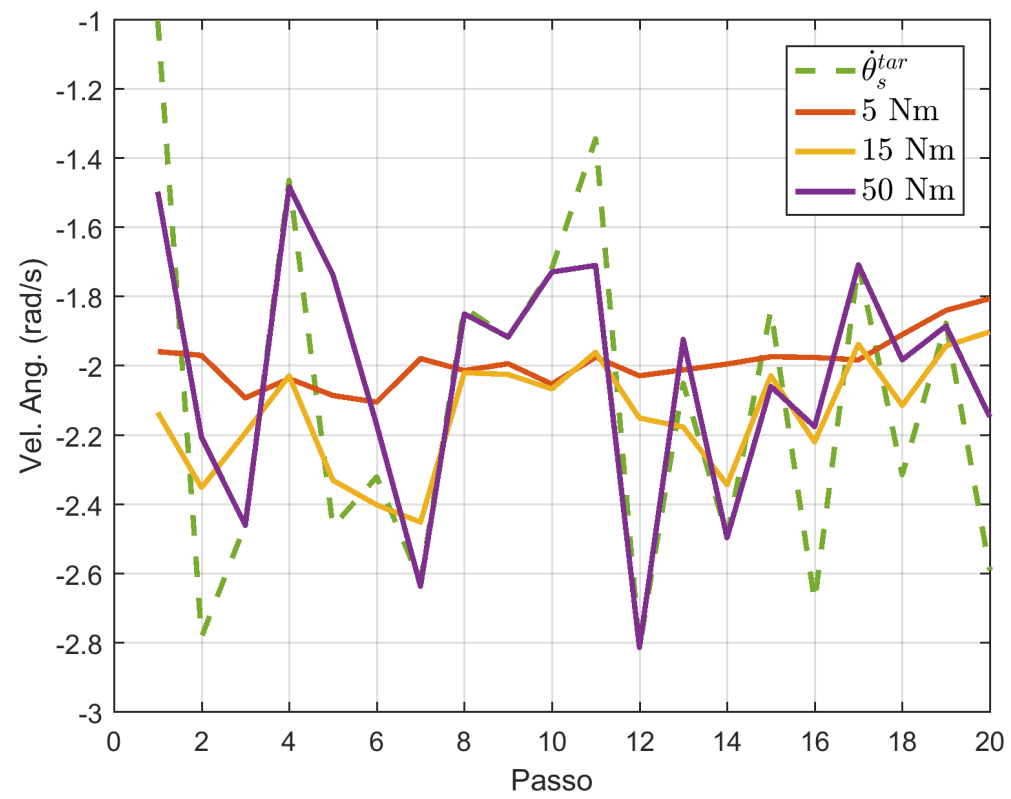

Figura 45: Comparação de $\dot{\theta}_{s}^{t a r} \times \dot{\theta}_{s}$ executado no teste: Inclinação $=20^{\circ}$ - Massa da Perna $=9 \mathrm{~kg}$ - Padrão: aleatório 
Com a inclinação de $30^{\circ}$, novamente, ambos os torques máximos $15 \mathrm{Nm}$ e 50 $\mathrm{Nm}$ puderam rastrear razoavelmente o $\dot{\theta}_{s}^{\text {tar }}$ quando o bípede tinha massa da perna de $1 \mathrm{~kg}$ (Figuras 46 e 47). O torque máximo de $5 \mathrm{Nm}$, novamente pode fornecer alguma inclinação para seguir o $\dot{\theta}_{s}^{\text {tar }}$, mas com menos limitação quando comparado à inclinação de $20^{\circ}$. Em ambos os casos de $5 \mathrm{~kg}$ e $9 \mathrm{~kg}$ (Figuras 48, 49, 50 e 51), apenas o torque máximo de $50 \mathrm{Nm}$ conseguiu convergir para a referencia razoavelmente para o padrão linear, porém o torque máximo de $15 \mathrm{Nm}$ apresentou alguma tendencia de rastreamento para o caso de $5 \mathrm{~kg}$ quando com o padrão aleatório.

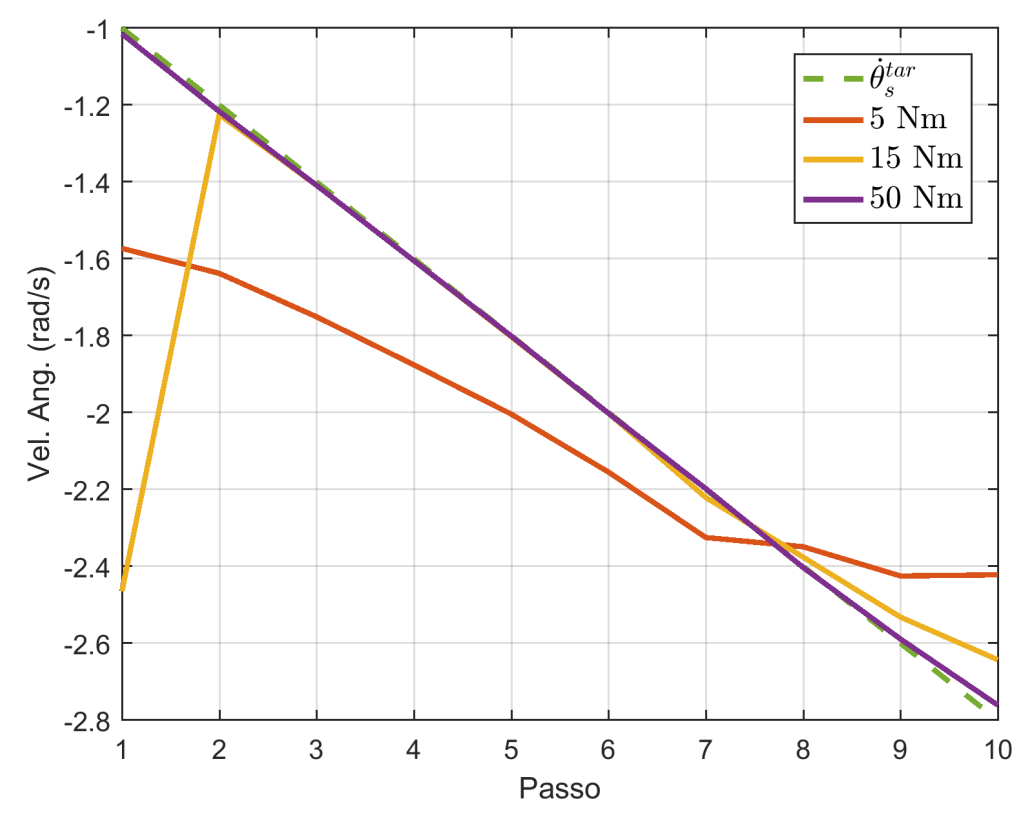

Figura 46: Comparação de $\dot{\theta}_{s}^{t a r} \times \dot{\theta}_{s}$ executado no teste: Inclinação $=30^{\circ}-$ Massa da Perna $=1 \mathrm{~kg}$ - Padrão: linear 


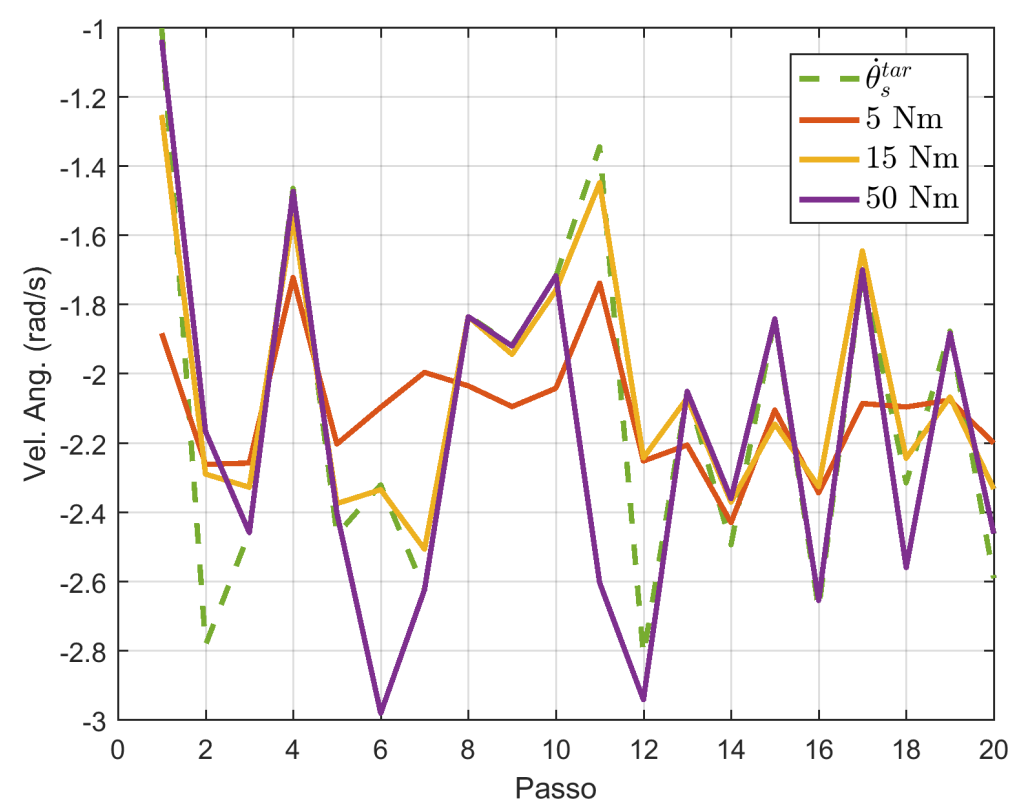

Figura 47: Comparação de $\dot{\theta}_{S}^{t a r} \times \dot{\theta}_{S}$ executado no teste: Inclinação $=30^{\circ}$ - Massa da Perna = 1 kg - Padrão: aleatório

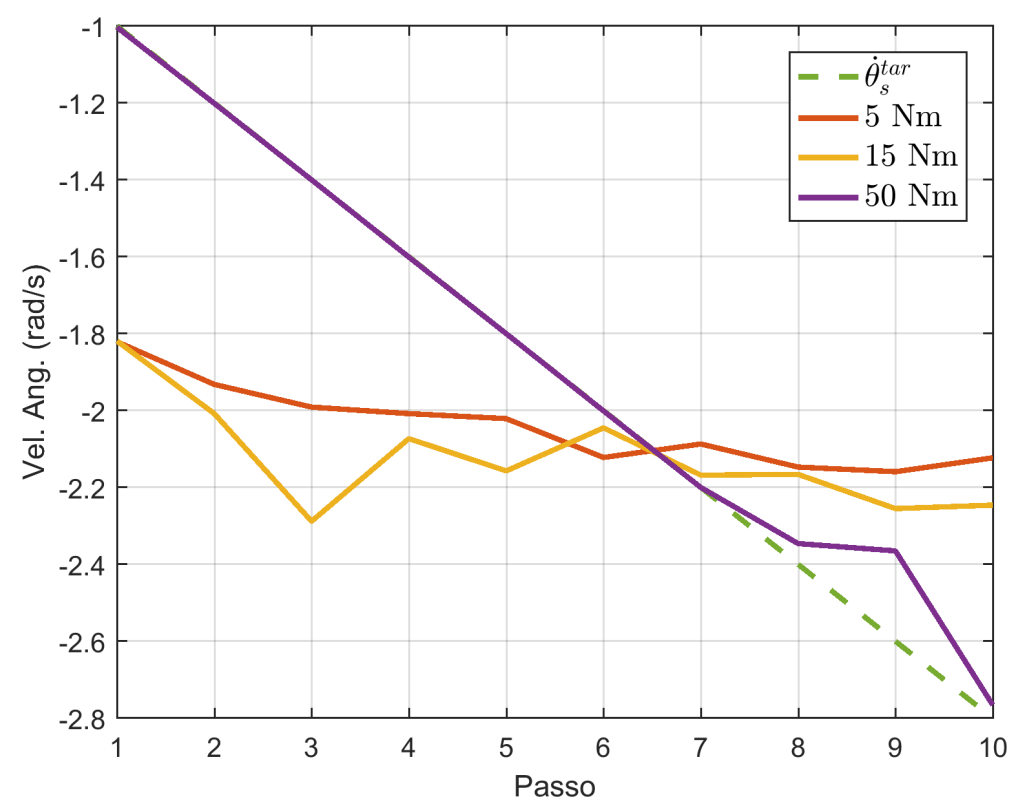

Figura 48: Comparação de $\dot{\theta}_{s}^{t a r} \times \dot{\theta}_{s}$ executado no teste: Inclinação $=30^{\circ}$ - Massa da Perna $=5$ kg - Padrão: linear 


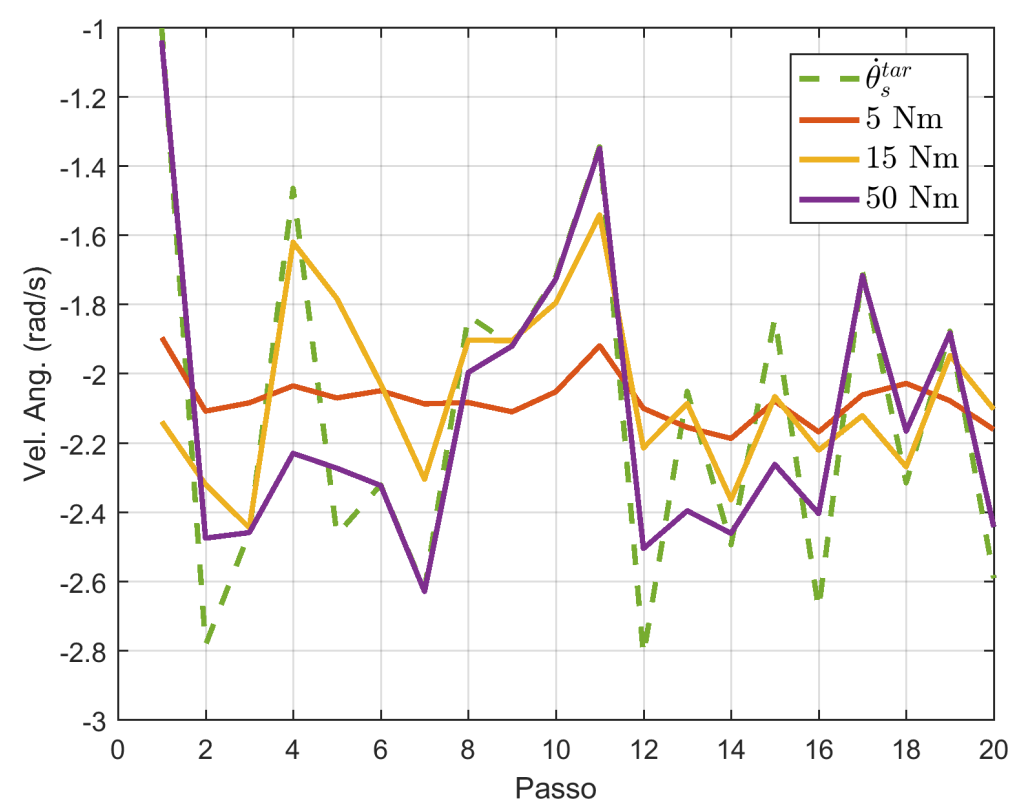

Figura 49: Comparação de $\dot{\theta}_{S}^{t a r} \times \dot{\theta}_{S}$ executado no teste: Inclinação $=30^{\circ}$ - Massa da Perna $=5 \mathrm{~kg}$ - Padrão: aleatório

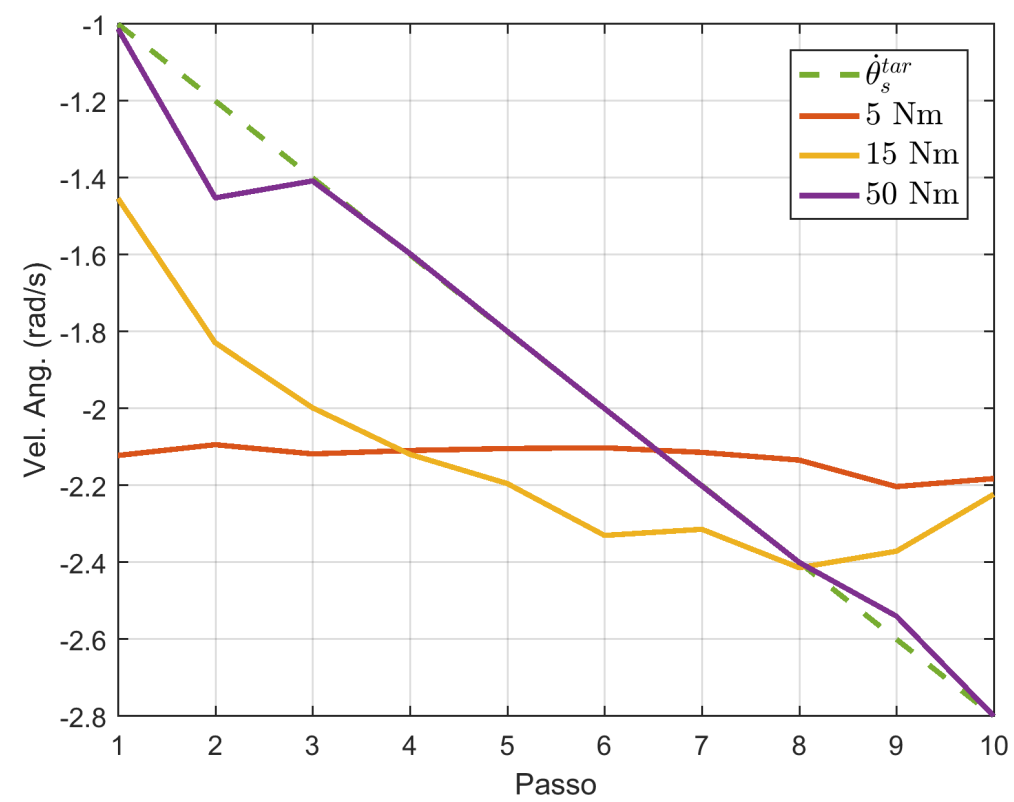

Figura 50: Comparação de $\dot{\theta}_{s}^{t a r} \times \dot{\theta}_{s}$ executado no teste: Inclinação $=30^{\circ}$ - Massa da Perna $=9$ kg - Padrão: linear 


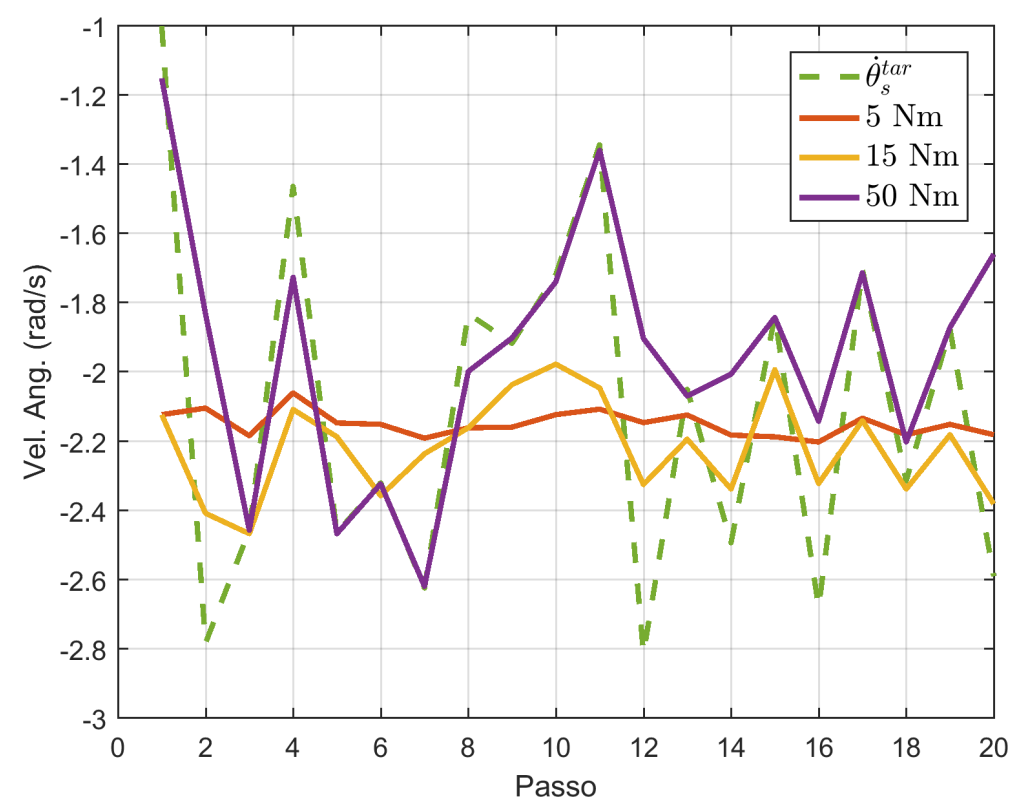

Figura 51: Comparação de $\dot{\theta}_{s}^{t a r} \times \dot{\theta}_{s}$ executado no teste: Inclinação $=30^{\circ}$ - Massa da Perna $=9$ kg - Padrão: aleatório

\subsubsection{Exemplo 2: Modelo Planar de 5 Segmentos}

\subsubsection{Modelo}

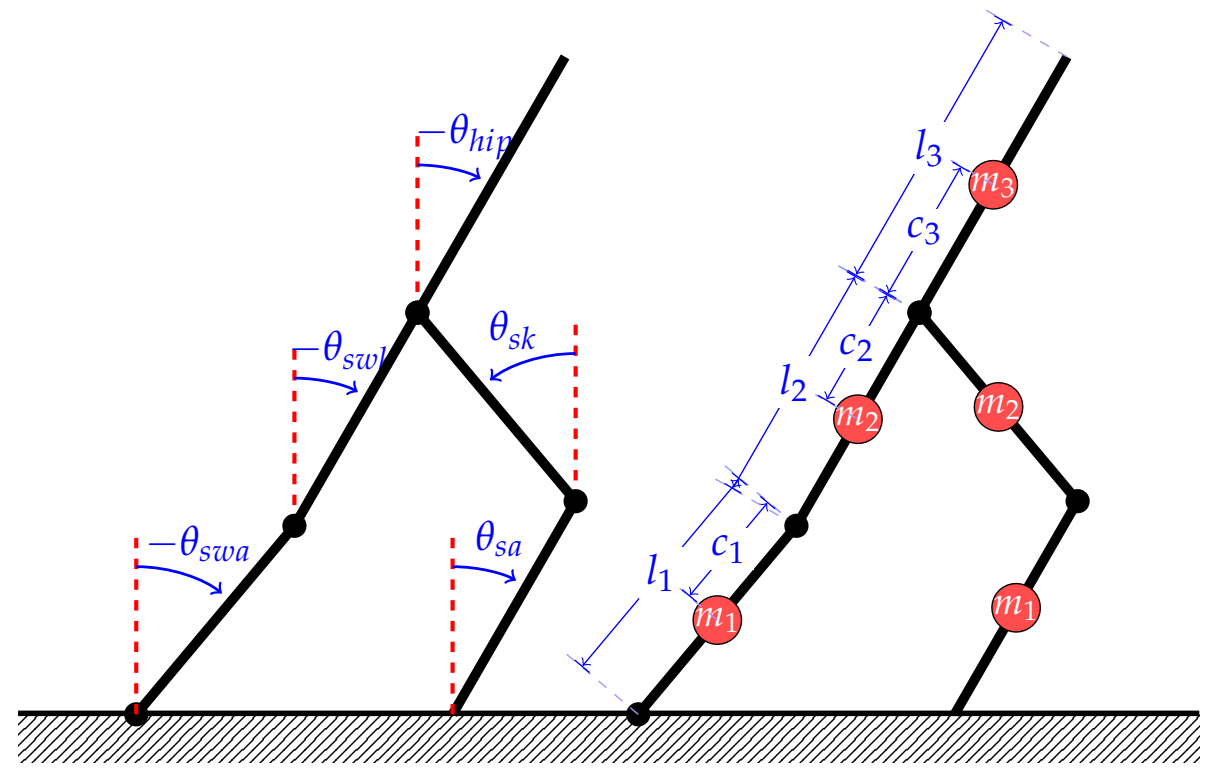

Figura 52: Modelo de 5 segmentos. 
O modelo (Figura 52) aqui utilizado é baseado no RABBIT (CHEVALLEREAU et al., 2003). As equações dinâmicas e as equações cinemáticas utilizadas são apresentadas no Apêndice C. O modelo é composto por 5 segmentos com todas as juntas atuadas com exceção da junta do tornozelo da perna de apoio. Os pés são pontuais e cada segmento é composto por uma massa $\mathrm{m}$, localizada com a distância c da junta, e um momento de inércia I. Os estados do bípede são descritos pelos ângulos absolutos de cada segmento com a vertical e suas respectivas velocidades angulares. O modelo de impacto segue as mesmas regras do modelo de impacto do Compass Gait.

\subsubsection{Implementação}

No modelo de 5 segmentos, o conceito do Step Viability foi implementado da mesma forma que no Compass Gait, porém o projeto da marcha é bem mais elaborado devido à quantidade de graus de liberdade existentes. Os seguintes aspectos da marcha foram controlados: tamanho do passo $P x_{s w}$, velocidade horizontal do quadril durante o passo $\dot{P} x_{h i p}$, altura do quadril $P y_{h i p}$, posição final do quadril $P x_{h i p} \mathrm{e}$ orientação do tronco $\theta_{\text {hip }}$. O problema foi proposto da seguinte forma:

$$
\begin{aligned}
& J=G_{f p o s}\left(P x_{s w}^{r e f}-P x_{s w}\left(t_{s t e p}^{-}\right)\right)^{2} \\
& \left.+G_{\text {hposx }} \arctan \left(\left(P x_{\text {hip }}^{\text {min }}-P x_{\text {hip }}\left(t_{\text {step }}^{-}\right)\right)\right) \gamma\right) \\
& \left.+G_{\text {fhpos }} \arctan \left(\left(\Delta P x^{m i n}-\left(P x_{s w}\left(t_{\text {step }}^{-}\right)-P x_{\text {hip }}\left(t_{\text {step }}^{-}\right)\right)\right)\right) \gamma\right) \\
& +G_{i c p} \arctan \left(\left(r_{i c}^{\min }-r_{i c}\left(\mathbf{s}\left(t_{\text {step }}^{+}\right)\right)\right) \gamma\right) \\
& +\int_{0}^{t_{f}} \mathbf{U}(t)^{2} G_{u}+G_{h o r}\left(\theta_{h i p}\right)^{2} \\
& +G_{\text {hvel }}\left(\dot{P} x_{\text {hip }}^{\text {tar }}-\dot{P} x_{\text {hip }}(t)\right)^{2} \\
& +G_{\text {hposy }}\left(P y_{\text {hip }}^{\text {tar }}-P y_{\text {hip }}(t)\right)^{2} \\
& +G_{h o r 2}\left(\pi / 2+\arctan \left(\left(\theta_{\text {hip }}-0.1\right) \gamma\right)\right) d t
\end{aligned}
$$

Sujeito às restrições do primeiro passo: 


$$
\begin{array}{r}
\mathbf{s}(0)=\mathbf{s}_{\mathbf{0}} \\
P x_{s w}\left(t_{s t e p}\right) \geq 0 \\
P y_{s w}\left(t_{s t e p}\right)=0 \\
\dot{P} y_{s w}\left(t_{s t e p}\right) \leq-0.01
\end{array}
$$

Sujeito às restrições de ligação no tempo $t_{\text {step }}$ :

$$
\begin{array}{r}
\dot{\theta}\left(t_{\text {step }}^{+}\right)=\mathbf{I}\left(\theta\left(t_{\text {step }}^{-}\right)\right) \dot{\theta}\left(t_{\text {step }}^{-}\right) \\
{\left[\begin{array}{c}
\theta_{s a} \\
\theta_{s k} \\
\theta_{\text {hip }} \\
\theta_{\text {swk }} \\
\theta_{\text {swa }}
\end{array}\right]=\left[\begin{array}{c}
\theta_{s w a} \\
\theta_{\text {swk }} \\
\theta_{\text {hip }} \\
\theta_{\text {sk }} \\
\theta_{s a}
\end{array}\right]}
\end{array}
$$

Sujeito às restrições do segundo passo:

$$
\begin{array}{r}
P x_{s w}\left(t_{f}\right) \geq 0 \\
P y_{s w}\left(t_{f}\right)=0 \\
\dot{P} y_{s w}\left(t_{f}\right) \leq-0.01 \\
r_{i c}\left(\mathbf{s}\left(t_{\text {step }}^{+}\right)\right)-r_{i c}\left(\mathbf{s}\left(t_{f}^{+}\right)\right) \geq 0.2
\end{array}
$$

Sujeito às restrições de estado e controle:

$$
\begin{array}{r}
\frac{-\pi}{2} \leq \theta \leq \frac{\pi}{2} \\
u_{\text {min }} \leq U \leq u_{\text {max }} \\
0.01 \leq t_{\text {step }} \leq 1.5 \\
t_{\text {step }}+0.01 \leq t_{f} \leq 3.0
\end{array}
$$


Sujeito às restrições de percurso:

$$
\begin{aligned}
\theta_{s a}-\theta_{s k} & \geq 0 \\
\theta_{s w a}-\theta_{s w k} & \geq 0 \\
P y_{s w} & \geq 0 \\
F y & \geq 0
\end{aligned}
$$

Comentando as principais novidades comparado ao teste do Compass Gait. No caso da orientação do quadril, existem dois componentes na função objetivo. O primeiro que utiliza o ganho $G_{h o l}$ é relacionado a tentar manter o tronco na vertical. O segundo que utiliza o ganho $G_{h o r 2}$ é relacionado a dar um custo maior quando o tronco se inclina para trás do que quando ele se inclina para frente, fazendo com que, se o modelo precisar inclinar o tronco, que ele de preferência que seja para frente. A componente relacionada à $G_{h p o s x}$ é utilizada para o passo terminar com a posição à frente da perna de apoio e o termo que tem o ganho $G_{f h p o s}$ é utilizado para o passo terminar com a perna de balanço (que vai virar a nova perna de apoio) a frente do quadril. As equações (6.56a) e (6.56b) servem para garantir que o joelho do modelo não dobre na direção errada e a equação (6.56c) garante que o pé do modelo não vá abaixo do nível do chão. A equação (6.56d) é usada para garantir que as forças de contacto com o chão sejam sempre positivas ou nulas, ou seja, o chão suporta o modelo mas ele não consegue se puxar em direção ao chão.

O calculo do $\Delta r_{i c p}$ é calculado da mesma forma utilizando a altura do centro de massas de $1.4 \mathrm{~m}$. O valor calculado é de $0.17 \mathrm{~m}$ (Figura 53), porém como o modelo tem muito mais fatores de incerteza, o mesmo foi utilizado como $0.2 \mathrm{~m}$.

\subsubsection{Simulação e Testes}

As simulações foram realizadas com o mesmo procedimento que com o modelo Compass Gait. Nos testes realizados não houve variação do modelo, apenas tendo variação do padrão de referência da marcha. No caso foi modulada a velocidade horizontal do quadril de forma aleatória e linear utilizando as seguintes variações.

Velocidade horizontal do quadril $\left(\dot{P} x_{\text {hip }}^{\text {tar }}\right)$ 


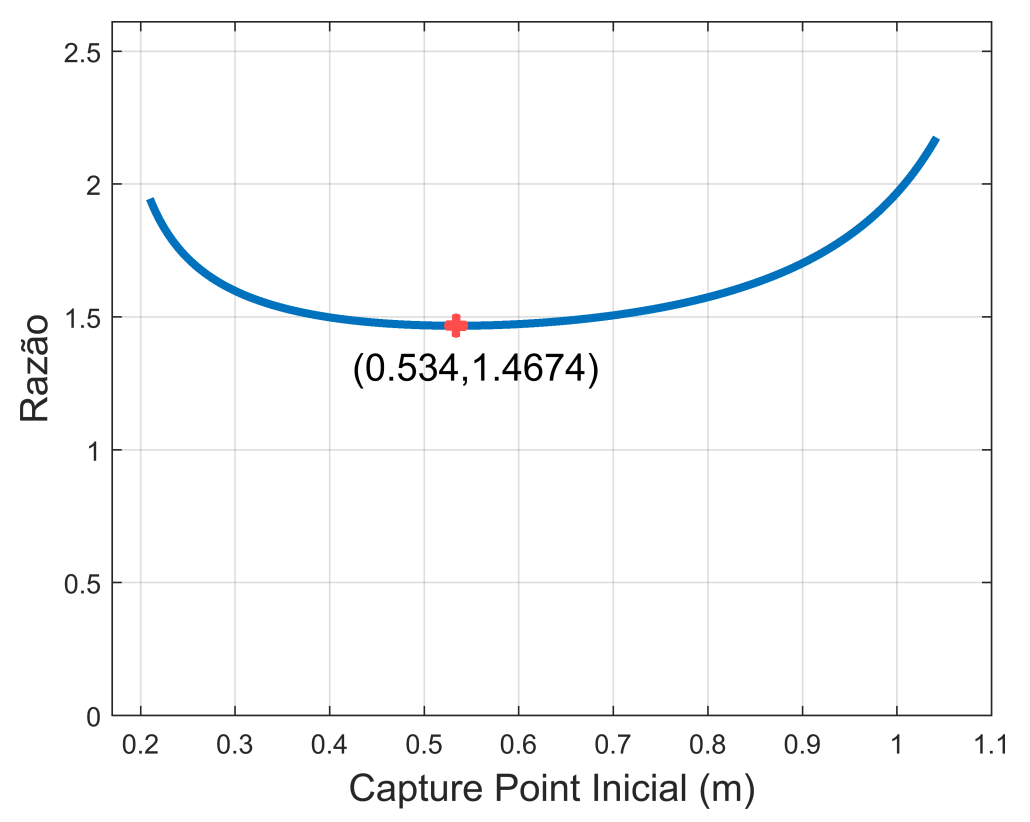

Figura 53: Razão do tempo calculada com a equação (6.42) considerando $x_{f}=1.2124$ $\mathrm{m}$ e $\Delta r_{i c}=0.17 \mathrm{~m}$ para $r_{i c 0}$ variando entre 0.21 até $1.042 \mathrm{~m}$. O ponto vermelho é o valor mínimo do intervalo.

- Variação linear: 20 passos, $\dot{P} x_{\text {hip }}^{\text {tar }}$, começando de $0.8 \mathrm{~m} / \mathrm{s}$ e acrescentando 0.2 $\mathrm{m} / \mathrm{s}$ a cada passo.

- Variação aleatória: 20 passos com um $\dot{P} x_{\text {hip }}^{t a r}$ aleatório entre $1.0 \mathrm{~m} / \mathrm{s}$ e $2.0 \mathrm{~m} / \mathrm{s}$ gerado para cada passo.

Os ganhos utilizados durante os testes foram:

Tabela 8: Ganhos da função objetivo utilizados durante os testes

\begin{tabular}{ll}
\hline Ganho & Valor \\
\hline$G_{\text {fpos }}$ & 5 \\
$G_{\text {hposx }}$ & 10 \\
$G_{\text {fhpos }}$ & 20 \\
$G_{\text {icp }}$ & 10 \\
$G_{u}$ & $1 / 300$ \\
$G_{\text {hor }}$ & 10 \\
$G_{\text {hvel }}$ & 20 \\
$G_{\text {hposy }}$ & 10 \\
$G_{\text {hor } 2}$ & 10 \\
\hline
\end{tabular}


O modelo utilizado foi:

Tabela 9: Parâmetros do modelo durante os testes

\begin{tabular}{ll}
\hline Parâmetros & Valor \\
\hline$m_{1}$ & $3.2 \mathrm{~kg}$ \\
$m_{2}$ & $6.8 \mathrm{Nm}$ \\
$m_{3}$ & $20 \mathrm{~kg}$ \\
$l_{1}$ & $0.4 \mathrm{~m}$ \\
$l_{2}$ & $0.4 \mathrm{~m}$ \\
$l_{3}$ & $0.625 \mathrm{~m}$ \\
$I_{1}$ & $0.93 \mathrm{~kg} \cdot \mathrm{m}^{2}$ \\
$I_{2}$ & $1.08 \mathrm{~kg} \cdot \mathrm{m}^{2}$ \\
$I_{3}$ & $2.22 \mathrm{~kg} \cdot \mathrm{m}^{2}$ \\
$c_{1}$ & $0.128 \mathrm{~m}$ \\
$c_{2}$ & $0.163 \mathrm{~m}$ \\
$c_{3}$ & $0.2 \mathrm{~m}$ \\
$u_{\max }$ & $300 \mathrm{Nm}$ \\
\hline
\end{tabular}

\subsubsection{Resultados}

Os dois testes obtiveram sucesso em realizar o número de passos estipulado de forma estável. A Figura 54 ilustra uma marcha gerada pelo teste com padrão aleatório. Adicionalmente foi realizado um teste sem o critério de Step Viability com o padrão linear (Figura 55). Pode-se ver que eventualmente o bípede não consegue mais realizar uma passada e caí.

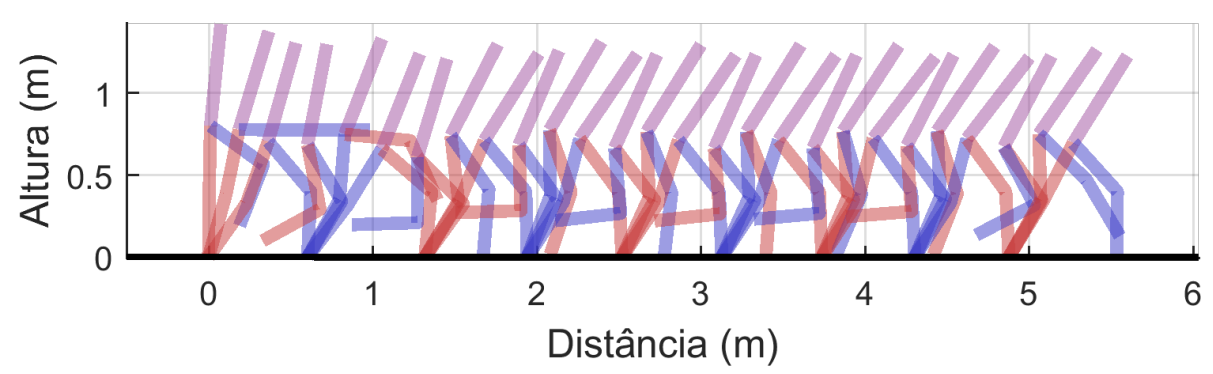

Figura 54: Exemplo de solução da marcha com padrão aleatório de referência.

Os resultados dos testes podem ser vistos nas figuras 56 e 57 . No caso do padrão 


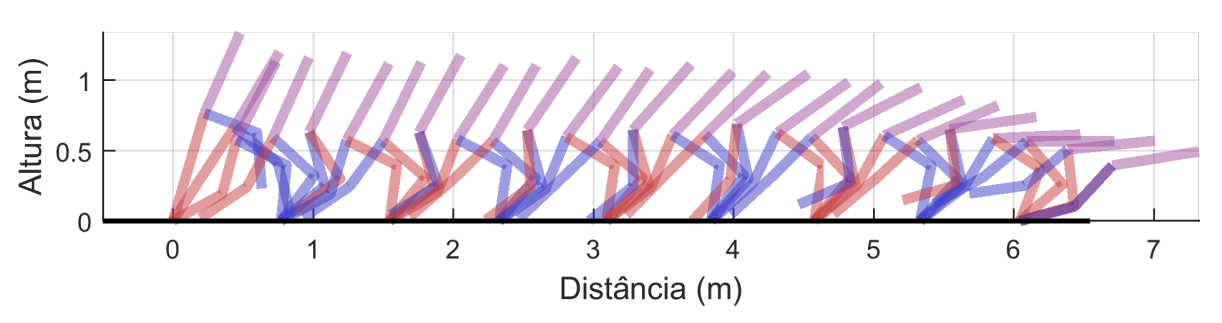

Figura 55: Exemplo de falha em gerar a marcha quando o critério de Step Viability não é usado.

linear o resultado foi como esperado. Enquanto o bípede era capaz de seguir o padrão desejado sem perder a estabilidade, o mesmo seguiu o padrão. A partir do momento que o bípede não podia mais seguir o padrão satisfazendo o critério, ele automaticamente deixou de seguir a referência mantendo sua estabilidade. No caso aleatório pode-se ver que a marcha do bípede seguiu o padrão proposto de forma razoável sem perder a estabilidade.

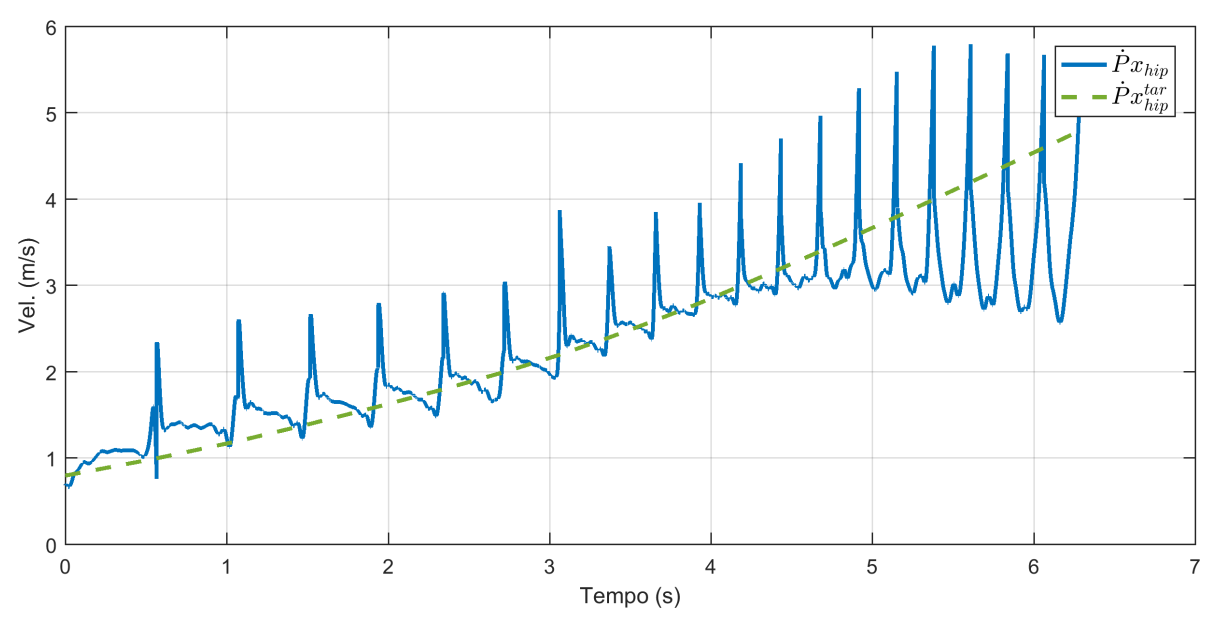

Figura 56: Resultado do teste com padrão linear

Um dos principais pontos que é importante se comentar dos testes realizados com o modelo de 5 segmentos é que existem muitos fatores que podem ser controlados durante a marcha que influenciaram a estabilidade do modelo. Um exemplo é a orientação do tronco. Em algumas simulações o custo da orientação do tronco foi relaxado o que levou ao modelo a jogar o tronco para trás e não ser capaz de traze-lo novamente para frente nas marchas de maior velocidade. Outro ponto que foi bastante relevante é o controle da altura da pélvis. Isso é criticamente necessário pois caso contrário o PSOPT converge para uma solução onde ele deixa a pélvis cair no chão próximo ao ponto de apoio. 


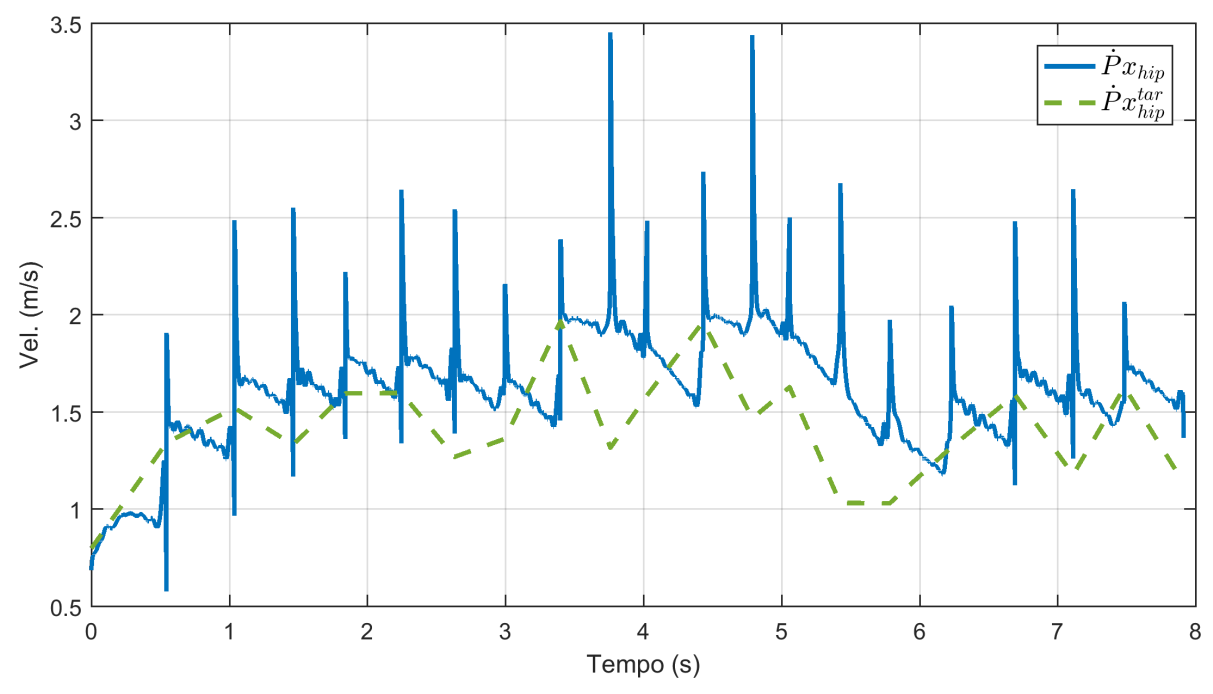

Figura 57: Resultado do teste com padrão aleatório

\subsubsection{Discussão}

Neste capítulo, foi proposto e testado um critério de estabilidade para a caminhada bípede inspirada na marcha humana e nos conceitos de Viability Kernel (WIEBER, 2002) e N-Step Capturability (KOOLEN et al., 2012). O critério de Step Viability, proposto aqui, prescreve um passo de tal forma que ele mantenha a capacidade de trazer o bípede para um ponto fixo em um tempo finito, sem restrições adicionais. Este critério de estabilidade é útil para projetar o controle da marcha e pode ser desacoplado do projeto da mesma.

Nos resultados o critério de estabilidade foi validado com o modelo Compass Gait em uma variedade de condições, incluindo três inclinações de rampa diferentes, bem como três tipos de distribuições de massa e torques máximos (Tabela 7 ). Além disso, foi possível gerar diferentes tipos de marchas, com a referência variando linearmente e aleatoriamente.

A massa do modelo foi ajustada para $20 \mathrm{~kg}$ e foi distribuída entre pernas e quadril de maneiras diferentes. A massa de cada perna foi variada de 1 a $9 \mathrm{~kg}$. Quando o torque máximo era pequeno ( $5 \mathrm{Nm}$ ), o bípede não foi capaz de acompanhar a variabilidade da marcha de referência, em especial nos casos de altas massas nas pernas (5 $\mathrm{kg}$ e $9 \mathrm{~kg}$ ). Como o modelo tem baixa capacidade de reduzir o Capture Point no Passo de Restrição, o Passo Planejado é sempre limitado para terminar em um estado que permite tal redução futura. Com o aumento do torque máximo, a capacidade de re- 
dução do Capture Point aumenta, portanto o Passo Planejado teve menos limitações para rastrear o padrão de marcha desejado.

Em seguida o critério foi validado com sucesso em um modelo bípede planar de 5 segmentos, implementando uma marcha com referência da velocidade horizontal da pélvis com crescimento linear e com variação aleatória.

O critério de Step Viability é versátil porque é capaz de gerar diferentes tipos de marchas com variações de modelo e ambientais como foi mostrado nos resultados. Embora não seja projetado para ser energeticamente eficiente, é possível incluir uma restrição para garantir baixo consumo de energia. Na função-objetivo o torque quadrado já é minimizado para evitar grandes picos de torque, mas como um efeito colateral está reduzindo o consumo de energia, sem sacrificar a estabilidade. É possível incluir diferentes funções de custo que incluem uma combinação de consumo de energia e margem de estabilidade.

Além disso, considerando a versatilidade deste critério, é possível planejar marchas estáveis com uma certa combinação de comprimento e velocidade de passo que garantam a eficiência energética, por exemplo convergindo para um ciclo-limite estável.

Adicionalmente, o critério proposto, tal como foi definido, é suficiente para a estabilidade, embora não seja necessário. Nas simulações, mostrou-se que quando o critério foi seguido, o robô caminhou estável.

Um inconveniente é que o critério de Step Viability não proporciona uma medida direta da estabilidade. No entanto, é possível incluir um índice de estabilidade na função-objetivo e defini-lo implicitamente no cálculo dos passos viáveis de tal forma que eles cumpram uma determinada exigência de índice de estabilidade.

Além disso, é possível estimar o esforço de passo como o a razão entre o torque necessário para realizar o passo comparado ao torque máximo disponível. Tomando a margem entre o máximo torque disponível e o torque necessário, isso poderia ser considerado como uma margem de estabilidade relativa. Como o cálculo do critério de Step Viability envolve duas fases, o esforço relativo com relação ao torque disponível em cada etapa fornecerá métricas diferentes. O esforço relativo do Passo Planejado está relacionado à rejeição de perturbações, enquanto o esforço no Passo de Restrição está relacionado com a robustez às variações do modelo e irregularidades do 
terreno.

Em comparação com outros critérios, a solução aqui proposta é contínua e não discreta, como proposto em Manchester e Umenberger (2013). Comparando com Koolen et al. (2012), N-Step Capturability funciona tão bem quanto o sistema se comporta como um pêndulo invertido linear, sem impactos durante os passos e com um passo de comprimento máximo e tempo mínimo fixos. O Step Viability, por outro lado, utiliza a dinâmica completa do sistema e depende de relações como $T\left(\mathbf{s}_{1}, \mathbf{X}\left(\mathbf{s}_{3}\right)\right)<T\left(\mathbf{s}_{1}, \mathbf{X}\left(\mathbf{s}_{2}\right)\right)$, que são muito mais fáceis de serem válidas.

Este critério foi inspirado na marcha humana. Observou-se que os seres humanos aprendem a completar o passo com segurança de tal forma que as condições iniciais para o passo subsequente também permitem a realização de um passo estável. Isso ainda mais evidente quando há uma restrição adicional sobre a marcha humana, como passar por cima de obstáculos (PATLA; RIETDYK, 1993).

Deve-se notar que este critério só foi testado em modelos bípede simplificados, que tem certas limitações. No entanto, é amplamente reconhecido que o modelo planar de 5 segmentos capta os aspectos essenciais da marcha bípede.

Um dos aspectos mais importantes é testar o critério com um modelo com mais graus de liberdade, como pés de tamanho finito, atuação no tornozelo e estendendo para modelos tridimensionais.

Outro aspecto a ser desenvolvido em pesquisas futuras é o ajuste do critério para ser compatível com uma implementação em tempo real para ser usado em bípedes reais. Neste contexto, uma possível solução seria usar a solução clássica do Model Predictive Control (MPC), já utilizada por muitos autores (KOENEMANN et al., 2015; POWELL; COUSINEAU; AMES, 2015; STEPHENS, 2011). Outra possível implementação seria então treinar uma rede neural (MORDATCH et al., 2015) para calcular a existência do Passo de Restrição.

\subsubsection{Publicações}

Parte deste capítulo foi submetido para o The International Journal of Robotics Research (ROSSI; FORNER-CORDERO, 2016). 


\section{CONCLUSÕES}

Nesta Tese foi abordado um problema central em robótica, a estabilidade da caminhada bípede. Muito embora o campo tinha se desenvolvido junto com os recentes avanços tecnológicos em atuadores, baterias e sensores. Ainda existem algumas lacunas que impossibilitam o seu uso massivo em aplicações reais. Dentre elas se destaca o controle da marcha, o qual é um aspecto essencial para possibilitar o uso de robôs em ambientes variados de uma forma robusta e confiável.

A marcha de robôs bípedes tem três pontos principais a serem considerados como críticos: consumo energético, robustez e versatilidade. Pode-se notar então, que o estado da arte em controle de marcha bípede consegue atender cada um dos requisitos de uma forma independente, porém nunca de uma forma abrangente. Algoritmos baseados em Zero Moment Point permitem robustez e versatilidade com um gasto energético altíssimo. Os bípedes baseados no conceito de Limit Cycle Walking oferecem uma grande eficiência energética, mas perdem em versatilidade e robustez. O conceito mais recente, N-Step Capturability proporciona um método para escolher posicionamento dos passos para síntese de marcha e recuperação de distúrbios de forma robusta, mas ainda não consegue atender todos os requisitos.

Um exemplo de marcha bípede versátil e robusta que é realizada em diversos tipos de terrenos e condições, sob a influencia de grandes perturbações e com um eficiente consumo energético é a marcha humana. Portanto, entender os princípios de geração e controle da marcha humana pode nos ajudar a projetar a estabilidade da caminhada de robôs bípedes.

O objetivo principal desta Tese foi desenvolver e implementar um critério de estabilidade para controle marcha de sistemas robóticos bípedes que tenha a capacidade de ser robusto, flexível e energeticamente eficiente. Dentro deste cenário, foram identificados 4 objetivos específicos apresentados a seguir. 


\subsection{Desenvolvimento de Ferramentas Abertas para Auxiliar no Desenvolvimento de Algoritmos de Controle de Robôs Bípedes}

A presente tese apresentou uma revisão de simuladores dinâmicos multi-corpos para robôs bípedes e definiu que atualmente o Gazebo oferece uma boa plataforma para simulações complexas, com diferentes ambientes e objetos, enquanto o Simbody oferece um melhor custo-benefício para simulações que tenham como objetivo testes conceituas. Por isto, este ultimo foi escolhido para o desenvolvimento deste tese pois oferece um motor de física preciso e uma boa estabilidade.

No contexto deste trabalho também foi desenvolvida uma toolbox para MATLAB e Octave de controle de robôs bípedes além de um módulo de Inter Process Communication entre o simulador Simbody e o MATLAB. Com esta ferramenta pudemos implementar marchas bípedes baseadas em ZMP, além de possibilitar a implementação de outras estrategias descritas na literatura. Também foi desenvolvido um controle baseado em Partial Feedback Linearization com referência comutada e simulado para controlar um modelo de um Compass Gait com sucesso, aumentando a bacia de atração do mesmo.

\subsection{Estudo da Marcha Humana e Comparação com os Critérios de Estabilidade de Robôs Bípedes}

Foi realizado um estudo da marcha humana avaliando humanos com visão e vendados comparando-os com um robô com um controle baseado em ZMP efetuando a mesma tarefa. Analisando a distância antero-posterior entre o quadril e o pé foi entendido que o ser humano vendado demonstrou uma estratégia de marcha mais conservadora quando comparado ao ser humano com visão, tendendo a um padrão mais próximo à marcha do robô baseada em ZMP. Destes resultados foi concluído que o ser humano tem um critério de estabilidade global, que leva em consideração a situação do centro de massas e a posição futura do pé em balanço. Estas duas variáveis determinam a configuração inicial do corpo para realizar a seguinte passada e foram a inspiração para o cálculo do critério de estabilidade em duas fases proposto nesta Tese. 


\subsection{Desenvolvimento de um Critério de Estabilidade que uma marcha versátil}

Como principal contribuição desta tese, foi apresentado um novo critério de estabilidade chamado Step Viability. Este critério possibilita a geração de marchas dinâmicas e estáticas assim como não cria restrições que limitam a robustez, eficiência energética e flexibilidade dos movimentos. O Step Viability é inspirado na marcha humana e prescreve um passo de tal forma que ele mantenha a capacidade de trazer o bípede para um ponto fixo em um tempo finito.

\subsection{Implementação e Avaliação de um Controlador Ba- seado no Critério de Estabilidade Desenvolvido}

O problema inteiro foi resolvido de uma vez como uma otimização de trajetória multi-fases. Na primeira fase, utilizamos os estados iniciais e condições de impacto do pé com o chão como restrições e na segunda fase usamos a condição de impacto e o critério de Step Viability como restrição. As restrições de ligação entre as fases são implementadas utilizando a função de transferência de impacto do modelo. Finalmente, o movimento desejado do seguinte passo é implementado na função de custo. Por meio deste algoritmo o critério desenvolvido foi testado com um modelo Compass Gait sob um total de 54 combinações de distribuição de massa, torque máximo, inclinação e padrões de marcha (variando a velocidade-alvo de forma linear e aleatória). O Step Viability também foi testado em um outro modelo clássico para o estudo da marcha de robôs bípedes: o modelo planar de 5 segmentos. O critério de Step Viability foi desenhado de forma a ser desacoplado do projeto da marcha, permitindo a realização de diferentes tipos de marcha com movimentos versáteis.

\subsection{Trabalhos Futuros}

Este trabalho respondeu as questões iniciais e também levantou novas perguntas e desafios. O desenvolvimento do critério de Step Viability não será completado até ser utilizado na marcha de um bípede real. Para isto é necessário testar o critério sobre 
um modelo com mais graus de liberdade, incluindo pés de tamanho finito e atuação no tornozelo. O modelo também dever ser estendido para três dimensões.

Um outro aspecto a ser desenvolvido em pesquisas futuras visando a aplicação a um bípede real é o ajuste do algoritmo que implementa o Step Viability para funcionar em tempo real. Neste contexto, uma possível solução seria usar a solução clássica do Model Predictive Control ou métodos de Machine Learning.

Desde o ponto de vista do avanço da compreensão da marcha humana, foi surpreendente a similaridade entre a ultrapassagem de obstáculos entre o robô com ZMP e o humano vendado. Abrem-se caminhos para novas experiências de análise biomecânica para comparar tanto a ultrapassagem de obstáculos como a recuperação frente a tropeços de humanos e de robôs. Neste caso, os robôs poderiam utilizar o ZMP mas também o critério de Step Viability. A hipótese de trabalho seria que este ultimo critério se aproxima à marcha humana com maior fidelidade.

Também foram desenvolvidas varias análises e ferramentas para o estudo de robôs bípedes. Estas foram adequadamente documentadas para ajudar ao desenvolvimento de futuras pesquisas na área. 


\section{REFERÊNCIAS}

BARAFF, D. Linear-time dynamics using lagrange multipliers. In: ACM. Proceedings of the 23rd annual conference on Computer graphics and interactive techniques. [S.I.], 1996. p. 137-146.

BECERRA, V. M. Solving complex optimal control problems at no cost with psopt. In: IEEE. 2010 IEEE International Symposium on Computer-Aided Control System Design. [S.I.], 2010. p. 1391-1396.

BHOUNSULE, P. A. et al. Low-bandwidth reflex-based control for lower power walking: $65 \mathrm{~km}$ on a single battery charge. The International Journal of Robotics Research, 2014. Disponível em: $<$ http://ijr.sagepub.com/content/early/2014/06/12/0278364914527485.abstract $>$.

BUSS, S. R. Introduction to inverse kinematics with jacobian transpose, pseudoinverse and damped least squares methods. IEEE Journal of Robotics and Automation, v. 17, p. 1-19, 2004.

CHEVALLEREAU, C. et al. Rabbit: a testbed for advanced control theory. IEEE Control Systems, v. 23, n. 5, p. 57-79, Oct 2003. ISSN 1066-033X.

COLLINS, S. et al. Efficient bipedal robots based on passive-dynamic walkers. Science, American Association for the Advancement of Science, v. 307, n. 5712, p. 1082-1085, 2005.

COUMANS, E. Bullet Physiscs Library. 2016. Disponível em: $<$ http://bulletphysics.org/>.

DALLALI, H. et al. Workshop on developments of simulation tools for robotics and biomechanics. In: 2013 IEEE International Conference on Robotics and Automation (ICRA). [S.I.: s.n.], 2013.

DARPA. DRC Home Page. Jan 2013. Disponível em:

$<$ http://www.theroboticschallenge.org $>$.

DIANKOV, R. Automated Construction of Robotic Manipulation Programs. Tese (Doutorado) - Carnegie Mellon University, Robotics Institute, August 2010.

DRC-TEAMS. What Happened at the DARPA Robotics Challenge? 2015. www. cs. cmu. edu/ cga/drc/events.

DYNAMICS, B. Atlas, The Next Generation. 2016. Disponível em: $<$ https://www.youtube.com/watch?v=rVlhMGQgDkY $>$. 
ENG, J. J.; WINTER, D. A.; PATLA, A. E. Strategies for recovery from a trip in early and late swing during human walking. Experimental Brain Research, Springer, v. 102, n. 2, p. 339-349, 1994.

FEATHERSTONE, R. Robot Dynamics Algorithm. Norwell, MA, USA: Kluwer Academic Publishers, 1987. ISBN 0898382300.

FENG, S. et al. Optimization based full body control for the atlas robot. In: IEEE. 2014 IEEE-RAS International Conference on Humanoid Robots. [S.I.], 2014. p. 120-127.

FORNER-CORDERO, A. et al. Obstacle crossing differences between blind and blindfolded subjects after haptic exploration. Journal of motor behavior, Taylor \& Francis, p. 1-11, 2016.

FORNER-CORDERO, A.; KOOPMAN, H.; HELM, F. C. van der. Mechanical model of the recovery from stumbling. Biological Cybernetics, Springer, v. 91, n. 4, p. 212-220, 2004.

. Energy analysis of human stumbling: the limitations of recovery. Gait \& posture, Elsevier, v. 21, n. 3, p. 243-254, 2005.

FORNER-CORDERO, A.; KOOPMAN, H.; HELM, F. van der. Multiple-step strategies to recover from stumbling perturbations. Gait and Posture, v. 18, n. 1, p. $47-59$, 2003. ISSN 0966-6362.

GALLEGO, J. et al. Detection of gait perturbations based on proprioceptive information. application to limit cycle walkers. Applied Bionics and Biomechanics, 2011.

GARCIA, M. et al. The simplest walking model: Stability, complexity, and scaling. ASME Journal of Biomechanical Engineering, v. 120, p. 281-288, 1998.

GOSWAMI, A.; ESPIAU, B.; KERAMANE, A. Limit cycles in a passive compass gaitbiped and passivity-mimicking control laws. Auton. Robots, Kluwer Academic Publishers, Hingham, MA, USA, v. 4, n. 3, p. 273-286, jul. 1997. ISSN 0929-5593.

GREGG, R. D. et al. Control and planning of 3-d dynamic walking with asymptotically stable gait primitives. Robotics, IEEE Transactions on, v. 28, n. 6, p. $1415-1423$, dec. 2012. ISSN 1552-3098.

HEERDEN, K. V. Joint state parameterization and forward kinematics. 02 de Julho 2014. Http://www.elysium-labs.com/.

HEERDEN, K. V.; KAWAMURA, A. Biped robot position control with stability-based ground reaction force and velocity constraints. IEEJ Journal of Industry Applications, v. 2, n. 1, p. 30-39, 2013.

HOBBELEN, D.; WISSE, M. Controlling the walking speed in limit cycle walking. Int. J. Rob. Res., Sage Publications, Inc., Thousand Oaks, CA, USA, v. 27, n. 9, p. 989-1005, set. 2008. ISSN 0278-3649. 
HOBBELEN, D. G.; WISSE, M. Humanoid robots, human-like machines. In: [S.I.]: I-Tech, 2007. cap. 14. Limit Cycle Walking, p. 277 - 294.

HOF, A. L. et al. Control of lateral balance in walking: experimental findings in normal subjects and above-knee amputees. Gait \& posture, Elsevier, v. 25, n. 2, p. 250-258, 2007.

HONDA. Start of Robot Development Modeled on Humans. 28 de Junho 2014. Http://world.honda.com/ASIMO/history/e0/index.html.

HUANG, Q. et al. Planning walking patterns for a biped robot. Robotics and Automation, IEEE Transactions on, v. 17, n. 3, p. $280-289$, jun 2001. ISSN 1042-296X.

IHMC. SimulationConstructionSet main page. 02 de Julho 2014. Http://www.inmc.us/groups/scs/.

IIDA, F.; TEDRAKE, R. Minimalistic control of biped walking in rough terrain. Auton. Robots, Kluwer Academic Publishers, Hingham, MA, USA, v. 28, n. 3, p. 355-368, abr. 2010. ISSN 0929-5593. Disponível em: <http://dx.doi.org/10.1007/s10514-0099174-3>.

KAJITA, S.; ESPIAUR, B. Springer handbook of robotics. In: [S.I.]: Springer, 2008. cap. 16. Legged Robots, p. $361-389$.

KAJITA, S. et al. The 3d linear inverted pendulum mode: a simple modeling for a biped walking pattern generation. In: Intelligent Robots and Systems, 2001. Proceedings. 2001 IEEE/RSJ International Conference on. [S.I.: s.n.], 2001. v. 1, p. 239 -246 vol.1.

. Biped walking pattern generation by using preview control of zero-moment point. In: IEEE. Robotics and Automation, 2003. Proceedings. ICRA'03. IEEE International Conference on. [S.I.], 2003. v. 2, p. 1620-1626.

KANEKO, K. et al. Humanoid robot hrp-3. In: Intelligent Robots and Systems, 2008. IROS 2008. IEEE/RSJ International Conference on. [S.I.: s.n.], 2008. p. 2471 -2478.

. Humanoid robot hrp-2. In: Robotics and Automation, 2004. Proceedings. ICRA '04. 2004 IEEE International Conference on. [S.I.: s.n.], 2004. v. 2, p. $1083-1090$. ISSN 1050-4729.

. Cybernetic human hrp-4c. In: Humanoid Robots, 2009. Humanoids 2009. 9th IEEE-RAS International Conference on. [S.I.: s.n.], 2009. p. $7-14$.

KARSSEN, J. Design and construction of the Cornell Ranger, a world record distance walking robot. [S.I.], 2006.

KOCHUVILA, S.; TRIPATHI, S.; SUDARSHAN, T. Control of a compass gait biped robot based on partial feedback linearization. In: HERRMANN, G. et al. (Ed.). Advances in Autonomous Robotics. [S.I.]: Springer Berlin / Heidelberg, 2012, (Lecture Notes in Computer Science, v. 7429). p. 117-127. ISBN 978-3-642-32526-7. 
KOENEMANN, J. et al. Whole-body model-predictive control applied to the hrp-2 humanoid. In: IEEE. Intelligent Robots and Systems (IROS), 2015 IEEE/RSJ International Conference on. [S.I.], 2015. p. 3346-3351.

KOENIG, N.; HOWARD, A. Design and use paradigms for gazebo, an open-source multi-robot simulator. In: Intelligent Robots and Systems, 2004. (IROS 2004).

Proceedings. 2004 IEEE/RSJ International Conference on. [S.I.: s.n.], 2004. v. 3, p. 2149-2154 vol.3.

KOOLEN, T. et al. Capturability-based analysis and control of legged locomotion, part 1: Theory and application to threenew simple gait models. Int. J. Rob. Res., Sage Publications, Inc., Thousand Oaks, CA, USA, v. 31, n. 9, p. 1094-1113, ago. 2012. ISSN 0278-3649.

MANCHESTER, I. R. et al. Stable dynamic walking over uneven terrain. The International Journal of Robotics Research, v. 30, n. 3, p. 265 - 279, Jan. 2011.

. Regions of attraction for hybrid limit cycles of walking robots. CoRR, $\overline{a b s / 1010.2247, ~} 2010$.

MANCHESTER, I. R.; UMENBERGER, J. Real-time planning with primitives for dynamic walking over uneven terrain. CoRR, abs/1310.7062, 2013.

MATHWORKS. 9.0.0.341360 (R2016a). Natick, Massachusetts: The MathWorks Inc., 2016.

MCGEER, T. Passive dynamic walking. Int. J. Rob. Res., Sage Publications, Inc., Thousand Oaks, CA, USA, v. 9, n. 2, p. 62-82, mar. 1990. ISSN 0278-3649.

Passive walking with knees. In: Robotics and Automation, 1990. Proceedings., 1990 IEEE International Conference on. [S.I.: s.n.], 1990. p. $1640-1645$ vol.3.

MORDATCH, I. et al. Interactive control of diverse complex characters with neural networks. In: Advances in Neural Information Processing Systems. [S.I.: s.n.], 2015. p. 3132-3140.

NAKAOKA, S. Choreonoid: Extensible virtual robot environment built on an integrated gui framework. In: System Integration (SII), 2012 IEEE/SICE International Symposium on. [S.I.: s.n.], 2012. p. 79-85.

NAKAOKA, S. et al. Constraint-based dynamics simulator for humanoid robots with shock absorbing mechanisms. In: Intelligent Robots and Systems, 2007. IROS 2007. IEEE/RSJ International Conference on. [S.I.: s.n.], 2007. p. 3641-3647.

PARK, I.-W. et al. Mechanical design of humanoid robot platform khr-3 (kaist humanoid robot 3: Hubo). In: IEEE. 5th IEEE-RAS International Conference on Humanoid Robots, 2005. [S.I.], 2005. p. 321-326.

PATLA, A.; RIETDYK, S. Visual control of limb trajectory over obstacles during locomotion: effect of obstacle height and width. Gait \& Posture, Elsevier, v. 1, n. 1, p. 45-60, 1993. 
PATLA, A. E.; DAVIES, T. C.; NIECHWIEJ, E. Obstacle avoidance during locomotion using haptic information in normally sighted humans. Experimental brain research, Springer, v. 155, n. 2, p. 173-185, 2004.

PATLA, A. E.; GREIG, M. Any way you look at it, successful obstacle negotiation needs visually guided on-line foot placement regulation during the approach phase. Neuroscience letters, Elsevier, v. 397, n. 1, p. 110-114, 2006.

PATLA, A. E. et al. Locomotor patterns of the leading and the trailing limbs as solid and fragile obstacles are stepped over: some insights into the role of vision during locomotion. Journal of motor behavior, Taylor \& Francis, v. 28, n. 1, p. 35-47, 1996.

PETERS, S.; HSU, J. Simple benchmarks for speed and accuracy of rigid body dynamic simulators. In: Proceedings of the ECCOMAS thematic conference multibody dynamics. [S.I.: s.n.], 2015.

POWELL, M. J.; COUSINEAU, E. A.; AMES, A. D. Model predictive control of underactuated bipedal robotic walking. In: IEEE. 2015 IEEE International Conference on Robotics and Automation (ICRA). [S.I.], 2015. p. 5121-5126.

PRATT, J. et al. Capture point: A step toward humanoid push recovery. In: Humanoid Robots, 2006 6th IEEE-RAS International Conference on. [S.I.: s.n.], 2006. p. 200 $-207$.

PRATT, J.; TEDRAKE, R. Velocity-based stability margins for fast bipedal walking. In: _. Fast Motions in Biomechanics and Robotics: Optimization and Feedback Control. Berlin, Heidelberg: Springer Berlin Heidelberg, 2006. p. 299-324. ISBN 978-3-540-36119-0.

PRATT, J. E. et al. Capturability-based analysis and control of legged locomotion, part 2: Application to m2v2, a lower-body humanoid. I. J. Robotic Res., v. 31, n. 10, p. 1117-1133, 2012.

QUIGLEY, M. et al. Ros: an open-source robot operating system. In: ICRA workshop on open source software. [S.I.: s.n.], 2009. v. 3, n. 3.2, p. 5.

RAIBERT, M. H. Legged Robots That Balance. Cambridge, MA, USA: Massachusetts Institute of Technology, 1986. ISBN 0-262-18117-7.

RODRIGUES, S. et al. Influence of visual information on optimal obstacle crossing. In: SPRINGER. 4th European Conference of the International Federation for Medical and Biological Engineering. [S.I.], 2009. p. 2133-2137.

ROSSI, L. F.; FORNER-CORDERO, A. Step viability: A step ahead bioinspired stability criterion for biped gait. Submitted. 2016.

ROSSI, L. F.; HEERDEN, K. V. MATLAB/Octave Humanoid Robot Toolbox. 13 de Janeiro 2014. Https://github.com/kirillvh/octaveHumanoidRobotics. 
ROSSI, L. F.; NICHILO, P.; FORNER-CORDERO, A. Compass gait control with switched reference partial feedback linearization. In: Biomedical Robotics and Biomechatronics, 2014. (BIOROB 2014). Proceedings. 5th IEEE RAS \& EMBS International Conference on. [S.I.: s.n.], 2014.

ROSSI, L. F.; RODRIGUES, S. T.; FORNER-CORDERO, A. Do humans walk humans like robots when crossing an obstacle without visual information? In: Biomedical Robotics and Biomechatronics, 2014. (BIOROB 2014). Proceedings. 5th IEEE RAS \& EMBS International Conference on. [S.I.: s.n.], 2014.

SAKAGAMI, Y. et al. The intelligent asimo: system overview and integration. In: Intelligent Robots and Systems, 2002. IEEE/RSJ International Conference on. [S.I.: s.n.], 2002. v. 3, p. $2478-2483$.

SHERMAN, M. A.; SETH, A.; DELP, S. L. Simbody: multibody dynamics for biomedical research. Procedia \{IUTAM\}, v. 2, n. 0, p. $241-261$, 2011. ISSN 2210-9838. \{IUTAM\} Symposium on Human Body Dynamics.

SHIMMYO, S.; SATO, T.; OHNISHI, K. Biped walking pattern generation by using preview control based on three-mass model. Industrial Electronics, IEEE Transactions on, PP, n. 99, p. 1, 2012. ISSN 0278-0046.

SMITH, R. Open Dynamics Engine. 2016. Disponível em: <http://www.ode.org/>.

STEPHENS, B. Push recovery control for force-controlled humanoid robots. Tese (Doutorado) - Carnegie Mellon University Pittsburgh, Pennsylvania USA, 2011.

TAKANISHI, A. et al. Realization of dynamic walking by the biped walking robot wl-10rd. In: Japan Industrial Robot Assoc. [S.I.: s.n.], 1985.

. The realization of dynamic walking by the biped walking robot wl10rd. Advanced Robotics, 1985.

TEDRAKE, R. et al. A closed-form solution for real-time zmp gait generation and feedback stabilization. In: IEEE. Humanoid Robots (Humanoids), 2015 IEEE-RAS 15th International Conference on. [S.I.], 2015. p. 936-940.

UGURLU, B.; KAWAMURA, A. Bipedal trajectory generation based on combining inertial forces and intrinsic angular momentum rate changes: Eulerian zmp resolution. Robotics, IEEE Transactions on, v. 28, n. 6, p. $1406-1415$, dec. 2012. ISSN 1552-3098.

VUKOBRATOVIC, M.; BOROVAC, B. Zero-moment point - thirty five years of its life. $I$. J. Humanoid Robotics, v. 1, n. 1, p. 157-173, 2004.

VUKOBRATOVIC, M.; BOROVAC, B.; POTKONJAK, V. Zmp: a review of some basic misunderstandings. I. J. Humanoid Robotics, v. 3, n. 2, p. 153-175, 2006.

VUKOBRATOVIC, M.; STEPANENKO, J. On the stability of anthropomorphic systems. Mathematical Biosciences, v. 15, n. 1-2, p. 1 - 37, 1972. ISSN 0025-5564. 
WESTERVELT, E.; GRIZZLE, J.; KODITSCHEK, D. Hybrid zero dynamics of planar biped walkers. Automatic Control, IEEE Transactions on, v. 48, n. 1, p. $42-56$, jan 2003. ISSN 0018-9286.

WIEBER, P.-B. On the stability of walking systems. In: Proceedings of the International Workshop on Humanoid and Human Friendly Robotics. Tsukuba, Japan: [s.n.], 2002.

Trajectory free linear model predictive control for stable walking in the presence of strong perturbations. In: IEEE. Humanoid Robots, 2006 6th IEEE-RAS International Conference on. [S.I.], 2006. p. 137-142.

WIGHT, D. L.; KUBICA, E. G.; WANG, D. W. Introduction of the foot placement estimator: A dynamic measure of balance for bipedal robotics. Journal of computational and nonlinear dynamics, American Society of Mechanical Engineers, v. 3, n. 1, p. 011009, 2008.

WINTER, D. A. Biomechanics and motor control of human movement. [S.I.]: John Wiley \& Sons, 2009.

WISSE, M. Essentials of dynamic walking; Analysis and design of two-legged robots. Tese (Doutorado), 2004.

YAMANE, K.; NAKAMURA, Y. A numerically robust Icp solver for simulating articulated rigid bodies in contact. In: BROCK, O.; TRINKLE, J.; RAMOS, F. (Ed.). Robotics: Science and Systems. [S.I.]: The MIT Press, 2008. ISBN 978-0-262-51309-8.

ZUTVEN, P. van; KOSTIC, D.; NIJMEIJER, H. Foot placement for planar bipeds with point feet. In: Robotics and Automation (ICRA), 2012 IEEE International Conference on. [S.I.: s.n.], 2012. p. 983-988. ISSN 1050-4729. 


\section{APÊNDICE A - TEORIA DE ROBÓTICA BÍPEDE}

\section{A.1 Matriz de Transformação}

Já existem diversas referências na literatura apresentando teoria de cinemática direta para manipuladores robóticos, desta forma o conceito de matriz de transformação não será detalhado.

A notação utilizada para a matriz de transformação utilizada neste trabalho é a seguinte:

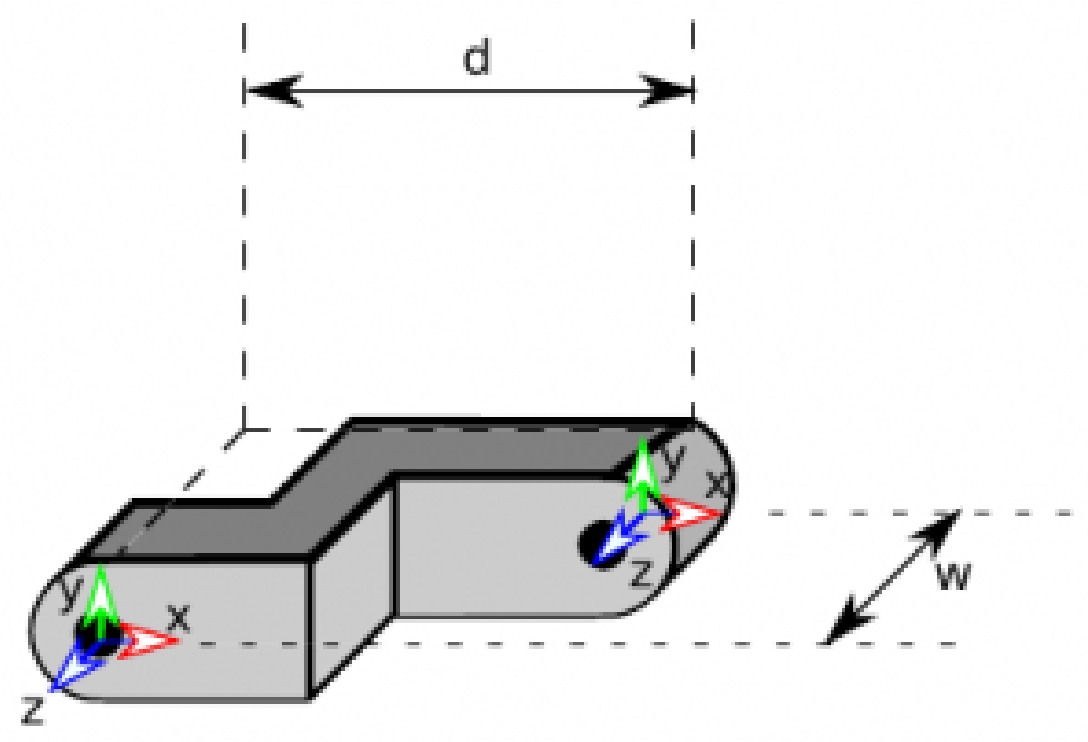

Figura 58: Notação utilizada para a matriz de transformação (HEERDEN, 2014). 


$$
T=\left[\begin{array}{cccc}
\cos \theta & -\sin \theta \cos \alpha & \sin \theta \sin \alpha & d \cos \theta \\
\sin \theta & \cos \theta \cos \alpha & -\cos \theta \sin \alpha & d \sin \theta \\
0 & \sin \alpha & \cos \alpha & w \\
0 & 0 & 0 & 1
\end{array}\right]
$$

\section{A.2 Cinemática Direta}

A cinemática direta consiste em calcular a posição cinemática e rotação da extremidade de um manipulador robótico, a partir dos ângulos de suas juntas e dimensões físicas. Por exemplo consideremos o seguinte manipulador de 3 graus de liberdade:

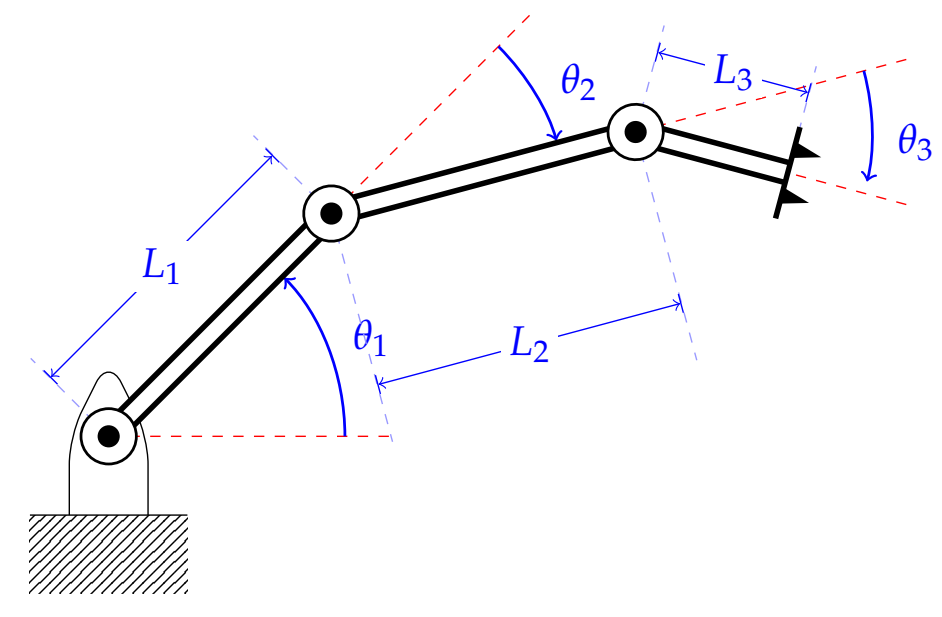

Figura 59: Manipulador de 3 graus de liberdade

É razoavelmente trivial se formular uma solução da cinemática direta deste mecanismo. Porém, podemos utilizar as matrizes de transformação de cada segmento para realizar o mesmo calculo.

Dado que as matrizes de transformação dos segmentos são dados por $T_{1}\left(\theta_{1}\right)$, $T_{2}\left(\theta_{2}\right)$ e $T_{3}\left(\theta_{3}\right)$, temos que a matriz de transformação resultante da base até a extremidade do manipulador é $T_{\text {base }}^{\text {extremidade }}\left(\theta_{1}, \theta_{2}, \theta_{3}\right)=T_{1}\left(\theta_{1}\right) T_{2}\left(\theta_{2}\right) T_{3}\left(\theta_{3}\right)$. A partir da matriz de transformação resultante, podemos retirar a matriz de rotação (aqui denominada $\mathrm{R}$ ) e a posição cartesiana (aqui denominada $\mathrm{P}$ ). Considerando que o componente da matriz de transformação relativo à posição $(i, j)$ da matriz como $T_{i, j}$ temos: 


$$
\begin{gathered}
R=\left[\begin{array}{lll}
T_{1,1} & T_{1,2} & T_{1,3} \\
T_{2,1} & T_{2,2} & T_{2,3} \\
T_{3,1} & T_{3,2} & T_{3,3}
\end{array}\right] \\
P=\left[\begin{array}{l}
T_{1,4} \\
T_{2,4} \\
T_{3,4}
\end{array}\right]
\end{gathered}
$$

Este procedimento pode ser utilizado para encontrar a posição cinemática de qualquer ponto de um manipulador robótico serial a partir de suas matrizes de transformação e posição angular das juntas.

\section{A.3 Jacobiano}

\section{A.3.1 Cinemático}

O Jacobiano é um dos conceitos chaves em aplicações de controle em robótica. Ele basicamente é uma matriz que relaciona dois sistemas de coordenadas. No caso do Jacobiano Cinemático de um manipulador robótico, ele relaciona a relação entre as velocidades angulares das juntas e o a velocidade linear ( $x, y$ e $z)$ e de rotação $(\gamma$, $\beta$ e $\alpha$ ) de um ponto especifico do manipulador, ou seja:

$$
J=\left[\begin{array}{llll}
\frac{\partial \theta_{1}}{\partial x} & \frac{\partial \theta_{2}}{\partial x} & \ldots & \frac{\partial \theta_{n}}{\partial x} \\
\frac{\partial \theta_{1}}{\partial y} & \frac{\partial \theta_{2}}{\partial y} & \ldots & \frac{\partial \theta_{n}}{\partial y} \\
\frac{\partial \theta_{1}}{\partial z} & \frac{\partial \theta_{2}}{\partial z} & \ldots & \frac{\partial \theta_{n}}{\partial z} \\
\frac{\partial \theta_{1}}{\partial \gamma} & \frac{\partial \theta_{2}}{\partial \gamma} & \ldots & \frac{\partial \theta_{n}}{\partial \gamma} \\
\frac{\partial \theta_{1}}{\partial \beta} & \frac{\partial \theta_{2}}{\partial \beta} & \ldots & \frac{\partial \theta_{n}}{\partial \beta} \\
\frac{\partial \theta_{1}}{\partial \alpha} & \frac{\partial \theta_{2}}{\partial \alpha} & \ldots & \frac{\partial \theta_{n}}{\partial \alpha}
\end{array}\right]
$$

Porem o calculo de tal matriz é extremamente complexo, em especial com um elevado número de graus de liberdade. Porém existe uma forma alternativa de calcular o Jacobiano instantâneo de um sistema.

Outra maneira de se representar a relação física entre velocidade linear e angular 
é dado por:

$$
\dot{P}=\omega \times P
$$

Se considerarmos $P$ como o vetor da base de um segmento de um manipulador robótico até a sua extremidade, a relação descrita nos daria basicamente a velocidade da extremidade em relação à rotação da respectiva junta de revolução. Se considerarmos este caso para todas os segmentos de um manipulador, teremos um conjunto de valores que representam o quanto a rotação de cada junta contribuí para a velocidade linear da extremidade do manipulador, ou seja efetivamente o mesmo que é definido pelo Jacobiano.

Desta forma podemos considerar que:

$$
\begin{aligned}
& J_{n}=\dot{X}_{n}=\left[\begin{array}{c}
z_{n} \times x_{n} \\
z_{n}
\end{array}\right] \\
& J=\left[\begin{array}{llll}
J_{0} & J_{1} & \cdots & J_{N}
\end{array}\right]
\end{aligned}
$$

\section{A.3.2 Centro de Massas}

Uma outra grandeza muito útil para se definir em um robô bípede é o Jacobiano do Centro de Massa, ou seja a relação da velocidade do centro de massas e da velocidade de rotação das juntas de seus manipuladores.

$$
\dot{x}_{C O M}=J^{C O M} \dot{\theta}
$$

Considerando que a posição do centro de massas de um robô pode ser definida por:

$$
x_{C O M}=\frac{\sum_{i=0}^{N} x_{i} m_{i}}{\sum_{i=0}^{N} m_{i}}
$$

Podemos definir o COM parcial de um manipulador como o COM de uma subcadeia de um manipulador, teremos: 


$$
x_{\mathrm{COM}}^{* j}=R_{0}^{j} \frac{\sum_{i=j}^{N} x_{i} m_{i}}{\sum_{i=j}^{N} m_{i}}
$$

Desta forma, utilizando o mesmo método que utilizado para achar o Jacobiano cinemático para o efeito da rotação de cada junta (escalonada pelo sua contribuição na massa total) temos:

$$
\begin{gathered}
J_{n}^{C O M}=\left[\begin{array}{cc}
\frac{\sum_{i=n}^{N} m_{i}}{\sum_{i=0}^{n} m_{i}}\left(z_{n} \times x_{C O M}^{* n}\right) \\
z_{n}
\end{array}\right] \\
J^{C O M}=\left[\begin{array}{llll}
J_{0}^{C O M} & J_{1}^{C O M} & \cdots & J_{N}^{C O M}
\end{array}\right]
\end{gathered}
$$

\section{A.4 Cinemática Inversa}

A cinemática inversa consiste em calcular os ângulos articulares de um manipulador, dada uma posição e pose desejados de um ponto cinemático do mesmo. Tal problema pode ser resolvido com solução numérica ou analítica. Apesar de para um problema bem definido a última opção gera uma solução mais adequada, quando estamos trabalhando com modelos não definidos um procedimento numérico é mais conveniente. Além disso, existem casos onde existem mais de uma solução para uma determinada condição desejada, como no caso da figura a seguir, a solução analítica se torna mais complexa de ser implementada pois requer uma métrica para escolher a solução mais adequada.

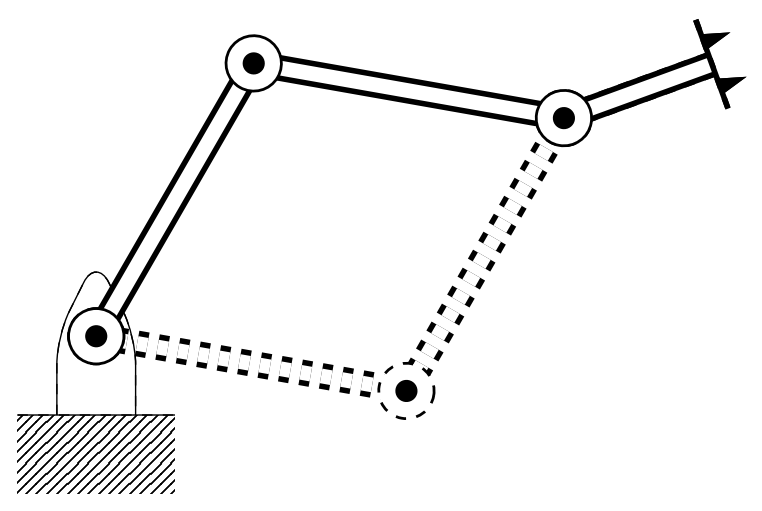

A seguir será dado uma breve explicação de com se resolver um problema de uma 
cinemática inversa considerando tanto uma posição desejada para uma extremidade de um manipulador, quanto para uma posição desejada do centro de massas de um robô. Ambos procedimentos são utilizados para sintetizar uma cinemática inversa de um robô bípede quando precisamos definir simultaneamente a posição do seu centro de massas (para satisfazer um critério de ZMP por exemplo) como de um manipulador (para controlar o pé de balanço pro exemplo). Em todos os casos, o método utilizado para resolver a cinemática inversa é baseado no gradiente descendente.

Considerando um pequeno intervalo de tempo é razoável afirmar que:

$$
\begin{gathered}
\frac{\Delta x}{\Delta T}=J \frac{\Delta \theta}{\Delta T} \\
\Delta x=J \Delta \theta \\
\Delta \theta=J^{-1} \Delta x \\
\theta_{T+1}=\theta_{T}+J^{-1} \Delta x
\end{gathered}
$$

Usando esta relação iterativa podemos mover o manipulador no sentido cartesiano. Então, se fizermos a velocidade cartesiana $\Delta x$ ser proporcional ao erro cartesiano então a iteração acima irá mover o manipulador em uma direção que reduz o erro cartesiano.

$$
\Delta x=x^{r e f}-x\left(\theta_{t}\right)
$$

Logo, basta iteramos a seguinte equação até que o erro entre a posição desejada e a atual esteja dentro de um limite aceitável. FK é uma função que calcula a cinemática direta do manipulador em questão.

$$
\theta_{T+1}=\theta_{T}+\left(x^{r e f}-F K\left(\theta_{T}\right)\right) \cdot J\left(\theta_{T}\right)^{-1}
$$

O procedimento descrito pode ser tanto utilizado para se definir os ângulos articu- 
lares de um manipulador que levem a sua extremidade à uma posição e pose desejadas, quanto para se definir a posição do centro de massas do robô. Basta utilizar o Jacobiano correspondente para cada caso.

Um ponto que é importante de se ressaltar é relacionado ao inverso do Jacobiano utilizado. Visto que o mesmo nem sempre sera uma matriz quadrada com determinante não nulo, nem sempre a inversa da matriz irá existir. Existem alguns métodos na literatura para se calcular uma matriz pseudo-inversa. Depois de testar alguns métodos, foi reconhecido o método do Dumped Least Square (DLS)(BUSS, 2004) tem um comportamento mais estável.

\section{A.4.1 Bípede}

No caso de um robô bípede, muitas vezes precisamos conseguir poses articulares que satisfaçam mais de um requisito por vez, como por exemplo a posição do centro de massas e da extremidade o pé de balanço. Além disso, tais requisitos normalmente são definidos referenciados em um sistema de coordenadas diferente do sistema de coordenadas de base do robô (normalmente definido como a pélvis ou o tronco). A Figura 60 ilustra a situação descrita. 


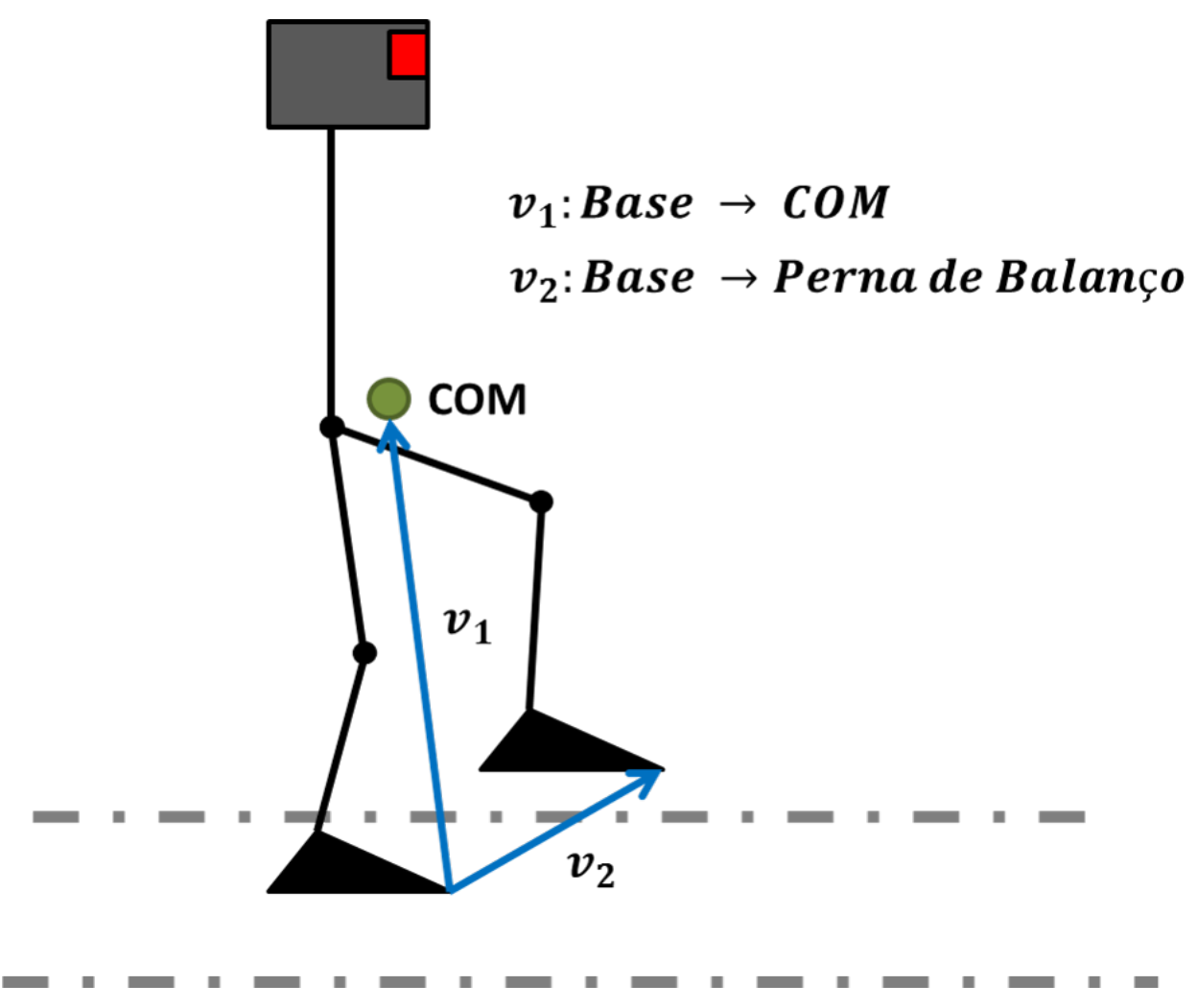

Figura 60: Cinemática Inversa em um robô bípede

Neste caso, alguns procedimentos a mais são necessários. O primeiro ponto adicional a ser tratado é a mudança de base. É mais conveniente tratar a cinemática inversa cinemática referenciada no sistemas de coordenada de base do robô bípede, porém, como ja descrito, normalmente as referências a serem seguidas são feitas em relação à um outro sistema de coordenadas, normalmente o pé de apoio. Desta forma precisamos fazer uma mudança de base na referência passada. Dado um vetor $P_{s f o o t}^{r e f}$ descrito no sistemas de coordenada do pé de apoio, uma matriz de transformação $T_{\text {base }}^{\text {sfoot }}$, sendo a matriz de transformação calculada entre a base do robô e a o segmento do pé de apoio do robô, e extraindo as matrizes $R_{\text {base }}^{\text {sfoot }}$ e $P_{\text {base }}^{\text {sfoot }}$ como descrito nas equações (A.2) e (A.3) respectivamente, temos:

$$
P_{\text {base }}^{\text {ref }}=\left(R_{\text {base }}^{\text {sfoot }}\right)^{T}\left(P_{\text {sfoot }}^{\text {ref }}-P_{\text {base }}^{\text {sfoot }}\right)
$$

Onde $P_{\text {base }}^{r e f}$ é o vetor $P_{\text {sfoot }}^{r e f}$ transformado para o sistema de coordenadas de base do robô.

Tendo as referências a serem seguidas no sistema de coordenadas do robô, basta 
implementar duas cinemáticas inversas simultâneas. Uma que controla a perna de apoio e rastreia o centro de massas de referência ( $v 1$ na Figura 60 ) e outra que controla a perna de balanço e rastreia a posição da perna de balanço de referência ( $v 2$ na Figura 60).

Outra abordagem possível para o problema de mudanças de base é, ao invés de modificar o vetor de referência de base, modificar a o valor da variável rastreada atual de base. Neste caso a mudança de base seria do sistema de coordenadas do robô para o sistemas de coordenada do pé de apoio. Esse procedimento pode ser realizado simplesmente através da matriz de transformação $T_{b a s e}^{\text {sfoot }}$ diretamente. Porém, o Jacobiano utilizado também precisa ser modificado de base. Para tal precisamos utilizar o procedimento descrito em (HEERDEN; KAWAMURA, 2013).

\section{A.5 Zero Moment Point}

Via de regra, existem infinitas soluções de trajetória em um robô bípede para se satisfazer um ZMP de referência. Porém, a teoria de controle ótimo fornece uma solução elegante para encontrarmos uma solução que satisfaça alguma função objetivo proposta como proposto em (WIEBER, 2006).

\section{A.5.1 Quadratic Programming}

Dado o sistema linear:

$$
\begin{gathered}
X_{k+1}=A X_{k}+B u_{k} \\
z_{k}=C X_{k} \\
X=\left[\begin{array}{l}
x \\
\dot{x} \\
\ddot{x}
\end{array}\right]
\end{gathered}
$$

E façamos $u$ ser o jerk, ou: 


$$
u=\dddot{x}
$$

A saída do sistema pode ser descrita pelo seguinte sistema linear:

$$
\bar{Z}=\bar{M} X_{0}+\bar{N} \bar{u}
$$

Onde $X_{0}$ é a condição inicial do sistema, $\bar{M}$ e $\bar{N}$ podem ser descritos como:

$$
\begin{gathered}
\bar{M}=\left[\begin{array}{c}
C A \\
C A^{2} \\
\vdots \\
C A^{N}
\end{array}\right] \\
\bar{N}=\left[\begin{array}{cccc}
C & 0 & \cdots & 0 \\
C A B & C B & \cdots & 0 \\
\vdots & \vdots & \ddots & \vdots \\
C A^{N-1} B & C A^{N-2} B & \cdots & B
\end{array}\right]
\end{gathered}
$$

O objetivo é fazer com que as saídas de sistemas convirjam para uma determinada condição cinemática, minimizando o esforço do atuador. A função objetivo resultante pode ser descrita por:

$$
J=\frac{1}{2} Q\left(\bar{Z}-\bar{Z}^{r e f}\right)^{2}+\frac{1}{2} R \ddot{x}
$$

Onde:

$$
\bar{Z}=\left[\begin{array}{c}
z_{0} \\
z_{1} \\
\vdots \\
z_{N}
\end{array}\right]
$$




$$
\begin{gathered}
\bar{Z}^{r e f}=\left[\begin{array}{c}
z_{0}^{r e f} \\
z_{1}^{r e f} \\
\vdots \\
z_{N}^{r e f}
\end{array}\right] \\
\bar{X}=\left[\begin{array}{c}
X_{0} \\
X_{1} \\
\vdots \\
X_{N}
\end{array}\right]
\end{gathered}
$$

Neste caso $Q$ e $R$ são respectivamente os índices de desempenho e custo, e $z_{k}^{r e f}$ representa o estado de saída desejado no momento k. O sistema acima pode ser resolvido através de Quadratic Programming rearranjando-o na forma mostrada abaixo:

$$
\min _{\ddot{x}} f(\ddot{x})=\frac{1}{2} \ddot{x}^{T} w \ddot{x}+v \ddot{x}
$$

Onde:

$$
\begin{gathered}
w=Q N^{T} N+R I_{N \times N} \\
v=Q N^{T} M x_{0}-Q N^{T} \bar{Z}^{r e f}
\end{gathered}
$$

A solução do problema acima pode ser resolvida com o seguinte equacionamento.

$$
\dddot{x}=-w^{-1} v
$$

Tendo um método geral de gerar trajetórias usando programação quadrática, o ZMP Preview Control pode ser implementado utilizando as seguintes matrizes A, B e C: 


$$
\begin{gathered}
A=\left[\begin{array}{lll}
1 & T & \frac{T^{2}}{2} \\
0 & 1 & T \\
0 & 0 & 1
\end{array}\right] \\
B=\left[\begin{array}{c}
\frac{T^{3}}{6} \\
\frac{T^{2}}{2} \\
T
\end{array}\right] \\
C=\left[\begin{array}{lll}
1 & 0 & -h_{\text {com }} / g
\end{array}\right]
\end{gathered}
$$

Onde $h_{\text {com }}$ representa a altura do centro de massas, $g$ é a constante gravitacional e $T$ é o período da discretização. As matrizes A e B implementam um integrador e a matriz $C$ representa o equacionamento para se calcular o ZMP. Iterando como mostra o seguinte algoritmo, podemos encontrar o posicionamento do COM para cada instante de forma a satisfazer o posicionamento do ZMP seguindo a nossa função objetivo apresentada.

$$
\begin{aligned}
& \text { for } i=1 \text { to } N \text { do } \\
& \qquad \begin{array}{l}
X_{i}=A X_{i-1}+B u_{i} \\
Z_{i}=C X_{i}
\end{array} \\
& \text { end for }
\end{aligned}
$$




\section{APÊNDICE B - INSTRUÇÕES DE INSTALAÇÃO E USO DA TOOLBOX}

\section{B.1 Instalação}

A Toolbox atualmente se encontra em um repositório Git no GitHub em https://github.com/kirillvh/octaveHumanoidRobotics. O mesmo pode ser baixado diretamente do site ou clonado através do Git dentro do computador. O Código pode ser utilizado diretamente com o MATLAB depois de baixado.

\section{B.2 Instruções Uso}

Dentro do MATLAB adicione a pasta da Toolbox dentro do path e ela estará pronta para uso. Grande parte das funções apresentam funções de teste, possibilitando a comprovação de seu funcionamento assim como entregando um exemplo de uso. 


\section{APÊNDICE C - EQUAÇÕES DO MODELO DE 5 SEGMENTOS}

As variáveis de estado foram renomeadas da seguinte maneira nas equações:

$$
\left[\begin{array}{c}
\theta_{1} \\
\theta_{2} \\
\theta_{3} \\
\theta_{4} \\
\theta_{5}
\end{array}\right]=\left[\begin{array}{c}
\theta_{s w a} \\
\theta_{s w k} \\
\theta_{h i p} \\
\theta_{s k} \\
\theta_{s a}
\end{array}\right]
$$

\section{C.1 Dinâmica Contínua}

$$
\begin{gathered}
\mathbf{M}(\theta) \ddot{\theta}+\mathbf{N}(\theta, \dot{\theta}) \dot{\theta}+\mathbf{G}(\theta)=\mathbf{B u} \\
\mathbf{M}(\theta)=\left[\begin{array}{lllll}
M_{11} & M_{12} & M_{13} & M_{14} & M_{15} \\
M_{21} & M_{22} & M_{23} & M_{24} & M_{25} \\
M_{31} & M_{32} & M_{33} & M_{34} & M_{35} \\
M_{41} & M_{42} & M_{43} & M_{44} & M_{45} \\
M_{51} & M_{52} & M_{53} & M_{54} & M_{55}
\end{array}\right]
\end{gathered}
$$




$$
\begin{aligned}
M_{11}= & -I_{1}-m_{1}\left(c_{1} \cos \left(\theta_{1}\right)-l_{1} \cos \left(\theta_{1}\right)\right)^{2}-m_{1}\left(c_{1} \sin \left(\theta_{1}\right)-l_{1} \sin \left(\theta_{1}\right)\right)^{2} \\
& -l_{1} m_{3} \sin \left(\theta_{1}\right)\left(-c_{3} \sin \left(\theta_{3}\right)+l_{1} \sin \left(\theta_{1}\right)+l_{2} \sin \left(\theta_{2}\right)+l_{3} \sin \left(\theta_{3}\right)\right) \\
& +l_{1} m_{5} \sin \left(\theta_{1}\right)\left(c_{5} \sin \left(\theta_{5}\right)-l_{1} \sin \left(\theta_{1}\right)-l_{2} \sin \left(\theta_{2}\right)+l_{4} \sin \left(\theta_{4}\right)\right) \\
& -l_{1} m_{2} \cos \left(\theta_{1}\right)\left(-c_{2} \cos \left(\theta_{2}\right)+l_{1} \cos \left(\theta_{1}\right)+l_{2} \cos \left(\theta_{2}\right)\right) \\
& -l_{1} m_{4} \cos \left(\theta_{1}\right)\left(-c_{4} \cos \left(\theta_{4}\right)+l_{1} \cos \left(\theta_{1}\right)+l_{2} \cos \left(\theta_{2}\right)\right) \\
& -l_{1} m_{2} \sin \left(\theta_{1}\right)\left(-c_{2} \sin \left(\theta_{2}\right)+l_{1} \sin \left(\theta_{1}\right)+l_{2} \sin \left(\theta_{2}\right)\right) \\
& -l_{1} m_{4} \sin \left(\theta_{1}\right)\left(-c_{4} \sin \left(\theta_{4}\right)+l_{1} \sin \left(\theta_{1}\right)+l_{2} \sin \left(\theta_{2}\right)\right) \\
& -l_{1} m_{3} \cos \left(\theta_{1}\right)\left(-c_{3} \cos \left(\theta_{3}\right)+l_{1} \cos \left(\theta_{1}\right)+l_{2} \cos \left(\theta_{2}\right)+l_{3} \cos \left(\theta_{3}\right)\right) \\
& +l_{1} m_{5} \cos \left(\theta_{1}\right)\left(c_{5} \cos \left(\theta_{5}\right)-l_{1} \cos \left(\theta_{1}\right)-l_{2} \cos \left(\theta_{2}\right)+l_{4} \cos \left(\theta_{4}\right)\right)
\end{aligned}
$$

$$
\begin{aligned}
M_{12}= & -I_{2}+m_{2}\left(c_{2} \cos \left(\theta_{2}\right)-l_{2} \cos \left(\theta_{2}\right)\right)\left(-c_{2} \cos \left(\theta_{2}\right)+l_{1} \cos \left(\theta_{1}\right)+l_{2} \cos \left(\theta_{2}\right)\right) \\
& +m_{2}\left(c_{2} \sin \left(\theta_{2}\right)-l_{2} \sin \left(\theta_{2}\right)\right)\left(-c_{2} \sin \left(\theta_{2}\right)+l_{1} \sin \left(\theta_{1}\right)+l_{2} \sin \left(\theta_{2}\right)\right) \\
& -l_{2} m_{3} \sin \left(\theta_{2}\right)\left(-c_{3} \sin \left(\theta_{3}\right)+l_{1} \sin \left(\theta_{1}\right)+l_{2} \sin \left(\theta_{2}\right)+l_{3} \sin \left(\theta_{3}\right)\right) \\
& +l_{2} m_{5} \sin \left(\theta_{2}\right)\left(c_{5} \sin \left(\theta_{5}\right)-l_{1} \sin \left(\theta_{1}\right)-l_{2} \sin \left(\theta_{2}\right)+l_{4} \sin \left(\theta_{4}\right)\right) \\
& -l_{2} m_{4} \cos \left(\theta_{2}\right)\left(-c_{4} \cos \left(\theta_{4}\right)+l_{1} \cos \left(\theta_{1}\right)+l_{2} \cos \left(\theta_{2}\right)\right) \\
& -l_{2} m_{4} \sin \left(\theta_{2}\right)\left(-c_{4} \sin \left(\theta_{4}\right)+l_{1} \sin \left(\theta_{1}\right)+l_{2} \sin \left(\theta_{2}\right)\right) \\
& -l_{2} m_{3} \cos \left(\theta_{2}\right)\left(-c_{3} \cos \left(\theta_{3}\right)+l_{1} \cos \left(\theta_{1}\right)+l_{2} \cos \left(\theta_{2}\right)+l_{3} \cos \left(\theta_{3}\right)\right) \\
& +l_{2} m_{5} \cos \left(\theta_{2}\right)\left(c_{5} \cos \left(\theta_{5}\right)-l_{1} \cos \left(\theta_{1}\right)-l_{2} \cos \left(\theta_{2}\right)+l_{4} \cos \left(\theta_{4}\right)\right)
\end{aligned}
$$

$$
\begin{aligned}
M_{13}= & -I_{3}+m_{3}\left(c_{3} \cos \left(\theta_{3}\right)-l_{3} \cos \left(\theta_{3}\right)\right)\left(-c_{3} \cos \left(\theta_{3}\right)+l_{1} \cos \left(\theta_{1}\right)+l_{2} \cos \left(\theta_{2}\right)+l_{3} \cos \left(\theta_{3}\right)\right) \\
& +m_{3}\left(c_{3} \sin \left(\theta_{3}\right)-l_{3} \sin \left(\theta_{3}\right)\right)\left(-c_{3} \sin \left(\theta_{3}\right)+l_{1} \sin \left(\theta_{1}\right)+l_{2} \sin \left(\theta_{2}\right)+l_{3} \sin \left(\theta_{3}\right)\right)
\end{aligned}
$$

$$
\begin{aligned}
M_{14}= & -I_{4}-l_{4} m_{5} \sin \left(\theta_{4}\right)\left(c_{5} \sin \left(\theta_{5}\right)-l_{1} \sin \left(\theta_{1}\right)-l_{2} \sin \left(\theta_{2}\right)+l_{4} \sin \left(\theta_{4}\right)\right) \\
& +c_{4} m_{4} \cos \left(\theta_{4}\right)\left(-c_{4} \cos \left(\theta_{4}\right)+l_{1} \cos \left(\theta_{1}\right)+l_{2} \cos \left(\theta_{2}\right)\right) \\
& +c_{4} m_{4} \sin \left(\theta_{4}\right)\left(-c_{4} \sin \left(\theta_{4}\right)+l_{1} \sin \left(\theta_{1}\right)+l_{2} \sin \left(\theta_{2}\right)\right) \\
& -l_{4} m_{5} \cos \left(\theta_{4}\right)\left(c_{5} \cos \left(\theta_{5}\right)-l_{1} \cos \left(\theta_{1}\right)-l_{2} \cos \left(\theta_{2}\right)+l_{4} \cos \left(\theta_{4}\right)\right)
\end{aligned}
$$

$$
\begin{aligned}
M_{15}= & -I_{5}-c_{5} m_{5} \sin \left(\theta_{5}\right)\left(c_{5} \sin \left(\theta_{5}\right)-l_{1} \sin \left(\theta_{1}\right)-l_{2} \sin \left(\theta_{2}\right)+l_{4} \sin \left(\theta_{4}\right)\right) \\
& -c_{5} m_{5} \cos \left(\theta_{5}\right)\left(c_{5} \cos \left(\theta_{5}\right)-l_{1} \cos \left(\theta_{1}\right)-l_{2} \cos \left(\theta_{2}\right)+l_{4} \cos \left(\theta_{4}\right)\right)
\end{aligned}
$$

$$
\begin{aligned}
M_{21}= & -l_{1} m_{3} \cos \left(\theta_{1}\right)\left(-c_{3} \cos \left(\theta_{3}\right)+l_{2} \cos \left(\theta_{2}\right)+l_{3} \cos \left(\theta_{3}\right)\right) \\
& +l_{1} m_{5} \cos \left(\theta_{1}\right)\left(c_{5} \cos \left(\theta_{5}\right)-l_{2} \cos \left(\theta_{2}\right)+l_{4} \cos \left(\theta_{4}\right)\right) \\
& -l_{1} m_{3} \sin \left(\theta_{1}\right)\left(-c_{3} \sin \left(\theta_{3}\right)+l_{2} \sin \left(\theta_{2}\right)+l_{3} \sin \left(\theta_{3}\right)\right) \\
& +l_{1} m_{5} \sin \left(\theta_{1}\right)\left(c_{5} \sin \left(\theta_{5}\right)-l_{2} \sin \left(\theta_{2}\right)+l_{4} \sin \left(\theta_{4}\right)\right) \\
& +l_{1} m_{2} \cos \left(\theta_{1}\right)\left(c_{2} \cos \left(\theta_{2}\right)-l_{2} \cos \left(\theta_{2}\right)\right)+l_{1} m_{4} \cos \left(\theta_{1}\right)\left(c_{4} \cos \left(\theta_{4}\right)-l_{2} \cos \left(\theta_{2}\right)\right) \\
& +l_{1} m_{2} \sin \left(\theta_{1}\right)\left(c_{2} \sin \left(\theta_{2}\right)-l_{2} \sin \left(\theta_{2}\right)\right)+l_{1} m_{4} \sin \left(\theta_{1}\right)\left(c_{4} \sin \left(\theta_{4}\right)-l_{2} \sin \left(\theta_{2}\right)\right)
\end{aligned}
$$




$$
\begin{aligned}
M_{22}= & -I_{2}-m_{2}\left(c_{2} \cos \left(\theta_{2}\right)-l_{2} \cos \left(\theta_{2}\right)\right)^{2}-m_{2}\left(c_{2} \sin \left(\theta_{2}\right)-l_{2} \sin \left(\theta_{2}\right)\right)^{2} \\
& -l_{2} m_{3} \cos \left(\theta_{2}\right)\left(-c_{3} \cos \left(\theta_{3}\right)+l_{2} \cos \left(\theta_{2}\right)+l_{3} \cos \left(\theta_{3}\right)\right) \\
& +l_{2} m_{5} \cos \left(\theta_{2}\right)\left(c_{5} \cos \left(\theta_{5}\right)-l_{2} \cos \left(\theta_{2}\right)+l_{4} \cos \left(\theta_{4}\right)\right) \\
& -l_{2} m_{3} \sin \left(\theta_{2}\right)\left(-c_{3} \sin \left(\theta_{3}\right)+l_{2} \sin \left(\theta_{2}\right)+l_{3} \sin \left(\theta_{3}\right)\right) \\
& +l_{2} m_{5} \sin \left(\theta_{2}\right)\left(c_{5} \sin \left(\theta_{5}\right)-l_{2} \sin \left(\theta_{2}\right)+l_{4} \sin \left(\theta_{4}\right)\right) \\
& +l_{2} m_{4} \cos \left(\theta_{2}\right)\left(c_{4} \cos \left(\theta_{4}\right)-l_{2} \cos \left(\theta_{2}\right)\right)+l_{2} m_{4} \sin \left(\theta_{2}\right)\left(c_{4} \sin \left(\theta_{4}\right)-l_{2} \sin \left(\theta_{2}\right)\right)
\end{aligned}
$$

$$
\begin{aligned}
M_{23}= & -I_{3}+m_{3}\left(c_{3} \cos \left(\theta_{3}\right)-l_{3} \cos \left(\theta_{3}\right)\right)\left(-c_{3} \cos \left(\theta_{3}\right)+l_{2} \cos \left(\theta_{2}\right)+l_{3} \cos \left(\theta_{3}\right)\right) \\
& +m_{3}\left(c_{3} \sin \left(\theta_{3}\right)-l_{3} \sin \left(\theta_{3}\right)\right)\left(-c_{3} \sin \left(\theta_{3}\right)+l_{2} \sin \left(\theta_{2}\right)+l_{3} \sin \left(\theta_{3}\right)\right)
\end{aligned}
$$

$$
\begin{aligned}
M_{24}= & -I_{4}-l_{4} m_{5} \cos \left(\theta_{4}\right)\left(c_{5} \cos \left(\theta_{5}\right)-l_{2} \cos \left(\theta_{2}\right)+l_{4} \cos \left(\theta_{4}\right)\right) \\
& -l_{4} m_{5} \sin \left(\theta_{4}\right)\left(c_{5} \sin \left(\theta_{5}\right)-l_{2} \sin \left(\theta_{2}\right)+l_{4} \sin \left(\theta_{4}\right)\right) \\
& -c_{4} m_{4} \cos \left(\theta_{4}\right)\left(c_{4} \cos \left(\theta_{4}\right)-l_{2} \cos \left(\theta_{2}\right)\right)-c_{4} m_{4} \sin \left(\theta_{4}\right)\left(c_{4} \sin \left(\theta_{4}\right)-l_{2} \sin \left(\theta_{2}\right)\right)
\end{aligned}
$$

$$
\begin{aligned}
M_{25}= & -I_{5}-c_{5} m_{5} \cos \left(\theta_{5}\right)\left(c_{5} \cos \left(\theta_{5}\right)-l_{2} \cos \left(\theta_{2}\right)+l_{4} \cos \left(\theta_{4}\right)\right) \\
& -c_{5} m_{5} \sin \left(\theta_{5}\right)\left(c_{5} \sin \left(\theta_{5}\right)-l_{2} \sin \left(\theta_{2}\right)+l_{4} \sin \left(\theta_{4}\right)\right)
\end{aligned}
$$

$$
\begin{aligned}
M_{31}= & l_{1} m_{3} \cos \left(\theta_{1}\right)\left(c_{3} \cos \left(\theta_{3}\right)-l_{3} \cos \left(\theta_{3}\right)\right)+l_{1} m_{5} \cos \left(\theta_{1}\right)\left(c_{5} \cos \left(\theta_{5}\right)+l_{4} \cos \left(\theta_{4}\right)\right) \\
& +l_{1} m_{3} \sin \left(\theta_{1}\right)\left(c_{3} \sin \left(\theta_{3}\right)-l_{3} \sin \left(\theta_{3}\right)\right)+l_{1} m_{5} \sin \left(\theta_{1}\right)\left(c_{5} \sin \left(\theta_{5}\right)+l_{4} \sin \left(\theta_{4}\right)\right) \\
& +c_{4} l_{1} m_{4} \cos \left(\theta_{1}\right) \cos \left(\theta_{4}\right)+c_{4} l_{1} m_{4} \sin \left(\theta_{1}\right) \sin \left(\theta_{4}\right)
\end{aligned}
$$

$$
\begin{aligned}
M_{32}= & l_{2} m_{3} \cos \left(\theta_{2}\right)\left(c_{3} \cos \left(\theta_{3}\right)-l_{3} \cos \left(\theta_{3}\right)\right)+l_{2} m_{5} \cos \left(\theta_{2}\right)\left(c_{5} \cos \left(\theta_{5}\right)+l_{4} \cos \left(\theta_{4}\right)\right) \\
& +l_{2} m_{3} \sin \left(\theta_{2}\right)\left(c_{3} \sin \left(\theta_{3}\right)-l_{3} \sin \left(\theta_{3}\right)\right)+l_{2} m_{5} \sin \left(\theta_{2}\right)\left(c_{5} \sin \left(\theta_{5}\right)+l_{4} \sin \left(\theta_{4}\right)\right) \\
& +c_{4} l_{2} m_{4} \cos \left(\theta_{2}\right) \cos \left(\theta_{4}\right)+c_{4} l_{2} m_{4} \sin \left(\theta_{2}\right) \sin \left(\theta_{4}\right) \\
& M_{33}=-I_{3}-m_{3}\left(c_{3} \cos \left(\theta_{3}\right)-l_{3} \cos \left(\theta_{3}\right)\right)^{2}-m_{3}\left(c_{3} \sin \left(\theta_{3}\right)-l_{3} \sin \left(\theta_{3}\right)\right)^{2} \\
M_{34}=- & I_{4}-\left(c_{4} c_{4}\right) m_{4} \cos \left(\theta_{4}\right)^{2}-\left(c_{4} c_{4}\right) m_{4} \sin \left(\theta_{4}\right)^{2} \\
& -l_{4} m_{5} \cos \left(\theta_{4}\right)\left(c_{5} \cos \left(\theta_{5}\right)+l_{4} \cos \left(\theta_{4}\right)\right)-l_{4} m_{5} \sin \left(\theta_{4}\right)\left(c_{5} \sin \left(\theta_{5}\right)+l_{4} \sin \left(\theta_{4}\right)\right)
\end{aligned}
$$

$$
M_{35}=-I_{5}-c_{5} m_{5} \cos \left(\theta_{5}\right)\left(c_{5} \cos \left(\theta_{5}\right)+l_{4} \cos \left(\theta_{4}\right)\right)-c_{5} m_{5} \sin \left(\theta_{5}\right)\left(c_{5} \sin \left(\theta_{5}\right)+l_{4} \sin \left(\theta_{4}\right)\right)
$$




$$
\begin{aligned}
M_{41}= & l_{1} m_{5} \cos \left(\theta_{1}\right)\left(c_{5} \cos \left(\theta_{5}\right)+l_{4} \cos \left(\theta_{4}\right)\right)+l_{1} m_{5} \sin \left(\theta_{1}\right)\left(c_{5} \sin \left(\theta_{5}\right)+l_{4} \sin \left(\theta_{4}\right)\right) \\
& +c_{4} l_{1} m_{4} \cos \left(\theta_{1}\right) \cos \left(\theta_{4}\right)+c_{4} l_{1} m_{4} \sin \left(\theta_{1}\right) \sin \left(\theta_{4}\right)
\end{aligned}
$$

$$
\begin{aligned}
M_{42}= & l_{2} m_{5} \cos \left(\theta_{2}\right)\left(c_{5} \cos \left(\theta_{5}\right)+l_{4} \cos \left(\theta_{4}\right)\right)+l_{2} m_{5} \sin \left(\theta_{2}\right)\left(c_{5} \sin \left(\theta_{5}\right)+l_{4} \sin \left(\theta_{4}\right)\right) \\
& +c_{4} l_{2} m_{4} \cos \left(\theta_{2}\right) \cos \left(\theta_{4}\right)+c_{4} l_{2} m_{4} \sin \left(\theta_{2}\right) \sin \left(\theta_{4}\right)
\end{aligned}
$$

$$
M_{43}=0
$$

$$
\begin{aligned}
M_{44}= & -I_{4}-\left(c_{4} c_{4}\right) m_{4} \cos \left(\theta_{4}\right)^{2}-\left(c_{4} c_{4}\right) m_{4} \sin \left(\theta_{4}\right)^{2} \\
& -l_{4} m_{5} \cos \left(\theta_{4}\right)\left(c_{5} \cos \left(\theta_{5}\right)+l_{4} \cos \left(\theta_{4}\right)\right)-l_{4} m_{5} \sin \left(\theta_{4}\right)\left(c_{5} \sin \left(\theta_{5}\right)+l_{4} \sin \left(\theta_{4}\right)\right)
\end{aligned}
$$

$$
M_{45}=-I_{5}-c_{5} m_{5} \cos \left(\theta_{5}\right)\left(c_{5} \cos \left(\theta_{5}\right)+l_{4} \cos \left(\theta_{4}\right)\right)-c_{5} m_{5} \sin \left(\theta_{5}\right)\left(c_{5} \sin \left(\theta_{5}\right)+l_{4} \sin \left(\theta_{4}\right)\right)
$$

$$
\begin{aligned}
& M_{51}=c_{5} l_{1} m_{5} \cos \left(\theta_{1}\right) \cos \left(\theta_{5}\right)+c_{5} l_{1} m_{5} \sin \left(\theta_{1}\right) \sin \left(\theta_{5}\right) \\
& M_{52}=c_{5} l_{2} m_{5} \cos \left(\theta_{2}\right) \cos \left(\theta_{5}\right)+c_{5} l_{2} m_{5} \sin \left(\theta_{2}\right) \sin \left(\theta_{5}\right)
\end{aligned}
$$

$$
M_{53}=0
$$

$$
M_{54}=-c_{5} l_{4} m_{5} \cos \left(\theta_{4}\right) \cos \left(\theta_{5}\right)-c_{5} l_{4} m_{5} \sin \left(\theta_{4}\right) \sin \left(\theta_{5}\right)
$$

$$
M_{55}=-I_{5}-\left(c_{5} c_{5}\right) m_{5} \cos \left(\theta_{5}\right)^{2}-\left(c_{5} c_{5}\right) m_{5} \sin \left(\theta_{5}\right)^{2}
$$

$$
\mathbf{f}(\theta, \dot{\theta})=\mathbf{B u}-(\mathbf{N}(\theta, \dot{\theta}) \dot{\theta}+\mathbf{G}(\theta))
$$

$$
\mathbf{f}(\theta, \dot{\theta})=\left[\begin{array}{l}
f_{1} \\
f_{2} \\
f_{3} \\
f_{4} \\
f_{5}
\end{array}\right]
$$




$$
\begin{aligned}
& f_{1}=-u_{1}-g m_{3}\left(-c_{3} \sin \left(\theta_{3}\right)+l_{1} \sin \left(\theta_{1}\right)+l_{2} \sin \left(\theta_{2}\right)+l_{3} \sin \left(\theta_{3}\right)\right) \\
& +g m_{5}\left(c_{5} \sin \left(\theta_{5}\right)-l_{1} \sin \left(\theta_{1}\right)-l_{2} \sin \left(\theta_{2}\right)+l_{4} \sin \left(\theta_{4}\right)\right) \\
& -g m_{2}\left(-c_{2} \sin \left(\theta_{2}\right)+l_{1} \sin \left(\theta_{1}\right)+l_{2} \sin \left(\theta_{2}\right)\right)-g m_{4}\left(-c_{4} \sin \left(\theta_{4}\right)+l_{1} \sin \left(\theta_{1}\right)+l_{2} \sin \left(\theta_{2}\right)\right) \\
& -m_{2}\left(\dot{\theta}_{2} \dot{\theta}_{2}^{2}\left(c_{2} \cos \left(\theta_{2}\right)-l_{2} \cos \left(\theta_{2}\right)\right)-\dot{\theta}_{2} \dot{\theta}_{1}^{2} l_{1} \cos \left(\theta_{1}\right)\right)\left(-c_{2} \sin \left(\theta_{2}\right)+l_{1} \sin \left(\theta_{1}\right)+l_{2} \sin \left(\theta_{2}\right)\right) \\
& +m_{2}\left(\dot{\theta}_{2} \dot{\theta}_{2}^{2}\left(c_{2} \sin \left(\theta_{2}\right)-l_{2} \sin \left(\theta_{2}\right)\right)-\dot{\theta}_{2} \dot{\theta}_{1}^{2} l_{1} \sin \left(\theta_{1}\right)\right)\left(-c_{2} \cos \left(\theta_{2}\right)+l_{1} \cos \left(\theta_{1}\right)+l_{2} \cos \left(\theta_{2}\right)\right) \\
& -m_{4}\left(-c_{4} \cos \left(\theta_{4}\right)+l_{1} \cos \left(\theta_{1}\right)+l_{2} \cos \left(\theta_{2}\right)\right)\left(-c_{4} \dot{\theta}_{2} \dot{\theta}_{4}^{2} \sin \left(\theta_{4}\right)+\dot{\theta}_{2} \dot{\theta}_{1}^{2} l_{1} \sin \left(\theta_{1}\right)\right. \\
& \left.+\dot{\theta}_{2} \dot{\theta}_{2}^{2} l_{2} \sin \left(\theta_{2}\right)\right)+m_{4}\left(-c_{4} \sin \left(\theta_{4}\right)+l_{1} \sin \left(\theta_{1}\right)+l_{2} \sin \left(\theta_{2}\right)\right)\left(-c_{4} \dot{\theta}_{2} \dot{\theta}_{4}^{2} \cos \left(\theta_{4}\right)\right. \\
& \left.+\dot{\theta}_{2} \dot{\theta}_{1}^{2} l_{1} \cos \left(\theta_{1}\right)+\dot{\theta}_{2} \dot{\theta}_{2}^{2} l_{2} \cos \left(\theta_{2}\right)\right)-m_{3}\left(-\dot{\theta}_{2} \dot{\theta}_{3}^{2}\left(c_{3} \sin \left(\theta_{3}\right)-l_{3} \sin \left(\theta_{3}\right)\right)+\dot{\theta}_{2} \dot{\theta}_{1}^{2} l_{1} \sin \left(\theta_{1}\right)\right. \\
& \left.+\dot{\theta}_{2} \dot{\theta}_{2}^{2} l_{2} \sin \left(\theta_{2}\right)\right)\left(-c_{3} \cos \left(\theta_{3}\right)+l_{1} \cos \left(\theta_{1}\right)+l_{2} \cos \left(\theta_{2}\right)+l_{3} \cos \left(\theta_{3}\right)\right) \\
& +m_{3}\left(-\dot{\theta}_{2} \dot{\theta}_{3}^{2}\left(c_{3} \cos \left(\theta_{3}\right)-l_{3} \cos \left(\theta_{3}\right)\right)+\dot{\theta}_{2} \dot{\theta}_{1}^{2} l_{1} \cos \left(\theta_{1}\right)+\dot{\theta}_{2} \dot{\theta}_{2}^{2} l_{2} \cos \left(\theta_{2}\right)\right)\left(-c_{3} \sin \left(\theta_{3}\right)\right. \\
& \left.+l_{1} \sin \left(\theta_{1}\right)+l_{2} \sin \left(\theta_{2}\right)+l_{3} \sin \left(\theta_{3}\right)\right)+m_{5}\left(c_{5} \sin \left(\theta_{5}\right)-l_{1} \sin \left(\theta_{1}\right)-l_{2} \sin \left(\theta_{2}\right)\right. \\
& \left.+l_{4} \sin \left(\theta_{4}\right)\right)\left(c_{5} \dot{\theta}_{2} \dot{\theta}_{5}^{2} \cos \left(\theta_{5}\right)-\dot{\theta}_{2} \dot{\theta}_{1}^{2} l_{1} \cos \left(\theta_{1}\right)-\dot{\theta}_{2} \dot{\theta}_{2}^{2} l_{2} \cos \left(\theta_{2}\right)+\dot{\theta}_{2} \dot{\theta}_{4}^{2} l_{4} \cos \left(\theta_{4}\right)\right) \\
& -m_{5}\left(c_{5} \dot{\theta}_{2} \dot{\theta}_{5}^{2} \sin \left(\theta_{5}\right)-\dot{\theta}_{2} \dot{\theta}_{1}^{2} l_{1} \sin \left(\theta_{1}\right)-\dot{\theta}_{2} \dot{\theta}_{2}^{2} l_{2} \sin \left(\theta_{2}\right)+\dot{\theta}_{2} \dot{\theta}_{4}^{2} l_{4} \sin \left(\theta_{4}\right)\right)\left(c_{5} \cos \left(\theta_{5}\right)\right. \\
& \left.-l_{1} \cos \left(\theta_{1}\right)-l_{2} \cos \left(\theta_{2}\right)+l_{4} \cos \left(\theta_{4}\right)\right)+g m_{1}\left(c_{1} \sin \left(\theta_{1}\right)-l_{1} \sin \left(\theta_{1}\right)\right)
\end{aligned}
$$

$$
\begin{aligned}
f_{2}= & -u_{2}-m_{4}\left(c_{4} \sin \left(\theta_{4}\right)-l_{2} \sin \left(\theta_{2}\right)\right)\left(-c_{4} \dot{\theta}_{2} \dot{\theta}_{4}^{2} \cos \left(\theta_{4}\right)+\dot{\theta}_{2} \dot{\theta}_{1}^{2} l_{1} \cos \left(\theta_{1}\right)+\dot{\theta}_{2} \dot{\theta}_{2}^{2} l_{2} \cos \left(\theta_{2}\right)\right) \\
& -m_{2}\left(c_{2} \cos \left(\theta_{2}\right)-l_{2} \cos \left(\theta_{2}\right)\right)\left(\dot{\theta}_{2} \dot{\theta}_{2}^{2}\left(c_{2} \sin \left(\theta_{2}\right)-l_{2} \sin \left(\theta_{2}\right)\right)-\dot{\theta}_{2} \dot{\theta}_{1}^{2} l_{1} \sin \left(\theta_{1}\right)\right) \\
& +m_{3}\left(-c_{3} \sin \left(\theta_{3}\right)+l_{2} \sin \left(\theta_{2}\right)+l_{3} \sin \left(\theta_{3}\right)\right)\left(-\dot{\theta}_{2} \dot{\theta}_{3}^{2}\left(c_{3} \cos \left(\theta_{3}\right)-l_{3} \cos \left(\theta_{3}\right)\right)\right. \\
& \left.\quad+\dot{\theta}_{2} \dot{\theta}_{1}^{2} l_{1} \cos \left(\theta_{1}\right)+\dot{\theta}_{2} \dot{\theta}_{2}^{2} l_{2} \cos \left(\theta_{2}\right)\right) \\
& +m_{4}\left(c_{4} \cos \left(\theta_{4}\right)-l_{2} \cos \left(\theta_{2}\right)\right)\left(-c_{4} \dot{\theta}_{2} \dot{\theta}_{4}^{2} \sin \left(\theta_{4}\right)+\dot{\theta}_{2} \dot{\theta}_{1}^{2} l_{1} \sin \left(\theta_{1}\right)+\dot{\theta}_{2} \dot{\theta}_{2}^{2} l_{2} \sin \left(\theta_{2}\right)\right) \\
& +m_{5}\left(c_{5} \sin \left(\theta_{5}\right)-l_{2} \sin \left(\theta_{2}\right)+l_{4} \sin \left(\theta_{4}\right)\right)\left(c_{5} \dot{\theta}_{2} \dot{\theta}_{5}^{2} \cos \left(\theta_{5}\right)-\dot{\theta}_{2} \dot{\theta}_{1}^{2} l_{1} \cos \left(\theta_{1}\right)\right. \\
& \left.-\dot{\theta}_{2} \dot{\theta}_{2}^{2} l_{2} \cos \left(\theta_{2}\right)+\dot{\theta}_{2} \dot{\theta}_{4}^{2} l_{4} \cos \left(\theta_{4}\right)\right)-m_{3}\left(-\dot{\theta}_{2} \dot{\theta}_{3}^{2}\left(c_{3} \sin \left(\theta_{3}\right)-l_{3} \sin \left(\theta_{3}\right)\right)+\dot{\theta}_{2} \dot{\theta}_{1}^{2} l_{1} \sin \left(\theta_{1}\right)\right. \\
& \left.\quad+\dot{\theta}_{2} \dot{\theta}_{2}^{2} l_{2} \sin \left(\theta_{2}\right)\right)\left(-c_{3} \cos \left(\theta_{3}\right)+l_{2} \cos \left(\theta_{2}\right)+l_{3} \cos \left(\theta_{3}\right)\right)-m_{5}\left(c_{5} \cos \left(\theta_{5}\right)-l_{2} \cos \left(\theta_{2}\right)\right. \\
& \left.\quad+l_{4} \cos \left(\theta_{4}\right)\right)\left(c_{5} \dot{\theta}_{2} \dot{\theta}_{5}^{2} \sin \left(\theta_{5}\right)-\dot{\theta}_{2} \dot{\theta}_{1}^{2} l_{1} \sin \left(\theta_{1}\right)-\dot{\theta}_{2} \dot{\theta}_{2}^{2} l_{2} \sin \left(\theta_{2}\right)+\dot{\theta}_{2} \dot{\theta}_{4}^{2} l_{4} \sin \left(\theta_{4}\right)\right) \\
& -g m_{3}\left(-c_{3} \sin \left(\theta_{3}\right)+l_{2} \sin \left(\theta_{2}\right)+l_{3} \sin \left(\theta_{3}\right)\right)+g m_{5}\left(c_{5} \sin \left(\theta_{5}\right)-l_{2} \sin \left(\theta_{2}\right)+l_{4} \sin \left(\theta_{4}\right)\right) \\
& +g m_{2}\left(c_{2} \sin \left(\theta_{2}\right)-l_{2} \sin \left(\theta_{2}\right)\right)+g m_{4}\left(c_{4} \sin \left(\theta_{4}\right)-l_{2} \sin \left(\theta_{2}\right)\right) \\
& +m_{2}\left(\dot{\theta}_{2} \dot{\theta}_{2}^{2}\left(c_{2} \cos \left(\theta_{2}\right)-l_{2} \cos \left(\theta_{2}\right)\right)-\dot{\theta}_{2} \dot{\theta}_{1}^{2} l_{1} \cos \left(\theta_{1}\right)\right)\left(c_{2} \sin \left(\theta_{2}\right)-l_{2} \sin \left(\theta_{2}\right)\right)
\end{aligned}
$$

$$
\begin{aligned}
f_{3}= & -u_{3}+m_{5}\left(c_{5} \sin \left(\theta_{5}\right)+l_{4} \sin \left(\theta_{4}\right)\right)\left(c_{5} \dot{\theta}_{2} \dot{\theta}_{5}^{2} \cos \left(\theta_{5}\right)-\dot{\theta}_{2} \dot{\theta}_{1}^{2} l_{1} \cos \left(\theta_{1}\right)-\dot{\theta}_{2} \dot{\theta}_{2}^{2} l_{2} \cos \left(\theta_{2}\right)\right. \\
& \left.+\dot{\theta}_{2} \dot{\theta}_{4}^{2} l_{4} \cos \left(\theta_{4}\right)\right)-m_{5}\left(c_{5} \cos \left(\theta_{5}\right)+l_{4} \cos \left(\theta_{4}\right)\right)\left(c_{5} \dot{\theta}_{2} \dot{\theta}_{5}^{2} \sin \left(\theta_{5}\right)-\dot{\theta}_{2} \dot{\theta}_{1}^{2} l_{1} \sin \left(\theta_{1}\right)\right. \\
& \left.-\dot{\theta}_{2} \dot{\theta}_{2}^{2} l_{2} \sin \left(\theta_{2}\right)+\dot{\theta}_{2} \dot{\theta}_{4}^{2} l_{4} \sin \left(\theta_{4}\right)\right)+g m_{5}\left(c_{5} \sin \left(\theta_{5}\right)+l_{4} \sin \left(\theta_{4}\right)\right) \\
& -m_{3} \sin \left(\theta_{3}\right)\left(c_{3}-l_{3}\right)\left(-c_{3} \dot{\theta}_{2} \dot{\theta}_{3}^{2} \cos \left(\theta_{3}\right)+\dot{\theta}_{2} \dot{\theta}_{1}^{2} l_{1} \cos \left(\theta_{1}\right)+\dot{\theta}_{2} \dot{\theta}_{2}^{2} l_{2} \cos \left(\theta_{2}\right)+\dot{\theta}_{2} \dot{\theta}_{3}^{2} l_{3} \cos \left(\theta_{3}\right)\right) \\
& +m_{3} \cos \left(\theta_{3}\right)\left(c_{3}-l_{3}\right)\left(-c_{3} \dot{\theta}_{2} \dot{\theta}_{3}^{2} \sin \left(\theta_{3}\right)+\dot{\theta}_{2} \dot{\theta}_{1}^{2} l_{1} \sin \left(\theta_{1}\right)+\dot{\theta}_{2} \dot{\theta}_{2}^{2} l_{2} \sin \left(\theta_{2}\right)+\dot{\theta}_{2} \dot{\theta}_{3}^{2} l_{3} \sin \left(\theta_{3}\right)\right) \\
& +c_{4} g m_{4} \sin \left(\theta_{4}\right)-c_{4} m_{4} \sin \left(\theta_{4}\right)\left(-c_{4} \dot{\theta}_{2} \dot{\theta}_{4}^{2} \cos \left(\theta_{4}\right)+\dot{\theta}_{2} \dot{\theta}_{1}^{2} l_{1} \cos \left(\theta_{1}\right)+\dot{\theta}_{2} \dot{\theta}_{2}^{2} l_{2} \cos \left(\theta_{2}\right)\right) \\
& +g m_{3} \sin \left(\theta_{3}\right)\left(c_{3}-l_{3}\right)+c_{4} m_{4} \cos \left(\theta_{4}\right)\left(-c_{4} \dot{\theta}_{2} \dot{\theta}_{4}^{2} \sin \left(\theta_{4}\right)+\dot{\theta}_{2} \dot{\theta}_{1}^{2} l_{1} \sin \left(\theta_{1}\right)+\dot{\theta}_{2} \dot{\theta}_{2}^{2} l_{2} \sin \left(\theta_{2}\right)\right)
\end{aligned}
$$




$$
\begin{aligned}
f_{4}= & -u_{4}+m_{5}\left(c_{5} \sin \left(\theta_{5}\right)+l_{4} \sin \left(\theta_{4}\right)\right)\left(c_{5} \dot{\theta}_{2} \dot{\theta}_{5}^{2} \cos \left(\theta_{5}\right)-\dot{\theta}_{2} \dot{\theta}_{1}^{2} l_{1} \cos \left(\theta_{1}\right)-\dot{\theta}_{2} \dot{\theta}_{2}^{2} l_{2} \cos \left(\theta_{2}\right)\right. \\
& \left.+\dot{\theta}_{2} \dot{\theta}_{4}^{2} l_{4} \cos \left(\theta_{4}\right)\right)-m_{5}\left(c_{5} \cos \left(\theta_{5}\right)+l_{4} \cos \left(\theta_{4}\right)\right)\left(c_{5} \dot{\theta}_{2} \dot{\theta}_{5}^{2} \sin \left(\theta_{5}\right)-\dot{\theta}_{2} \dot{\theta}_{1}^{2} l_{1} \sin \left(\theta_{1}\right)\right. \\
& \left.-\dot{\theta}_{2} \dot{\theta}_{2}^{2} l_{2} \sin \left(\theta_{2}\right)+\dot{\theta}_{2} \dot{\theta}_{4} l_{4} \sin \left(\theta_{4}\right)\right)+g m_{5}\left(c_{5} \sin \left(\theta_{5}\right)+l_{4} \sin \left(\theta_{4}\right)\right) \\
& +c_{4} g m_{4} \sin \left(\theta_{4}\right)-c_{4} m_{4} \sin \left(\theta_{4}\right)\left(-c_{4} \dot{\theta}_{2} \dot{\theta}_{4}^{2} \cos \left(\theta_{4}\right)+\dot{\theta}_{2} \dot{\theta}_{1}^{2} l_{1} \cos \left(\theta_{1}\right)+\dot{\theta}_{2} \dot{\theta}_{2}^{2} l_{2} \cos \left(\theta_{2}\right)\right) \\
& +c_{4} m_{4} \cos \left(\theta_{4}\right)\left(-c_{4} \dot{\theta}_{2} \dot{\theta}_{4}^{2} \sin \left(\theta_{4}\right)+\dot{\theta}_{2} \dot{\theta}_{1}^{2} l_{1} \sin \left(\theta_{1}\right)+\dot{\theta}_{2} \dot{\theta}_{2}^{2} l_{2} \sin \left(\theta_{2}\right)\right)
\end{aligned}
$$

$$
\begin{aligned}
f_{5}= & -u_{5}+c_{5} g m_{5} \sin \left(\theta_{5}\right)+c_{5} \dot{\theta}_{2} \dot{\theta}_{1}^{2} l_{1} m_{5} \sin \left(\theta_{1}-\theta_{5}\right) \\
& +c_{5} \dot{\theta}_{2} \dot{\theta}_{2}^{2} l_{2} m_{5} \sin \left(\theta_{2}-\theta_{5}\right)-c_{5} \dot{\theta}_{2} \dot{\theta}_{4}^{2} l_{4} m_{5} \sin \left(\theta_{4}-\theta_{5}\right)
\end{aligned}
$$

\section{C.2 Equções de Impacto}

$$
\begin{gathered}
\dot{\theta}\left(T^{+}\right)=Q(\alpha)^{-1} P(\alpha) \dot{\theta}\left(T^{-}\right) \\
P(\alpha) \dot{\theta}=\left[\begin{array}{c}
F F_{1} \\
F F_{2} \\
F F_{3} \\
F F_{4} \\
F F_{5}
\end{array}\right]
\end{gathered}
$$




$$
\begin{aligned}
F F_{1}= & -I_{1} \dot{\theta}_{1}^{-}-I_{2} \dot{\theta}_{2}^{-}-I_{3} \dot{\theta}_{3}^{-}-I_{4} \dot{\theta}_{4}^{-}-I_{5} \dot{\theta}_{5}^{-} \\
& +m_{2}\left(\dot{\theta}_{2}^{-}\left(c_{2} \sin \left(\theta_{2}^{-}\right)-l_{2} \sin \left(\theta_{2}^{-}\right)\right)-\dot{\theta}_{1}^{-} l_{1} \sin \left(\theta_{1}^{-}\right)\right)\left(-c_{2} \sin \left(\theta_{2}^{-}\right)+l_{4} \sin \left(\theta_{4}^{-}\right)+l_{5} \sin \left(\theta_{5}^{-}\right)\right) \\
& -m_{5}\left(c_{5} \sin \left(\theta_{5}^{-}\right)-l_{5} \sin \left(\theta_{5}^{-}\right)\right)\left(c_{5} \dot{\theta}_{5}^{-} \sin \left(\theta_{5}^{-}\right)-\dot{\theta}_{1}^{-} l_{1} \sin \left(\theta_{1}^{-}\right)-\dot{\theta}_{2}^{-} l_{2} \sin \left(\theta_{2}^{-}\right)\right. \\
& \left.\quad+\dot{\theta}_{4}^{-} l_{4} \sin \left(\theta_{4}^{-}\right)\right)-m_{3}\left(-\dot{\theta}_{3}^{-}\left(c_{3} \cos \left(\theta_{3}^{-}\right)-l_{3} \cos \left(\theta_{3}^{-}\right)\right)+\dot{\theta}_{1}^{-} l_{1} \cos \left(\theta_{1}^{-}\right)\right. \\
& \left.\quad+\dot{\theta}_{2}^{-} l_{2} \cos \left(\theta_{2}^{-}\right)\right)\left(-c_{3} \cos \left(\theta_{3}^{-}\right)+l_{3} \cos \left(\theta_{3}^{-}\right)+l_{4} \cos \left(\theta_{4}^{-}\right)+l_{5} \cos \left(\theta_{5}^{-}\right)\right) \\
& -m_{4}\left(-c_{4} \cos \left(\theta_{4}^{-}\right)+l_{4} \cos \left(\theta_{4}^{-}\right)+l_{5} \cos \left(\theta_{5}^{-}\right)\right)\left(\dot{\theta}_{1}^{-} l_{1} \cos \left(\theta_{1}^{-}\right)+\dot{\theta}_{2}^{-} l_{2} \cos \left(\theta_{2}^{-}\right)\right. \\
& \left.\quad-c_{4} \dot{\theta}_{4}^{-} \cos \left(\theta_{4}^{-}\right)\right)+m_{2}\left(\dot{\theta}_{2}^{-}\left(c_{2} \cos \left(\theta_{2}^{-}\right)-l_{2} \cos \left(\theta_{2}^{-}\right)\right)-\dot{\theta}_{1}^{-} l_{1} \cos \left(\theta_{1}^{-}\right)\right)\left(-c_{2} \cos \left(\theta_{2}^{-}\right)\right. \\
& \left.+l_{4} \cos \left(\theta_{4}^{-}\right)+l_{5} \cos \left(\theta_{5}^{-}\right)\right)-m_{4}\left(-c_{4} \sin \left(\theta_{4}^{-}\right)+l_{4} \sin \left(\theta_{4}^{-}\right)+l_{5} \sin \left(\theta_{5}^{-}\right)\right)\left(-c_{4} \dot{\theta}_{4}^{-} \sin \left(\theta_{4}^{-}\right)\right. \\
& \left.\quad+\dot{\theta}_{1}^{-} l_{1} \sin \left(\theta_{1}^{-}\right)+\dot{\theta}_{2}^{-} l_{2} \sin \left(\theta_{2}^{-}\right)\right)+m_{5}\left(c_{5} \cos \left(\theta_{5}^{-}\right)-l_{5} \cos \left(\theta_{5}^{-}\right)\right)\left(\dot{\theta}_{1}^{-} l_{1} \cos \left(\theta_{1}^{-}\right)\right. \\
& \left.+\dot{\theta}_{2}^{-} l_{2} \cos \left(\theta_{2}^{-}\right)-\dot{\theta}_{4}^{-} l_{4} \cos \left(\theta_{4}^{-}\right)-c_{5} \dot{\theta}_{5}^{-} \cos \left(\theta_{5}^{-}\right)\right)-m_{3}\left(-\dot{\theta}_{3}^{-}\left(c_{3} \sin \left(\theta_{3}^{-}\right)-l_{3} \sin \left(\theta_{3}^{-}\right)\right)\right. \\
& \left.\quad+\dot{\theta}_{1}^{-} l_{1} \sin \left(\theta_{1}^{-}\right)+\dot{\theta}_{2}^{-} l_{2} \sin \left(\theta_{2}^{-}\right)\right)\left(-c_{3} \sin \left(\theta_{3}^{-}\right)+l_{3} \sin \left(\theta_{3}^{-}\right)+l_{4} \sin \left(\theta_{4}^{-}\right)+l_{5} \sin \left(\theta_{5}^{-}\right)\right) \\
- & \dot{\theta}_{1}^{-} m_{1}\left(c_{1} \cos \left(\theta_{1}^{-}\right)-l_{1} \cos \left(\theta_{1}^{-}\right)\right)\left(c_{1} \cos \left(\theta_{1}^{-}\right)+l_{2} \cos \left(\theta_{2}^{-}\right)-l_{4} \cos \left(\theta_{4}^{-}\right)-l_{5} \cos \left(\theta_{5}^{-}\right)\right) \\
- & \dot{\theta}_{1}^{-} m_{1}\left(c_{1} \sin \left(\theta_{1}^{-}\right)-l_{1} \sin \left(\theta_{1}^{-}\right)\right)\left(c_{1} \sin \left(\theta_{1}^{-}\right)+l_{2} \sin \left(\theta_{2}^{-}\right)-l_{4} \sin \left(\theta_{4}^{-}\right)-l_{5} \sin \left(\theta_{5}^{-}\right)\right)
\end{aligned}
$$

$$
\begin{aligned}
F F_{2}= & -I_{1} \dot{\theta}_{1}^{-}-I_{2} \dot{\theta}_{2}^{-}-I_{3} \dot{\theta}_{3}^{-}-I_{4} \dot{\theta}_{4}^{-} \\
& +m_{4}\left(c_{4} \sin \left(\theta_{4}^{-}\right)-l_{4} \sin \left(\theta_{4}^{-}\right)\right)\left(-c_{4} \dot{\theta}_{4}^{-} \sin \left(\theta_{4}^{-}\right)+\dot{\theta}_{1}^{-} l_{1} \sin \left(\theta_{1}^{-}\right)+\dot{\theta}_{2}^{-} l_{2} \sin \left(\theta_{2}^{-}\right)\right) \\
& -m_{2}\left(c_{2} \cos \left(\theta_{2}^{-}\right)-l_{4} \cos \left(\theta_{4}^{-}\right)\right)\left(\dot{\theta}_{2}^{-}\left(c_{2} \cos \left(\theta_{2}^{-}\right)-l_{2} \cos \left(\theta_{2}^{-}\right)\right)-\dot{\theta}_{1}^{-} l_{1} \cos \left(\theta_{1}^{-}\right)\right) \\
& -m_{3}\left(-\dot{\theta}_{3}^{-}\left(c_{3} \sin \left(\theta_{3}^{-}\right)-l_{3} \sin \left(\theta_{3}^{-}\right)\right)+\dot{\theta}_{1}^{-} l_{1} \sin \left(\theta_{1}^{-}\right)+\dot{\theta}_{2}^{-} l_{2} \sin \left(\theta_{2}^{-}\right)\right)\left(-c_{3} \sin \left(\theta_{3}^{-}\right)\right. \\
& \left.+l_{3} \sin \left(\theta_{3}^{-}\right)+l_{4} \sin \left(\theta_{4}^{-}\right)\right) \\
& -m_{2}\left(c_{2} \sin \left(\theta_{2}^{-}\right)-l_{4} \sin \left(\theta_{4}^{-}\right)\right)\left(\dot{\theta}_{2}^{-}\left(c_{2} \sin \left(\theta_{2}^{-}\right)-l_{2} \sin \left(\theta_{2}^{-}\right)\right)-\dot{\theta}_{1}^{-} l_{1} \sin \left(\theta_{1}^{-}\right)\right) \\
& -m_{3}\left(-c_{3} \cos \left(\theta_{3}^{-}\right)+l_{3} \cos \left(\theta_{3}^{-}\right)+l_{4} \cos \left(\theta_{4}^{-}\right)\right)\left(-\dot{\theta}_{3}^{-}\left(c_{3} \cos \left(\theta_{3}^{-}\right)-l_{3} \cos \left(\theta_{3}^{-}\right)\right)\right. \\
& \left.\quad+\dot{\theta}_{1}^{-} l_{1} \cos \left(\theta_{1}^{-}\right)+\dot{\theta}_{2}^{-} l_{2} \cos \left(\theta_{2}^{-}\right)\right) \\
& +m_{4}\left(c_{4} \cos \left(\theta_{4}^{-}\right)-l_{4} \cos \left(\theta_{4}^{-}\right)\right)\left(\dot{\theta}_{1}^{-} l_{1} \cos \left(\theta_{1}^{-}\right)+\dot{\theta}_{2}^{-} l_{2} \cos \left(\theta_{2}^{-}\right)-c_{4} \dot{\theta}_{4}^{-} \cos \left(\theta_{4}^{-}\right)\right) \\
& -\dot{\theta}_{1}^{-} m_{1}\left(c_{1} \sin \left(\theta_{1}^{-}\right)-l_{1} \sin \left(\theta_{1}^{-}\right)\right)\left(c_{1} \sin \left(\theta_{1}^{-}\right)+l_{2} \sin \left(\theta_{2}^{-}\right)-l_{4} \sin \left(\theta_{4}^{-}\right)\right) \\
& -\dot{\theta}_{1}^{-} m_{1}\left(c_{1} \cos \left(\theta_{1}^{-}\right)-l_{1} \cos \left(\theta_{1}^{-}\right)\right)\left(c_{1} \cos \left(\theta_{1}^{-}\right)+l_{2} \cos \left(\theta_{2}^{-}\right)-l_{4} \cos \left(\theta_{4}^{-}\right)\right)
\end{aligned}
$$

$$
\begin{aligned}
F F_{3}= & -I_{1} \dot{\theta}_{1}^{-}-I_{2} \dot{\theta}_{2}^{-}-I_{3} \dot{\theta}_{3}^{-}+m_{3}\left(c_{3} \cos \left(\theta_{3}^{-}\right)-l_{3} \cos \left(\theta_{3}^{-}\right)\right)\left(-\dot{\theta}_{3}^{-}\left(c_{3} \cos \left(\theta_{3}^{-}\right)-l_{3} \cos \left(\theta_{3}^{-}\right)\right)\right. \\
& \left.+\dot{\theta}_{1}^{-} l_{1} \cos \left(\theta_{1}^{-}\right)+\dot{\theta}_{2}^{-} l_{2} \cos \left(\theta_{2}^{-}\right)\right) \\
& +m_{3}\left(c_{3} \sin \left(\theta_{3}^{-}\right)-l_{3} \sin \left(\theta_{3}^{-}\right)\right)\left(-\dot{\theta}_{3}^{-}\left(c_{3} \sin \left(\theta_{3}^{-}\right)-l_{3} \sin \left(\theta_{3}^{-}\right)\right)+\dot{\theta}_{1}^{-} l_{1} \sin \left(\theta_{1}^{-}\right)\right. \\
& \left.\quad+\dot{\theta}_{2}^{-} l_{2} \sin \left(\theta_{2}^{-}\right)\right)-c_{2} m_{2} \sin \left(\theta_{2}^{-}\right)\left(\dot{\theta}_{2}^{-}\left(c_{2} \sin \left(\theta_{2}^{-}\right)-l_{2} \sin \left(\theta_{2}^{-}\right)\right)-\dot{\theta}_{1}^{-} l_{1} \sin \left(\theta_{1}^{-}\right)\right) \\
& -\dot{\theta}_{1}^{-} m_{1}\left(c_{1} \cos \left(\theta_{1}^{-}\right)-l_{1} \cos \left(\theta_{1}^{-}\right)\right)\left(c_{1} \cos \left(\theta_{1}^{-}\right)+l_{2} \cos \left(\theta_{2}^{-}\right)\right) \\
& -\dot{\theta}_{1}^{-} m_{1}\left(c_{1} \sin \left(\theta_{1}^{-}\right)-l_{1} \sin \left(\theta_{1}^{-}\right)\right)\left(c_{1} \sin \left(\theta_{1}^{-}\right)+l_{2} \sin \left(\theta_{2}^{-}\right)\right) \\
& -c_{2} m_{2} \cos \left(\theta_{2}^{-}\right)\left(\dot{\theta}_{2}^{-}\left(c_{2} \cos \left(\theta_{2}^{-}\right)-l_{2} \cos \left(\theta_{2}^{-}\right)\right)-\dot{\theta}_{1}^{-} l_{1} \cos \left(\theta_{1}^{-}\right)\right)
\end{aligned}
$$




$$
\begin{aligned}
F F_{4}= & -I_{1} \dot{\theta}_{1}^{-}-I_{2} \dot{\theta}_{2}^{-}-c_{2} m_{2} \sin \left(\theta_{2}^{-}\right)\left(\dot{\theta}_{2}^{-}\left(c_{2} \sin \left(\theta_{2}^{-}\right)-l_{2} \sin \left(\theta_{2}^{-}\right)\right)-\dot{\theta}_{1}^{-} l_{1} \sin \left(\theta_{1}^{-}\right)\right) \\
& -\dot{\theta}_{1}^{-} m_{1}\left(c_{1} \cos \left(\theta_{1}^{-}\right)-l_{1} \cos \left(\theta_{1}^{-}\right)\right)\left(c_{1} \cos \left(\theta_{1}^{-}\right)+l_{2} \cos \left(\theta_{2}^{-}\right)\right) \\
& -\dot{\theta}_{1}^{-} m_{1}\left(c_{1} \sin \left(\theta_{1}^{-}\right)-l_{1} \sin \left(\theta_{1}^{-}\right)\right)\left(c_{1} \sin \left(\theta_{1}^{-}\right)+l_{2} \sin \left(\theta_{2}^{-}\right)\right) \\
& -c_{2} m_{2} \cos \left(\theta_{2}^{-}\right)\left(\dot{\theta}_{2}^{-}\left(c_{2} \cos \left(\theta_{2}^{-}\right)-l_{2} \cos \left(\theta_{2}^{-}\right)\right)-\dot{\theta}_{1}^{-} l_{1} \cos \left(\theta_{1}^{-}\right)\right)
\end{aligned}
$$

$$
\begin{aligned}
F F_{5}= & -I_{1} \dot{\theta}_{1}^{-}-c_{1} \dot{\theta}_{1}^{-} m_{1} \sin \left(\theta_{1}^{-}\right)\left(c_{1} \sin \left(\theta_{1}^{-}\right)-l_{1} \sin \left(\theta_{1}^{-}\right)\right) \\
& -c_{1} \dot{\theta}_{1}^{-} m_{1} \cos \left(\theta_{1}^{-}\right)\left(c_{1} \cos \left(\theta_{1}^{-}\right)-l_{1} \cos \left(\theta_{1}^{-}\right)\right)
\end{aligned}
$$

$$
Q(\alpha)=\left[\begin{array}{llllll}
Q_{11} & Q_{12} & Q_{13} & Q_{14} & Q_{15} & Q_{16} \\
Q_{21} & Q_{22} & Q_{23} & Q_{24} & Q_{25} & Q_{26} \\
Q_{31} & Q_{32} & Q_{33} & Q_{34} & Q_{35} & Q_{36} \\
Q_{41} & Q_{42} & Q_{43} & Q_{44} & Q_{45} & Q_{46} \\
Q_{51} & Q_{52} & Q_{53} & Q_{54} & Q_{55} & Q_{56}
\end{array}\right]
$$

$$
\begin{aligned}
Q_{11}= & -l_{1}-m_{1}\left(c_{1} \cos \left(\theta_{1}^{+}\right)-l_{1} \cos \left(\theta_{1}^{+}\right)\right)^{2}-m_{1}\left(c_{1} \sin \left(\theta_{1}^{+}\right)-l_{1} \sin \left(\theta_{1}^{+}\right)\right)^{2} \\
& -l_{1} m_{3} \sin \left(\theta_{1}^{+}\right)\left(-c_{3} \sin \left(\theta_{3}^{+}\right)+l_{1} \sin \left(\theta_{1}^{+}\right)+l_{2} \sin \left(\theta_{2}^{+}\right)+l_{3} \sin \left(\theta_{3}^{+}\right)\right) \\
& +l_{1} m_{5} \sin \left(\theta_{1}^{+}\right)\left(c_{5} \sin \left(\theta_{5}^{+}\right)-l_{1} \sin \left(\theta_{1}^{+}\right)-l_{2} \sin \left(\theta_{2}^{+}\right)+l_{4} \sin \left(\theta_{4}^{+}\right)\right) \\
& -l_{1} m_{2} \cos \left(\theta_{1}^{+}\right)\left(-c_{2} \cos \left(\theta_{2}^{+}\right)+l_{1} \cos \left(\theta_{1}^{+}\right)+l_{2} \cos \left(\theta_{2}^{+}\right)\right) \\
& -l_{1} m_{4} \cos \left(\theta_{1}^{+}\right)\left(-c_{4} \cos \left(\theta_{4}^{+}\right)+l_{1} \cos \left(\theta_{1}^{+}\right)+l_{2} \cos \left(\theta_{2}^{+}\right)\right) \\
& -l_{1} m_{2} \sin \left(\theta_{1}^{+}\right)\left(-c_{2} \sin \left(\theta_{2}^{+}\right)+l_{1} \sin \left(\theta_{1}^{+}\right)+l_{2} \sin \left(\theta_{2}^{+}\right)\right) \\
& -l_{1} m_{4} \sin \left(\theta_{1}^{+}\right)\left(-c_{4} \sin \left(\theta_{4}^{+}\right)+l_{1} \sin \left(\theta_{1}^{+}\right)+l_{2} \sin \left(\theta_{2}^{+}\right)\right) \\
& -l_{1} m_{3} \cos \left(\theta_{1}^{+}\right)\left(-c_{3} \cos \left(\theta_{3}^{+}\right)+l_{1} \cos \left(\theta_{1}^{+}\right)+l_{2} \cos \left(\theta_{2}^{+}\right)+l_{3} \cos \left(\theta_{3}^{+}\right)\right) \\
& +l_{1} m_{5} \cos \left(\theta_{1}^{+}\right)\left(c_{5} \cos \left(\theta_{5}^{+}\right)-l_{1} \cos \left(\theta_{1}^{+}\right)-l_{2} \cos \left(\theta_{2}^{+}\right)+l_{4} \cos \left(\theta_{4}^{+}\right)\right)
\end{aligned}
$$

$$
\begin{aligned}
Q_{12}= & -I_{2}+m_{2}\left(c_{2} \cos \left(\theta_{2}^{+}\right)-l_{2} \cos \left(\theta_{2}^{+}\right)\right)\left(-c_{2} \cos \left(\theta_{2}^{+}\right)+l_{1} \cos \left(\theta_{1}^{+}\right)+l_{2} \cos \left(\theta_{2}^{+}\right)\right) \\
& +m_{2}\left(c_{2} \sin \left(\theta_{2}^{+}\right)-l_{2} \sin \left(\theta_{2}^{+}\right)\right)\left(-c_{2} \sin \left(\theta_{2}^{+}\right)+l_{1} \sin \left(\theta_{1}^{+}\right)+l_{2} \sin \left(\theta_{2}^{+}\right)\right) \\
& -l_{2} m_{3} \sin \left(\theta_{2}^{+}\right)\left(-c_{3} \sin \left(\theta_{3}^{+}\right)+l_{1} \sin \left(\theta_{1}^{+}\right)+l_{2} \sin \left(\theta_{2}^{+}\right)+l_{3} \sin \left(\theta_{3}^{+}\right)\right) \\
& +l_{2} m_{5} \sin \left(\theta_{2}^{+}\right)\left(c_{5} \sin \left(\theta_{5}^{+}\right)-l_{1} \sin \left(\theta_{1}^{+}\right)-l_{2} \sin \left(\theta_{2}^{+}\right)+l_{4} \sin \left(\theta_{4}^{+}\right)\right) \\
& -l_{2} m_{4} \cos \left(\theta_{2}^{+}\right)\left(-c_{4} \cos \left(\theta_{4}^{+}\right)+l_{1} \cos \left(\theta_{1}^{+}\right)+l_{2} \cos \left(\theta_{2}^{+}\right)\right) \\
& -l_{2} m_{4} \sin \left(\theta_{2}^{+}\right)\left(-c_{4} \sin \left(\theta_{4}^{+}\right)+l_{1} \sin \left(\theta_{1}^{+}\right)+l_{2} \sin \left(\theta_{2}^{+}\right)\right) \\
& -l_{2} m_{3} \cos \left(\theta_{2}^{+}\right)\left(-c_{3} \cos \left(\theta_{3}^{+}\right)+l_{1} \cos \left(\theta_{1}^{+}\right)+l_{2} \cos \left(\theta_{2}^{+}\right)+l_{3} \cos \left(\theta_{3}^{+}\right)\right) \\
& +l_{2} m_{5} \cos \left(\theta_{2}^{+}\right)\left(c_{5} \cos \left(\theta_{5}^{+}\right)-l_{1} \cos \left(\theta_{1}^{+}\right)-l_{2} \cos \left(\theta_{2}^{+}\right)+l_{4} \cos \left(\theta_{4}^{+}\right)\right)
\end{aligned}
$$




$$
\begin{aligned}
Q_{13}= & -I_{3}+m_{3}\left(c_{3} \cos \left(\theta_{3}^{+}\right)-l_{3} \cos \left(\theta_{3}^{+}\right)\right)\left(-c_{3} \cos \left(\theta_{3}^{+}\right)+l_{1} \cos \left(\theta_{1}^{+}\right)+l_{2} \cos \left(\theta_{2}^{+}\right)+l_{3} \cos \left(\theta_{3}^{+}\right)\right) \\
& +m_{3}\left(c_{3} \sin \left(\theta_{3}^{+}\right)-l_{3} \sin \left(\theta_{3}^{+}\right)\right)\left(-c_{3} \sin \left(\theta_{3}^{+}\right)+l_{1} \sin \left(\theta_{1}^{+}\right)+l_{2} \sin \left(\theta_{2}^{+}\right)+l_{3} \sin \left(\theta_{3}^{+}\right)\right)
\end{aligned}
$$

$$
\begin{aligned}
Q_{14}= & -I_{4}-l_{4} m_{5} \sin \left(\theta_{4}^{+}\right)\left(c_{5} \sin \left(\theta_{5}^{+}\right)-l_{1} \sin \left(\theta_{1}^{+}\right)-l_{2} \sin \left(\theta_{2}^{+}\right)+l_{4} \sin \left(\theta_{4}^{+}\right)\right) \\
& +c_{4} m_{4} \cos \left(\theta_{4}^{+}\right)\left(-c_{4} \cos \left(\theta_{4}^{+}\right)+l_{1} \cos \left(\theta_{1}^{+}\right)+l_{2} \cos \left(\theta_{2}^{+}\right)\right) \\
& +c_{4} m_{4} \sin \left(\theta_{4}^{+}\right)\left(-c_{4} \sin \left(\theta_{4}^{+}\right)+l_{1} \sin \left(\theta_{1}^{+}\right)+l_{2} \sin \left(\theta_{2}^{+}\right)\right) \\
& -l_{4} m_{5} \cos \left(\theta_{4}^{+}\right)\left(c_{5} \cos \left(\theta_{5}^{+}\right)-l_{1} \cos \left(\theta_{1}^{+}\right)-l_{2} \cos \left(\theta_{2}^{+}\right)+l_{4} \cos \left(\theta_{4}^{+}\right)\right)
\end{aligned}
$$

$$
\begin{aligned}
Q_{15}= & -I_{5}-c_{5} m_{5} \sin \left(\theta_{5}^{+}\right)\left(c_{5} \sin \left(\theta_{5}^{+}\right)-l_{1} \sin \left(\theta_{1}^{+}\right)-l_{2} \sin \left(\theta_{2}^{+}\right)+l_{4} \sin \left(\theta_{4}^{+}\right)\right) \\
& -c_{5} m_{5} \cos \left(\theta_{5}^{+}\right)\left(c_{5} \cos \left(\theta_{5}^{+}\right)-l_{1} \cos \left(\theta_{1}^{+}\right)-l_{2} \cos \left(\theta_{2}^{+}\right)+l_{4} \cos \left(\theta_{4}^{+}\right)\right)
\end{aligned}
$$

$$
\begin{aligned}
Q_{21}= & -l_{1} m_{3} \cos \left(\theta_{1}^{+}\right)\left(-c_{3} \cos \left(\theta_{3}^{+}\right)+l_{2} \cos \left(\theta_{2}^{+}\right)+l_{3} \cos \left(\theta_{3}^{+}\right)\right) \\
& +l_{1} m_{5} \cos \left(\theta_{1}^{+}\right)\left(c_{5} \cos \left(\theta_{5}^{+}\right)-l_{2} \cos \left(\theta_{2}^{+}\right)+l_{4} \cos \left(\theta_{4}^{+}\right)\right) \\
& -l_{1} m_{3} \sin \left(\theta_{1}^{+}\right)\left(-c_{3} \sin \left(\theta_{3}^{+}\right)+l_{2} \sin \left(\theta_{2}^{+}\right)+l_{3} \sin \left(\theta_{3}^{+}\right)\right) \\
& +l_{1} m_{5} \sin \left(\theta_{1}^{+}\right)\left(c_{5} \sin \left(\theta_{5}^{+}\right)-l_{2} \sin \left(\theta_{2}^{+}\right)+l_{4} \sin \left(\theta_{4}^{+}\right)\right) \\
& +l_{1} m_{2} \cos \left(\theta_{1}^{+}\right)\left(c_{2} \cos \left(\theta_{2}^{+}\right)-l_{2} \cos \left(\theta_{2}^{+}\right)\right)+l_{1} m_{4} \cos \left(\theta_{1}^{+}\right)\left(c_{4} \cos \left(\theta_{4}^{+}\right)-l_{2} \cos \left(\theta_{2}^{+}\right)\right) \\
& +l_{1} m_{2} \sin \left(\theta_{1}^{+}\right)\left(c_{2} \sin \left(\theta_{2}^{+}\right)-l_{2} \sin \left(\theta_{2}^{+}\right)\right)+l_{1} m_{4} \sin \left(\theta_{1}^{+}\right)\left(c_{4} \sin \left(\theta_{4}^{+}\right)-l_{2} \sin \left(\theta_{2}^{+}\right)\right)
\end{aligned}
$$

$$
\begin{aligned}
Q_{22}= & -I_{2}-m_{2}\left(c_{2} \cos \left(\theta_{2}^{+}\right)-l_{2} \cos \left(\theta_{2}^{+}\right)\right)^{2}-m_{2}\left(c_{2} \sin \left(\theta_{2}^{+}\right)-l_{2} \sin \left(\theta_{2}^{+}\right)\right)^{2} \\
& -l_{2} m_{3} \cos \left(\theta_{2}^{+}\right)\left(-c_{3} \cos \left(\theta_{3}^{+}\right)+l_{2} \cos \left(\theta_{2}^{+}\right)+l_{3} \cos \left(\theta_{3}^{+}\right)\right) \\
& +l_{2} m_{5} \cos \left(\theta_{2}^{+}\right)\left(c_{5} \cos \left(\theta_{5}^{+}\right)-l_{2} \cos \left(\theta_{2}^{+}\right)+l_{4} \cos \left(\theta_{4}^{+}\right)\right) \\
& -l_{2} m_{3} \sin \left(\theta_{2}^{+}\right)\left(-c_{3} \sin \left(\theta_{3}^{+}\right)+l_{2} \sin \left(\theta_{2}^{+}\right)+l_{3} \sin \left(\theta_{3}^{+}\right)\right) \\
& +l_{2} m_{5} \sin \left(\theta_{2}^{+}\right)\left(c_{5} \sin \left(\theta_{5}^{+}\right)-l_{2} \sin \left(\theta_{2}^{+}\right)+l_{4} \sin \left(\theta_{4}^{+}\right)\right) \\
& +l_{2} m_{4} \cos \left(\theta_{2}^{+}\right)\left(c_{4} \cos \left(\theta_{4}^{+}\right)-l_{2} \cos \left(\theta_{2}^{+}\right)\right)+l_{2} m_{4} \sin \left(\theta_{2}^{+}\right)\left(c_{4} \sin \left(\theta_{4}^{+}\right)-l_{2} \sin \left(\theta_{2}^{+}\right)\right)
\end{aligned}
$$

$$
\begin{aligned}
Q_{23}= & -I_{3}+m_{3}\left(c_{3} \cos \left(\theta_{3}^{+}\right)-l_{3} \cos \left(\theta_{3}^{+}\right)\right)\left(-c_{3} \cos \left(\theta_{3}^{+}\right)+l_{2} \cos \left(\theta_{2}^{+}\right)+l_{3} \cos \left(\theta_{3}^{+}\right)\right) \\
& +m_{3}\left(c_{3} \sin \left(\theta_{3}^{+}\right)-l_{3} \sin \left(\theta_{3}^{+}\right)\right)\left(-c_{3} \sin \left(\theta_{3}^{+}\right)+l_{2} \sin \left(\theta_{2}^{+}\right)+l_{3} \sin \left(\theta_{3}^{+}\right)\right)
\end{aligned}
$$

$$
\begin{aligned}
Q_{24}= & -I_{4}-l_{4} m_{5} \cos \left(\theta_{4}^{+}\right)\left(c_{5} \cos \left(\theta_{5}^{+}\right)-l_{2} \cos \left(\theta_{2}^{+}\right)+l_{4} \cos \left(\theta_{4}^{+}\right)\right) \\
& -l_{4} m_{5} \sin \left(\theta_{4}^{+}\right)\left(c_{5} \sin \left(\theta_{5}^{+}\right)-l_{2} \sin \left(\theta_{2}^{+}\right)+l_{4} \sin \left(\theta_{4}^{+}\right)\right) \\
& -c_{4} m_{4} \cos \left(\theta_{4}^{+}\right)\left(c_{4} \cos \left(\theta_{4}^{+}\right)-l_{2} \cos \left(\theta_{2}^{+}\right)\right)-c_{4} m_{4} \sin \left(\theta_{4}^{+}\right)\left(c_{4} \sin \left(\theta_{4}^{+}\right)-l_{2} \sin \left(\theta_{2}^{+}\right)\right)
\end{aligned}
$$




$$
\begin{gathered}
Q_{25}=-I_{5}-c_{5} m_{5} \cos \left(\theta_{5}^{+}\right)\left(c_{5} \cos \left(\theta_{5}^{+}\right)-l_{2} \cos \left(\theta_{2}^{+}\right)+l_{4} \cos \left(\theta_{4}^{+}\right)\right) \\
-c_{5} m_{5} \sin \left(\theta_{5}^{+}\right)\left(c_{5} \sin \left(\theta_{5}^{+}\right)-l_{2} \sin \left(\theta_{2}^{+}\right)+l_{4} \sin \left(\theta_{4}^{+}\right)\right) \\
Q_{31}=l_{1} m_{3} \cos \left(\theta_{1}^{+}\right)\left(c_{3} \cos \left(\theta_{3}^{+}\right)-l_{3} \cos \left(\theta_{3}^{+}\right)\right)+l_{1} m_{5} \cos \left(\theta_{1}^{+}\right)\left(c_{5} \cos \left(\theta_{5}^{+}\right)+l_{4} \cos \left(\theta_{4}^{+}\right)\right) \\
+l_{1} m_{3} \sin \left(\theta_{1}^{+}\right)\left(c_{3} \sin \left(\theta_{3}^{+}\right)-l_{3} \sin \left(\theta_{3}^{+}\right)\right)+l_{1} m_{5} \sin \left(\theta_{1}^{+}\right)\left(c_{5} \sin \left(\theta_{5}^{+}\right)+l_{4} \sin \left(\theta_{4}^{+}\right)\right) \\
+c_{4} l_{1} m_{4} \cos \left(\theta_{1}^{+}\right) \cos \left(\theta_{4}^{+}\right)+c_{4} l_{1} m_{4} \sin \left(\theta_{1}^{+}\right) \sin \left(\theta_{4}^{+}\right)
\end{gathered}
$$

$Q_{35}=-I_{5}-c_{5} m_{5} \cos \left(\theta_{5}^{+}\right)\left(c_{5} \cos \left(\theta_{5}^{+}\right)+l_{4} \cos \left(\theta_{4}^{+}\right)\right)-c_{5} m_{5} \sin \left(\theta_{5}^{+}\right)\left(c_{5} \sin \left(\theta_{5}^{+}\right)+l_{4} \sin \left(\theta_{4}^{+}\right)\right)$

$$
\begin{aligned}
Q_{41}= & l_{1} m_{5} \cos \left(\theta_{1}^{+}\right)\left(c_{5} \cos \left(\theta_{5}^{+}\right)+l_{4} \cos \left(\theta_{4}^{+}\right)\right)+l_{1} m_{5} \sin \left(\theta_{1}^{+}\right)\left(c_{5} \sin \left(\theta_{5}^{+}\right)+l_{4} \sin \left(\theta_{4}^{+}\right)\right) \\
& +c_{4} l_{1} m_{4} \cos \left(\theta_{1}^{+}\right) \cos \left(\theta_{4}^{+}\right)+c_{4} l_{1} m_{4} \sin \left(\theta_{1}^{+}\right) \sin \left(\theta_{4}^{+}\right)
\end{aligned}
$$

$$
\begin{aligned}
Q_{42}= & l_{2} m_{5} \cos \left(\theta_{2}^{+}\right)\left(c_{5} \cos \left(\theta_{5}^{+}\right)+l_{4} \cos \left(\theta_{4}^{+}\right)\right)+l_{2} m_{5} \sin \left(\theta_{2}^{+}\right)\left(c_{5} \sin \left(\theta_{5}^{+}\right)+l_{4} \sin \left(\theta_{4}^{+}\right)\right) \\
& +c_{4} l_{2} m_{4} \cos \left(\theta_{2}^{+}\right) \cos \left(\theta_{4}^{+}\right)+c_{4} l_{2} m_{4} \sin \left(\theta_{2}^{+}\right) \sin \left(\theta_{4}^{+}\right)
\end{aligned}
$$

$$
Q_{43}=0
$$


$\begin{aligned} Q_{44}= & -I_{4}-\left(c_{4} c_{4}\right) m_{4} \cos \left(\theta_{4}^{+}\right)^{2}-\left(c_{4} c_{4}\right) m_{4} \sin \left(\theta_{4}^{+}\right)^{2} \\ & -l_{4} m_{5} \cos \left(\theta_{4}^{+}\right)\left(c_{5} \cos \left(\theta_{5}^{+}\right)+l_{4} \cos \left(\theta_{4}^{+}\right)\right)-l_{4} m_{5} \sin \left(\theta_{4}^{+}\right)\left(c_{5} \sin \left(\theta_{5}^{+}\right)+l_{4} \sin \left(\theta_{4}^{+}\right)\right)\end{aligned}$

$Q_{45}=-I_{5}-c_{5} m_{5} \cos \left(\theta_{5}^{+}\right)\left(c_{5} \cos \left(\theta_{5}^{+}\right)+l_{4} \cos \left(\theta_{4}^{+}\right)\right)-c_{5} m_{5} \sin \left(\theta_{5}^{+}\right)\left(c_{5} \sin \left(\theta_{5}^{+}\right)+l_{4} \sin \left(\theta_{4}^{+}\right)\right)$

$Q_{51}=c_{5} l_{1} m_{5} \cos \left(\theta_{1}^{+}\right) \cos \left(\theta_{5}^{+}\right)+c_{5} l_{1} m_{5} \sin \left(\theta_{1}^{+}\right) \sin \left(\theta_{5}^{+}\right)$

$Q_{52}=c_{5} l_{2} m_{5} \cos \left(\theta_{2}^{+}\right) \cos \left(\theta_{5}^{+}\right)+c_{5} l_{2} m_{5} \sin \left(\theta_{2}^{+}\right) \sin \left(\theta_{5}^{+}\right)$

$$
Q_{53}=0
$$

$Q_{54}=-c_{5} l_{4} m_{5} \cos \left(\theta_{4}^{+}\right) \cos \left(\theta_{5}^{+}\right)-c_{5} l_{4} m_{5} \sin \left(\theta_{4}^{+}\right) \sin \left(\theta_{5}^{+}\right)$

$$
Q_{55}=-I_{5}-\left(c_{5} c_{5}\right) m_{5} \cos \left(\theta_{5}^{+}\right)^{2}-\left(c_{5} c_{5}\right) m_{5} \sin \left(\theta_{5}^{+}\right)^{2}
$$

